\title{
Hymenopteran Parasitoid Diversity \& Tri-Trophic Interactions: The Effects of Habitat Fragmentation in Wellington, New Zealand
}

\section{Franz-Rudolf Schnitzler}

\author{
A thesis \\ submitted to the Victoria University of Wellington \\ in fulfilment of the requirements for the degree of \\ Doctor of Philosophy \\ in Ecology and Biodiversity
}

Victoria University of Wellington

Te Whare Wānanga o te Úpoko o te Ika Māui 


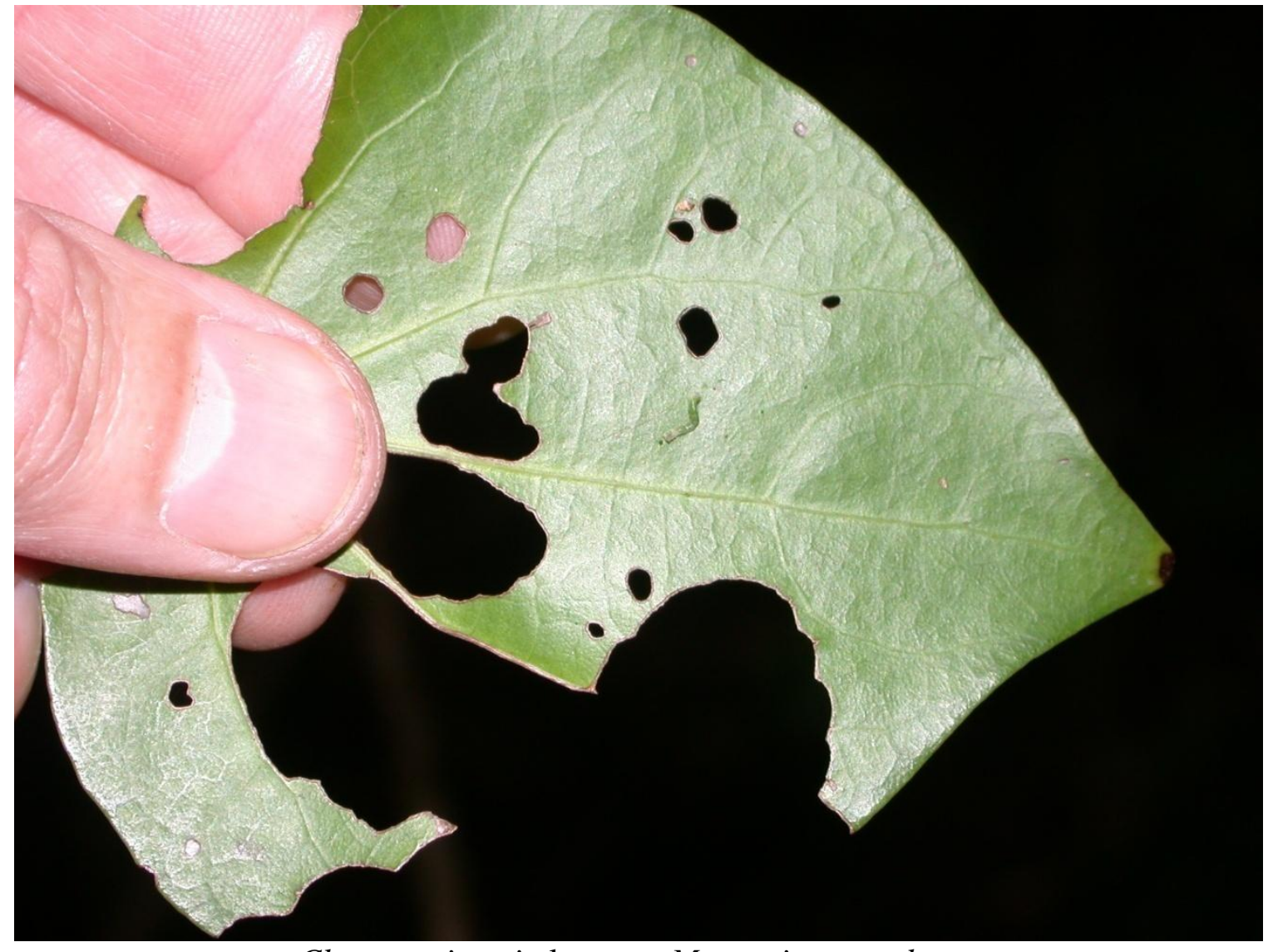

Cleora scriptaria larva on Macropiper excelsum

With all those in mind that are close to me

All denen gewidmet, die mir nahe stehen 


\begin{abstract}
Habitat fragmentation and the resulting decline in biodiversity through the loss of habitat are thought to be the main threat to insect extinctions. According to the trophic level hypothesis, habitat fragmentation affects parasitoids more severely than their herbivorous hosts. Parasitoids also may be correlated with plant species richness, because plants host a variety of phytophagous insects acting as hosts for parasitoids, or plants provide food or act as shelter for parasitoids.
\end{abstract}

In this study, the effects of the forest fragment properties; area, isolation, percentage of residential area surrounding focal fragments and plant richness on parasitic wasps and their interactions were examined. These fragmentation effects were examined in 10 urban native bush remnants in the Wellington and Hutt Valley region of the lower North Island, New Zealand. Fragmentation effects on species abundance, richness and diversity and on community assemblages were examined for the wasp families Ichneumonidae, Pompilidae and Proctotrupidae. Correlations between beta diversity of the plant community and the parasitoid community were analysed and the study investigated whether individual parasitoid occurrences can be predicted by the range of their host's host plants. This study focused on interactions between the kawakawa moth larva Cleora scriptaria, its primary host plant Macropiper excelsum and the parasitism rates by two parasitoids Aleiodes declanae (an endemic species) and Meteorus pulchricornis (an exotic species) and the herbivory caused by $C$. scriptaria larvae. In addition to interaction responses to forest fragmentation properties, interaction responses were also examined with respect to the properties of the plot and individual plant. 
Individual species showed different trends in response to the fragmentation properties, making interpretation of a general community response difficult. The abundance, richness and diversity of small-bodied parasitoids were inversely related to increasing area and plant species richness. Parasitoid community composition changed with fragment isolation and plant species richness. Ichneumonidae strongly responded to isolation in one year, whereas the Pompilidae responded to plant species richness. The Proctotrupidae community structure showed no response to any of the fragmentation properties. Correlations between plant and parasitoid community structures were not significant and individual parasitoid-plant associations were weak and inconclusive. Parasitism rates for A. declanae were significantly higher in more isolated fragments with smaller trees, and were negatively affected by overall parasitism rates, more so in isolated fragments. Parasitism rates by $M$. pulchricornis responded positively to larval densities and declined with increasing plant richness. Herbivory was positively related to the abundance of $M$. excelsum, tree size and larval density.

The current study provides evidence that the forest fragment properties examined are, on their own, not always sufficient predictors of community structure and interactions for parasitoids. Aspects of the results from this thesis conflict with the trophic-level hypothesis with species responding in a negative or positive way, or not responding at all to forest fragmentation effects. The findings of this thesis support to conserving species diversity by maintaining and enhancing all types of existing forest fragments to prevent species extinctions. 


\section{Acknowledgements}

Foremost I would like to thank my supervisors Phil Lester and Stephen Hartley. Without their help and support this thesis would never have happened. I surely must have tested Phil's patience to its limits and I am very grateful for his thought-provoking comments and ideas from the very start until the very end. Many thanks also go to Stephen who joined my project as second supervisor and has spent much time with me sorting out those bloody statistics. Many thanks go to Shirley Pledger and Clare Salmond whose statistical knowledge has been invaluable.

Eleven years ago, prompted by my partner Jutta Humpfer, I started my university studies and enrolled for a Bachelor of Social Sciences. At that time I did not envisage that I would end my studies by writing this thesis. Jutta's support through all those years meant a lot to me and it was also she who encouraged me to enrol in Biology alongside Psychology. I will never forget the day when I sought permission from the Biology Department at Waikato University to double major. I remember appearing forlorn in the Biology Department's corridors asking someone where the office was so I could have my enrolment signed. This person happened to be Peter Molan, who proudly announced ' $I$ am Biology' and signed my life away for the next 11 years.

From then on it became all too clear. After my very first assignment about compost toilets for the New Start course offered by Waikato University, to changing my degree to a Bachelor of Science, the discovery of my real passion, entomology, to the very end of this thesis, I would like to thank all of you who have contributed and supported me along 
the way in whatever form. Without this support I would not be here and I would not have written this thesis.

Other people have contributed their time and expertise, for which I am greatly thankful: John Brightwell, Travis Chellman, Adrian Pike, Nick Rawlence, Megan Sarty and Lloyd Stringer for the assistance in the lab and sorting of insects with special thanks to Megan for her help looking after the live larvae whilst I was in the field. For help with some of the species identification I would like to thank Jo Berry, John Dugdale, Allen Heath, Phil Lester and Gregor Yeates. For the use of their Hymenoptera collections special thanks to Jo Berry (New Zealand Arthropod Collection), John Early (Auckland Museum) and Ricardo Palma and Phil Sirvid (Museum of New Zealand Te Papa Tongarewa). Many thanks go to Cleland Wallace for surveying the plant communities. I thank the New Zealand Department of Conservation for the loan of Malaise traps especially Ian Stringer and Mike Wakelin. The Department of Conservation also supplied me with Topo Vector Data for the Wellington region.

Thanks also to the bug-club of the School of Biological Sciences at Victoria University of Wellington for valuable comments on my thesis during the research, analysis and writing process. Special thanks go to Kirsti Abbot, Vaughn Bell, Catherine Duthie, Marc Hasenbank, Angela Moles and Adrian Pike. I would like to thank all my friends and coffee mates, especially James Mathew, Adele White, Bruce Norris, Sonja Miller and Phil James, who had to share an office with me and endure my ups and downs during all this time. It was especially handy to share an office with the ever charming Bruce. His PC and IT knowledge certainly made life and computer usage much easier and I learned a lot from him. 
I also would like to thank the Karori Wildlife Sanctuary (Raewyn Empson), the Otari Botanical Gardens, the Wellington City Council (Joanna Gillanders and Jane Wright), the Hutt City Council (Kelly Crandle), the Upper Hutt City Council (Brett Latimer), and the Wellington Regional Council (Philippa Crisp and Chris Wootton) for permission to establish traps in native bush fragments.

A very big thank you goes to the School of Biological Sciences, with special thanks to Marry Murray, Delwyn Carter and Patricia Stein. I enjoyed my time and felt very much at home within the whole department and I am very grateful for the support and encouragement I have experienced from all staff and students alike.

Many thanks also go to Paul Blackman for making the final professional proof reading of my thesis possible, which was carried out by Dick Ward from Write You Are.

With so many people to thank I am bound to have unintentionally overlooked some and sincerely apologise for this.

For funding I would like to thank the Victoria University of Wellington, for providing research funds, a $\mathrm{PhD}$ scholarship and a $\mathrm{PhD}$ finishing scholarship. This research was also funded by the 21st Anniversary Fund from the Entomological Society of NZ and the Claude McCarthy scholarship allowed me to present my work at an international entomology conference. 


\section{Table of Contents}

Abstract................................................................. i

Acknowledgements............................................... iii

CHAPTER 1. Forest fragmentation and trophic levels: Introduction and overview

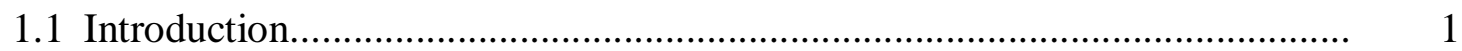

1.1.1 Habitat fragmentation........................................ 5

1.1.2 Habitat fragmentation effects on arthropods.......................... 7

1.1.3 Habitat fragmentation responses at higher trophic levels.............. 11

1.1.4 Conclusions..................................................... 18

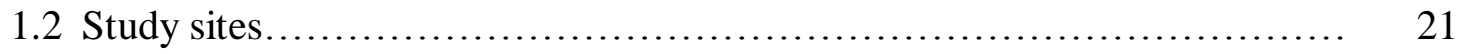

1.3 Parasitoids......................................................... 22

1.4 Thesis outline.................................................... 27

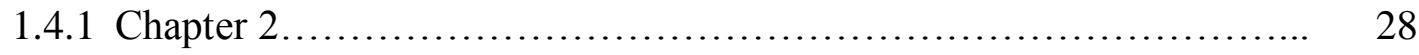

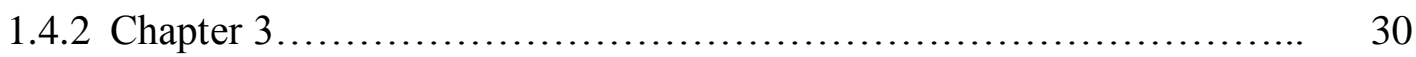

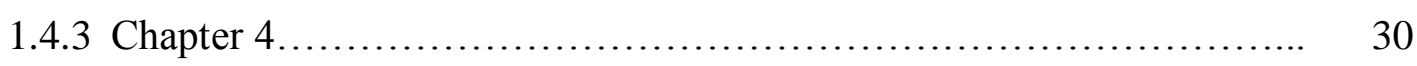

1.5 Literature cited....................................................... 31

CHAPTER 2. The effect of habitat area, isolation and plant diversity on parasitoid community structure: A study in urban forest fragments

2.1 Abstract............................................................. 47

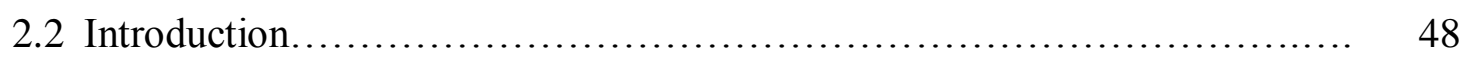

2.3 Methods......................................................... 52

2.3.1 Study sites.................................................. 52

2.3.2 Insect sampling................................................. 54

2.3.3 Parasitoid abundance, richness \& diversity....................... 55 
2.3.4 Parasitoid community composition................................. 59

2.3.5 Individual species responses.................................... 60

2.4 Results.............................................................. 60

2.4.1 Parasitoid species abundance, richness, diversity.................... 63

2.4.2 Parasitoid community composition............................ 70

2.4.3 Individual species responses................................... 74

2.5 Discussion...................................................... 74

2.5.1 Parasitoid abundance, richness \& diversity........................ 76

2.5.2 Parasitoid community composition............................. 78

2.5.3 Individual species responses................................. 81

2.5.4 Implications for conservation.................................. 82

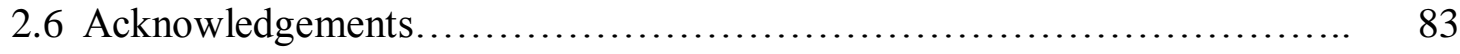

2.7 Literature cited.................................................... 84

Appendix 2.1 Fragment indices and insect collection schedule.................. 91

Appendix 2.2 Stepwise search for the best approximating model describing the 92 response of the parasitoid communities to the different combinations of covariates

Appendix 2.3 Indices examined. Number of individuals, species numbers and

Simpson index for each site per fragment and year of the different species assemblages analysed.

Appendix 2.4 Pooled species richness per fragment and year................... 98

Appendix 2.5 Parasitoids isolated from Malaise trap catches.................... 99

CHAPTER 3. On the relationship between plant and parasitoid community structure: Do plant communities predict structure at higher trophic levels across a fragmented forest landscape?

3.1 Abstract........................................................... 103

3.2 Introduction...................................................... 105

3.3 Methods............................................................ 107

3.3.1 Study sites and sampling.................................... 107

3.3.2 Community responses to fragment area and isolation................ 110 
3.3.4 Responses of individual parasitoid species ........................ 113

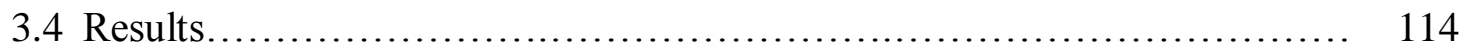

3.4.1 Community responses to fragment area and isolation.................. 115

3.4.2 Plant-parasitoid relationships..................................... 118

3.4.3 Responses of individual parasitoid species...................... 120

3.5 Discussion..................................................... 122

3.6 Acknowledgements.............................................. 129

3.7 Literature cited..................................................... 129

Appendix 3.1 Fragment indices and insect collection schedule................. 135

Appendix 3.2 Plant species and their relative abundances for each research site... 136 Appendix 3.3 Parasitoids from Stokes Valley............................... 145

Appendix 3.4 Parasitoid species and plant species that best describe the relationship between parasitoid abundance patterns and the plant community composition.

Appendix 3.5 Correlations between parasitoids and the host plants associated with the parasitoids' hosts.

CHAPTER 4. Hierarchical influences on tri-trophic interactions:

Parasitism of Cleora scriptaria (Lepidoptera: Geometridae)

larvae and herbivory of Macropiper excelsum (Piperaceae) plant, plot and fragment effects

4.1 Abstract............................................................ 149

4.2 Introduction......................................................... 151

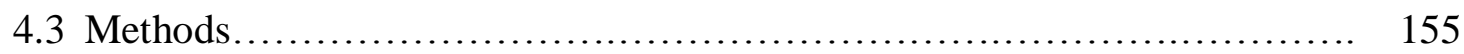

4.3 .1 Study sites............................................. 155

4.3.2 Study species: plant, herbivore and parasitoids.................... 157

4.3 .3 Statistical analysis............................................ 158

4.3.4 Model building................................................ 161

4.4 Results.............................................................. 163

4.4.1 Parasitism....................................................... 168 
4.4.2 Aleiodes declanae................................................ 168

4.4.3 Meteorus pulchricornis......................................... 170

4.4 .4 Herbivory ........................................................ 173

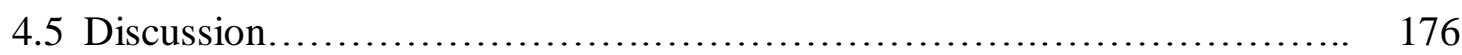

4.5.1 Hierarchy of fragment, plot and plant level influences............... 176

4.5.2 Effects of isolation on parasitism rates and herbivory ................ 177

4.5.3 Responses to forest edges and landscape matrix.................... 178

4.5.4 Aleiodes declanae responses to host densities........................ 179

4.5.5 Influence of larval densities on M. pulchricornis and influences of plant species richness................................................ 179

4.5.6 Influences of tree size on herbivory and parasitism rates............. 180

4.5.7 Info-chemicals.................................................. 181

4.5.8 Parthenogenesis................................................ 182

4.5.9 Implications for invasive species biology and habitat fragmentation..... 183

4.5.10 Summary................................................... 184

4.6 Acknowledgements.............................................. 184

4.7 Literature cited..................................................... 185

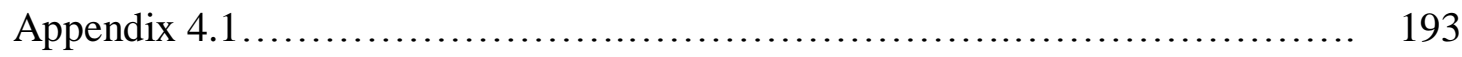

Appendix 4.2 Model rational........................................... 194

4.2.1 Parasitism........................................................ 194

4.2.2 Herbivory.................................................... 196

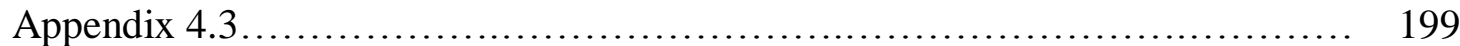

Appendix 4.4 Summary of results for A. declanae at each level of model building process............................................... 201

Appendix 4.5 Summary of results for M. pulchricornis at each level of model building process.....................................................

Appendix 4.6 Summary of results for herbivory at each level of model building process.

Appendix 4.7 Larval parasitoids reared from C. scriptaria (Geometridae: Ennominae). 
CHAPTER 5. Trophic level responses to forest fragmentation: Effects and implications

5.1 Introduction................................................... 235

5.2 Effects of the fragment properties area, isolation, percentage residential area and plant species richness

5.2.1 Area and Isolation....

5.2.2 Plant richness.

5.2.3 Percentage residential area.

5.2.4 Fragment properties other than area, isolation, percentage residential and plant species richness.......................................... 241

5.3 Limitations..................................................... 243

5.4 Recommendations for future studies.............................. 244

5.5 What are the consequences of fragmentation and isolation for the management of urban habitat reserves and forest fragments?............... 250

5.6 Synopsis...................................................... 252

5.7 Literature cited.................................................... 253 


\section{List of Figures}

Figure 1.1: Higher trophic levels are expected to respond more strongly to forest fragmentation....

Figure 1.2: Conceptual model of hypothesised host-parasitoid-plant relationships in forest fragments

Figure 1.3: Percent of the native forest area investigated in relation to the surrounding land cover within a range of $1 \mathrm{~km}$ distance from the edge of each research fragment.

Figure 1.4: Malaise trap with collecting container topmost and kawakawa trees marked with flagging tape.

Figure 1.5: Specimens representing parasitoid families included in the parasitoid community studies

Figure 1.6: Collecting C. scriptaria larvae from a beating sheet 25

Figure 1.7: Cleora scriptaria larvae in rearing tubes containing artificial diet

Figure 1.8: The kawakawa moth C. scriptaria (Walker 1860) (=Selidosema panagrata) (Lepidoptera: Geometridae).

Figure 1.9: Small kawakawa plant.

Figure 2.1: The Wellington and Hutt Valley region with the location of nine native forest research fragments and the surrounding $1 \mathrm{~km}$ range included in the study.

Figure 2.2: Coleman rarefaction curve for cumulative mean number of parasitoid species and number of samples

Figure 2.3: Scatter plot showing the Bray-Curtis dissimilarities from the univariate species abundance, richness and diversity, and the multivariate community assemblage in relation to the geographic distances (Euclidian distance) between sites of the fragments.

Figure 2.4: Total parasitoid species richness pooled for each fragment per year in response to fragment area, isolation, percentage residential area and number of plant species per fragment. 
Figure 2.5: Non-metric multidimensional scaling based on Bray-Curtis dissimilarities for the ichneumonid species community of year 1, year 2 and years 1 and 2 between sites.

Figure 3.1: The Wellington and Hutt Valley region with the location of 10 native forest research fragments and the surrounding $1 \mathrm{~km}$ range included in the study. ...

Figure 3.2: Cumulative rarefaction curve for the 116 plant and 103 parasitoid species found in 29 research sites from 10 native urban forest fragments.

Figure 3.3: Plant and parasitoid species richness and parasitoid abundance for each site in relation to fragment area and isolation. Linear regression lines are fitted to indicate trends in the response variables.

Figure 3.4: MDS ordination showing the extent to which sites in 10 fragments have similar parasitoid and plant composition in relation to area and isolation......

Figure 3.5: Correlations between Bray-Curtis dissimilarity matrices for each of the parasitoid and plant community measures between pairs of sites for relative plant species abundance, plant richness, parasitoid species abundance and parasitoid richness.

Figure 3.6: Beta diversity between pairs of sites regressed against their geographical separation

Figure 3.7: Trophic interaction web of Ichneumonidae identified to species, their known herbivorous hosts and their host plants present in 10 native forest fragments. ...

Figure 4.1: The Wellington and Hutt Valley regions: Location of 10 native forest research fragments and the surrounding $1 \mathrm{~km}$ range included in the study

Figure 4.2: Mean kawakawa moth abundance per kawakawa leaf; mean kawakawa tree herbivory; and parasitism rate for A. declanae and M. pulchricornis and for overall parasitism summarised over two southern hemisphere summer periods.

Figure 4.3: Parasitism rate by A. declanae as a function of fragment isolation. The probability of a larvae being parasitised by A. declanae is shown in relation to the average upper and lower quartiles of total parasitism minus A. declanae and tree size. 
Figure 4.4: Probability of a larvae being parasitised by M. pulchricornis as a

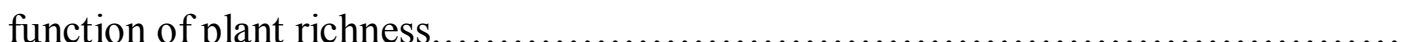

Figure 4.5: Probability of herbivory as a function of kawakawa abundance. The probability of herbivory is shown in relation to the average upper and lower quartiles for abundance of kawakawa moth and for kawakawa tree size............. 175 Figure 4.6: Relationship between number of leaves per tree and per leaf rate for

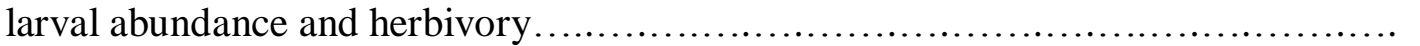




\section{List of Tables}

Table 2.1: Division of the total community into sub-communities defined by family or size class

Table 2.2: Pearson's correlation between area, isolation index, percentage of residential area and number of plant species.

Table 2.3: Permutated p-values for the species abundance, richness and Simpson index per site of all species, Ichneumonidae, Pompilidae and Proctotrupidae.

Table 2.4: Permutated p-values for the species abundance, richness and Simpson index per site of the different size groups

Table 2.5: Combination of area and plant richness indices as the model best describing the variation for the univariate indices of the small-bodied parasitoid community years 1 and 2 combined....

Table 2.6: Permutated p-values for the total species communities and the community of Ichneumonidae, Pompilidae, Proctotrupidae and the different size classes for year 1 and year 2 .....

Table 2.7: Subsequent analysis of parasitoid communities from Table 2.6 that showed a response to the combined covariates with $\mathrm{p}<0.2$.

Table 2.8: Number of negative and positive (beta) individual species responses to the factor year and the four fragment indices.

Table 3.1: PERMANOVA results of the parasitoid and plant community responses to the covariates area and isolation combined and alone using a MANCOVA analysis design.

Table 3.2: Names of hosts and plants from Figure 3.7.

Table 4.1: Three-level model showing the possible predictors at each level for the responses of parasitism by A. declanae and M. pulchricornis as well as for herbivory.....

Table 4.2: Summary of variables and their abbreviations for each level used in this study.... 
Table 4.3: Pearson's correlations between relevant covariates at the individual

Table 4.4: Pearson's correlation between kawakawa abundance and number of plant species at the plot level and at the fragment level between area, isolation and percentage residential area...............................................

Table 4.5: Proportion of the total variation $(\rho)$ accounted for by the variation of the responses in parasitism of $A$. declanae and $M$. pulchricornis and final estimation of fixed effects of the unconditional three-level model.................

Table 4.6: Parameter estimates for the final fixed effect three-level regression model for the log likelihood of parasitism by A. declanae.

Table 4.7: Parameter estimates for the final fixed effects three-level regression model for the log likelihood of parasitism by M. pulchricornis. .

Table 4.8: Parameter estimates for the final fixed effects two-level regression model with robust standard errors for herbivory 


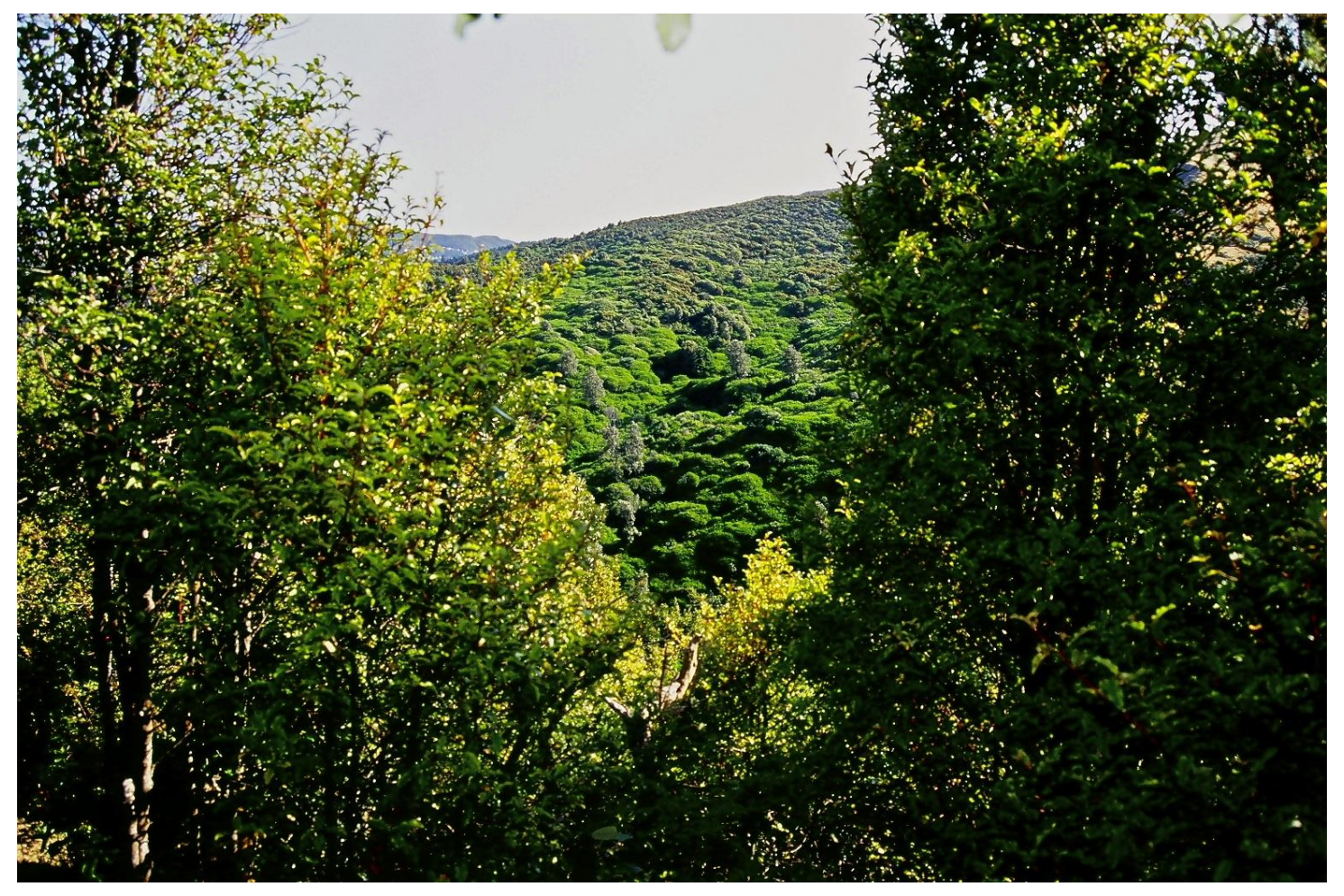

Overlooking Belmont Reserve in Lower Hutt, New Zealand 


\section{Forest fragmentation and trophic levels: Introduction and overview}

\subsection{Introduction}

Islands such as New Zealand are known for their unique indigenous flora and fauna, as well as their unique ecosystems. The influence of humans on this biodiversity has been of concern for some time. Many species have been lost (locally as well as world-wide) due to human activities such as urbanisation, agriculture and forestry (Challis, 1994; Jeffries, 1997; Samways, 1994; Wood, Stedman-Edwards \& Mang, 2000). Habitat loss due to fragmentation poses one of the greatest threats to species survival (Henle et al., 2004b).

Within many ecosystems, a high proportion of plant and invertebrate species are unknown. Numerous aspects of species biology such as species' niches and functions in ecosystems await discovery and description (Myers, 1997; Raven \& Yeates, 2007). All organisms, including humans, are interdependent on food webs and the cycling of nutrients within ecosystems (Patrick, 1997). Many of these known and unknown species could serve as a potential source for clothing, food, and medicine or as bio-control agents in agricultural and horticultural environments. For this reason the economic value of biodiversity and ecological services is realised. Biodiversity prospecting has become a major industry and biological pest control has become an important factor in pest management (Reid et al., 1993). For example, natural control by insects has been estimated to be worth billions of dollars alone and important species providing such services are often lost in the first place in human modified landscapes (Larsen, Williams \& Kremen, 2005; Losey \& Vaughan, 2006). 
Increasing urbanisation associated with an increasing world population is the severest form of landscape modification posing a threat to the conservation of biodiversity (Alberti et al., 2003; Collins et al., 2000). But urban greenspaces can play an important part in species conservation (Goldstein-Golding, 1991). An understanding of urban biodiversity is important for future planning of urban environments. Such planning is an essential component of successful conservation and bio-security management. Furthermore, understanding urban biodiversity can act as an educational tool that incorporates the human environment with the natural environment. This way, public awareness of the importance of biodiversity and biotic interactions may be heightened, which if acted upon could lead to a healthier and more aesthetically pleasing urban landscape (Pesci, 1996; Vida, 1996).

Biodiversity in urban settings has often been neglected (Heywood, 1996; Miyawaki, 1996), if not even deliberately excluded by some authors (Reduron, 1996). It is this lack of knowledge that led to this thesis's study of biodiversity in an urban environment. In general, urbanisation is seen as a threat reducing biodiversity, negatively affecting ecosystem function (Schmid, 1996). More recent discussion papers concentrating on ecological systems and biodiversity in urban planning, however, show an increasing awareness of the impact of urbanisation on biodiversity (i. e. Bryant, 2006; Niemelä, 1999; Savard, Clergeau \& Mennechez, 2000; Shochat, Warren \& Faeth, 2006; Shochat et al., 2006; Vuorisalo, Lahtinen \& Laaksonen, 2001; Whitford, Ennos \& Handley, 2001) and some more recent studies focused on the effects of urban habitat fragmentation on, for example, plants, turtles, amphibians and birds (i. e. Budischak et al., 2006; Kühn \& Klotz, 2006; Murgui, 2007; Price et al., 2006; Ranta et al., 1999; Urban et al., 2006). The fragmentation of New Zealand's landscape through agriculture, urbanisation and 
introduction of foreign species is one of the main modifiers of New Zealand's biodiversity (Ewers et al., 2006). As a consequence, many species are known to have become extinct or threatened, while others have established themselves well in a new environment alongside accidentally or purposely introduced species (Simpson, 1994). Some native species adapt to urban life while at the same time some urban properties may enhance alien elements that are different from the native fauna (Luniak, 1996).

Arthropods are a critical part of urban biodiversity, yet they are regularly overlooked (New, 1993; Samways, 1994) and are, due to human influences, as much if not even more under threat of extinction than other organisms (Samways, 2007). The fact that arthropods are often overlooked is reflected in the gap in knowledge relating to New Zealand's land-based invertebrates and their interactions with the environment, as outlined in The New Zealand Biodiversity Strategy (DOC, 2000). Studies of biodiversity until recently have often concentrated on the conservation of species in their "natural environment" or on species that are either beneficial or considered a pest for economic reasons in modified habitats such as agricultural and horticultural land or urban environments (i. e. McIntyre, 2000; Raupp et al., 2001). Arthropods are the subject of my urban biodiversity studies described within this thesis.

The urban environment can potentially be seen as a place where many insect species might be able to take refuge from a depleted habitat in a barren pasture environment. Urban parks, gardens and roadside plantings may provide refuges for a diverse range of insect species (Clark \& Samways, 1997). In urban areas such patches are often removed in order to make way for economic development. This fragmentation often leaves isolated trees as a degraded insect habitat (Samways, 1994). To date few studies have 
investigated arthropod diversity or individual insect distributions in relation to urbanisation. Most studies are relatively recent and are dated after I began my study for this thesis. Clark and Samways (1997) and Smith et al. (2006) used different trapping methods to assess general arthropod diversity in two urban parks. These authors encountered logistical constrains, and Clark and Samways (1997) recommended concentrating on target species or host/plant interactions for such studies.

Using pitfall traps, ground arthropod community composition was found to differ markedly with land use (McIntyre et al., 2001), while species richness of carabid beetles was found to decline noticeably along a gradient from forested to suburban to urban areas (Elek \& Lovei, 2007). Within an urban environment the composition of phytophagous insect communities changes with a successive gradient of vegetation structure (Strauss \& Biedermann, 2006). Urban habitat quality in the form of the absence/presence of a beetle's host plant, but also in the form of host plant density and the presence of larger, more mature plants determines the distributions of the beetle species Desmocerus californicus dimorphus Fisher (Coleoptera: Cerambycidae) (Talley et al., 2007). Beetle and wasp communities estimated from pitfall traps in urban habitats of high complexity have higher species richness and vary significantly in species composition when compared to less complex habitats (Lassau \& Hochuli, 2005; Lassau et al., 2005). However the same authors found no such differences in community estimates from flight intercept traps.

Using pitfall traps and yellow pan traps, Gibb and Hochuli (2002) examined the effects of habitat fragmentation on different arthropod assemblages within an urban environment. One of these authors' main questions was whether differences in arthropod assemblages 
between small and larger habitats are more pronounced at higher trophic levels, such as parasitic wasps or predatory spiders, than at lower trophic levels such as ants, beetles or flies. Within two different vegetation types (heath and woodland), they found significant differences in community assemblages between smaller and larger fragments for spiders, and significant differences for wasps in heathland and marginally different in woodland.

This thesis similarly investigates forest fragmentation effects on insect communities across an urban landscape matrix. The main questions asked will be whether the size of a forest fragment or to what degree the isolation of a forest fragment from neighbouring fragments influences insect species richness, abundance and diversity, or changes insect community assemblages or insect interactions. In addition, I will address the question of whether the level of residential build-up surrounding a fragment or the habitat quality in the form of local plant species richness will influence the insect communities studied herein.

\subsubsection{Habitat fragmentation}

The model that the number of species in an area increases with increasing area size (Preston, 1962) has been extended into the equilibrium theory of island biogeography by MacArthur \& Wilson (1963; 1967). Briefly, the theory states that the number of species on an island is dependent on island size and also on the distance between islands, with fewer species present on either smaller islands or on islands that are at a greater distance from the mainland. The equilibrium theory of island biogeography has since been applied to fragmentation effects on mainland habitats (Harris, 1984). Patchy habitat occurs naturally (Leisnham \& Jamieson, 2002) but the main driver of habitat fragmentation is the modification of the landscape by humans (Lindenmayer \& Fischer, 2006). There are 
four major processes of fragmentation: reduction in habitat amount, increase in number of habitat patches, decrease in habitat size, and increase in habitat isolation (Fahrig, 2003). However,

The effects of habitat fragmentation have been studied widely on a variety of organisms. Turner (1996) reviewed studies on tropical forest fragmentation and found a bias towards research on birds, whereas invertebrates have received little attention. He also remarked about the heavy reliance on one project, namely the Biological Dynamics of Forest Fragmentation Project (BDFFP) (Manaus, Brazil) for conclusions of forest fragmentation effects on biodiversity. Turner (1996) therefore states that it is difficult to refute the hypothesis that fragmentation generally leads to the local loss of diversity. The project at Manaus is a large-scale experiment that started in 1979 to address how tropical rainforest fragmentation effects the biotic communities inhabiting these forests (Bierregaard Jr. et al., 1992; Lovejoy et al., 1986). Turner (1996) proposed a number of possible studies in order to gain insight into the process of species loss through fragmentation. These processes are deforestation-related disturbances, restriction of population size, prevention or reduction of immigration, edge effects and higher order effects. Since then Laurance et al (2002) synthesized over 340 publications and discussed the key BDFFP findings, such as sampling -, area -, edge -, matrix -, and isolation effects on the various groups studied. The underlying mechanisms leading to species loss, especially for arthropods at the higher trophic levels, are however, barely understood (Turner, 1996). Arthropods at the higher trophic levels are the subject of a relatively recent extensive review on species sensitivity to fragmentation (Henle et al., 2004a). This review only mentions one study involving predatory beetles as an example of higher trophic level effects of 
fragmentation, ignoring several important studies involving parasitoids, which I will address within this work.

Habitat fragmentation acts in several ways on biodiversity. The most common cause of fragmentation leading to loss of biodiversity is the loss of suitable habitat, which results in reduction of habitat area and or in the increase in habitat isolation (Fahrig, 2003). Increasing habitat isolation prevents poor dispersers from travelling to or leaving a habitat fragment. I will use both measures in this thesis. As the quality of the matrix is known to influence functional isolation (Ricketts, 2001) I will introduce, in Chapters 2 and 4 , the percentage of residential build-up surrounding a research fragment as a further measure of isolation.

As I mentioned previously in this introduction, vegetation structure or absence/presence of plant species can determine the community assemblages of arthropods. Here, I chose a single study system and examined community responses in native forest fragments from the Wellington area in New Zealand. However, some changes in plant composition are to be expected in relation to fragment area and isolation. Therefore, plant richness will be used in Chapters 2 and 4 as an additional indicator for the insect communities to be examined in this study. In Chapter 3 I will specifically concentrate on the association between plant communities and insect communities.

\subsubsection{Habitat fragmentation effects on arthropods}

Didham et al. (1996) concluded that some field studies on arthropod communities and experimental evidence have confirmed that species richness and abundance as well as community biomass and biotic interactions are negatively affected by decreasing 
fragment area and isolation in a fragmented landscape. However, at the same time, these authors suggested that the study of insects in fragmented forests is still in its infancy (Didham et al., 1996). Studies that I have reviewed may be summarised as follows: Carvalho \& Vasconcelos (1999) found fragment isolation to affect species richness and nest density of litter-dwelling ant communities in Amazonian forest remnants. Similarly, isolation rather than area size was observed to be the main factor influencing butterfly communities in central Spain (Baz \& Garciaboyero, 1995). However, if corridors provide a connection between smaller and larger habitats for arthropods, no differences of species richness between fragments are apparent (Gonzalez \& Chaneton, 2002). Differences in species richness are seen as an effect of fragment isolation rather than fragment size by Miyashita et al. (1998). However, changes in species richness alone are too simple to reveal any effects associated with habitat fragmentation (Davies \& Margules, 1998; Gibb \& Hochuli, 2002) and species are likely to respond differently to habitat fragmentation (Hambäck et al., 2007). For example, the density of insect herbivore species in relation to patch or habitat area may be influenced by processes such as body size and the form of host searching behaviour such as visual searches in butterflies, olfactory searches in moths, or the passive distribution of aphids (Bukovinszky et al., 2005; Englund \& Hambäck, 2007; Hambäck \& Englund, 2005; Hambäck et al., 2007). Such processes mask fragmentation effects on species richness and shape the make-up and persistence of meta-populations within the habitat matrix (Ewers \& Didham, 2006). In addition, an increase in edge habitat and the habitat matrix in a fragmented landscape also regulate dispersal and therefore determine different related fragmentation responses for generalists or specialist species (Ewers \& Didham, 2006). However, (Hambäck et al., 2007) suggested that different aspects of habitat fragmentation affect small and large species differently. Small species may be affected by the reduction in size of available habitat 
and be unable to sustain local populations even in small patches. In contrast, larger species may be able to utilise multiple patches and therefore be more dependent on the total amount of suitable habitat available in the landscape matrix (Hambäck et al., 2007).

Another example is a study showing that forest fragmentation can negatively influence pollinator communities (Aizen \& Feinsinger, 1994b; Murren, 2002). Aizen \& Feinsinger (1994b) reported that forest fragmentation facilitated access to floral resources for the exotic and feral honeybee Apis mellifera L., but percentage of flower visits by native flower visitors were lower in smaller fragment sizes. This result might be reflected in the reduced pollination and seed production observed in plants in forest fragments compared to continuous forest (Aizen \& Feinsinger, 1994a). However, through a literature review, Aizen, Ashworth \& Galetto (2002) concluded that no generalisation could be made about the susceptibility of plants to fragmentation based on whether the plants were selfcompatible pollinators or self-incompatible and therefore reliant predominately on pollinators. Nor were there differences in the responses to habitat fragmentation between specialized plants relying on specialist pollinators and generalist plants having numerous pollinators (Aizen, Ashworth \& Galetto, 2002). Similarly self-incompatible plants were not more susceptible to habitat fragmentation related Allee effects than self-compatible plants (Ghazoul, 2005). Conversely, however, a meta-analysis revealed that selfincompatible plants were highly dependent on animal pollinators and more susceptible to habitat fragmentation than plants with a self-compatible reproductive system (Aguilar et al., 2006).

Another example of fragmentation effects on insect communities is given by Collinge \& Forman (1998). These authors created grassland fragments experimentally that resulted in 
different responses from different insect groups due to their displacement from mown areas. Kruess \& Tscharntke (2000) concluded from their work on endophagous insects on Trifolium pratense L. and Vicia sepium L. that decreasing habitat size and increasing habitat isolation dramatically reduce species diversity. Whereas Miyashita et al. (1998) found that differences in species density was a result of fragment size. Further, Gibb \& Hochuli (2002) and Didham et al. (1998) concluded that differences in arthropod assemblages were a characteristic of different responses from different species. Miyashita et al. (1998) compared species richness of spiders within and between urban forest fragments, and found that web builders and the larger spider groups where most affected by fragmentation. Margules et al. (1994) strongly emphasised different species responses to fragmentation. Their paper showed different responses by a scorpion and amphipod due to their differences in biology or ecology. The abundance of the amphipod in the fragment remnants decreased significantly in comparison to the scorpion. As a result of fragmentation, the humid habitat necessary for the amphipod had been lost. As shown by Didham et al. (1998) arthropod assemblages rather than species richness are affected by fragment size. These authors also mentioned that most studies on effects of habitat fragmentation concentrated either on single species or species within one trophic level, and changes in food webs were seldom investigated, yet species at the higher trophic level seem to be disproportionately affected by fragmentation (Ewers \& Didham, 2006). The latter was shown experimentally, testing the impact of peat bog habitat loss and isolation through peat mining on the invertebrate community associated with Sporadanthus ferrugineus (Restionaceae) Species richness and predator-prey ratio (including parasitoids) were significantly negatively affected with increasing isolation. A successful restoration of mined peat bog and its community structure would therefore 
depend on the spacing and placement of restoration islands as stepping stones outward from existing areas of intact peat bog habitat (Watts \& Didham, 2006).

Reports published since the beginning of my studies have shown the important influence of fragment edge to area ratios on insect communities (Ewers, Thorpe \& Didham, 2007) and the potential effects of fragment shape and species' sensitivity to habitat edges on insect population size (Ewers \& Didham, 2007). Beetle populations that preferred forest habitat were found to be absent from small fragments, which were dominated by a matrix-dwelling fauna. The assumption that the rate of species loss is directly proportional to habitat area may therefore not be true if edge effects are found to be stronger in smaller fragments than in larger ones (Ewers, Thorpe \& Didham, 2007). In addition, the population size of core-dwelling species might be threatened by the shape complexity of larger forest fragments which are frequently found to contain multiple, disjunct core areas, resulting in less habitat being available for core-dwelling species (Ewers \& Didham, 2007).

In Chapter 2, I will examine the effects of habitat fragmentation on insect communities at the third and fourth trophic level, and in Chapter 4, I will investigate whether interactions between species across three trophic levels are affected by habitat fragmentation.

\subsubsection{Habitat fragmentation responses at higher trophic levels}

The trophic-level hypothesis of island biogeography states that species at higher trophic levels in a community are more prone to the effects of fragmentation than species at lower levels (Holt et al., 1999; Kareiva, 1987; Kruess \& Tscharntke, 1994). The composition of wasps, which are mainly parasitoids or predators of arthropods 
(Naumann, 1991), was found to be completely different when comparing larger and small fragments. Different species responses are therefore particularly apparent for predators and parasitoids (see also Kareiva, 1987; Kruess \& Tscharntke, 1994; Miyashita, Shinkai \& Chida, 1998). Particularly, specialists at the higher trophic levels may be negatively affected by habitat fragmentation because their distributions are restricted by means of their own activities as well as by those of the lower trophic levels. However, such responses might also be counter intuitively dependent on the structure of multi-trophic webs (Holt et al., 1999). Kruess \& Tscharntke (2000) realised that parasitoids responded to fragmentation effects more strongly than their herbivorous hosts (Fig. 1.1). Assemblages of predators and parasitoids showed the strongest differences between fragments in comparison to assemblages of generalised species that were more common in highly disturbed smaller fragments (Gibb \& Hochuli, 2002). More recently, Rand \& Tscharntke (2007) demonstrated the complexity of the mechanisms involved in determining species' responses to changes in the landscape. These authors found similar individual and patch characteristics for the nettle Urtica dioica Linn. within both simple and complex landscapes. Aphid densities found on these nettles were higher in complex landscapes, but were found to be determined by local host availability rather than independent effects of landscape type. Densities of specialist predators of aphids were higher in complex landscapes than in simple landscapes, and abundances of generalist predators appeared to be independent from local host densities (Rand \& Tscharntke, 2007).

Interactions between parasitoids and their hosts take place in a heterogeneous and structured environment, which is likely to influence such interactions (Roland, 2000). For example, the absence or presence of a parasitic Sarcophagidae species (a parasitic flesh 
fly) in small and large habitat fragments has been shown to have effects on snail populations that are difficult to predict (McKillup \& McKillup, 2000). These authors demonstrated that relatively isolated habitat patches that are free of the larger fly species appear to provide a refuge for host populations. From there, snail larvae were able to recolonise larger patches, from which they almost became extinct. Van Nouhuys \& Hanski (2002) found that the ability of the butterfly (Melitaea cinxia [L.], Lepidoptera: Nymphalidae) to occupy habitat patches increased with patch connectivity, which was almost equal with the ability to disperse by one of its wasp parasitoids Hyposoter horticola (Gravenhorst) (Ichneumonidae: Campopleginae). This was in contrast to another wasp parasitoid species Cotesia melitaearum (Wilkinson) (Braconidae: Microgastrinae) that was not able to disperse at the same rate as the former two. However, the parasitoid that was the stronger disperser seemed to be the inferior competitor when both parasitoids where present together within a patch.

The ability of a species to occupy isolated habitats seems not only dependent on the biology of the species but also on the size and variability of its populations (Kruess \& Tscharntke, 1994). Therefore, the successful establishment of parasitoid populations will depend on the establishment of their host populations, which are likely to be smaller in smaller habitat fragments or may depend on the degree of fragment isolation. However, other local mechanisms might be responsible for parasitoid persistence in a habitat such as host egg productivity (Amarasekare, 2000a; 2000b). 


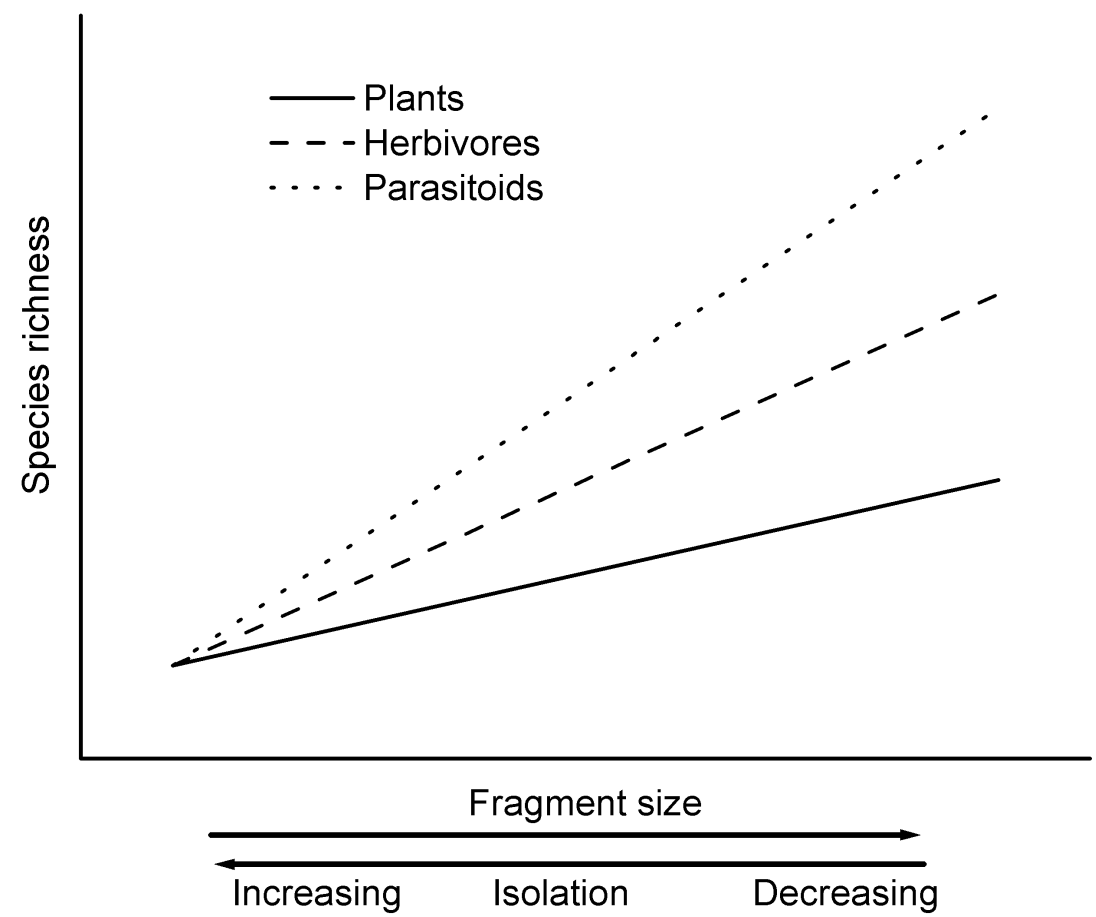

Figure 1.1: Higher trophic levels are expected to respond more strongly to forest fragmentation than lower trophic levels. (Adapted from Steffan-Dewenter \& Tscharntke 2002).

In their study, Komonen et al. (2000) explored the structure of the insect community inhabiting an old growth specialist bracket fungus Fomitopsis rosea (Alb. \& Schw. Fr.) P. Karsten. This fungus has greatly declined in Finland's forests due to forestry related habitat loss. The presence of $F$. rosea was lower in fragments that had been isolated for longer and in those with larger ratio of edge to area. The moth Agnathosia mendicella (Denis \& Schiffermüller) further affected the presence of $F$. rosea. The parasitoid Elfia cingulata (Robineau-Desvoidy) was found to be completely absent from fragments that had been isolated for 12-32 years. 
In a review of habitat fragmentation effects on insect communities in calcareous grasslands, Steffan-Dewenter \& Tscharntke (2002) found that abundance of single species and species richness of butterflies was lower in smaller and more isolated habitat patches. Local populations in small and isolated patches were more likely to become extinct, and emigration rates declined with increasing patch size. When I set out to undertake the studies described in this thesis, studies analysing the abundance of insect species in relation to area and isolation were rare and responses varied for different insect groups. Insect community structure, however, was known to be strongly influenced by habitat fragmentation and patch isolation. This was most apparent in the higher trophic levels. Landscape structure such as connectivity between fragments again was shown to affect insect communities at higher trophic levels. Species persistence was higher in connected fragments than in unconnected fragments (see also Kruess \& Tscharntke, 2000). Since beginning my studies, several more recent studies (described below) have been carried out on parasitism responses to habitat fragmentation, with varying outcomes.

In such recent studies, herbivore and parasitoid responses to fragmentation were often found to be inconsistent (Hunter, 2002; van Nouhuys, 2005). For example, negative as well as positive responses by parasitoids to fragmentation have been found (Doak, 2000; Roland, 2000; Roland \& Taylor, 1997; Roth, Roland \& Roslin, 2006). Parasitism rates by a small fly Carcelia malacosomae (Sellers) (Tachinidae) on the forest tent caterpillar Malacosoma disstria Hübner (Lepidoptera: Lasiocampidae) were higher in forest fragments than in continuous forest and in comparison to three larger parasitoids affecting the same host (Roland \& Taylor, 1997). However, a second study did not confirm the response for C. malacosomae except for another tachinid species (Lespesia frenchii [Williston]) (Roth, Roland \& Roslin, 2006). Likewise, parasitism by Aleiodes n. 
sp. was found to be higher in smaller and isolated patches, opposite to the response by a tachinid parasitoid from the same study (Doak, 2000). Elevated parasitism in forest fragments was also found by another Aleiodes species, A. malacosomatus (Roland, 2000).

Higher parasitism rates in isolated patches have been explained by species-specific differences in movement-capabilities within the landscape matrix, (Roland \& Taylor, 1997), or as a parasitoid's response to the distribution of its alternative hosts (Roth, Roland \& Roslin, 2006), or by parasitoids following an optimal foraging strategy (Doak, 2000; Roth, Roland \& Roslin, 2006). Time and energy invested in travelling to an isolated patch might determine subsequent search time and oviposition effort, which had been shown to be the case by a small egg parasitoid (Cronin, 2003; Cronin \& Strong, 1999). Alternatively, a parasitoid might be less likely to leave a small forest fragment than an equivalent area of continuous forest (Roth, Roland \& Roslin, 2006).

Most interestingly, Thiel et al. (2006) found different responses to habitat isolation in a parasitoid with two different reproductive modes. Increased patch encounter, which might be viewed as being equivalent to connected habitats, resulted in decreased parasitism by the parasitoid wasp Venturia canescens (Gravenhorst) (Hymenoptera: Ichneumonidae), where both males and females were present in the population. In comparison, females in female-only populations of the same species were found to maximise their parasitism efficiency. This behaviour by the female wasps, where males are present in the population, might lead to a spreading of offspring reducing the risk of sib-mating (Thiel, Driessen \& Hoffmeister, 2006). 
Furthermore, inconsistencies between herbivore and parasitoid responses to habitat fragmentation may be due to whether the parasitoids or herbivores are generalist or specialist species. Where a generalist parasitoid has a specialist host, it could be expected that the herbivore specialist would show greater vulnerability to habitat fragmentation than the generalist parasitoid. This hypothesis was the subject of investigation by Valladares, Salvo \& Cagnolo (2006), who found a similar decline in both the herbivory and parasitism rate of leafminers and their parasitoids in response to fragment area reduction. However, herbivory was found to be higher at the core of fragments than at the fragment edge, and vice versa for parasitism rates, despite a higher parasitoid abundance at the core than at the edge. In this case, the higher herbivory is presumed to be a response to unfavourable microclimatic changes at the fragment edge rather than a release from parasitoids because the reduction in parasitism rates in their study seemed to be too small to be responsible for a doubling in herbivory rate (Valladares, Salvo \& Cagnolo, 2006).

Species' responses to habitat fragmentation, therefore, can be the result of complex interactions between a species' biology and environmental conditions. For example the ratio between the most abundant host-specific hemipteran sap-feeders on the perennial cordgrass Spartina patens (Aiton) Muhl and their most abundant predators (web-building and hunting spiders) was influenced by fragment area and the nitrogen input into the food-web structure (Hines, Lynch \& Denno, 2005). Herbivore responses differed in relation to their dispersal ability and over-wintering strategy. Immobile species that overwintered in exposed stages responded more strongly to patch size than more mobile species that over wintered in concealed microhabitats. Similarly, lower predator-prey ratios between the native pine engraver beetle (Ips pini (Say)) and its coleopteran 
predators were found in isolated red pine stands (Pinus resinosa Ait.) than in non-isolated pine forests (Ryall \& Fahrig, 2005). However, research examining the effects of habitat fragmentation on herbivory alone on the plant Betonica officinalis L. by gastropods and grasshoppers showed varying responses depending on site and season (Stoll et al., 2006). The variation in herbivore damage found on B. officinalis between the different study sites in that study highlighted the need for a careful study design at possibly even larger spatial and temporal scales than that used in the herbivory fragmentation experiment (Stoll et al., 2006). The need to study several processes to detect multiple responses to habitat fragmentation was outlined by McEuen \& Curran (2006), who found woody plant species' richness declined with increasingly isolated fragments. Tree species with heavy seeds, such as Lindera benzoin L. Blume, were poor dispersers but seedling survival also depended on herbivory, which was highest in isolated fragments. Similarly, cork oak gall wasp abundance was found to be highest where forest cover loss was highest, but parasitism rates were unrelated to forest fragmentation and could not explain the hyperabundance of gall wasps in small forests (Chust, Garbin \& Pujade-Villar, 2007).

\subsubsection{Conclusions}

The literature cited above does demonstrate that habitat fragmentation influences individual insect species, insect communities and their biotic interactions, some of which I illustrated in Figure 1.2. Fragmentation seems to affect insect groups such as herbivores, pollinators and parasitoids. Two important processes related to habitat fragmentation are repeatedly emerging from a number of studies I have discussed here. Firstly, the effect of habitat loss due to area reduction and, secondly, fragment isolation effects vary across trophic levels. But also fragment edge, shape and microclimatic conditions determine positive, negative or no response to habitat fragmentation. As I pointed out earlier, 
several studies showed that higher trophic levels seem to be more affected than their hosts, but responses might differ between generalist and specialist parasitoids or hosts. Responses to habitat fragmentation may also vary in accordance to the dispersal ability of the species under study and on the spatial and temporal scale measured.

Some studies of insect communities across different trophic levels have analysed herbivores and predators (Miyashita, Shinkai \& Chida, 1998; Steffan-Dewenter \& Tscharntke, 2002; Zabel \& Tscharntke, 1998). Kruess \& Tscharntke (2000) believe that research based on host-parasitoid relationships would be more likely to show any habitat fragmentation effects than research on predators that are on average less host specific. As Didham et al. (1996) pointed out, there is a basic lack of data on the functional roles of insects in forest fragments and a more focused approach is needed to fill the numerous gaps in the current knowledge of fragmentation effects on insect communities. Using an experimental study within an urban setting Denys \& Schmidt (1998) tested the effects of increasing building development, pavements, roads and other vegetation, free hard surfaces, and the associated habitat fragmentation on insect communities colonising potted plants of mugwort Artemisia vulgaris L., which were placed in green spaces dominated by grass. No study to my knowledge has tested the hypothesis that parasitoid communities and host-parasitoid-plant relationships in urban forest fragments respond negatively to habitat loss determined by habitat area and/or isolation. The investigation in this thesis of plant-host-parasitoid relations in urban forest fragments therefore is a novel contribution to an understanding of insect interactions with their natural environment and to the implementation of nature conservation. In addition, this thesis contributes to New Zealand's knowledge of native and exotic parasitoids. Many hymenopteran parasitoids are under-described or undescribed and their host relationships are unknown. 


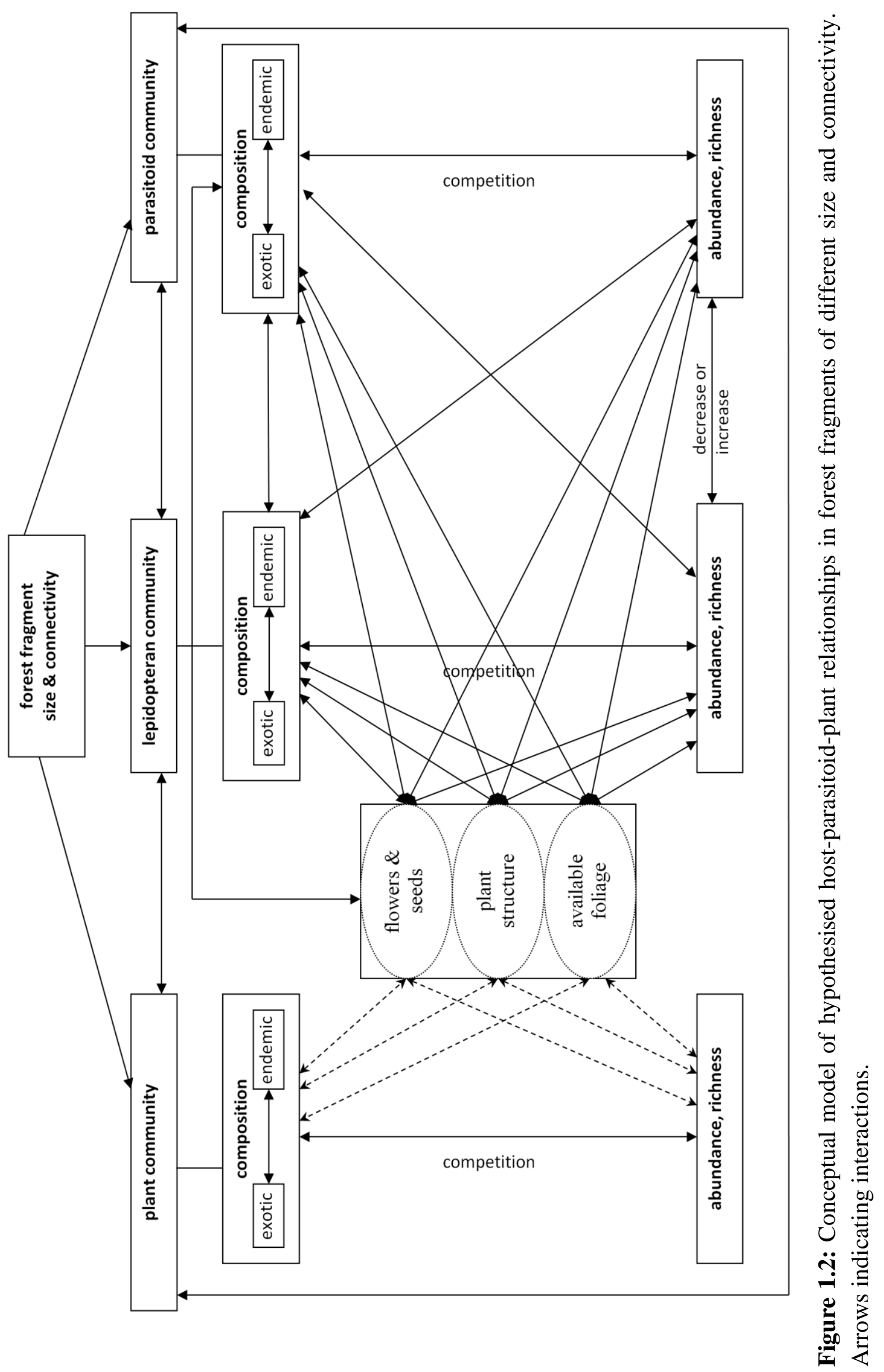




\subsection{Study sites}

The native forest fragments examined within this thesis are all located in the Wellington and Hutt Valley region in the North Island of New Zealand. Prior to European settlement towards the end of the $18^{\text {th }}$ century this region had extensive native forest cover most of which has been cleared to make way for European settlements. Generally the trees in the fragments I surveyed are between 50 - 100 years old (Gabites, 1993; Shepherd, 2000). Native forest covers around $15 \%$ of this region, $20 \%$ is covered by regenerating scrub, $25 \%$ is residential and $40 \%$ is open grassland in the form of parks or pasture (Fig. 1.3).

The area of the study fragments ranged from 12 to 1068 ha. Fragment isolation was

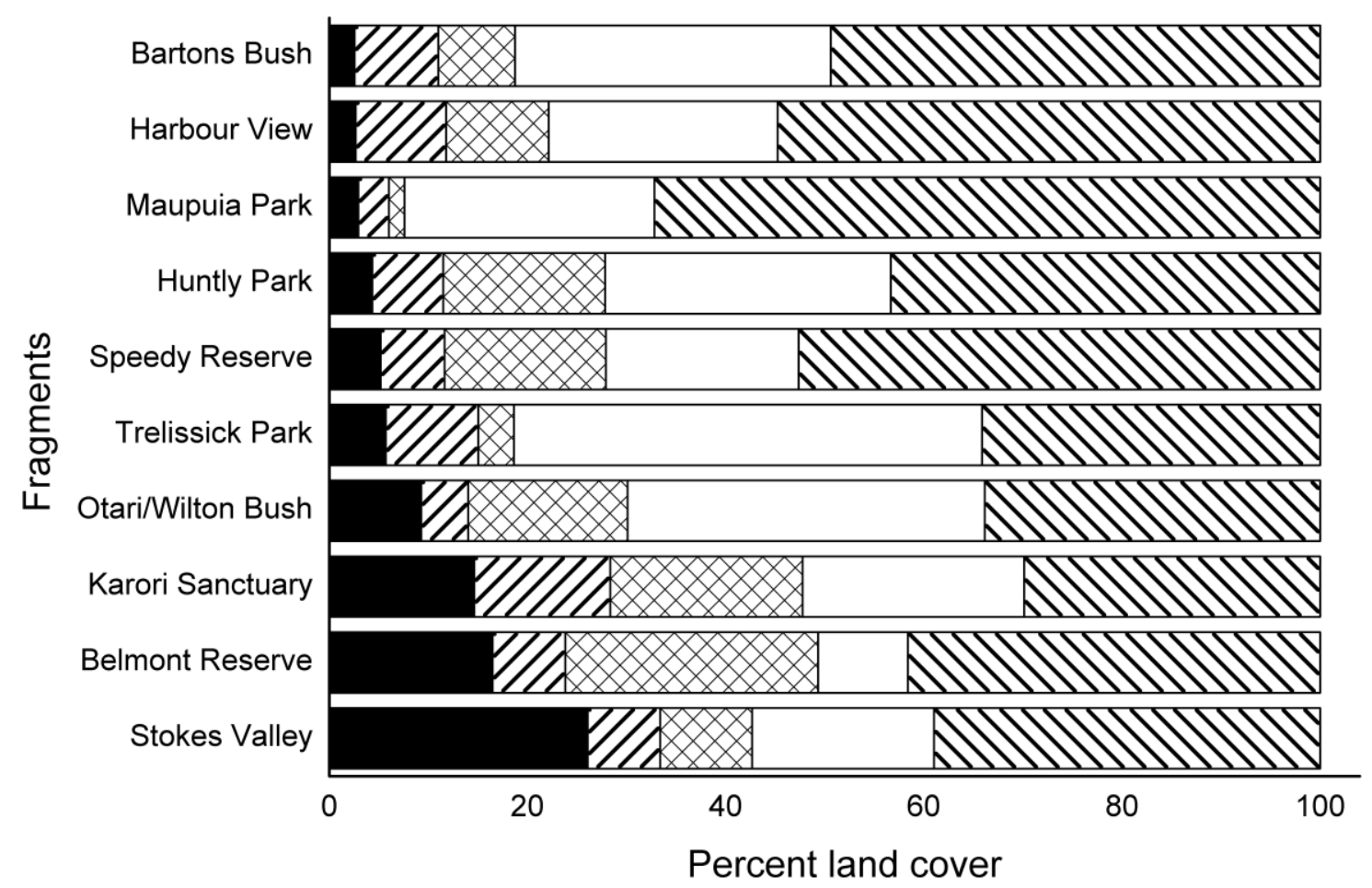

Figure 1.3: Percent of the native forest area investigated in relation to the surrounding land cover within a range of $1 \mathrm{~km}$ distance from the edge of each research fragment. Study fragments $\square$; surrounding native forest fragments $\mathbb{Z}$; scrub land $\square$; residential area $\square$; open area $\mathbf{W}$. 


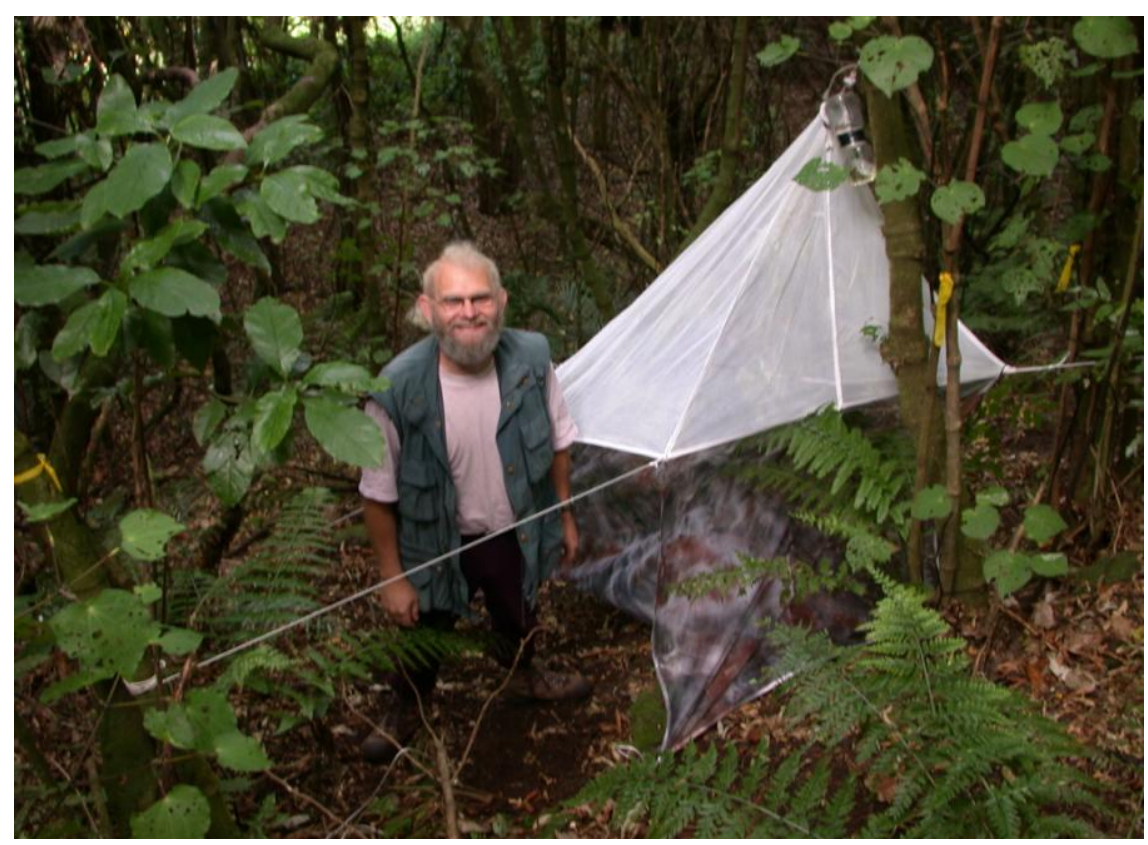

Figure 1.4: Malaise trap with collecting container topmost and kawakawa trees marked with flagging tape.

determined by distance to surrounding fragments and their area within a range of $1 \mathrm{~km}$ distance from the edge of each research fragment. The percentage of residential area surrounding each fragment also was determined within the area covered by the $1 \mathrm{~km}$ surrounding the fragment.

\subsection{Parasitoids}

To collect hymenopteran parasitoids and to examine the parasitoid diversity in the forest fragments I used Malaise traps (Fig. 1.4). A Malaise trap is a flight intercept trap originally developed by the Swedish entomologist René Malaise. Malaise traps have been successfully used in a variety of studies to collect large number of specimens (see Schauff, 1997 and references therein) particularly in parasitic hymenoptera (see Fraser, Dytham \& Mayhew, 2007 and references therein). Ichneumonidae, in terms of species richness, dominated the Malaise trap catches and varied in size from several millimetres 
to around two centimetres. New Zealand's Ichneumonidae are poorly described with many unknown endemic species and a wide variety of hosts. Ichneumonidae are the largest family within the Hymenoptera (Wahl, 1993) and their biology varies depending on the species. Ichneumonidae parasitise immature life stages across a wide range of insect orders and spiders. Amongst the Ichneumonidae individual species may be specialist or generalist parasitoids, the larvae feeding either inside or outside the body of the host (endo- or ectoparasitic) or parasitise arthropod eggs or are hyperparasitic, parasitising other parasitoid larvae (Gauld, 1984). Because of their relatively species rich diversity and the wide size range encountered, this family might be ideal to show different species responses to habitat fragmentation. I therefore included this family in the studies in Chapters 2 and 3.
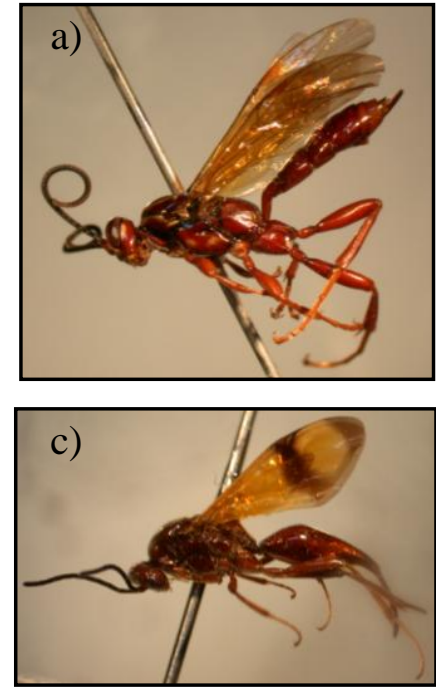

Figure 1.5: Specimens representing parasitoid families included in the parasitoid community studies from Chapters 2 and 3: a) Aucklandella sp., Ichneumonidae; b) Sphictostethus calvus Harris, Pompilidae; c) Fustiserphys longiceps Townes, Proctotrupidae.

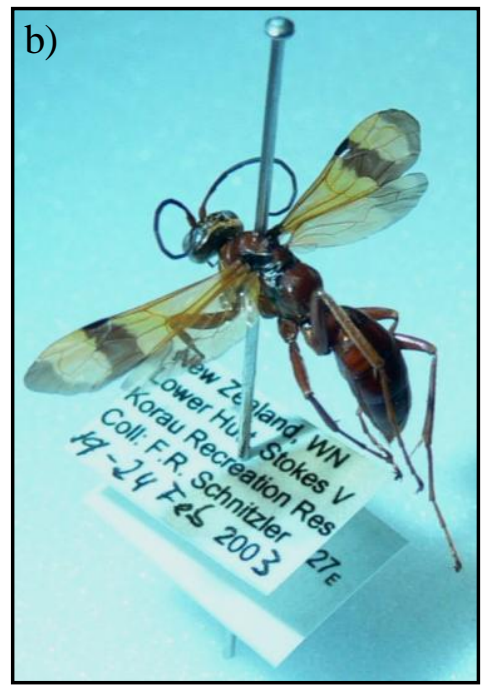


New Zealand's Pompilidae are well studied and there are eleven species known, of which ten are endemic. Pompilidae are ectoparasitic spider hunting wasps and are therefore considered to occupy an even higher trophic level. Pompilids therefore may, as discussed previously, be particularly sensitive to habitat loss. However they are known to be generalists, each species parasitising a wide variety of prey species (Harris, 1987), and they are mostly large and strong flyers. Therefore this family could be less responsive to the fragment elements studied in Chapter 2 and 3. The Proctotrupidae in this study are also understudied and host associations are mostly unknown. The Proctotrupidae are thought to be generalist parasitoids, inhabiting a variety of habitats such as native forests, forest margins, scrubland and semi-woodland suburban gardens (Early \& Dugdale, 1994). Because of their generalist nature they could be expected to be less sensitive to forest fragmentation, due to their small body size $(2-4 \mathrm{~mm})$; however, their distributions might be dependent on their dispersal abilities. This family is also included in the parasitoid community studies in Chapters 2 and 3.

Several studies suggest that the rate of parasitism is dependent on the herbivore's host plants (Barbosa et al., 2001; Lill, Marquis \& Ricklefs, 2002). Collecting from several host plant species, therefore, may obscure forest fragment effects on the rate of parasitism. To reduce the effects of different host plants on the rate of parasitism studied in Chapter 4, I will concentrate on kawakawa Macropiper excelsum Forst. f. (Piperaceae) (also commonly known as New Zealand pepper tree) as the study plant. I selected fragments where kawakawa plants would be present in each fragment. Kawakawa is a small forest tree, usually found in the sub-canopy of native New Zealand forest, mixed bush and scrub (Smith, 1975). According to Spiller \& Wise (1982) kawakawa is host to four lepidopteran species: the kawakawa moth Cleora scriptaria (Walker 1860) 
(=Selidosema panagrata) (Lepidoptera: Geometridae) (Fig. 1.5, the cutworm or armyworm Rhapsa scotosialis Walker (Lepidoptera: Noctuidae), the leafroller Epalxiphora axenana Meyrick (Lepidoptera: Tortricidae), and the brownheaded leafroller Ctenopseustis obliquana Walker (Lepidoptera: Tortricidae). The larvae of these four lepidopteran species are easy to distinguish. Kawakawa is the primary host plant of the kawakawa moth larvae (Hudson, 1928), which is the predominant herbivore on kawakawa (Beever, 1987; Hudson, 1928; Spiller \& Wise 1982). I estimated larval densities using a beating sheet (Fig. 1.6), and collected larvae for rearing of parasitoids (Fig. 1.7). The kawakawa moth larvae were the only larvae I found in high numbers and the other species were rarely encountered and are not included in the study described in Chapter 4. The kawakawa moth, C. scriptaria is found throughout the North, South and Stewart Islands. It is the feeding behaviour of the larvae that causes the characteristic 'riddled' look of the kawakawa leaves (Fig. 1.8).

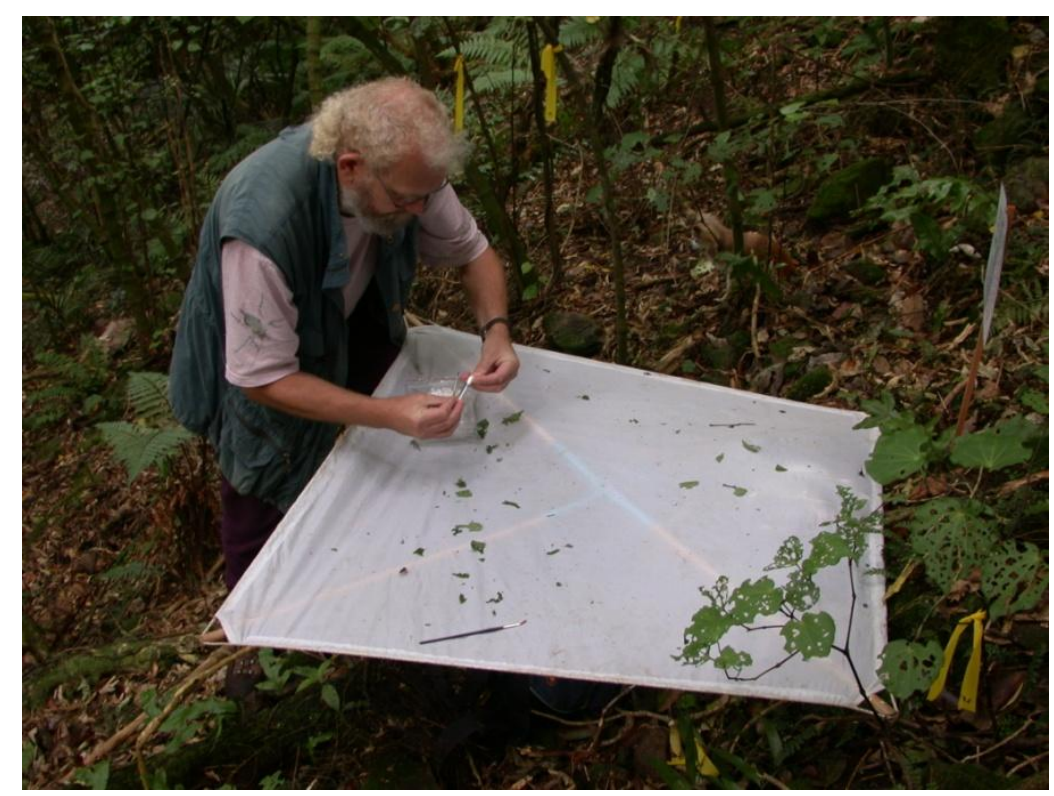

Figure 1.6: Collecting C. scriptaria larvae from a beating sheet. The kawakawa to the bottom right shows signs of herbivory by the kawakawa moth larvae. Flagging tape can also be seen on marked kawakawa trees. 


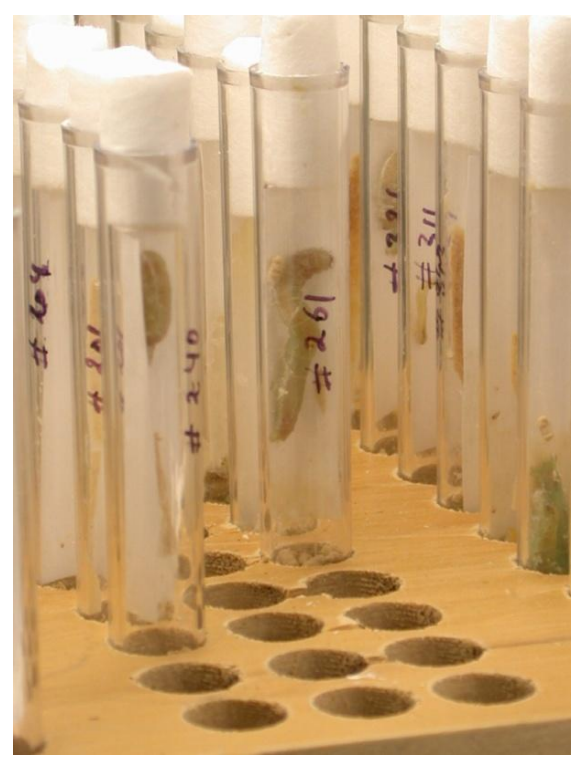

Figure 1.7: Cleora scriptaria larvae in rearing tubes containing artificial diet. The rearing method is described by (Schnitzler, Sarty \& Lester, 2004) (see also Chapter 4, Appendix 4.7).

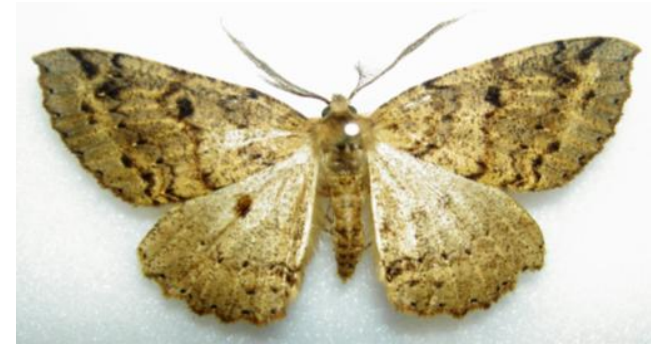

Figure 1.8: The kawakawa moth Cleora scriptaria

(Walker 1860) (=Selidosema panagrata) (Lepidoptera:

Geometridae). 


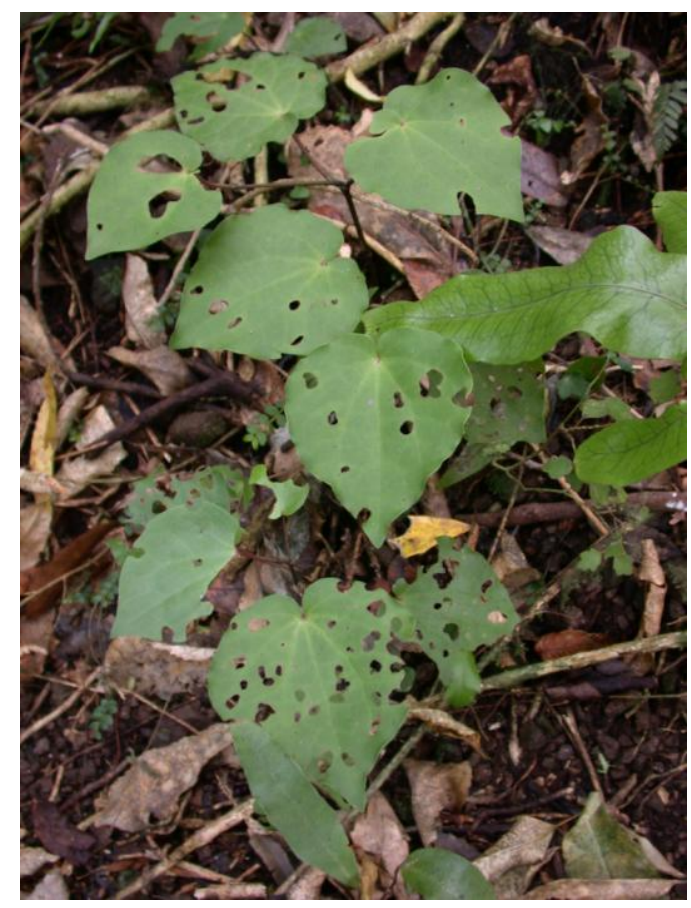

Figure 1.9: Small kawakawa plant with the typically encountered "riddled" appearance of leaf damage caused by the kawakawa moth larvae's feeding behaviour.

\subsection{Thesis outline}

In summary, the objectives of my study are to explore the following questions:

1) Does habitat fragment size and isolation negatively affect parasitoid species richness (number of species), abundance and diversity (Simpson diversity) or do community assemblages change with the habitat fragment area and isolation? For this I concentrate on the diversity of parasitoid families Ichneumonidae, Pompilidae and Proctotrupidae (the latter two thought to be generalists) found in natural forest fragments in the Wellington region (Chapters $2 \& 3$ ). 
2) Are these effects of habitat reduction and fragmentation equal for parasitoids and their hosts and host-parasitoid interactions (i.e. rate of parasitism) within to urban habitat fragments? The trophic system studied here comprises the plant-herbivoreparasitoid communities of the naturally occurring kawakawa $M$. excelsum, its herbivore C. scriptaria and its parasitoids (Chapter 4).

3) What are the consequences of fragmentation and isolation for the management of urban habitat reserves and forest fragments?

Chapters $2-4$ are intended for publication and therefore will be written in the style of a paper. Writing thesis chapters in this format is very much encouraged by the University to increase publication output. There is therefore inevitably some repetition in each chapter, particularly in the method sections in relation to the fragments studied. In addition publications usually acknowledge the advisory role supervisors have during the research process and the chapters therefore are written in the "we" form. This should not detract from the fact that this work is the outcome based on my original ideas for this thesis project and the practical field and lab work and theoretical work carried out by me. For a list of help and advice I received see the acknowledgement section. The individual chapters within this thesis are as follows:

\subsubsection{Chapter 2}

In spite of the importance of wasps as parasitoids of a wide variety of arthropods, there have been very few studies of wasp species richness and community composition in forest habitats in relation to habitat area and isolation effects in an urban environment. In 
Chapter 2 I investigate such parasitoid communities in urban forest fragments. I hypothesised that parasitoid communities would differ in response to habitat loss as well as the nature of the matrix surrounding each fragment. For this I examined differences in parasitoid abundance, richness and diversity as well as differences in the parasitoid community composition in response to the fragmentation indices: fragment area, isolation, plant species richness and percentage residential area in the surrounding area. In addition, I expected specialist species to show stronger responses to fragmentation than generalists, and I expected small-bodied species to be especially sensitive to fragment isolation. My hypotheses in Chapter 2 are:

1. a) The abundance, richness and diversity of parasitoids in urban native forest remnants will be a result of habitat area, isolation, urbanisation of the surrounding matrix and local plant diversity;

b) these relationships differ between different parasitoid families and smallbodied wasps would respond more strongly to isolation than large-bodied wasps;

2. a) Community composition would vary in response to changes in habitat area, isolation, plant richness and matrix quality;

b) these relationships differ between assemblages of different parasitoid families and that community composition of small-bodied wasps would be affected more strongly by isolation than community composition of large-bodied wasps.

In addition, I examine the response of several individual species to changes in habitat size, isolation, percentage residential area and plant diversity, in an attempt to explain the processes leading to the above patterns. 


\subsubsection{Chapter 3}

Effects of habitat fragmentation do not always adequately explain the parasitoid community patterns. Parasitoids may be correlated with plant species richness because plants host a variety of phytophagous insects acting as hosts for parasitoids, or plants provide food or act as shelter for parasitoids. To investigate this I assessed the plant and parasitoid communities and I examined the multivariate relationship between plant and parasitoid community composition across a set of fragments in relation to fragment area and isolation. I analysed correlations between beta diversity of the plant community and the parasitoid community and I investigated whether individual parasitoid occurrences can be predicted by the range of their host's host plants. In Chapter 3 the following hypotheses will be tested:

1. Plant and parasitoid community compositions are independent of one another and unaffected by fragment area and isolation;

2. Parasitoid beta diversity between sites is independent of plant beta diversity;

3. Individual parasitoid absence/presence is independent of the absence/presence of their host's host plants.

\subsubsection{Chapter 4}

According to the trophic level hypothesis habitat fragmentation should affect parasitoids more negatively than herbivores, however herbivore and parasitoid responses to fragmentation have been found to be inconsistent. In Chapter 4 I investigate parasitism rates as well as herbivory caused by $C$. scriptaria larvae in response to properties of the 
fragment, plot and plant. These properties were fragment area, isolation and percentage residential area surrounding fragments; relative $M$. excelsum abundance and plant richness at the plot level; and $C$. scriptaria larval densities, herbivory, tree size and overall parasitism rate at the plant level. I will address the question whether parasitism rate by individual parasitoid species and herbivory are affected differently:

1. At the fragment level by habitat area, habitat isolation, percentage residential area.

2. At the plot level by host plant abundance and plant richness.

3. At the plant level by host larval abundances, overall parasitism rate, and degree of herbivory on an individual tree and individual tree size.

Prior to this study the parasitic fly Pales feredayi (Hutton) (Diptera: Tachinidae) was the only recorded parasitoid known to parasitise C. scriptaria (see Valentine, 1967). The parasitoids reared from the rearing experiments are summarised in a resulting publication by Schnitzler et al. (2004), which is appended to Chapter 4 .

\subsection{Literature cited}

Aguilar, R., Ashworth, L., Galetto, L. \& Aizen, M.A. (2006) Plant reproductive susceptibility to habitat fragmentation: review and synthesis through a meta-analysis. Ecology Letters, 9(8), 968-80.

Aizen, M.A., Ashworth, L. \& Galetto, L. (2002) Reproductive success in fragmented habitats: do compatibility systems and pollination specialization matter? Journal of Vegetation Science, 13(6), 885-92. 
Aizen, M.A. \& Feinsinger, P. (1994a) Forest fragmentation, pollination, and plant reproduction in a Chaco dry forest, Argentina. Ecology, 75(2), 330-51.

Aizen, M.A. \& Feinsinger, P. (1994b) Habitat fragmentation, native insect pollinators, and feral honey bees in Argentine Chaco Serrano. Ecological Applications, 4(2), 37892.

Alberti, M., Marzluff, J.M., Shulenberger, E., Bradley, G., Ryan, C. \& ZumBrunnen, C. (2003) Integrating humans into ecology: opportunities and challenges for studying urban ecosystems. BioScience, 53(12), 1169(11).

Amarasekare, P. (2000a) Coexistence of competing parasitoids on a patchily distributed host: Local vs. spatial mechanisms. Ecology, 81(5), 1286-96.

Amarasekare, P. (2000b) Spatial dynamics in a host-multiparasitoid community. Journal of Animal Ecology, 69(2), 201-13.

Barbosa, P., Segarra, A.E., Gross, P., Caldas, A., Ahlstrom, K., Carlson, R.W., Ferguson, D.C., Grissell, E.E., Hodges, R.W., Marsh, P.M., Poole, R.W., Schauff, M.E., Shaw, S.R., Whitfield, J.B. \& Woodley, N.E. (2001) Differential parasitism of macrolepidopteran herbivores on two deciduous tree species. Ecology, 82(3), 698704.

Baz, A. \& Garciaboyero, A. (1995) The effects of forest fragmentation on butterfly communities in central Spain. Journal of Biogeography, 22(1), 129-40.

Beever, R.E. (1987) The holes in the leaves of kawakawa (Macropiper excelsum). Auckland Botanical Society Newsletter, 42(1), 9-11.

Bierregaard Jr., R.O., Lovejoy, T.E., Kapos, V., Augusto dos Santos, A. \& Hutchings, R.W. (1992) The biological dynamics of tropical forest fragments. BioScience, 42(11), 859-66. 
Bryant, M.M. (2006) Urban landscape conservation and the role of ecological greenways at local and metropolitan scales. Landscape and Urban Planning, 76(1-4), 23-44.

Budischak, S.A., Hester, J.M., Price, S.J. \& Dorcas, M.E. (2006) Natural history of Terrapene carolina (Box Turtles) in an urbanized landscape. Southeastern Naturalist, 5(2), 191-204.

Bukovinszky, T., Potting, R.P.J., Clough, Y., van Lenteren, J.C. \& Vet, L.E.M. (2005) The role of pre- and post-alighting detection mechanisms in the responses to patch size by specialist herbivores. Oikos, 109(3), 435-46.

Carvalho, K.S. \& Vasconcelos, H.L. (1999) Forest fragmentation in central Amazonia and its effects on litter-dwelling ants. Biological Conservation, 91(2-3), 151-57.

Challis, A.J. (1994). The human parameters of biodiversity. In Biodiversity: Papers from a Seminar Series on Biodiversity, hosted by Science and Research Division, Dept. of Conservation, Wellington, 14 June - 26 July 1994 (eds B. McFadgen \& P. Simpson), pp. 43-55. Department of Conservation, Wellington.

Chust, G., Garbin, L. \& Pujade-Villar, J. (2007) Gall wasps and their parasitoids in cork oak fragmented forests. Ecological Entomology, 32(1), 82-91.

Clark, T.E. \& Samways, M.J. (1997) Sampling arthropod diversity for urban ecological landscaping in a species-rich southern hemisphere botanic garden. Journal of Insect Conservation, 1(4), 221-34.

Collinge, S.K. \& Forman, R.T.T. (1998) A conceptual model of land conversion processes - predictions and evidence from a microlandscape experiment with grassland insects. Oikos, 82(1), 66-84.

Collins, J.P., Kinzig, A., Grimm, N.B., Fagan, W.F., Hope, D., Wu, J.G. \& Borer, E.T. (2000) A new urban ecology. American Scientist, 88(5), 416-25. 
Cronin, J.T. (2003) Patch structure, oviposition behavior, and the distribution of parasitism risk. Ecological Monographs, 73(2), 283-300.

Cronin, J.T. \& Strong, D.R. (1999) Dispersal-Dependent Oviposition and the Aggregation of Parasitism. The American Naturalist, 154(1), 23-36.

Davies, K.F. \& Margules, C.R. (1998) Effects of habitat fragmentation on carabid beetles - experimental evidence. Journal of Animal Ecology, 67(3), 460-71.

Denys, C. \& Schmidt, H. (1998) Insect communities on experimental mugwort (Artemisia vulgaris L.) plots along an urban gradient. Oecologia, 113(2), 269-77.

Didham, R.K., Ghazoul, J., Stork, N.E. \& Davis, A.J. (1996) Insects in fragmented forests - a functional approach. Trends in Ecology \& Evolution, 11(6), 255-60.

Didham, R.K., Hammond, P.M., Lawton, J.H., Eggleton, P. \& Stork, N.E. (1998) Beetle species responses to tropical forest fragmentation. Ecological Monographs, 68(3), 295-323.

Doak, P. (2000) The effects of plant dispersion and prey density on parasitism rates in a naturally patchy habitat. Oecologia, 122(4), 556-67.

DOC. (2000) The New Zealand Biodiversity Strategy: February 2000. Dept. of Conservation: Ministry for the Environment.

Early, J.W. \& Dugdale, J.S. (1994) Fustiserphus (Hymenoptera, Proctotrupidae) parasitizes Lepidoptera in leaf-litter in New-Zealand. New Zealand Journal of Zoology, 21(3), 249-52.

Elek, Z. \& Lovei, G.L. (2007) Patterns in ground beetle (Coleoptera: Carabidae) assemblages along an urbanisation gradient in Denmark. Acta Oecologica, 32(1), 10411.

Englund, G. \& Hambäck, P.A. (2007) Scale dependence of immigration rates: models, metrics and data. Journal of Animal Ecology, 76(1), 30-35. 
Ewers, R.M. \& Didham, R.K. (2006) Confounding factors in the detection of species responses to habitat fragmentation. Biological Reviews, 81(1), 117-42.

Ewers, R.M. \& Didham, R.K. (2007) The effect of fragment shape and species' sensitivity to habitat edges on animal population size. Conservation Biology, 21(4), 926-36.

Ewers, R.M., Kliskey, A.D., Walker, S., Rutledge, D., Harding, J.S. \& Didham, R.K. (2006) Past and future trajectories of forest loss in New Zealand. Biological Conservation, 133(3), 312-25.

Ewers, R.M., Thorpe, S. \& Didham, R.K. (2007) Synergistic interactions between edge and area effects in a heavily fragmented landscape. Ecology, 88(1), 96-106.

Fahrig, L. (2003) Effects of habitat fragmentation on biodiversity. Annual Review of Ecology, Evolution, and, 34, 487-515.

Fraser, S.E.M., Dytham, C. \& Mayhew, P.J. (2007) Determinants of parasitoid abundance and diversity in woodland habitats. Journal of Applied Ecology, 44(2), 352-61.

Gabites, I. (1993) Wellington's Living Cloak: A Guide to the Natural Plant Communities. Wellington Botanical Society, Wellington.

Gauld, I.D. (1984) An Introduction to the Ichneumonidae of Australia. British Museum (Natural History), London.

Ghazoul, J. (2005) Pollen and seed dispersal among dispersed plants. Biological Reviews, 80(3), 413-43.

Gibb, H. \& Hochuli, D.F. (2002) Habitat fragmentation in an urban environment: large and small fragments support different arthropod assemblages. Biological Conservation, 106(1), 91-100. 
Goldstein-Golding, E.L. (1991). The ecology and structure of urban greenspaces. In Habitat structure: The physical arrangment of objects in space (eds S.S. Bell, E.D. McCoy \& H.R. Mushinsky), pp. 392-411. Chapman and Hall, London.

Gonzalez, A. \& Chaneton, E.J. (2002) Heterotroph species extinction, abundance and biomass dynamics in an experimentally fragmented microecosystem. Journal of Animal Ecology, 71(4), 594-602.

Hambäck, P.A. \& Englund, G. (2005) Patch area, population density and the scaling of migration rates: the resource concentration hypothesis revisited. Ecology Letters, 8(10), 1057-65.

Hambäck, P.A., Summerville, K.S., Steffan-Dewenter, I., Krauss, J., Englund, G. \& Crist, T.O. (2007) Habitat specialization, body size, and family identity explain lepidopteran density-area relationships in a cross-continental comparison. Proceedings of the National Academy of Sciences of the United States of America, 104(20), 8368-73.

Harris, A.C. (1987) Pompilidae (Insecta: Hymenoptera). Fauna of New Zealand, 12.

Harris, L.D. (1984). Applicability of insular biogeography. In The fragmented forest (ed L.D. Harris). University of Chigaco Press, Chicago.

Henle, K., Davies, K.F., Kleyer, M., Margules, C. \& Settele, J. (2004a) Predictors of Species Sensitivity to Fragmentation. Biodiversity and Conservation, 13, 207-51.

Henle, K., Lindenmayer, D.B., Margules, C.R., Saunders, D.A. \& Wissel, C. (2004b) Species Survival in Fragmented Landscapes: Where are We Now? Biodiversity and Conservation, 13, 1-8.

Heywood, V.H. (1996). The importance of urban environments in maintaining biodiversity. In Biodiversity, science and development. Towards a new partnership. (eds F.d. Castri \& T. Younès), pp. 543-50. CAB International, Wallingford, UK. 
Hines, J., Lynch, M.E. \& Denno, R.F. (2005) Sap-feeding Insect Communities as Indicators of Habitat Fragmentation and Nutrient Subsidies. Journal of Insect Conservation, 9(4), 261-80.

Holt, R.D., Lawton, J.H., Polis, G.A. \& Martinez, N.D. (1999) Trophic rank and the species-area realtionship. Ecology, 80(5), 1495-504.

Hudson, G.V. (1928) The butterflies and moths of New Zealand. Ferguson and Osborne, New Zealand.

Hunter, M.D. (2002) Landscape structure, habitat fragmentation, and the ecology of insects. Agricultural and Forest Entomology, 4(3), 159-66.

Jeffries, M.J. (1997) Biodiversity and conservation. Routledge, London.

Kareiva, P. (1987) Habitat Fragmentation and the Stability of Predator Prey Interactions. Nature, 326(6111), 388-90.

Komonen, A., Penttila, R., Lindgren, M. \& Hanski, I. (2000) Forest fragmentation truncates a food chain based on an old-growth forest bracket fungus. Oikos, 90(1), $119-26$.

Kruess, A. \& Tscharntke, T. (1994) Habitat fragmentation, species loss, and biological control. Science, 264(5165), 1581-84.

Kruess, A. \& Tscharntke, T. (2000). Effects of habitat fragmentation on plant-insect communities. In Interchanges of Insects between Agriculture and surrounding Landscapes. (eds B. Eckboom, M. Irwin \& Y. Robert), pp. 53-70. Kluwer, Dordrecht.

Kühn, I. \& Klotz, S. (2006) Urbanization and homogenization - Comparing the floras of urban and rural areas in Germany. Biological Conservation, 127(3), 292-300.

Larsen, T.H., Williams, N.M. \& Kremen, C. (2005) Extinction order and altered community structure rapidly disrupt ecosystem functioning. Ecology Letters, 8(5), $538-47$. 
Lassau, S.A. \& Hochuli, D.F. (2005) Wasp community responses to habitat complexity in Sydney sandstone forests. Austral Ecology, 30(2), 179-87.

Lassau, S.A., Hochuli, D.F., Cassis, G. \& Reid, C.A.M. (2005) Effects of habitat complexity on forest beetle diversity: do functional groups respond consistently? Diversity and Distributions, 11(1), 73-82.

Laurance, W.F., Lovejoy, T.E., Vasconcelos, H.L., Bruna, E.M., Didham, R.K., Stouffer, P.C., Gascon, C., Bierregaard, R.O., Laurance, S.G. \& Sampaio, E. (2002) Ecosystem decay of Amazonian forest fragments: A 22-year investigation. Conservation Biology, 16(3), 605-18.

Leisnham, P.T. \& Jamieson, I.G. (2002) Metapopulation dynamics of a flightless alpine insect Hemideina maori in a naturally fragmented habitat. Ecological Entomology, 27(5), 574-80.

Lill, J.T., Marquis, R.J. \& Ricklefs, R.E. (2002) Host plants influence parasitism of forest caterpillars. Nature, 417(6885), 170-73.

Lindenmayer, D.B. \& Fischer, J. (2006) Habitat fragmentation and landscape change: An ecological and conservation synthesis Island Press, Washington.

Losey, J.E. \& Vaughan, M. (2006) The economic value of ecological services provided by insects. BioScience, 56(4), 311-23.

Lovejoy, T.E., Bierregaard Jr., R.O., Rylands, A.B., Malcom, J.R., Quintela, C.E., Harper, L.H., Brown Jr. , K.S., Powell, A.H., Powell, G.V.N., Schubart, H.O.R. \& Hays, M.B. (1986). Edge and other effects of isolation on Amazon forest fragments. In Conservation Biology: The science of scarcity and diversity. (ed M.E. Soulé), pp. 257-85. Sinauer, Sunderland, MA. 
Luniak, M. (1996). Synurbanisation of animals as a factor of increasing diversity of urban fauna. In Biodiversity, science and development. Towards a new partnership. (eds F.d. Castri \& T. Younès), pp. 566-75. CAB International, Wallingford, UK.

MacArthur, R.H. \& Wilson, E.O. (1963) An equilibrium theory of insular zoogeography. Evolution, 17, 373-87.

MacArthur, R.H. \& Wilson, E.O. (1967) The theory of island biogeography. Princeton University Press, Princeton.

Margules, C.R., Milkovits, G.A. \& Smith, G.T. (1994) Contrasting effects of habitat fragmentation on the scorpion Cercophonius squama and an Amphipod. Ecology, 75(7), 2033-42.

McEuen, A.B. \& Curran, L.M. (2006) Plant recruitment bottlenecks in temperate forest fragments: seed limitation and insect herbivory. Plant Ecology, 184(2), 297-309.

McIntyre, N.E. (2000) Ecology of urban arthropods: A review and a call to action. Annals of the Entomological Society of America, 93(4), 825-35.

McIntyre, N.E., Rango, J., Fagan, W.F. \& Faeth, S.H. (2001) Ground arthropod community structure in a heterogeneous urban environment. Landscape and Urban Planning, 52(4), 257-74.

McKillup, S.C. \& McKillup, R.V. (2000) The effects of two parasitoids on the life history and metapopulation structure of the intertidal snail Littoraria filosa in different-sized patches of mangrove forest. Oecologia, 123(4), 525-34.

Miyashita, T., Shinkai, A. \& Chida, T. (1998) The effects of forest fragmentation on web spider communities in urban areas. Biological Conservation, 86(3), 357-64.

Miyawaki, A. (1996). Restoration of biodiversity in urban and peri-urban environments with native forests. In Biodiversity, science and development. Towards a new 
partnership. (eds F.d. Castri \& T. Younès), pp. 558-65. CAB International, Wallingford, UK.

Murgui, E. (2007) Effects of seasonality on the species-area relationship: a case study with birds in urban parks. Global Ecology and Biogeography, 16(3), 319-29.

Murren, C.J. (2002) Effects of habitat fragmentation on pollination: pollinators, polliniation viability and reproductive success. Journal of Ecology, 90(1), 100-07.

Myers, N. (1997). The rich diversity of biodiversity issues. In Biodiversity II. (eds M.L. Reaka-Kudla, Wilson, D. E. \& Wilson, E. O.), pp. 125-38. Joseph Henry Press, Washington.

Naumann, I.D. (1991). Hymenoptera. In The insects of Australia. A textbook for students and research workers. (ed C. Division of Entomology), Vol. II, pp. 916-1000. Cornell University Press, Ithaca, New York.

New, T.R. (1993) Angels on a pin - dimensions of the crisis in invertebrate conservation. American Zoologist, 33(6), 623-30.

Niemelä, J. (1999) Ecology and urban planning. Biodiversity and Conservation, 8(1), 119-31.

Patrick, R. (1997). Biodiversity: Why is it important. In Biodiversity II. (eds M.L. ReakaKudla, D.E. Wilson \& E.O. Wilson), pp. 15-24. Joseph Henry Press, Washington.

Pesci. (1996). The urban dimension of diversity. In Biodiversity, science and development. Towards a new partnership. (eds F.d. Castri \& T. Younès), pp. 584-95. CAB International, Wallingford, UK.

Preston, F.W. (1962) The canonical distribution of commonness and rarity: Parts 1 and 2. Ecology, 43, 185-215, 410-32. 
Price, S.J., Dorcas, M.E., Gallant, A.L., Klaver, R.W. \& Willson, J.D. (2006) Three decades of urbanization: Estimating the impact of land-cover change on stream salamander populations. Biological Conservation, 133(4), 436-41.

Rand, T.A. \& Tscharntke, T. (2007) Contrasting effects of natural habitat loss on generalist and specialist aphid natural enemies. Oikos, 116(8), 1353-62.

Ranta, P., Tanskanen, A., Niemelä, J. \& Kurtto, A. (1999) Selection of islands for conservation in the urban archipelago of Helsinki, Finland. Conservation Biology, 13(6), 1293-300.

Raupp, M.J., Shrewsbury, P.M., Holmes, J.J. \& Davidson, J.A. (2001) Plant species diversity and abundance affects the number of arthropod pests in residential landscapes. Journal of Arboriculture, 27(4), 222-29.

Raven, P.H. \& Yeates, D.K. (2007) Australian biodiversity: threats for the present, opportunities for the future. Australian Journal of Entomology, 46(3), 177-87.

Reduron, J.-P. (1996). The role of biodiversity in urban areas and the role of cities in biodiversity conservation. In Biodiversity, science and development. Towards a new partnership. (eds F.d. Castri \& T. Younès), pp. 551-57. CAB International, Wallingford, UK.

Reid, W.V., Laird, S.A., Gamez, R., Sittenfeld, A., Janzen, D.H., Gollin, M.A. \& Juma, C. (1993). A new lease on life. In Biodiversity prospecting. (eds W.V. Reid, S.A. Laird, C.A. Meyer, R. Gamez, A. Sittenfeld, D.H. Janzen, M.A. Gollin \& C. Juma), pp. 1-52. World Resources Institute, Washington.

Ricketts, T.H. (2001) The matrix matters: Effective isolation in fragmented landscapes. American Naturalist, 158(1), 87-99.

Roland, J. (2000). Landscape ecology of parasitism. In Parasitoid population biology. (eds M.E. Hochberg \& A.R. Ives), pp. 83-99. Princeton University Press, Princeton. 
Roland, J. \& Taylor, P.D. (1997) Insect parasitoid species respond to forest structure at different spatial scales. Nature, 386(6626), 710-13.

Roth, D., Roland, J. \& Roslin, T. (2006) Parasitoids on the loose - experimental lack of support of the parasitoid movement hypothesis. Oikos, 115(2), 277-85.

Ryall, K.L. \& Fahrig, L. (2005) Habitat loss decreases predator-prey ratios in a pine-bark beetle system. Oikos, 110(2), 265-70.

Samways, M.J. (1994) Insect conservation biology, 1st edition. Chapman \& Hall.

Samways, M.J. (2007) Insect conservation: A synthetic management approach. Annual Review of Entomology, 52, 465-87.

Savard, J.P.L., Clergeau, P. \& Mennechez, G. (2000) Biodiversity concepts and urban ecosystems. Landscape and Urban Planning, 48(3-4), 131-42.

Schauff, M.E. (1997). Collecting and preserving insects and mites: Techniques and tools. In. Systematic Entomology Laboratory, USDA. National Museum of Natural History, NHB 168., Washington.

http://www.ars.usda.gov/Main/site_main.htm?docid=10141\&page=1.

Schmid, B. (1996). Biodiversity management in peri-urban environments in Switzerland. In Biodiversity, science and development. Towards a new partnership. (eds F.d. Castri \& T. Younès), pp. 576-77. CAB International, Wallingford, UK.

Schnitzler, F.-R., Sarty, M. \& Lester, P.J. (2004) Larval parasitoids reared from Cleora scriptaria (Geometridae: Ennominae). The Weta, 28, 13-18.

Shepherd, W. (2000) Wellington's Heritage: Plants, Gardens, and Landscape. Te Papa Press, Wellington.

Shochat, E., Warren, P.S. \& Faeth, S.H. (2006) Future directions in urban ecology. Trends in Ecology \& Evolution, 21(12), 661-62. 
Shochat, E., Warren, P.S., Faeth, S.H., McIntyre, N.E. \& Hope, D. (2006) From patterns to emerging processes in mechanistic urban ecology. Trends in Ecology \& Evolution, 21(4), 186-91.

Simpson, P. (1994). The consequences of human settlement. In Biodiversity: Papers from a Seminar Series on Biodiversity, hosted by Science and Research Division, Dept. of Conservation, Wellington, 14 June - 26 July 1994 (eds B. McFadgen \& P. Simpson), pp. 57-67. Department of Conservation, Wellington.

Smith, A.C. (1975) Genus Macropiper (Piperaceae). Botanical Journal of the Linnean Society, 71(1), 1-\&.

Smith, R.M., Warren, P.H., Thompson, K. \& Gaston, K.J. (2006) Urban domestic gardens (VI): environmental correlates of invertebrate species richness. Biodiversity and Conservation, 15(8), 2415-38.

Spiller, D.M. \& Wise , K.A.J. (1982). A catalogue (1860-1960) of New Zealand insects and their host plants. DSIR Science Information Division Bulletin. In, Vol. 231. DSIR, Wellington.

Steffan-Dewenter, I. \& Tscharntke, T. (2002) Insect communities and biotic interactions on fragmented calcareous grasslands - a mini review. Biological Conservation, 104(3), 275-84.

Stoll, P., Dolt, C., Goverde, M. \& Baur, B. (2006) Experimental habitat fragmentation and invertebrate grazing in a herbaceous grassland species. Basic and Applied Ecology, 7(4), 307-19.

Strauss, B. \& Biedermann, R. (2006) Urban brownfields as temporary habitats: driving forces for the diversity of phytophagous insects. Ecography, 29(6), 928-40. 
Talley, T.S., Fleishman, E., Holyoak, M., Murphy, D.D. \& Ballard, A. (2007) Rethinking a rare-species conservation strategy in an urban landscape: The case of the valley elderberry longhorn beetle. Biological Conservation, 135(1), 21-32.

Thiel, A., Driessen, G. \& Hoffmeister, T.S. (2006) Different habitats, different habits? Response to foraging information in the parasitic wasp Venturia canescens. Behavioral Ecology and Sociobiology, 59(5), 614-23.

Turner, I.M. (1996) Species loss in fragments of tropical rain forest - a review of the evidence. Journal of Applied Ecology, 33(2), 200-09.

Urban, M.C., Skelly, D.K., Burchsted, D., Price, W. \& Lowry, S. (2006) Stream communities across a rural-urban landscape gradient. Diversity and Distributions, 12(4), 337-50.

Valentine, E.W. (1967) A list of the hosts of entomophagous insects of New Zealand. New Zealand Journal of Science, 10(4), 1100-209.

Valladares, G., Salvo, A. \& Cagnolo, L. (2006) Habitat fragmentation effects on trophic processes of insect-plant food webs. Conservation Biology, 20(1), 212-17.

van Nouhuys, S. (2005) Effects of habitat fragmentation at different trophic levels in insect communities. Annales Zoologici Fennici, 42(4), 433-47.

van Nouhuys, S. \& Hanski, I. (2002) Colonization rates and distances of a host butterfly and two specific parasitoids in a fragmented landscape. Journal of Animal Ecology, 71(4), 639-50.

Vida, G. (1996). General considerations on the biodiversity of urban and peri-urban environments. In Biodiversity, science and development. Towards a new partnership.F., di Castri//T., Younès (ed C. International), pp. 581-83. Wallingford, UK. 
Vuorisalo, T., Lahtinen, R. \& Laaksonen, H. (2001) Urban biodiversity in local newspapers: a historical perspective. Biodiversity and Conservation, 10(10), 1739-56.

Wahl, D.B. (1993). Family Ichneumonidae. In Hymenoptera of the World: An Identification Guide to Families. (eds H. Goulet \& J.T. Huber), pp. 395-448. Agriculture Canada Research Branch Monograph No. 1894E, Ottawa.

Watts, C.H. \& Didham, R.K. (2006) Influences of habitat isolation on invertebrate colonization of Sporadanthus ferrugineus in a mined peat bog. Restoration Ecology, 14(3), 412-19.

Whitford, V., Ennos, A.R. \& Handley, J.F. (2001) "City form and natural process" indicators for the ecological performance of urban areas and their application to Merseyside, UK. Landscape and Urban Planning, 57(2), 91-103.

Wood, A., Stedman-Edwards \& Mang, J. (2000) The Root Causes of Biodiversity Loss. Earthscan Publications Ltd.

Zabel, J. \& Tscharntke, T. (1998) Does fragmentation of Urtica habitats affect phytophagous and predatory insects differentially? Oecologia, 116(3), 419-25. 


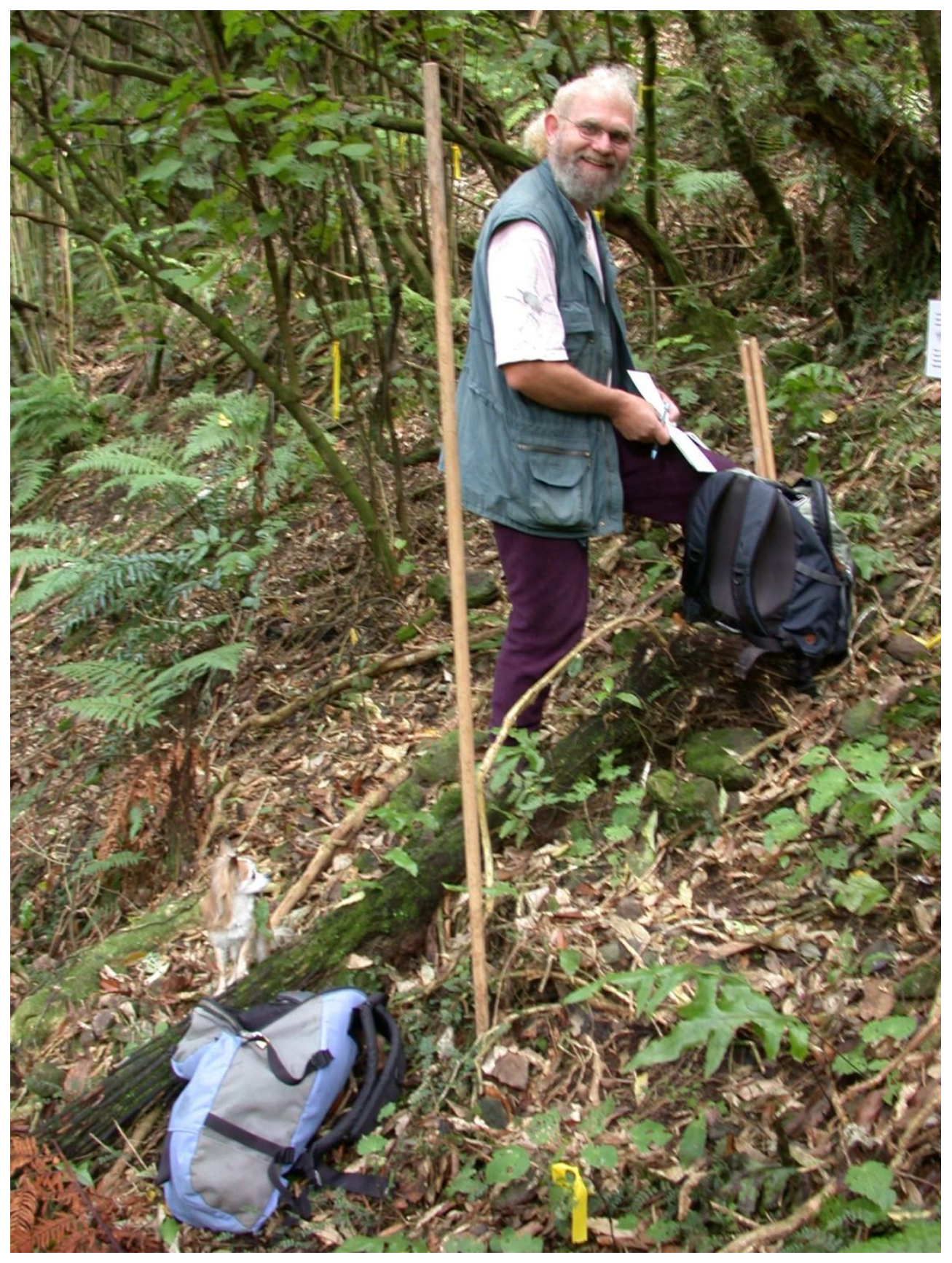

In one of my research sites 


\section{The effect of habitat area, isolation and plant diversity on parasitoid community structure: A study in urban forest fragments ${ }^{1}$}

\subsection{Abstract}

1. Community-level responses to habitat fragmentation are predicted to be strongest at higher trophic levels. To investigate this hypothesis we assessed the plant and parasitoid communities of nine fragments of native forest within the Wellington and Hutt Valley regions of the North Island of New Zealand.

2. Insects were sampled from three sites per fragment during the southern summer months December and February 2002/2003 and 2003/2004. A total of 1343 individual females and 100 morpho-species from the families Ichneumonidae, Pompilidae and Proctotrupidae were selected for this study.

3. Differences in parasitoid abundance, richness and diversity as well as differences in the parasitoid community composition were investigated in response to the fragmentation indices: fragment area, isolation, plant species richness and percentage residential area in the surrounding area.

4. The abundance, richness and diversity of the small-bodied parasitoids were negatively related to increasing area and plant species richness. Multivariate analyses showed fragment isolation and plant species richness affected the overall parasitoid community composition. Ichneumonidae showed a strong response to isolation in one year only. The generalist Pompilidae responded to plant species richness. The Proctotrupidae community structure showed no

\footnotetext{
${ }^{1}$ Co-authors: Pledger, S., Hartley, S., and Lester, P. J.
} 
responses to any of the fragmentation indices. Individual species, however, show different trends in response to the fragmentation indices, making interpretation of a generalised community response difficult.

5. Synthesis and applications. While not quantified in this study, habitat characteristics of each fragment appear to contribute to the distribution of parasitoids across the landscape matrix and are likely to influence individual species responses. We therefore suggest, as a best strategy for conserving parasitoid diversity, to value small as well as large fragments and to conserve a variety of habitat types spread over a geographical region.

Keywords: urban forest fragmentation, parasitoid community, hymenoptera species diversity, isolation, higher trophic levels, insect conservation, nature reserve management, habitat conservation.

\subsection{Introduction}

Human activities such as agriculture, deforestation and urbanisation have led to the fragmentation of natural environments that provide habitat for a variety of organisms. Fragmentation results in a reduction in habitat area and a decrease in habitat connectivity, both of which can reduce plant and animal species richness (Fahrig, 2003; Turner, 1996; Wood, Stedman-Edwards \& Mang, 2000). Although habitat fragmentation is considered a threat to biodiversity worldwide, the mechanisms behind the decline of biological diversity are poorly understood. Insects are under as much threat as many other organisms (Samways, 2005). Several observational studies of arthropod communities, as well as experimental evidence, have shown that species richness, community biomass 
and biotic interactions are all influenced by the area and isolation of habitats in a fragmented landscape (Collinge \& Forman, 1998; Didham et al., 1996; Gonzalez \& Chaneton, 2002). However, certain animals or plants might respond differently to fragmentation than others, and changes in the community at lower trophic levels may result in indirect and cascading effects (Turner, 1996).

Species richness of a variety of insects is known to decline with the decrease in habitat area or an increase in habitat isolation. For example, the species richness of grassland butterflies was reduced by decreasing habitat area and increasing isolation (SteffanDewenter \& Tscharntke, 2002) and the species diversity of endophagous insects on Trifolium pratense and Vicia sepium was dramatically reduced with decreasing area and increasing isolation of grass land habitats (Kruess \& Tscharntke, 2000). However, differences in fragment area are not always reflected in species richness but support different species compositions (Gibb \& Hochuli, 2002).

Measuring changes in species richness alone, therefore, may be too simplistic to reveal any effects associated with habitat fragmentation (Davies \& Margules, 1998; Gibb \& Hochuli, 2002). An organism's response to fragmentation might be more apparent in its biotic interactions. For example, in forest fragments pollination and seed production can be reduced in plants due to impoverishing pollinator communities (Aizen \& Feinsinger, 1994; Murren, 2002). Different responses in abundance to habitat fragmentation were also illustrated in a comparative study of a scorpion and amphipod due to differences in their biology and ecology (Margules, Milkovits \& Smith, 1994). Spider communities in urban forest fragments have also shown a loss of species associated with forest fragmentation. Larger spiders were most sensitive to fragmentation and the body size of 
Nephila clavata was found to be smaller in smaller fragments (Miyashita, Shinkai \& Chida, 1998). The ability of a species to occupy isolated habitats can also depend on the size and variability of the species' populations (Kruess \& Tscharntke, 1994) and its dispersal ability (Didham et al., 1998). Insect community structure, therefore, is influenced by habitat fragmentation and isolation (Steffan-Dewenter \& Tscharntke, 2002).

Contrasting responses to habitat fragmentation and isolation are particularly apparent when involving higher trophic levels such as predators and parasitoids (Kruess \& Tscharntke, 1994; Miyashita, Shinkai \& Chida, 1998). Parasitoids (mainly wasps) play a considerable role in the functioning of ecosystems and form part of the complex interactions that play an important role in the regulation of arthropod populations (Shaw \& Hochberg, 2001). However, due to their biology, hymenoptera populations are prone to reduction or to extinctions (Shaw \& Hochberg, 2001), and are therefore considered to function as sensitive environmental indicators (Fraser, Dytham \& Mayhew, 2008). Parasitoids that use certain arthropod species as food for their larvae further increase their value to humans. Consequently, parasitoids are frequently used in the biological control of agricultural and horticultural pest species, however research to determine their conservation status has been neglected (Shaw \& Hochberg, 2001). Because parasitoids are dependent on the presence of their host-insect populations, which in turn depend on the populations of their own host-plants parasitoids are expected to be more sensitive to the effects of habitat fragmentation than their herbivorous hosts. This is (Kruess \& Tscharntke, 2000; Steffan-Dewenter \& Tscharntke, 2002; van Nouhuys, 2005). Parasitoid's host populations are likely to be smaller in smaller habitat fragments or are dependent on the degree of fragment isolation (Kruess \& Tscharntke, 1994). For 
example, snail populations were higher in isolated habitats where the parasitic Sarcophagidae (flesh fly) was mostly absent and lower in the fly's presence in larger habitats (McKillup \& McKillup, 2000). Parasitoid species persistence is higher in connected fragments than in isolated fragments (Kruess \& Tscharntke, 2000), and the community composition of wasps, which are mainly parasitoids or predators of arthropods, varies with fragment size (Naumann, 1991).

Most studies investigating parasitoid responses to fragmentation are concentrated around agro-ecosystems (Shaw \& Hochberg, 2001). In spite of the importance of wasps as parasitoids of a wide variety of arthropods, there have been very few studies of wasp species richness and community composition in forest habitats, particularly in relation to habitat area and isolation effects in an urban environment. In this study we concentrated on parasitic wasp communities. We surveyed abundance, species richness and diversity, and assemblages of the hymenopteran families of Ichneumonidae, Pompilidae and Proctotrupidae in native forest fragments of different sizes in the Wellington and Hutt Valley regions of the North Island of New Zealand. We hypothesised that parasitoid communities would differ in response to the area, isolation and plant species richness of the fragment, as well as the nature of the matrix surrounding each fragment.

In addition we expected specialist species to show stronger responses to fragmentation than generalists, and we expected small-bodied species to be especially sensitive to fragment isolation. Finally, we examined the responses of several individual species in an attempt to explain the processes leading to the community-level patterns. 


\subsection{Methods}

\subsubsection{Study sites}

We studied nine fragments of native forest within the Wellington and Hutt Valley region in the North Island (New Zealand) (Fig. 2.1). Prior to European settlement towards the end of the $18^{\text {th }}$ century this region had extensive native forest cover most of which has been cleared to make way for European settlements. Generally the trees in the fragments we surveyed are between 50 - 100 years old (Gabites, 1993; Shepherd, 2000). Native forest covers around $15 \%$ of this region, $20 \%$ is covered by regenerating scrub, $25 \%$ is residential and $40 \%$ is open grassland in the form of parks or pasture. The area of the study fragments ranged from 12 to 276 ha (see Appendix 2.1, Table 2.1.1 for fragment indices). The location of fragments, their area, and distances from the edge of the fragment to the edges of neighbouring native fragments were measured using ESRI®ArcGISTM 9.0 (ESRI, 2004). Distances of up to $1415 \mathrm{~m}$ from the nearest natural forest were used in a study to measure the effect of distance from a forest on the insect communities in coffee plantations (Klein, Steffan-Dewenter \& Tscharntke, 2003, 2004, 2006). Social bee abundance, bee and wasp species richness, number of parasitoid species, number of parasitized brood cells, and the number of brood cells were all at their lowest at approximately $1000 \mathrm{~m}$ away from the forest (Klein, Steffan-Dewenter \& Tscharntke, 2003, 2004, 2006). To reduce the risk of too much overlap (i.e. isolation index) within our study, we therefore measured isolation within a range of $1 \mathrm{~km}$ distance from the edge of each research fragment. We calculated an isolation index for each fragment, based on the commonly-used formula proposed by Hanski, Kuussaari \& Nieminen (1994): 


$$
I_{j}=\sum_{j=1}^{n} \exp \left(-d_{i j}\right) A_{j}, \quad j \neq i
$$

where, $d_{i j}$ is the minimum distance (in $\mathrm{km}$ ) from the focal fragment $i$ to the neighbouring native fragment $j, n$ is the number of neighbouring fragments, and $A_{j}$ is the area (in $\mathrm{m}^{2}$ ) of the neighbouring native fragments. A lower value of $I$ indicates a more isolated fragment in comparison to less isolated fragments with larger $I$ values. Fragment area and isolation were $\log _{10}$ transformed prior to analysis. Within the same $1 \mathrm{~km}$ range around each fragment, we calculated the relative cover of residential area as a measure of matrix quality that may be related to functional isolation.

Edge effects, such as differences in light, wind and humidity often mean that forest fragments contained different faunal compositions in the centre compared to the fragment edges (Didham et al., 1998; Gibb \& Hochuli, 2002; Turner, 1996). As a control for this possibility, three randomly selected collection sites were placed inside each fragment at a consistent distance of $30 \pm 5$ meters from the fragment edge. As a measure of habitat quality we recorded the abundance of plant species using the Reconnaissance (RECCE) description procedure (Allen, 1992). Plant species lists were pooled across the three sites $(20 \times 20 \mathrm{~m})$ to generate a single measure of plant species richness for each fragment. As part of initial exploratory data analysis we examined the correlation structure between the four indices of fragmentation, using Pearson's correlation coefficient. 


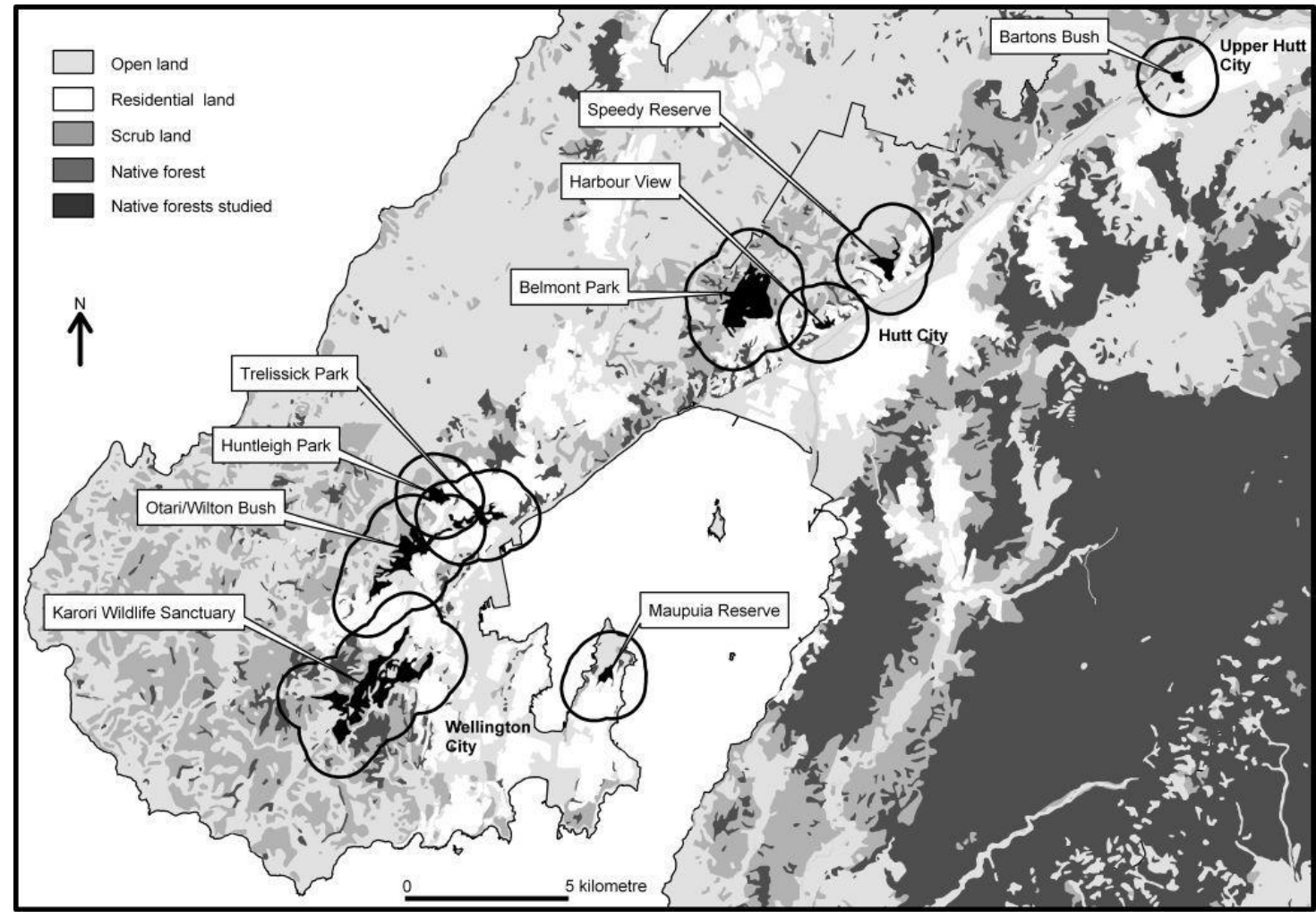

Figure 2.1: The Wellington and Hutt Valley region with the location of nine native forest research fragments and the surrounding $1 \mathrm{~km}$ range included in the study. (Data and land cover shape files courtesy of New Zealand Department of Conservation http://extranet.doc.govt.nz/bip).

\subsubsection{Insect sampling}

Temporal abundance of some insects and species richness of parasitoid hosts often varies over a period of several years (Barbosa et al., 2001), we therefore set up one Malaise trap per collecting site in December and February of the 2002/2003 and 2003/2004 summer periods (Appendix 2.1, Table 2.1.2). Logistical constraints meant we could not sample all 27 sites concurrently. Consequently, traps were set for a period of four to five days within the month, and rotated across fragments following a randomly determined sequence. Trap samples were sorted into Ichneumonidae, Pompilidae and Proctotrupidae for this study. Assigning male ichneumonids to corresponding females is almost impossible without a 
key or species knowledge. To prevent inflated species richness all males are therefore excluded from this study.

The collected specimens were stored in $70 \%$ ethanol and reference material was sorted, mounted and identified to subfamily and where possible to genus or species. Where identification to genus or species level was not possible specimens were sorted to morpho-species, which will be referred to as species from here on. For identification of Pompilidae we referred to Harris (1987), for identification of Proctotrupidae we used Townes \& Townes (1981) and for ichneumonid subfamilies and some genera Gauld (1984) and Wahl (1993). In addition, we compared our ichneumonid and proctotrupid specimens with collections held at the Auckland Museum, the New Zealand Arthropod Collection at Landcare Research (Manaaki Whenua) and the Museum of New Zealand, Wellington (Te Papa Tongarewa). Some voucher specimens were deposited at the Museum of New Zealand (Te Papa Tongarewa), Wellington.

\subsubsection{Parasitoid abundance, richness and diversity}

We pooled samples collected in the same summer and calculated the abundance of individuals across all species $(N)$, species richness $(\mathrm{S})$, and the reciprocal of the Simpson diversity index $(1 / D)$ of the assemblage on a site by site basis. The Simpson diversity index was calculated using the formula described by Magurran (2004):

$D=\sum\left(n_{i} / N\right)^{2}$

eqn. 2.2

where $n_{i}=$ the number of individuals per species $i$. We examined the univariate responses of the three indices of community structure $(N, S$ and $1 / D)$ to the four fragmentation 
indices: fragment area, isolation, percent residential area in the surrounding matrix and plant species richness. The four fragment properties were entered as covariates and "year" (1-2) and "fragment" (1-9) as crossed, fixed factors.

We used a non-parametric univariate analysis of variance with the software "PERMANOVA6", which has the advantage of good power coupled with an absence of assumptions of normality of the errors, a constant variance, and independent errors (Anderson, 2001; McArdle \& Anderson, 2001). This method can test one or more continuous variables for their response to one or more factors and covariates in a balanced ANOVA experimental design using permutation methods to calculate a p-value (Anderson, 2005). Any distance measure may be used for the response variable, which makes this method particularly useful for ecological data where the assumption of a multivariate normal distribution of the data is unrealistic (Anderson, 2001).

In all our analyses we used Bray-Curtis dissimilarity as our distance measure. The BrayCurtis distance measure ignores species jointly absent from sites and therefore is well suited for species abundance data (Quinn \& Keough, 2002) and is highly commended by Magurran (2004). Input data were not transformed or standardised. We used 4999 permutations in order to obtain reliable results at an $\alpha$-level of 0.01 . We used ' 3 ' as the seed integer for randomisations. This integer needs to be the same in a repeat analysis to achieve the exact same result (Anderson, 2005).

We used a two-factor crossed ANCOVA design, where "year" and "fragment" were the factors and properties of the fragment ("area", "isolation", "urbanisation of the surrounding matrix" and "plant richness") were entered as covariates. We calculated the 
influence of the covariates in combination with factor effects, but due to the nesting of sites within fragments the p-values for the factors and factor interactions had to be determined from a separate ANOVA without covariates. For these latter analyses we used the program's option of "unrestricted permutations of raw data". This option was not available for the analyses with the covariates and we chose the option of "permutation of the raw data". The empirical power (probability of rejecting the null hypothesis when it is false) of the first mentioned option may be less than for the second option (Anderson, 2005). We do not report the $F$-statistics produced in our analyses as they are pseudo $F$ statistics and do not represent Fisher's traditional $F$-ratio (Anderson, 2005).

Despite correlations between our covariates (correlations were not absolute, see result section for more details) we retained all four covariates in our initial model. Ecological responses (observational data) are often under the influence of several explanatory variables that are correlated with each other (collinear, multicollinear) and are not under experimental control (Graham, 2003; Quinn \& Keough, 2002). Collinearity may effect one's ability to correctly estimate model parameters (Legrendre \& Legrendre, 1998) and the sequence of covariates added to the model will effect the outcome (Type I sums of squares). One solution would be to omit the highly correlated covariates from the analysis. Excluding a variable however, would mean ignoring the unique contribution of the dropped variable, which can result in the loss of explanatory power (Graham, 2003). Another solution would be to use Type III sums of squares, where the full model is compared against a model without the main effect of interest added. The PERMANOVA method used in this study fits a linear model that is additive (Type I sums of squares) and can only calculate a single p-value for the combined effect of all the covariates in the model (Anderson, 2005). Since our primary interest was to discover which of the four 
covariates (i.e. the four fragmentation parameters) were important to community structure, we proceeded to search a series of reduced models (dropping individual covariates one at a time) whenever the full model showed a potential effect of all four covariates at $\mathrm{p}<0.2$. We continued to remove covariates as long as incremental reductions in the p-value were being achieved. The model with the lowest p-value was considered the "best approximating model" (for detailed methods and examples see Appendix 2.2, Figs 2.2.1 \& 2.2.2). We felt this to be an appropriate basis for model comparison and selection, because the significance of each model was determined from a permutation test which implicitly accounts for the number of terms in the model. Many of the statistics commonly used for this purpose, such as the Akaike Information Criterion (AIC), are only applicable within a likelihood or quasi-likelihood framework.

Indices of abundance, richness and diversity were also calculated separately for each of the three families and for four different assemblages defined by individual body size (see Appendix 2.3, Tables 2.3.1 \& 2.3.2). Body size has been related to dispersal in a fragmented landscape (Nieminen, 1996; Roslin, 2000). To determine the limits of each size class we measured overall body length excluding the ovipositor on average-sized specimens and used cluster analysis based on Bray-Curtis similarity with the software Primer 5 (Clarke, 1993). We examined, using the same method as described above, whether the combination of the four fragmentation indices and the factors could explain differences in the three indices for each of the three families and the four size groups. To investigate the explanatory power of the "best" models we calculated the $R^{2}$ values for the fragment and covariate terms:

$R_{\text {term }}^{2}=\mathrm{SS}_{\text {term }} / \mathrm{SS}_{\text {total }}$ eqn. 2.3 
Species richness per site (within each fragment) does not usually reflect the actual number of species per fragment. We therefore pooled species lists across the three study sites to calculate species richness per fragment $\left(S_{f r a g}\right)$ for each year (Appendix 2.4, Table 2.4.1). We used a one-way ANCOVA design to examine the response of the fragmentlevel species richness $\left(\mathrm{S}_{f r a g}\right)$ to the four covariates combined. For this design there were 18 observations, with fragment as factor (nine fragments) over two replicate years.

We were also interested in whether community assemblage, species abundance, richness or diversity displayed any broad-scale trends across the study area. Therefore we tested for a correlation of the Bray-Curtis dissimilarity of the total community assemblage, and of the species abundance, richness and Simpson diversity with the geographic (Euclidean) distances between sites using the RELATE function of PRIMER version 5.0 (Clarke, 1993). RELATE is similar to a Mantel test and uses the Spearman rank correlation coefficient $\rho$, which does not require the assumption of linearity. All data were non-transformed, non-standardised and correlations were calculated using 999 permutations.

\subsubsection{Parasitoid community composition}

A species $\times$ site community abundance matrix was created for each year of sampling. Separate matrices were also established for the three families and the four size groupings. For a detailed electronic dataset please contact the author.

Using the same permutation analytical approach as for the univariate analysis outlined above, we examined differences in the dissimilarities of the species communities as a multivariate community response to the covariates fragment area, isolation, percent 
residential area and plant species richness using a multi-factor crossed MANCOVA, while responses to the factor fragment and year were assessed from a separate MANOVA. In addition, where there was a significant fragment $\times$ year interaction $(\mathrm{p}<$ $0.05)$, we split the data into years 1 and 2 and reanalysed each year's data separately to better understand the relationship. We performed the same analyses on the subcommunities defined by the three taxonomic groups and the four size groups. As in the univariate analysis we calculated the $R^{2}$ for the factor "fragment" and for the set of the fragmentation indices that constituted the best model (i.e. the lowest p-value).

We used non-metric multi-dimensional scaling (nMDS) plots to illustrate the multivariate patterns of the community composition across fragments, using the PRIMER 5 software (Clarke, 1993).

\subsubsection{Individual species responses}

To better understand the community-level patterns of species abundance, richness and diversity as well as the patterns in the multivariate community composition, we examined the individual responses of the 20 most abundant species. We chose abundance (squareroot transformed) as a species-level response variable, with year as the factor and our four fragment indices combined as covariates using an ANCOVA.

\section{$2.4 \quad$ Results}

In total we collected 1343 individuals from 100 parasitoid species (Appendix 2.5, Table 2.5.1). Species assemblages differed between years 1 and 2, and accumulation curves of parasitoid species numbers versus the number of samples do not asymptote (Fig. 2.2) 
(Appendix 2.4, Table 2.4.1). The species assemblage was dominated by the Ichneumonidae, which also represented the majority of species in the different size groups (Table 2.1).

Across our study sites, as is typical of most modified landscapes, larger forest fragments tended to be less isolated from nearby forest habitat ( $p<0.01$, Table 2.2). The number of plant species is highest in the larger and least isolated fragments $(\mathrm{p}<0.05$, Table 2.2). Despite these correlations, we retained all four of the original covariates in our analyses, as the correlations were not absolute. The correlations between the remaining covariates were all non-significant ( $\mathrm{p}>0.05$, Table 2.2). 


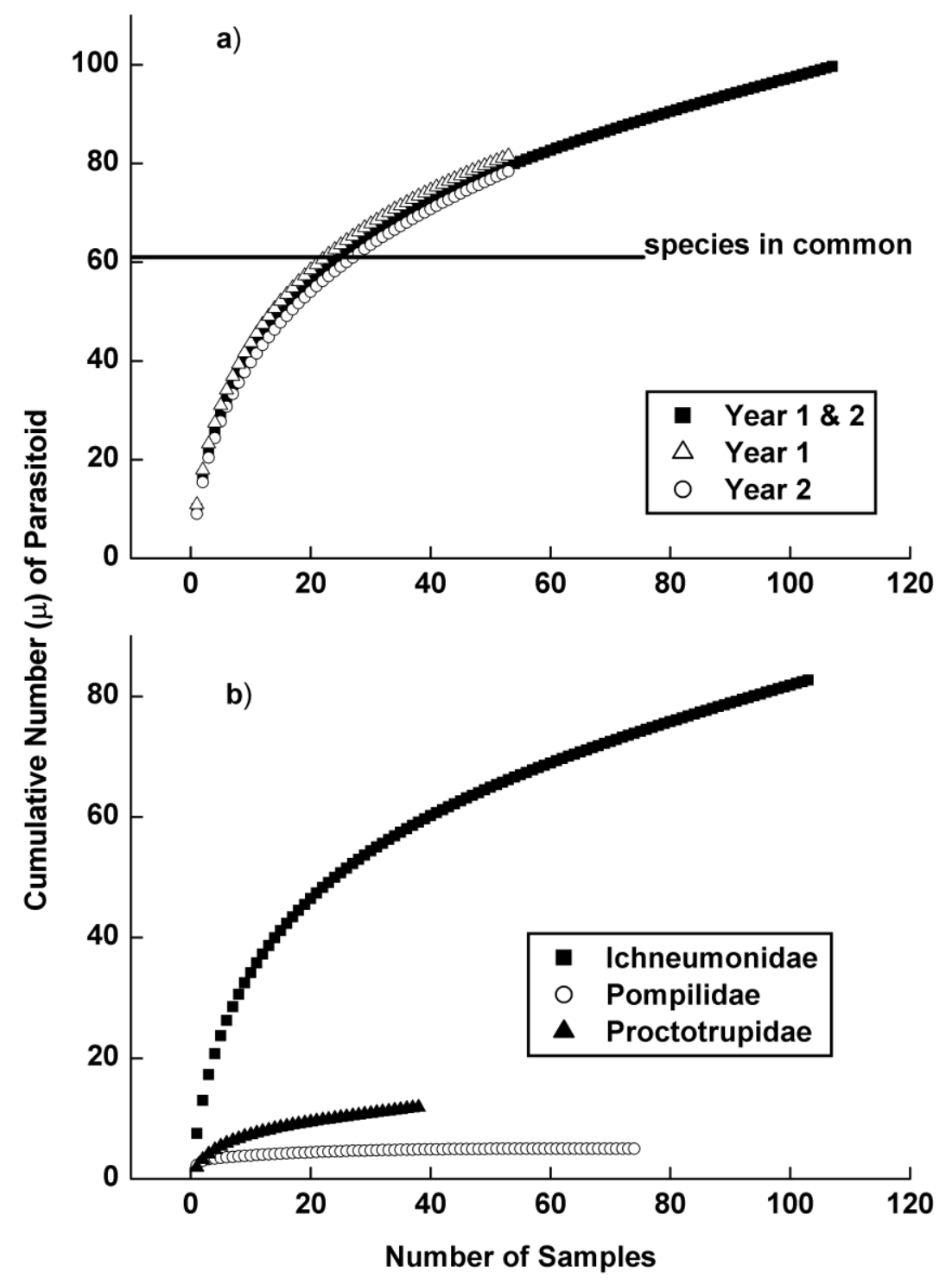

Figure 2.2: Coleman rarefaction curve for cumulative mean number of parasitoid species and number of samples: a) 100 species in 108 Malaise trap samples for years 1 and 2 (solid circles), 82 species year 1 (open circles), and 79 species in year 2 (open triangles). The horizontal line indicates 61 species in common between years 1 and 2; b) Cumulative mean number of species collected for the families of Ichneumonidae, Pompilidae and Proctotrupidae in years 1 and 2. Samples were randomised 100 times without replacement using EstimateS 7.5 (Colwell, 2005). 
Table 2.1: Division of the total community into sub-communities defined by family or size class. (Values $=$ number of species).

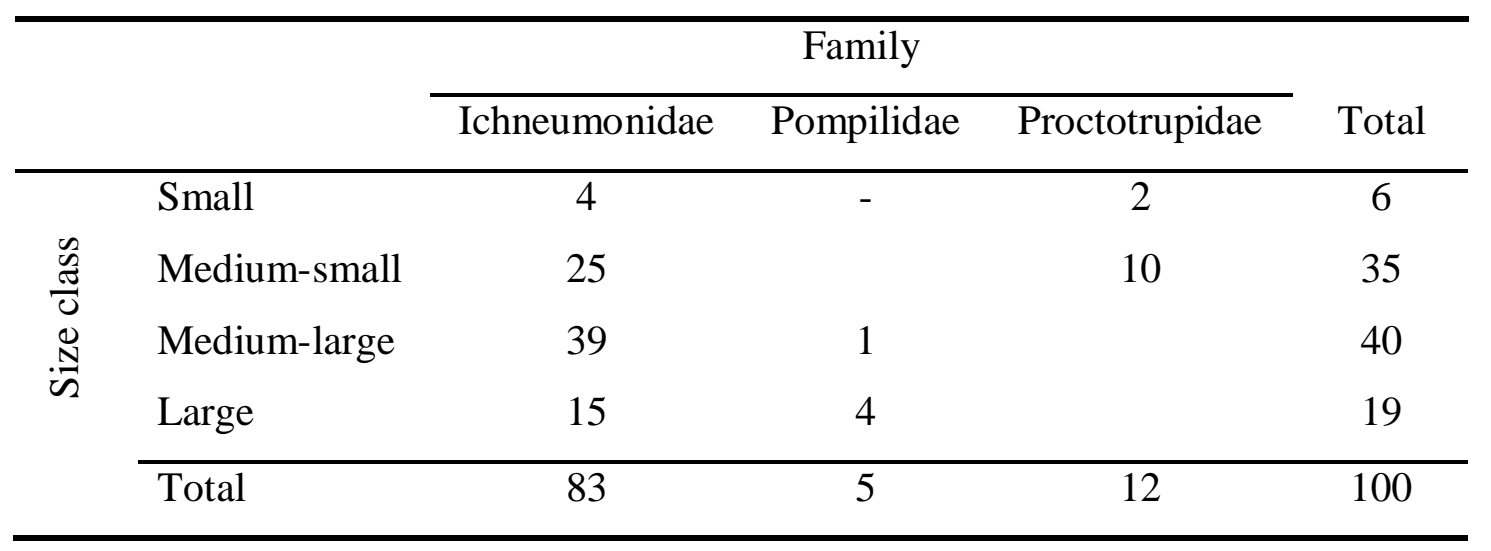

Table 2.2: Pearson's correlation between area, isolation index, percentage of residential area and number of plant species. $\mathrm{N}=9 ; d f=7$; $* \mathrm{p}<0.05$ (2-tailed);**p 0.01 (2-tailed).

\begin{tabular}{lllc}
\hline & Area & Isolation & Residential area \\
\hline Isolation & $0.804^{* *}$ & & \\
Residential area & -0.242 & -0.111 & \\
Plant richness & $0.690 *$ & $0.689 *$ & -0.317 \\
\hline
\end{tabular}

\subsubsection{Parasitoid species abundance, richness, diversity}

There appeared to be no effect of the combined fragmentation indices on the abundance, species richness and diversity of the total parasitoid community (Table 2.3). Similarly, no effects of the fragmentation indices were evident when the assemblages of the different families were analysed separately (Table 2.3) (Appendix 2.3, Table 2.3.1) nor of the medium-small, medium-large and large bodied parasitoid groupings (Table 2.4) (Appendix 2.3, Table 2.3.2). Only the assemblage of small-bodied parasitoids suggested that some of the fragmentation indices may be important in influencing community structure (combined effect of all four covariates, $\mathrm{p}<0.2$, Table 2.4). 
A backwards search of sub-models showed that the combination of fragment area and number of plant species best explained the variation in abundance, richness and diversity of the small-bodied parasitoids (Table 2.5). Closer inspection of the trend showed an overall negative response to increasing area and plant richness. However the abundance, richness and diversity of the small-bodied parasitoids vary hugely between fragments. In addition, the $R^{2}$ values indicate that these two covariates explain somewhat more of the variation in the community structure of small parasitoids than other unidentified factors associated with each fragment (Table 2.5). Area and plant richness alone, as well as the area + isolation and isolation + plant richness combinations, show no statistically significant relationship with the small-bodied abundance, richness or diversity ( $p>0.1)$.

Despite the general lack of response to the covariates, there were many cases of significant factor effects, indicating that community structure was highly dependent upon other properties of the fragment and the year outside the scope of this study (Tables $2.3 \&$ 2.4). We found that the Simpson diversity of the family Ichneumonidae differed significantly between fragments (Table 2.3) as did the Simpson diversity and species richness of the large-bodied parasitoids (Table 2.4). These responses were independent of the year of sampling. In contrast, there were significant fragment $\times$ year interactions for the species abundance and richness of the total assemblage and the ichneumonid assemblage, as well as for all three indices of the family Proctotrupidae (Table 2.3) and the medium-large size group (Table 2.4). These significant interactions indicate that the community structure observed differs between fragments in a way that cannot be adequately predicted by the covariates, and in a manner that is different from year to year. 


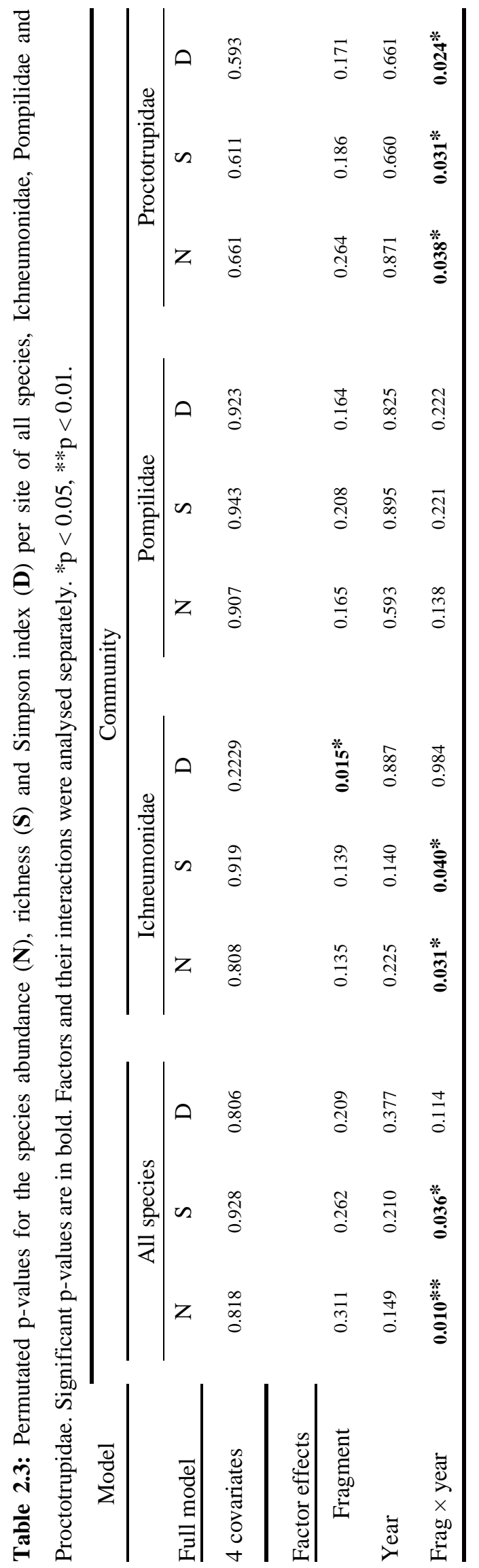




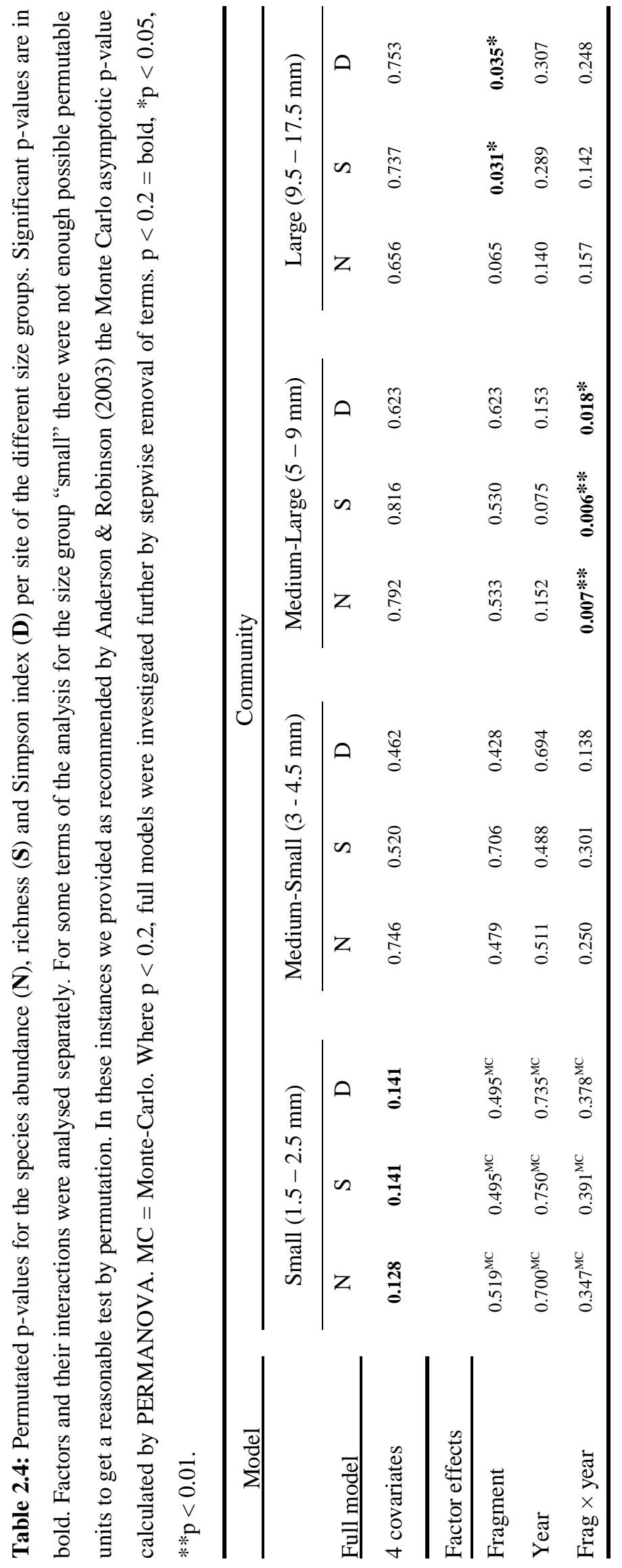


Table 2.5: Combination of area and plant richness indices as the model best describing the variation for the univariate indices of the small-bodied parasitoid community years 1 and 2 combined. Years 1 and 2 remained combined since there was no significant effect of year or fragment $\times$ year interaction. $R^{2}$-values are from the models with the lowest $\mathrm{p}$-value $\left({ }^{*} \mathrm{p}<0.05\right)$.

\begin{tabular}{lccc}
\hline $\begin{array}{l}\text { Response } \\
\text { variable }\end{array}$ & $\begin{array}{c}\text { P-value of best } \\
\text { model }\end{array}$ & $\begin{array}{c}R^{2} \text { covariates (area \& } \\
\text { plant richness) }\end{array}$ & $R^{2}$ fragment \\
\hline Abundance & $0.039^{*}$ & 0.146 & 0.103 \\
Richness & $0.046^{*}$ & 0.143 & 0.104 \\
Diversity & $0.046^{*}$ & 0.130 & 0.102 \\
\hline
\end{tabular}
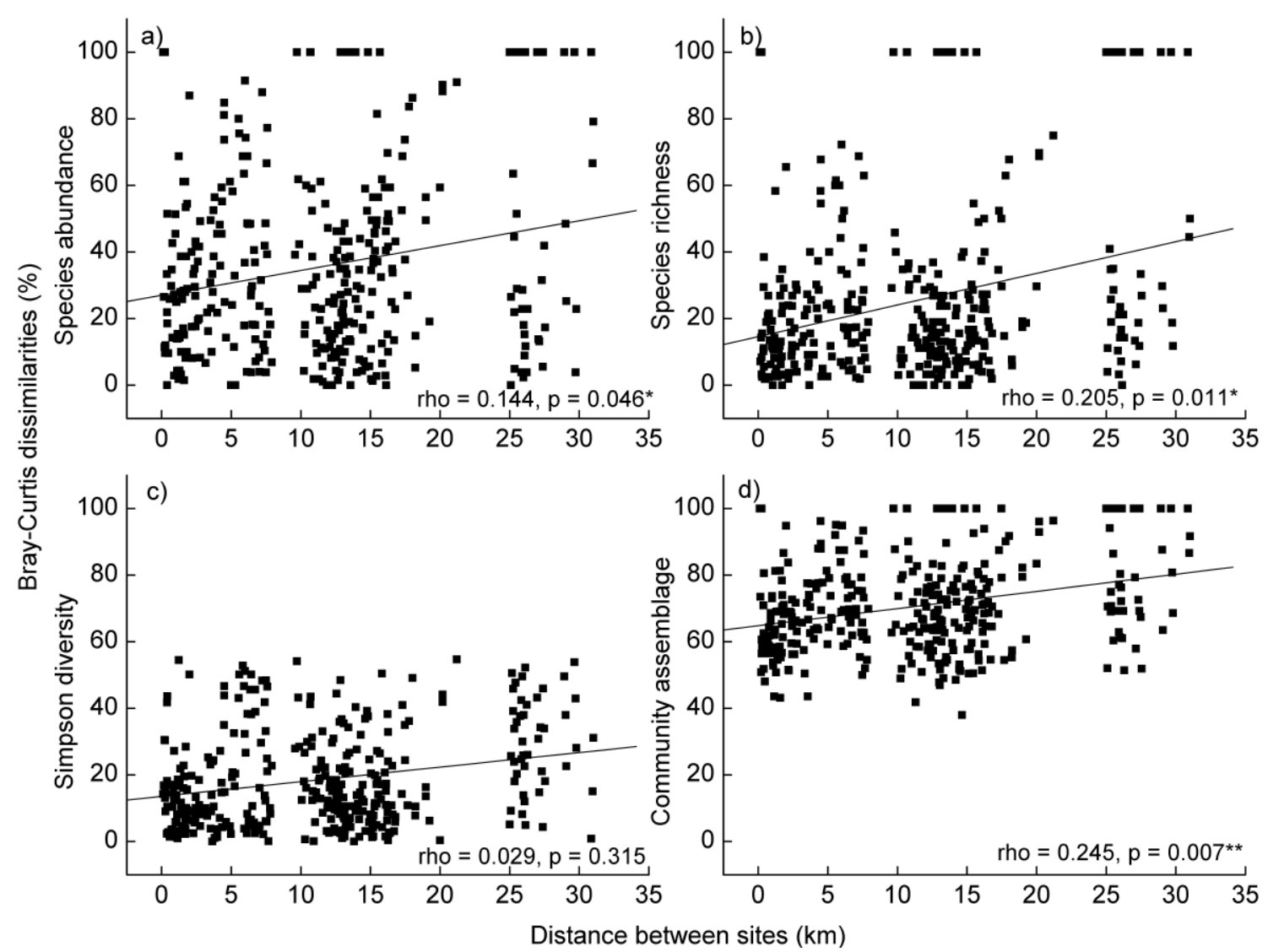

Figure 2.3: Scatter plot showing the Bray-Curtis dissimilarities from the univariate species abundance, richness and diversity $(\mathrm{a}-\mathrm{c})$, and the multivariate community assemblage (d) in relation to the geographic distances (Euclidian distance) between sites of the fragments. Data are pooled for years 1 and 2 . $\left(\mathrm{N}=27\right.$ number of sites; ${ }^{*} \mathrm{p}<0.05$, $* * \mathrm{p}<0.01)$. 
Species abundance and richness were significantly similar in sites that were closer to each other than sites that were further apart. However, these relationships appeared to be weak, indicated by low correlation coefficients. The relationship between the Simpson diversity and geographical distances was found to be non-significant (Fig. 2.3a-c). The additional analysis of the total species richness per fragment $\left(\mathrm{S}_{\text {frag }}\right)$ also showed a nonsignificant response to the four covariates ( $p=0.999$, Fig. 2.4).
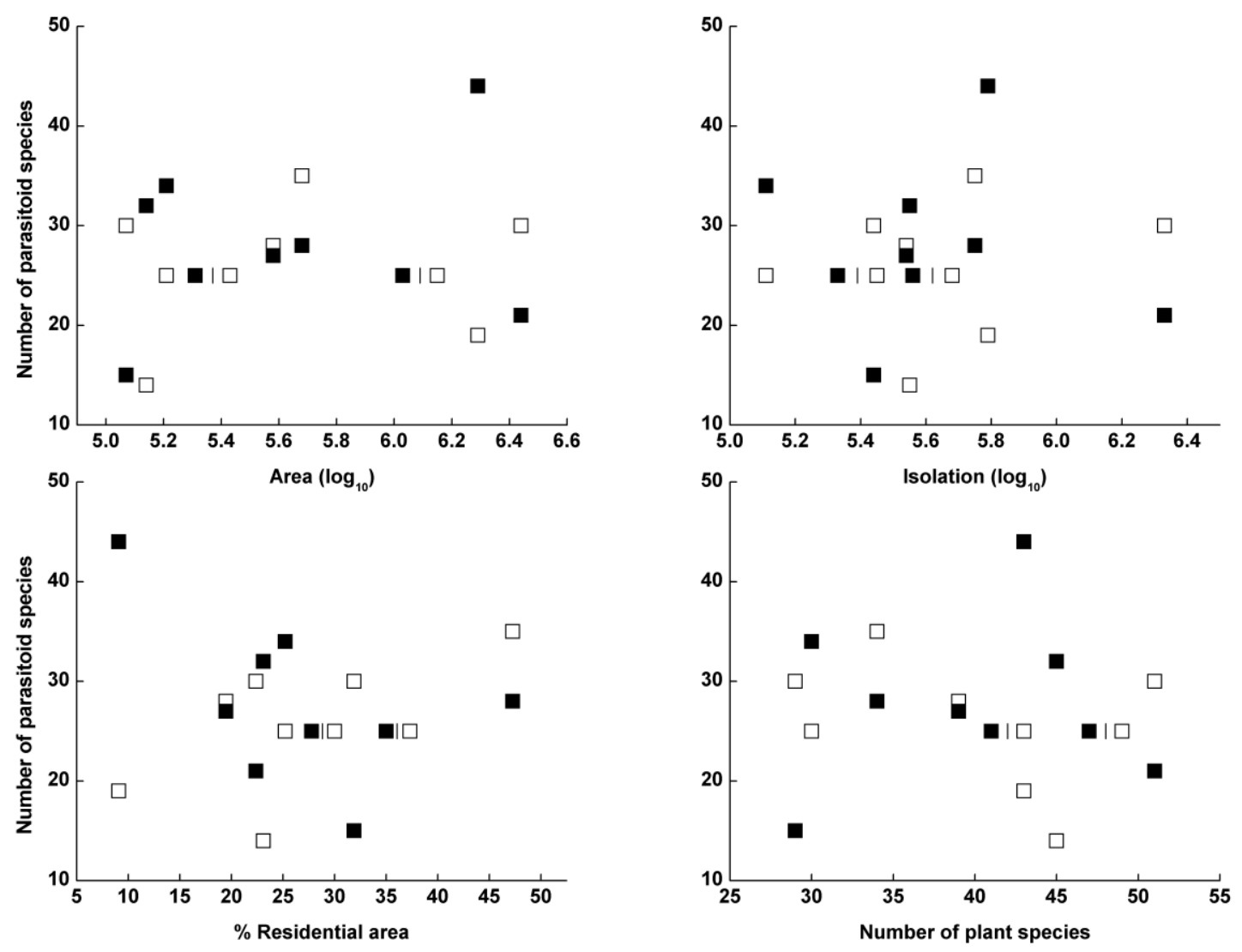

Figure 2.4: Total parasitoid species richness pooled for each fragment $(\mathrm{N}=9)$ per year. Species richness $\left(\mathrm{S}_{\text {frag }}\right)$ responses are to fragment area, isolation, percentage residential area and number of plant species per fragment (year1 $\square$ and year $2 \mathbf{m}$, overlapped points are plotted offset and are indicated by |). 


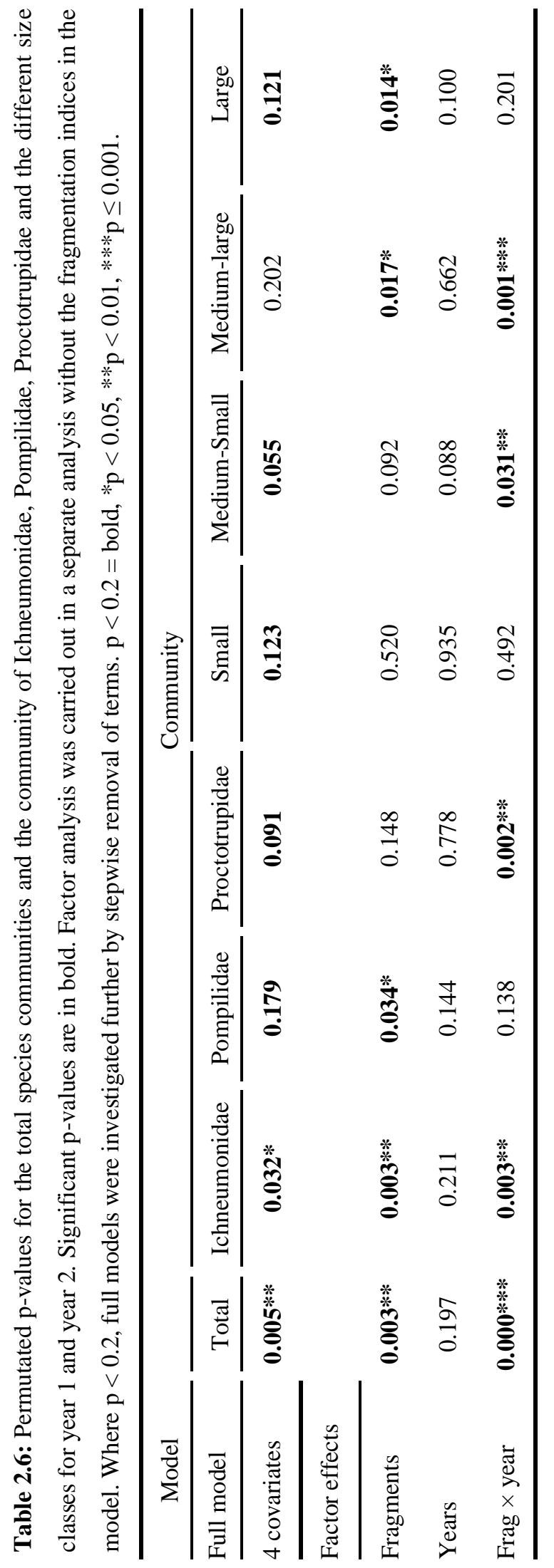




\subsubsection{Parasitoid community composition}

In contrast to the univariate analyses of abundance, richness and diversity, the multivariate analysis of the communities indicated that there may be significant effects of the fragmentation indices on the composition of the total species community, and on some of the sub-communities defined by taxon or body size (Table 2.6).

An analysis of factor effects also showed a significant fragment $\times$ year interaction for the total species community, the communities of Ichneumonidae and the medium-large bodied community, the Proctotrupidae and medium-small bodied community assemblages (Table 2.6). In the absence of a significant interaction, there were still significant effects of "fragment" for the Pompilidae assemblage and for the large-bodied community assemblages (Table 2.6). The response of the small-bodied parasitoid community to the combined fragmentation indices was consistent, regardless of the particular fragment or year of sampling (Table 2.6).

There appeared to be an effect of the combined fragmentation indices on the total parasitoid community in the first year only, which was best explained by the joint effect of plant species richness (patch quality) and isolation of the fragment (Table 2.7). The ichneumonid community also showed a similar response to the combined fragmentation indices in the first year only, which in their case was best explained by a strong relationship to fragment isolation (Table 2.7). In contrast, there appeared to be an effect of the combined fragmentation indices on the proctotrupid and the medium-small bodied community assemblages in the second year only (Table 2.7 ). Once again the combination of plant species richness and isolation best explained the composition of the mediumsmall bodied community, whereas no simpler statistically significant model presented 
itself for the Proctotrupidae (Table 2.7). Plant richness alone was the best predictor of variation in composition for the pompilid and the large-bodied communities, while plant richness combined with area best described the small-bodied community (Table 2.7). The percentage of the residential cover never contributed to a significant model of community structure, as a suitable fragmentation index to any of the communities and was found only once in combination with area, isolation and plant richness as the model best describing the proctotrupid community (Table 2.7).

In the "best" models for each community, the $R^{2}$-values for the factor "fragment" were always higher than for the fragmentation indices, except for the proctotrupid community, indicating that the variation of the communities might be due to properties of the fragments other than the measured covariates (Table 2.7). As with the univariate measures, the total parasitoid community composition appeared more similar in sites that were closer to each other than sites that were further apart, although this relationship was weak (Fig. 2.3d).

The nMDS plots provided below illustrate the response patterns of the ichneumonid community to fragment isolation (Fig. 2.5). The responses of the entire species community are very similar and are probably largely driven by the Ichneumonidae. 
Table 2.7: Subsequent analysis of parasitoid communities from Table 2.6 that showed a response to the combined covariates with $\mathrm{p}<0.2$. Best models are shown in bold, plus any other models with $\mathrm{p}<0.05$. The $R^{2}$ values are for the models with the lowest $\mathrm{p}$-value for each community (bold). ${ }^{*} \mathrm{p}<0.05, * * \mathrm{p}<0.01$.

\begin{tabular}{|c|c|c|c|c|c|c|c|}
\hline \multirow[b]{2}{*}{$\begin{array}{l}\text { Parasitoid } \\
\text { community }\end{array}$} & \multicolumn{4}{|c|}{ Covariates } & \multirow[b]{2}{*}{ P-value } & \multirow[b]{2}{*}{$\begin{array}{c}R^{2} \\
\text { covariate(s) }\end{array}$} & \multirow[b]{2}{*}{$R^{2}$ factor } \\
\hline & 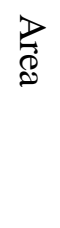 & $\begin{array}{l}\bar{v} \\
\frac{0}{0} \\
\stackrel{0}{0}\end{array}$ & $\begin{array}{l}d^{0} \\
\vec{D} \\
\stackrel{0}{0} \\
\stackrel{0}{0} \\
\stackrel{D}{D}\end{array}$ & 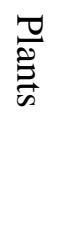 & & & \\
\hline \multirow{6}{*}{ Total Year 1} & $\checkmark$ & $\checkmark$ & & $\checkmark$ & $0.019 *$ & & \\
\hline & $\checkmark$ & $\checkmark$ & & & $0.036^{*}$ & & \\
\hline & $\checkmark$ & & & $\checkmark$ & $0.027 *$ & & \\
\hline & & $\checkmark$ & & $\checkmark$ & 0.011* & 0.105 & 0.322 \\
\hline & & $\checkmark$ & & & $0.013^{*}$ & & \\
\hline & & & & $\checkmark$ & $0.019 *$ & & \\
\hline \multirow{5}{*}{$\begin{array}{l}\text { Ichneumonidae } \\
\text { Year } 1\end{array}$} & $\checkmark$ & $\checkmark$ & & $\checkmark$ & $0.019 *$ & & \\
\hline & $\checkmark$ & $\checkmark$ & & & $0.033^{*}$ & & \\
\hline & $\checkmark$ & & & $\checkmark$ & $0.023 *$ & & \\
\hline & & $\checkmark$ & & $\checkmark$ & $0.019^{*}$ & & \\
\hline & & $\checkmark$ & & & $0.003 * *$ & 0.068 & 0.285 \\
\hline $\begin{array}{l}\text { Pompilidae } \\
\text { Year } 1+2\end{array}$ & & & & $\checkmark$ & $0.025 *$ & 0.046 & 0.181 \\
\hline $\begin{array}{l}\text { Proctotrupidae } \\
\text { Year } 2\end{array}$ & $\checkmark$ & $\checkmark$ & $\checkmark$ & $\checkmark$ & 0.126 & 0.192 & 0.162 \\
\hline $\begin{array}{l}\text { Small } \\
\text { Year } 1+2\end{array}$ & $\checkmark$ & & & $\checkmark$ & $0.035 *$ & 0.098 & 0.122 \\
\hline $\begin{array}{l}\text { Medium-small } \\
\text { Year } 2\end{array}$ & & $\checkmark$ & & $\checkmark$ & 0.033* & 0.111 & 0.287 \\
\hline $\begin{array}{l}\text { Large } \\
\text { Year } 1+2\end{array}$ & & & & $\checkmark$ & 0.081 & 0.030 & 0.202 \\
\hline
\end{tabular}



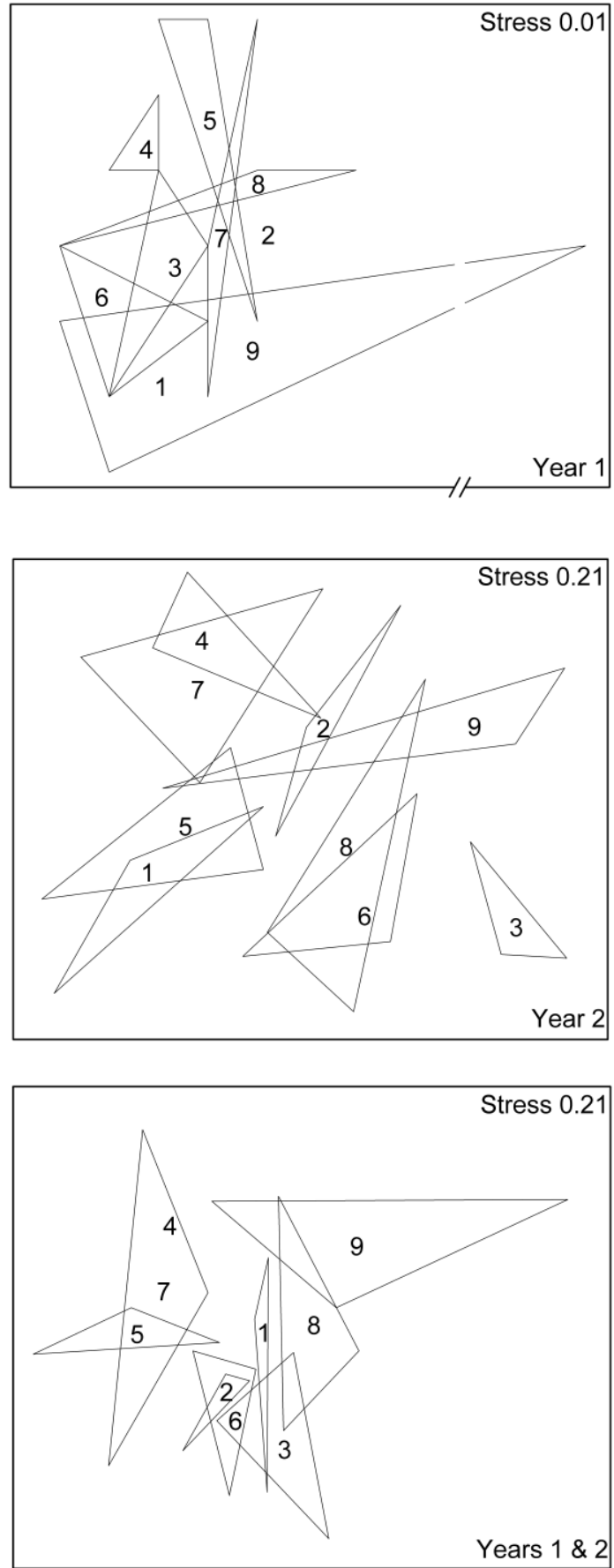

Figure 2.5: Non-metric multidimensional scaling based on Bray-Curtis dissimilarities for the ichneumonid species community of year 1, year 2 and years 1 and 2 between sites. Lines connect the three sites belonging to one fragment, each triangle labelled according to isolation and ranked $1-9$ from most to least isolated. 


\subsubsection{Individual species responses}

Individual parasitoid abundances showed both increase and decrease in their responses to the fragmentation indices. These responses were predominantly non-significant with the exception of one positive response each to area and isolation and three positive responses to plant richness and one positive response to residential area (Table 2.8).

Table 2.8: Number of negative and positive (beta) individual species responses to the factor year and the four fragment indices. Results are from an ANOVA performed with the software SPSS 13 (2004). $N=20, * p=<0.05$, $* * \mathrm{p}=<0.01$.

\begin{tabular}{lcccc}
\hline & \multicolumn{4}{c}{ Beta coefficients } \\
\cline { 2 - 5 } Terms tested & $<-0.5$ & $-0.5 \rightarrow 0$ & $0 \rightarrow+0.5$ & $>+0.5$ \\
\hline Year & $1^{*}$ & 6 & 14 & \\
Area & $1^{*}$ & 8 & 10 & \\
Isolation & & 9 & 11 & \\
Residential & & 10 & 7 & $1^{* *}$ \\
Plants & & & \\
\hline
\end{tabular}

\subsection{Discussion}

Except for the small-bodied parasitoid community there was no evidence for an influence of fragmentation on parasitoid abundance, richness and diversity. Differences in the multivariate parasitoid community structure across the different urban forest fragments appeared primarily due to plant richness and fragment isolation. These two fragmentation indices alone, as well as in combination, appeared to influence the parasitoid communities. Fragment area alone and the amount of residential area surrounding a fragment had no influence on the species community. Similarly to the univariate response, the small-bodied parasitoid assemblage seems to be influenced by area and 
plant richness combined. The medium-small bodied community responded to isolation and plant richness in combination, whereas the medium-large and large parasitoid community showed no significant responses to any of the fragmentation indices. Individual species abundances demonstrate differing responses to the fragmentation indices, which might help explain the apparent contradiction of a lack of response in the univariate analysis of overall abundance and community richness yet significant multivariate responses of community composition. Lower $R^{2}$-values for the fragmentation indices relative to the factor "fragment" suggest that habitat characteristics other than those measured are important factors contributing to changes in some parts of this parasitoid community.

The results and the following discussion need to be seen within the framework of the statistical method chosen for this thesis. The lack of significance of the covariates could be due to shared variance with the factor "fragment". If the shared variance is predominantly attributed to the fragments, then the $R^{2}$-values will always be higher for the fragments than, for example, the fragment index "isolation". One possible solution to this problem could be to re-analyse the present data to describe the partitioning of variance in the response variable (ignoring covariates) and split the data into "withinfragment" and "between-fragment" groups. This could be followed by pooling of sites within a fragment proceeded by an analysis of the fragment-level responses to the fragment-level covariates. 


\subsubsection{Parasitoid abundance, richness and diversity}

The combination of the fragmentation indices were not significant predictors of species abundance, species richness and species diversity, neither of the total species assemblage nor of the taxonomic divisions of the assemblage. Considering the significant positive correlation of number of plant species in relation to area and to isolation, we expected a much stronger response to the fragmentation indices at the higher trophic levels that parasitoids occupy. Species richness, is thought to respond strongly to habitat fragmentation (Steffan-Dewenter \& Tscharntke, 2002). Here, forest fragmentation did not lead to the local loss of biodiversity as discussed by Turner (1996). Similar results were obtained by Dauber, Bengtsson and Lenoir (2006) where the species richness and composition of ant communities were very similar between small and large grassland fragments. Also, no significant differences in species richness between small and large urban fragments were found for most of the arthropod taxa studied by Gibb and Hochuli (2002) in heath and woodland environments.

Continuity and predictability of a habitat are seen to shape species richness, counteracting species-area relationship effects (Dauber, Bengtsson \& Lenoir, 2006). Alternatively, species-area relationships might not be apparent due to "spillover" by species from the surrounding matrix (Dauber, Bengtsson \& Lenoir, 2006; Gibb \& Hochuli, 2002; Schoereder et al., 2004). In addition, the absence of one species could be cancelled out by the presence of another species, which would result in different species compositions yet equivalent species richness. Also, residential gardens and scrub areas interspersed amongst the native forest fragments might act as sufficient connectors to maintain insect populations in small and isolated fragments. This process could also explain why there 
was no significant effect of the percentage of residential area on the parasitoid abundance, richness and diversity in this study.

Despite the positive correlation of plant richness with fragment area parasitoid abundance, richness and diversity in the smaller or more isolated fragments may well be influenced by the flora and fauna from the surrounding landscape. Most studies that show a response to fragmentation at the higher trophic levels have been carried out in seminatural grassland environments (van Nouhuys, 2005). In this study, the combination of exotic and native plants in gardens, weedy scrubland and urban forest fragments might increase plant species richness providing richer habitat diversity. Elsewhere, for example, plant species richness on different-sized islands was the best single fragmentation index of ant species richness (Morrison, 1998). Smaller fragments do have a higher edge to area ratio and small fragments in our study sites might be much more under the influence of a species-rich plant environment from the surrounding scrub and gardens. This plant diversity may present a much richer environment for an increased number of herbivores as well as parasitoid species over a wider range of fragments. For example, parasitism rates by the relatively small tachinid fly Lespesia frenchii (Williston), a generalist parasitoid, were higher in forest fragments than in continuous forest and at forest edges as opposed to the interior (Roth, Roland \& Roslin, 2006), which was attributed to parasitoid movement between continuous forest and forest fragments.

The process of re-colonisation and spillover from the surrounding matrix implies that some species are capable of dispersing over a wider landscape. Considering the univariate responses of abundance, richness and diversity response, only the small-bodied parasitoids showed any indication of a response to the fragmentation indices. If body size 
is correlated with mobility then smaller-sized parasitoids would be expected to be the poorer dispersers responding primarily to isolation. In our study, the smaller-bodied parasitoids responded negatively to an increase in area and plant richness combined. However, these responses were only marginally significant (Table 2.5) and the correlation between these variables makes it difficult to disentangle effects due to fragment "area" from responses to "isolation", or vice versa. In addition, a low number of small-bodied species in combination with a rare occurrence might make interpretation of these results difficult. Reasons why the study does not show significant differences in species abundance, richness and diversity in relation to isolation might be: 1.) because the landscape is functionally well-connected for the majority of species investigated or 2.) the $1 \mathrm{~km}$ radius chosen to determine isolation was not the appropriate scale.

For the above reasons we would expect that variation in plant species composition as well as different habitat characteristics in the urban forest fragments influence parasitoid abundance, richness and diversity. Indeed, significant differences in species diversity between fragments were found for the Ichneumonidae and the large-sized group, the latter showing a significant result for species richness as well $(\mathrm{p}<0.05)$.

\subsubsection{Parasitoid community composition}

The ichneumonid community appeared to be predominantly influenced by isolation. Fragment area, percentage of residential area surrounding the fragments and plant richness were not found to be significant fragmentation indices on their own, a result similar to that found for the species composition of wasps between larger and smaller urban woodland fragments in Sydney, Australia (Gibb \& Hochuli, 2002). The total 
species set is dominated ( $83 \%$ ) by the Ichneumonidae; hence the significant responses of the overall species composition are most likely driven by the ichneumonids.

Diversity at the higher trophic levels is predicted to be most negatively affected by habitat fragmentation as a flow-on effect of a negative response to fragmentation at the lower trophic levels. For example, assemblages of spiders, which are predatory, differed significantly between smaller and larger fragments (Gibb \& Hochuli, 2002). It is therefore interesting to note that the Pompilidae, contrary to these predictions, do not show any responses to area or isolation, yet they can be placed at the fourth tropic level as they exclusively parasitise spiders. This result might not be surprising because New Zealand's pompilids are generalists, each parasitising a wide variety of prey species (Harris, 1987). However, New Zealand's pompilids are also known to partition their foraging by habitat (Harris, 1987). Plant richness being the best predictor for Pompilidae might be a reflection of subtle differences in habitat-type present across the forest fragments investigated. Such variation between fragments would also be reflected by the factor "fragment", which showed a much higher $R^{2}$-value relative to the covariate plant richness.

The Proctotrupidae in this study are also thought to be generalist parasitoids, inhabiting a variety of habitats such as native forests, forest margins, scrubland and semi-woodland suburban gardens (Early \& Dugdale, 1994). The proctotrupid species Fustiserphus intrudens (Smith), for example, parasitises species of the moth genus Tingena, which are generalist detritivores found in leaf litter. It is the most commonly collected proctotrupid in New Zealand (Early \& Dugdale, 1994), likely reflecting the widespread distribution of its host across many habitats (e.g. Patrick, 1989). The response of this and other 
proctotrupid responses in our study seem to confirm that generalist parasitoids are less affected by fragmentation than their counterparts, the specialist parasitoids - the Ichneumonidae.

Fragment isolation in particular, is thought to affect the survival of habitat specialists that are less able to disperse (Steffan-Dewenter \& Tscharntke, 2002; Thomas, 2000). From this process we might hypothesise that a large number of the ichneumonid parasitoids in our study may be specialist parasitoids mostly affected by fragment isolation. It is interesting to note that the medium-large and large-bodied parasitoid assemblages were not affected by any of the fragmentation indices. Only the medium-small and smallbodied communities are affected by isolation and area respectively in combination with plant richness. Due to a significant response to the factor "fragment" in the absence of a significant fragment $\times$ year interaction, the larger species might particularly respond to characteristics of the fragments other than those which we investigated. This supposition is reflected in the significant univariate community responses of the large-bodied parasitoid diversity and richness as well as differences in dissimilarity in the multivariate community of the medium-large and large size group, all in response to the factor fragment. Larger parasitoid species may therefore be less susceptible to fragmentation effects than the smaller species. Higher $R^{2}$ - values for the factor "fragment" in relation to the covariate $R^{2}$ - values, significant responses to the factor fragment as well as significant fragment $\times$ year interactions clearly suggest that there are environmental influences other than those measured, contributing to changes in some parts of this parasitoid community.

There were no broad-scale geographic trends in the Simpson Diversity index; however, the dissimilarities of the parasitoid assemblages did increase significantly with increasing 
distance between plots. Again, this result suggests that fragment characteristics other than the indices of fragmentation investigated may provide different habitats supporting different communities. Gibb and Hochuli (2002) also found arthropod assemblages to become increasingly dissimilar in increasingly distant fragments, and concluded that widespread distribution of suitable habitat across a geographic region might be important for conservation of arthropod diversity.

\subsubsection{Individual species responses}

We inferred that individual species are likely to respond differently to landscape fragmentation effects. Such responses have been shown to occur in other studies. For example Marshall, Walker \& Rypstra (2006) found opposing species abundance responses to area by two spider species. Indeed, in this study species responses to the fragmentation indices resulted in disparate trends (Table 8). Whilst some species show the predicted increase in abundance to an increase in area and number of plant species, or reduced isolation and a lesser percentage of residential area, others show the opposing trend. In addition most trends are non-significant. These results go some way towards explaining the predominantly non-significant results for the univariate community indices in relation to fragmentation combined with the predominantly significant community assemblage responses. Such responses may be due to different factors such as microhabitat, which contributes to the differences in arthropod assemblages detected between fragments of different size. Similarly, communities of ground-dwelling beetles may depend on the amount of leaf litter, logs, rocks, and debris (Lassau et al., 2005), which in turn might influence the community structure of the beetles' parasitoids. 
Van Nouhuys (2005) discussed studies with different responses of parasitoids to isolation and area. She concluded that there is no consensus between previous studies on the effects of fragment size and isolation on herbivores, their predators and parasitoids. We found species to respond differently to fragment area, isolation, percentage of residential area and the number of plant species; therefore a generalisation for their response is difficult. Similarly, a tropical beetle community also resulted in an invariant species richness, but individual beetle species showed varying responses to fragmentation (Didham et al., 1998). To fully understand the mechanisms of fragmentation, it is essential to understand the biology and individual species interactions of the community concerned (Stoll et al., 2006). This would require the study of individual parasitoid species' interactions and their habitat requirements. Given the variation in factors such as parasitoid size, dispersion characteristics and host range, the expectation of a generalised response to habitat fragmentation may be unreasonable.

\subsubsection{Implications for conservation}

This study showed that responses in the community composition of parasitoids varied significantly between fragments. Part of this variation can be explained by fragmentation indices (especially isolation, but never by the percentage of residential area in the surrounding matrix). These results mean that different habitats support different parasitoid communities. Even the smallest species, thought to be restricted in their dispersal due to their size, were found in the most isolated fragments. Out of six species classified as being small, two species of Tersilochinae (sp. 4 and sp. 7) were found in the larger as well as in the most isolated and smallest fragments, one species of Oxyserphus (sp. 5) and one of Phygadeuontinae (sp. 5) were present only in the isolated and smallest fragments, this is despite these species being rare in our study. Therefore, isolated 
habitats may play an important role in species conservation. In an urban environment the maintenance of different-sized habitats may play a crucial role in the conservation of species as species persistence may depend primarily on the variety of habitats and their spread over a geographical region. Habitat variation across a geographic region may be important for the conservation of arthropod diversity, a conclusion also drawn by Gibb et al. (2002). Our study also indicated that fragment characteristics, other than area and isolation effects influence species composition. This result implies that we need to look at for example habitat types as recommended by Gibb et al. (2002) because these features form the basis for existence and persistence of species within a fragment. New Zealand is estimated to have approximately 350 ichneumonid species, of which approximately two thirds are undescribed (Berry, 2006). Here we collected $\sim 23 \%$ of this diversity in the forest fragments around Wellington city. Moreover, the accumulation curve (Fig. 2) does not asymptote, suggesting that many more species are present in this urban environment. With an increase in the world's population living in urban areas (United Nations, 2004) comes an increasing call to maintain and provide living space for biodiversity in these areas. Even small and isolated forest fragments can have significant value in contributing to alpha biodiversity. This study highlights the importance of the maintenance of green space for species diversity in urban areas, and provides a basis for conservation management in urban areas.

\subsection{Acknowledgements}

We thank the bug-club members of the School of Biological Sciences, Victoria University of Wellington for valuable comments on this manuscript and Adrian Pike, John Brightwell, Megan Sarty, Nick Rawlence and Travis Chellman for the assistance in sorting insects. Many thanks go to Cleland Wallace for surveying the plant communities. 
We also thank the different park managements for the permission to establish traps in their native bush fragments. We thank the NZ Department of Conservation for the loan of traps. This research was funded by the 21 st Anniversary Fund from the Entomological Society of NZ and the Victoria University of Wellington, NZ.

\subsection{Literature cited}

Aizen, M.A. \& Feinsinger, P. (1994) Habitat fragmentation, native insect pollinators, and feral honey bees in Argentine Chaco Serrano. Ecological Applications, 4(2), 378-92.

Allen, R.B. (1992). RECCE - an inventory method for describing New Zealand vegetation. In Forest Research Institute Bulletin (ed F.R. Institute), Vol. 176, Christchurch, N. Z.

Anderson, M.J. (2001) A new method for non-parametric multivariate analysis of variance. Austral Ecology, 26(1), 32-46.

Anderson, M.J. (2005). PERMANOVA: a FORTRAN computer program for permutational multivariate analysis of variance. In. Department of Statistics, University of Auckland, New Zealand.

Anderson, M.J. \& Robinson, J. (2003) Generalized discriminant analysis based on distances. Australian \& New Zealand Journal of Statistics, 45(3), 301-18.

Barbosa, P., Segarra, A.E., Gross, P., Caldas, A., Ahlstrom, K., Carlson, R.W., Ferguson, D.C., Grissell, E.E., Hodges, R.W., Marsh, P.M., Poole, R.W., Schauff, M.E., Shaw, S.R., Whitfield, J.B. \& Woodley, N.E. (2001) Differential parasitism of macrolepidopteran herbivores on two deciduous tree species. Ecology, 82(3), 698704.

Berry, J.A. (2006). Checklist of New Zealand Hymenoptera. World Wide Web electronic publication. In. 
http://www.landcareresearch.co.nz/research/biosystematics/invertebrates/hymenopter a/checklist_index.asp (accessed 14/06/2007).

Clarke, K.R. (1993) Non-parametric multivariate analyses of changes in community structure. Australian Journal of Ecology, 18(1), 117-43.

Collinge, S.K. \& Forman, R.T.T. (1998) A conceptual model of land conversion processes - predictions and evidence from a microlandscape experiment with grassland insects. Oikos, 82(1), 66-84.

Colwell, R.K. (2005). EstimateS: Statistical estimation of species richness and shared species from samples. Version 7.5. User's Guide and application published at: http://pulr.oclc.org/estimates. In.

Dauber, J., Bengtsson, J. \& Lenoir, L. (2006) Evaluating effects of habitat loss and landuse continuity on ant species richness in seminatural grassland remnants. Conservation Biology, 20(4), 1150-60.

Davies, K.F. \& Margules, C.R. (1998) Effects of habitat fragmentation on carabid beetles - experimental evidence. Journal of Animal Ecology, 67(3), 460-71.

Didham, R.K., Ghazoul, J., Stork, N.E. \& Davis, A.J. (1996) Insects in fragmented forests - a functional approach. Trends in Ecology \& Evolution, 11(6), 255-60.

Didham, R.K., Hammond, P.M., Lawton, J.H., Eggleton, P. \& Stork, N.E. (1998) Beetle species responses to tropical forest fragmentation. Ecological Monographs, 68(3), 295-323.

Early, J.W. \& Dugdale, J.S. (1994) Fustiserphus (Hymenoptera, Proctotrupidae) parasitizes Lepidoptera in leaf-litter in New-Zealand. New Zealand Journal of Zoology, 21(3), 249-52.

ESRI. (2004). ESRI®ArcMap ${ }^{\text {TM }} 9.0$ Build 560. In. ESRI, Redlands, CA, USA. 
Fahrig, L. (2003) Effects of habitat fragmentation on biodiversity. Annual Review of Ecology, Evolution, and, 34, 487-515.

Fraser, S.E.M., Dytham, C. \& Mayhew, P.J. (2008) The effectiveness and optimal use of Malaise traps for monitoring parasitoid wasps. Insect Conservation and Diversity, 1(1), 22-31.

Gabites, I. (1993) Wellington's Living Cloak: A Guide to the Natural Plant Communities. Wellington Botanical Society, Wellington.

Gauld, I.D. (1984) An Introduction to the Ichneumonidae of Australia. British Museum (Natural History), London.

Gibb, H. \& Hochuli, D.F. (2002) Habitat fragmentation in an urban environment: large and small fragments support different arthropod assemblages. Biological Conservation, 106(1), 91-100.

Gonzalez, A. \& Chaneton, E.J. (2002) Heterotroph species extinction, abundance and biomass dynamics in an experimentally fragmented microecosystem. Journal of Animal Ecology, 71(4), 594-602.

Graham, M.H. (2003) Confronting Multicollinearity in Ecological Multiple Regression. Ecology, 84(11), 2809-15.

Hanski, I., Kuussaari, M. \& Nieminen, M. (1994) Metapopulation structure and migration in the butterfly Melitaea cinxia. Ecology, 75(3), 747-62.

Harris, A.C. (1987) Pompilidae (Insecta: Hymenoptera). Fauna of New Zealand, 12.

Klein, A.M., Steffan-Dewenter, I. \& Tscharntke, T. (2003) Pollination of Coffea canephora in relation to local and regional agroforestry management. Journal of Applied Ecology, 40(5), 837-45. 
Klein, A.M., Steffan-Dewenter, I. \& Tscharntke, T. (2004) Foraging trip duration and density of megachilid bees, eumenid wasps and pompilid wasps in tropical agroforestry systems. Journal of Animal Ecology, 73(3), 517-25.

Klein, A.M., Steffan-Dewenter, I. \& Tscharntke, T. (2006) Rain forest promotes trophic interactions and diversity of trap-nesting hymenoptera in adjacent agroforestry. Journal of Animal Ecology, 75(2), 315-23.

Kruess, A. \& Tscharntke, T. (1994) Habitat fragmentation, species loss, and biological control. Science, 264(5165), 1581-84.

Kruess, A. \& Tscharntke, T. (2000). Effects of habitat fragmentation on plant-insect communities. In Interchanges of Insects between Agriculture and surrounding Landscapes. (eds B. Eckboom, M. Irwin \& Y. Robert), pp. 53-70. Kluwer, Dordrecht.

Lassau, S.A., Hochuli, D.F., Cassis, G. \& Reid, C.A.M. (2005) Effects of habitat complexity on forest beetle diversity: do functional groups respond consistently? Diversity and Distributions, 11(1), 73-82.

Legrendre, P. \& Legrendre, L. (1998) Numerical Ecology, 2nd edn. Elsevier, Amsterdam, The Netherlands.

Magurran. (2004) Measuring Biological Diversity. Blackwell Science Ltd, Oxford. Margules, C.R., Milkovits, G.A. \& Smith, G.T. (1994) Contrasting effects of habitat fragmentation on the scorpion Cercophonius squama and an Amphipod. Ecology, 75(7), 2033-42.

Marshall, S.D., Walker, S.E. \& Rypstra, A.L. (2006) Two ecologically-divergent generalist predators have different responses to landscape fragmentation. Oikos, 114(2), 241-48.

McArdle, B.H. \& Anderson, M.J. (2001) Fitting multivariate models to community data: A comment on distance-based redundancy analysis. Ecology, 82(1), 290-97. 
McKillup, S.C. \& McKillup, R.V. (2000) The effects of two parasitoids on the life history and metapopulation structure of the intertidal snail Littoraria filosa in different-sized patches of mangrove forest. Oecologia, 123(4), 525-34.

Miyashita, T., Shinkai, A. \& Chida, T. (1998) The effects of forest fragmentation on web spider communities in urban areas. Biological Conservation, 86(3), 357-64.

Morrison, L.W. (1998) The spatiotemporal dynamics of insular ant metapopulations. Ecology, 79(4), 1135-46.

Murren, C.J. (2002) Effects of habitat fragmentation on pollination: pollinators, polliniation viability and reproductive success. Journal of Ecology, 90(1), 100-07.

Nations, U.N.U. (2004) World urbanization prospects: the 2003 revision. U.N.

Department of Economic and Social Affairs/Population Division.[online] URL: http://www.un.org/esa/population/publications/wup2003/2003WUPHighlights.pdf.

Naumann, I.D. (1991). Hymenoptera. In The insects of Australia. A textbook for students and research workers. (ed C. Division of Entomology), Vol. II, pp. 916-1000. Cornell University Press, Ithaca, New York.

Nieminen, M. (1996) Migration of moth species in a network of small islands. Oecologia, 108(4), 643-51.

Patrick, B.H. (1989) Survey of Lepidoptera at Tara Hills Research Station. New Zealand Entomologist, 12, 42-48.

Quinn, G.P. \& Keough, M.J. (2002) Experimental design and data analysis for biologists. Cambridge University Press, Cambridge, UK.

Roslin, T. (2000) Dung beetle movements at two spatial scales. Oikos, 91(2), 323-35.

Roth, D., Roland, J. \& Roslin, T. (2006) Parasitoids on the loose - experimental lack of support of the parasitoid movement hypothesis. Oikos, 115(2), 277-85. 
Samways, M.J. (2005) Insect Diversity Conservation. Cambridge University Press, Cambridge, UK.

Schoereder, J.H., Sobrinho, T.G., Ribas, C.R. \& Campos, R.B.F. (2004) Colonization and extinction of ant communities in a fragmented landscape. Austral Ecology, 29(4), $391-98$.

Shaw, M. \& Hochberg, M. (2001) The Neglect of Parasitic Hymenoptera in Insect Conservation Strategies: The British Fauna as a Prime Example. Journal of Insect Conservation, 5(4), 253-63.

Shepherd, W. (2000) Wellington's Heritage: Plants, Gardens, and Landscape. Te Papa Press, Wellington.

Steffan-Dewenter, I. \& Tscharntke, T. (2002) Insect communities and biotic interactions on fragmented calcareous grasslands - a mini review. Biological Conservation, 104(3), 275-84.

Stoll, P., Dolt, C., Goverde, M. \& Baur, B. (2006) Experimental habitat fragmentation and invertebrate grazing in a herbaceous grassland species. Basic and Applied Ecology, 7(4), 307-19.

Thomas, C.D. (2000) Dispersal and extinction in fragmented landscapes. Proceedings of the Royal Society of London Series B-Biological Sciences, 267(1439), 139-45.

Townes, H.K. \& Townes, M. (1981) A revision of the Sirphidae (Hymenoptera). Memoirs of the American Entomological Institute, 32, 1-541.

Turner, I.M. (1996) Species loss in fragments of tropical rain forest - a review of the evidence. Journal of Applied Ecology, 33(2), 200-09.

van Nouhuys, S. (2005) Effects of habitat fragmentation at different trophic levels in insect communities. Annales Zoologici Fennici, 42(4), 433-47. 
Wahl, D.B. (1993). Family Ichneumonidae. In Hymenoptera of the World: An Identification Guide to Families. (eds H. Goulet \& J.T. Huber), pp. 395-448. Agriculture Canada Research Branch Monograph No. 1894E, Ottawa.

Wood, A., Stedman-Edwards \& Mang, J. (2000) The Root Causes of Biodiversity Loss. Earthscan Publications Ltd. 
Appendix 2.1: Fragment indices and insect collection schedule

Table 2.1.1: Fragment area, isolation index, percentage of residential area in $1000 \mathrm{~m}$ buffer around fragments and number of plant species of nine native urban bush fragments.

\begin{tabular}{crrrrr}
\hline Fragment & $\begin{array}{c}\text { Fragment } \\
\text { ID }\end{array}$ & Area $\mathrm{m}^{2}$ & $\begin{array}{c}\text { Isolation } \\
\text { index }\end{array}$ & $\begin{array}{l}\text { Residential } \\
\text { area (\%) }\end{array}$ & $\begin{array}{l}\text { Number of } \\
\text { Plant } \\
\text { Species }\end{array}$ \\
\hline Maupuia Reserve & 1 & 1635 & 130008 & 25.2 & 30 \\
Karori Sanctuary & 2 & 27616 & 2126344 & 22.4 & 51 \\
Otari/Wilton Bush & 3 & 12190 & 414122 & 36.1 & 47 \\
Huntleigh Park & 4 & 2319 & 247604 & 28.8 & 41 \\
Trelissick Park & 5 & 4738 & 565475 & 47.3 & 34 \\
Belmont Park & 6 & 19525 & 616690 & 9.1 & 43 \\
Harbour View & 7 & 1386 & 353955 & 23.1 & 45 \\
Speedy Reserve & 8 & 3804 & 350115 & 19.5 & 39 \\
Bartons Bush & 10 & 1180 & 274226 & 31.9 & 29 \\
\hline
\end{tabular}

Table 2.1.2: Malaise trapping schedule for each fragment over a period of two summers.

\begin{tabular}{lcccc}
\hline \multicolumn{1}{c}{ Fragment } & December & February & December & February \\
& 2002 & 2003 & 2003 & 2004 \\
\hline Maupuia Reserve & $09-13$ & $19-23$ & $09-13$ & $10-14$ \\
Karori Sanctuary & $18-23$ & $10-14$ & $11-15$ & $04-08$ \\
Otari/Wilton Bush & $05-10$ & $04-09$ & $17-21$ & $02-06$ \\
Huntleigh Park & $10-14$ & $12-16$ & $10-14$ & $20-24$ \\
Trelissick Park & $10-14$ & $13-17$ & $19-23$ & $18-22$ \\
Belmont Park & $27-31$ & $18-22$ & $03-07$ & $09-13$ \\
Harbour View & $03-08$ & $07-11$ & $18-22$ & $03-07$ \\
Speedy Reserve & $16-20$ & 26 Feb-02 Mar & $08-12$ & $19-23$ \\
Bartons Bush & $19-23$ & $20-25$ & $04-08$ & $05-09$ \\
\hline
\end{tabular}


Appendix 2.2: Stepwise search for the best approximating model describing the response of the parasitoid communities to the different combinations of covariates.

\section{Total parasitoid community}

As explained in the main method section; where there was an effect of the four covariates combined $(\mathrm{p}<0.20)$ as well as a significant $(\mathrm{p}<0.05)$ fragment $\mathrm{x}$ year interaction we split the data into years 1 and 2 separately to better understand the relationship. For each year beginning with the full model with four covariates, if $p<0.20$ each covariate was dropped in turn to create a series of three-term models. The best of the three-term models was identified as long as $\mathrm{p}<0.10$ and each of its terms was dropped in turn to create a series of two-term models. As long as $\mathrm{p}<0.10$ the better of the two-term models, was split into two single-term models. From the above sequence the best model was identified as that with the lowest $\mathrm{p}$-value $(\mathrm{p}<0.05)$. These were, for example for the total parasitoid community the two-term model with the combined covariates isolation and number of plant species $(\mathrm{p}=0.011)$ (Fig. 2.2.1), and for the Ichneumonidae community the singleterm model with the covariate isolation $(\mathrm{p}=0.003)$ (Fig. 2.2.2). 


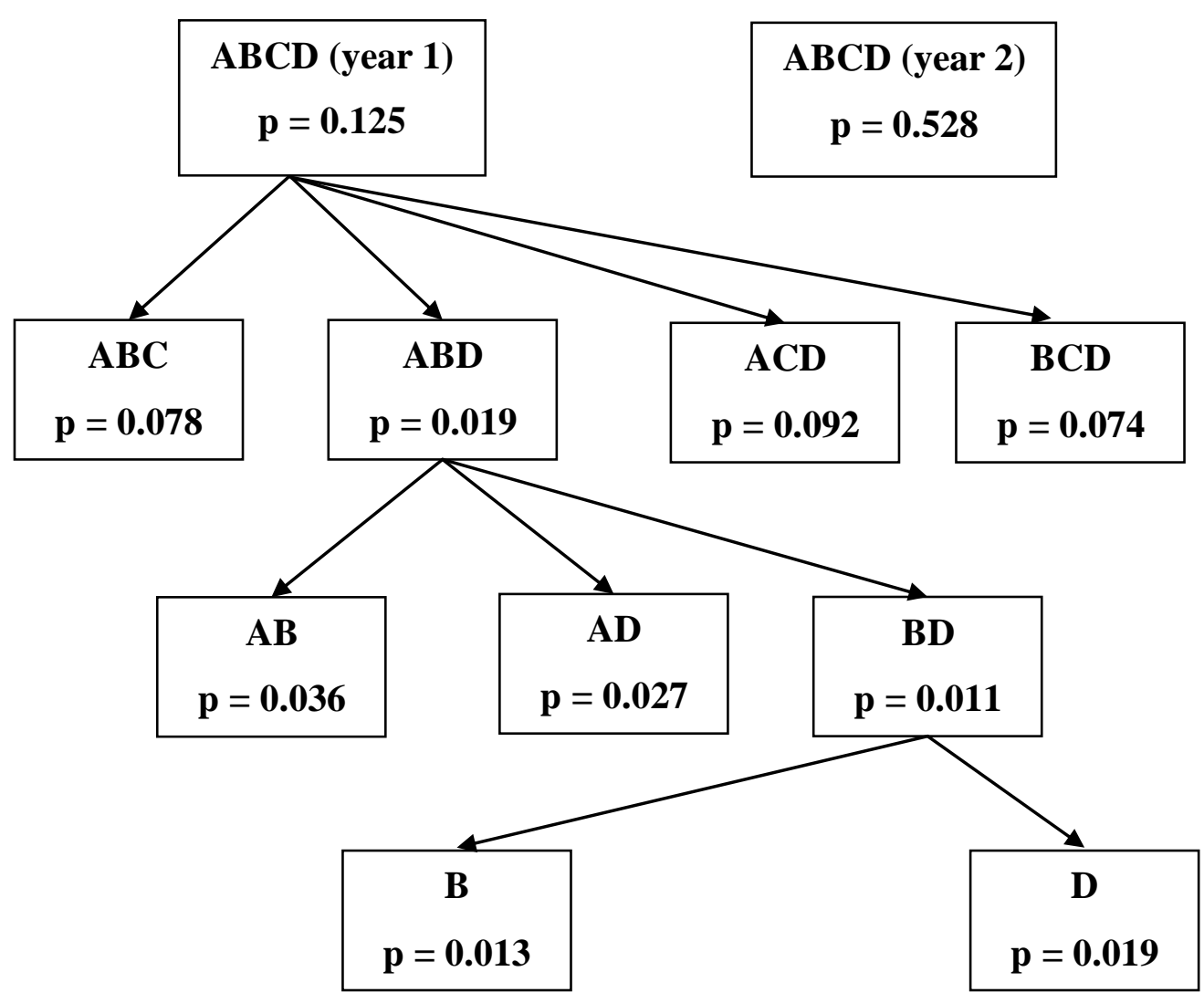

Figure 2.2.1: Flowchart showing break-up of analysis for the different combination of covariates added to the model of the total species community. The covariates are fragment area (A), isolation (B), percent residential area (C) and number of plant species (D). 


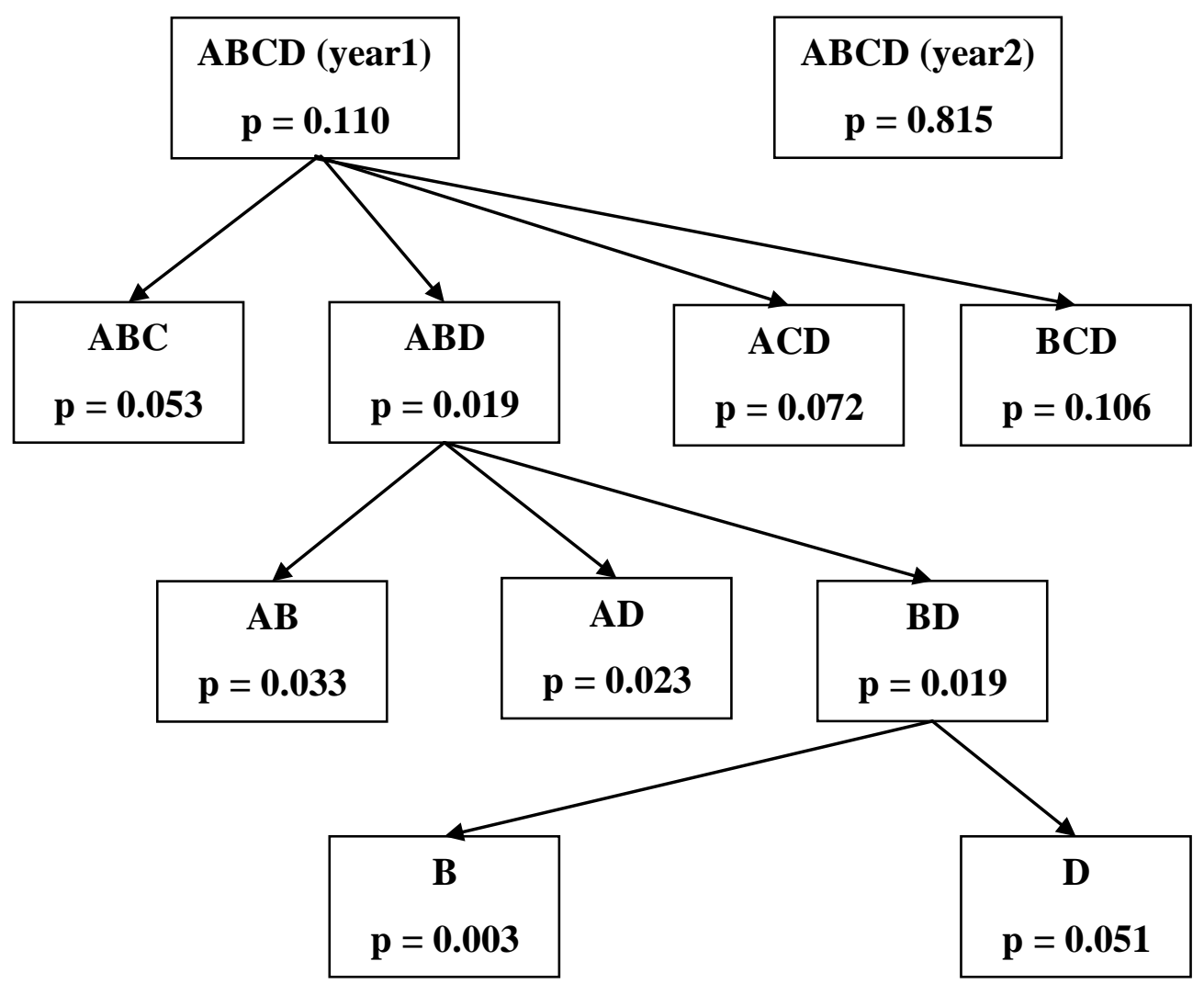

Figure 2.2.2: Flowchart showing break-up of analysis for the different combination of covariates added to the model of the ichneumonid species community. The covariates are fragment area (A), isolation (B), percent residential area (C) and number of plant species (D). 
Appendix 2.3: Indices examined. Number of individuals $(\mathrm{N})$, species numbers $(\mathrm{S})$ and Simpson index $(1 / D)$ for each site per fragment (Frag) and year of the different species assemblages analysed (Table 2.3.1 \& 2.3.2).

Table 2.3.1: Indices for the total species assemblage and the family assemblages of Ichneumonidae (Ich), Pompilidae (Pom) and Proctotrupidae (Proc)

\begin{tabular}{|c|c|c|c|c|c|c|c|c|c|c|c|c|c|c|}
\hline Frag & Year & Site & $\begin{array}{c}S \\
\text { total }\end{array}$ & $\begin{array}{c}\mathrm{N} \\
\text { total }\end{array}$ & $\begin{array}{l}1 / D \\
\text { total }\end{array}$ & $\begin{array}{c}\text { S } \\
\text { Ich }\end{array}$ & $\begin{array}{c}\text { S } \\
\text { Pom }\end{array}$ & $\begin{array}{c}S \\
\text { Proc }\end{array}$ & $\begin{array}{c}\mathrm{N} \\
\text { Ich }\end{array}$ & $\begin{array}{c}\mathrm{N} \\
\text { Pom }\end{array}$ & $\begin{array}{c}\mathrm{N} \\
\text { Proc }\end{array}$ & $\begin{array}{l}1 / D \\
\text { Ich }\end{array}$ & $\begin{array}{l}1 / D \\
\text { Pom }\end{array}$ & $\begin{array}{c}1 / D \\
\text { Proc } \\
\end{array}$ \\
\hline 1 & 1 & $A$ & 14 & 30 & 7.76 & 9 & 2 & 3 & 9 & 11 & 10 & 9.00 & 1.98 & 2.17 \\
\hline 1 & 1 & B & 9 & 13 & 7.35 & 8 & 0 & 1 & 12 & 0 & 1 & 2.91 & 0.00 & 1.00 \\
\hline 1 & 1 & $C$ & 9 & 19 & 3.72 & 8 & 0 & 1 & 18 & 0 & 1 & 0.67 & 0.00 & 1.00 \\
\hline 2 & 1 & A & 1 & 1 & 1.00 & 0 & 0 & 1 & 0 & 0 & 1 & 0.00 & 0.00 & 1.00 \\
\hline 2 & 1 & B & 14 & 17 & 12.57 & 10 & 1 & 3 & 12 & 1 & 4 & 6.25 & 1.00 & 2.67 \\
\hline 2 & 1 & C & 16 & 36 & 12.23 & 13 & 3 & 0 & 28 & 8 & 0 & 2.06 & 2.67 & 0.00 \\
\hline 3 & 1 & $A$ & 12 & 19 & 8.40 & 11 & 1 & 0 & 16 & 3 & 0 & 3.56 & 1.00 & 0.00 \\
\hline 3 & 1 & B & 22 & 43 & 16.08 & 15 & 3 & 4 & 27 & 12 & 4 & 3.69 & 2.88 & 4.00 \\
\hline 3 & 1 & C & 15 & 30 & 10.47 & 12 & 3 & 0 & 23 & 7 & 0 & 2.44 & 1.81 & 0.00 \\
\hline 4 & 1 & $A$ & 4 & 5 & 3.57 & 4 & 0 & 0 & 5 & 0 & 0 & 2.29 & 0.00 & 0.00 \\
\hline 4 & 1 & B & 10 & 13 & 8.05 & 8 & 2 & 0 & 11 & 2 & 0 & 3.37 & 2.00 & 0.00 \\
\hline 4 & 1 & C & 9 & 13 & 7.35 & 8 & 1 & 0 & 11 & 2 & 0 & 3.37 & 1.00 & 0.00 \\
\hline 5 & 1 & $A$ & 21 & 61 & 9.72 & 15 & 4 & 2 & 37 & 19 & 5 & 0.98 & 2.56 & 1.92 \\
\hline 5 & 1 & B & 11 & 24 & 8.47 & 9 & 2 & 0 & 19 & 5 & 0 & 1.47 & 1.92 & 0.00 \\
\hline 5 & 1 & C & 12 & 23 & 9.28 & 10 & 1 & 1 & 19 & 2 & 2 & 2.04 & 1.00 & 1.00 \\
\hline 6 & 1 & A & 9 & 13 & 6.26 & 7 & 2 & 0 & 11 & 2 & 0 & 1.96 & 2.00 & 0.00 \\
\hline 6 & 1 & B & 12 & 16 & 8.53 & 9 & 3 & 0 & 13 & 3 & 0 & 3.00 & 3.00 & 0.00 \\
\hline 6 & 1 & C & 10 & 26 & 5.93 & 8 & 2 & 0 & 22 & 4 & 0 & 0.62 & 1.60 & 0.00 \\
\hline 7 & 1 & A & 19 & 36 & 9.13 & 15 & 3 & 1 & 29 & 6 & 1 & 1.77 & 2.57 & 1.00 \\
\hline 7 & 1 & B & 11 & 19 & 7.68 & 8 & 3 & 0 & 11 & 8 & 0 & 2.78 & 2.67 & 0.00 \\
\hline 7 & 1 & C & 12 & 21 & 7.74 & 11 & 1 & 0 & 16 & 5 & 0 & 3.78 & 1.00 & 0.00 \\
\hline 8 & 1 & A & 22 & 65 & 11.83 & 18 & 2 & 2 & 41 & 18 & 6 & 1.92 & 1.91 & 2.00 \\
\hline 8 & 1 & B & 29 & 64 & 18.12 & 22 & 3 & 4 & 35 & 15 & 14 & 7.22 & 2.92 & 2.39 \\
\hline 8 & 1 & C & 22 & 47 & 11.33 & 18 & 3 & 1 & 33 & 13 & 1 & 2.59 & 2.45 & 1.00 \\
\hline 10 & 1 & A & 8 & 17 & 4.31 & 7 & 1 & 0 & 16 & 1 & 0 & 0.74 & 1.00 & 0.00 \\
\hline 10 & 1 & B & 11 & 30 & 4.79 & 9 & 2 & 0 & 17 & 13 & 0 & 1.88 & 1.17 & 0.00 \\
\hline 10 & 1 & C & 17 & 52 & 8.24 & 16 & 1 & 0 & 40 & 12 & 0 & 1.39 & 1.00 & 0.00 \\
\hline 1 & 2 & A & 21 & 48 & 14.77 & 13 & 4 & 4 & 28 & 11 & 9 & 1.88 & 3.10 & 3.00 \\
\hline 1 & 2 & B & 19 & 26 & 14.70 & 15 & 0 & 4 & 22 & 0 & 4 & 5.36 & 0.00 & 4.00 \\
\hline 1 & 2 & C & 4 & 6 & 3.00 & 2 & 1 & 1 & 4 & 1 & 1 & 0.40 & 1.00 & 1.00 \\
\hline 2 & 2 & A & 4 & 4 & 4.00 & 3 & 0 & 1 & 3 & 0 & 1 & 3.00 & 0.00 & 1.00 \\
\hline 2 & 2 & B & 9 & 10 & 8.33 & 7 & 0 & 2 & 8 & 0 & 2 & 4.90 & 0.00 & 2.00 \\
\hline 2 & 2 & C & 16 & 36 & 11.78 & 14 & 1 & 1 & 32 & 3 & 1 & 1.96 & 1.00 & 1.00 \\
\hline 3 & 2 & $A$ & 9 & 14 & 7.00 & 6 & 3 & 0 & 7 & 7 & 0 & 4.00 & 2.58 & 0.00 \\
\hline 3 & 2 & B & 10 & 18 & 5.06 & 5 & 3 & 2 & 6 & 10 & 2 & 3.13 & 1.85 & 2.00 \\
\hline 3 & 2 & $C$ & 10 & 18 & 6.23 & 9 & 1 & 0 & 14 & 4 & 0 & 2.25 & 1.00 & 0.00 \\
\hline 4 & 2 & A & 15 & 22 & 12.10 & 13 & 2 & 0 & 20 & 2 & 0 & 4.45 & 2.00 & 0.00 \\
\hline 4 & 2 & B & 12 & 14 & 10.89 & 9 & 1 & 2 & 10 & 2 & 2 & 6.75 & 1.00 & 2.00 \\
\hline 4 & 2 & C & 11 & 21 & 6.04 & 8 & 2 & 1 & 10 & 10 & 1 & 4.57 & 1.72 & 1.00 \\
\hline 5 & 2 & A & 24 & 51 & 19.56 & 18 & 3 & 3 & 37 & 8 & 6 & 3.34 & 2.91 & 2.57 \\
\hline 5 & 2 & B & 14 & 21 & 11.92 & 11 & 2 & 1 & 16 & 4 & 1 & 4.65 & 1.60 & 1.00 \\
\hline
\end{tabular}




\begin{tabular}{rrrrrrrrrrrrrrr}
\hline Frag & Year & Site & $\begin{array}{c}\text { S } \\
\text { total }\end{array}$ & $\begin{array}{c}\text { total } \\
\text { total }\end{array}$ & $\begin{array}{c}\text { t/D } \\
\text { tch }\end{array}$ & $\begin{array}{c}\text { Pom } \\
\text { Pom }\end{array}$ & $\begin{array}{c}\text { Proc } \\
\text { Pr }\end{array}$ & $\begin{array}{c}\mathrm{N} \\
\text { Ich }\end{array}$ & $\begin{array}{c}\mathrm{N} \\
\text { Pom }\end{array}$ & $\begin{array}{c}\mathrm{N} \\
\text { Proc }\end{array}$ & $\begin{array}{c}1 / \mathrm{D} \\
\text { Ich }\end{array}$ & $\begin{array}{c}1 / \mathrm{D} \\
\text { Pom }\end{array}$ & $\begin{array}{c}1 / \mathrm{D} \\
\text { Proc }\end{array}$ \\
\hline 5 & 2 & $\mathrm{C}$ & 12 & 13 & 11.27 & 9 & 2 & 1 & 10 & 2 & 1 & 6.75 & 2.00 & 1.00 \\
6 & 2 & $\mathrm{~A}$ & 10 & 15 & 8.33 & 9 & 1 & 0 & 12 & 3 & 0 & 4.50 & 1.00 & 0.00 \\
6 & 2 & $\mathrm{~B}$ & 9 & 11 & 8.07 & 7 & 2 & 0 & 9 & 2 & 0 & 3.77 & 2.00 & 0.00 \\
6 & 2 & $\mathrm{C}$ & 13 & 23 & 8.67 & 9 & 3 & 1 & 13 & 9 & 1 & 3.00 & 2.45 & 1.00 \\
7 & 2 & $\mathrm{~A}$ & 11 & 20 & 6.67 & 8 & 1 & 2 & 17 & 1 & 2 & 1.12 & 1.00 & 2.00 \\
7 & 2 & $\mathrm{~B}$ & 8 & 14 & 6.13 & 6 & 2 & 0 & 9 & 5 & 0 & 2.40 & 1.47 & 0.00 \\
7 & 2 & $\mathrm{C}$ & 22 & 47 & 12.62 & 18 & 3 & 1 & 29 & 17 & 1 & 4.70 & 2.75 & 1.00 \\
8 & 2 & $\mathrm{~A}$ & 14 & 32 & 7.11 & 11 & 3 & 0 & 17 & 15 & 0 & 3.90 & 1.99 & 0.00 \\
8 & 2 & $\mathrm{~B}$ & 19 & 42 & 10.02 & 15 & 3 & 1 & 28 & 11 & 3 & 2.08 & 2.05 & 1.00 \\
8 & 2 & $\mathrm{C}$ & 16 & 33 & 9.15 & 12 & 3 & 1 & 21 & 9 & 3 & 1.78 & 2.79 & 1.00 \\
10 & 2 & $\mathrm{~A}$ & 6 & 8 & 4.57 & 6 & 0 & 0 & 8 & 0 & 0 & 2.57 & 0.00 & 0.00 \\
10 & 2 & $\mathrm{~B}$ & 7 & 13 & 6.26 & 4 & 2 & 1 & 7 & 5 & 1 & 1.23 & 1.92 & 1.00 \\
10 & 2 & $\mathrm{C}$ & 8 & 10 & 7.14 & 6 & 1 & 1 & 8 & 1 & 1 & 3.00 & 1.00 & 1.00 \\
\hline
\end{tabular}

Table 2.3.2: Indices for the species assemblages of the different size groups small, medium-small (Msmal), medium-large (Mlarg) and large (Lg).

\begin{tabular}{|c|c|c|c|c|c|c|c|c|c|c|c|c|c|c|}
\hline Frag & Year & Site & $\begin{array}{c}\mathrm{S} \\
\text { small }\end{array}$ & $\begin{array}{c}\mathrm{N} \\
\text { small }\end{array}$ & $\begin{array}{c}1 / D \\
\text { small }\end{array}$ & $\begin{array}{c}\text { S } \\
\text { Msmal }\end{array}$ & $\begin{array}{c}\mathrm{N} \\
\text { Msmal }\end{array}$ & $\begin{array}{c}1 / D \\
\text { Msmal }\end{array}$ & $\begin{array}{c}\text { S } \\
\text { MLarg }\end{array}$ & $\begin{array}{c}\mathrm{N} \\
\text { MLarg }\end{array}$ & $\begin{array}{c}1 / D \\
\text { MLarg }\end{array}$ & $\begin{array}{c}\mathrm{S} \\
\mathrm{Lg}\end{array}$ & $\begin{array}{l}\mathrm{N} \\
\mathrm{Lg}\end{array}$ & $\begin{array}{l}1 / D \\
\mathrm{Lg}\end{array}$ \\
\hline 1 & 1 & A & 0 & 0 & 0 & 6 & 13 & 3.45 & 4 & 4 & 4.00 & 4 & 13 & 2.68 \\
\hline 1 & 1 & B & 1 & 1 & 1 & 5 & 8 & 4.00 & 3 & 4 & 2.67 & 0 & 0 & 0.00 \\
\hline 1 & 1 & C & 1 & 1 & 1 & 3 & 5 & 2.27 & 5 & 13 & 1.99 & 0 & 0 & 0.00 \\
\hline 2 & 1 & A & 0 & 0 & 0 & 1 & 1 & 1.00 & 0 & 0 & 0.00 & 0 & 0 & 0.00 \\
\hline 2 & 1 & B & 0 & 0 & 0 & 3 & 4 & 2.67 & 8 & 9 & 7.36 & 3 & 4 & 2.67 \\
\hline 2 & 1 & C & 1 & 3 & 1 & 3 & 7 & 2.33 & 8 & 12 & 6.55 & 4 & 14 & 3.63 \\
\hline 3 & 1 & A & 0 & 0 & 0 & 3 & 3 & 3.00 & 6 & 11 & 4.17 & 3 & 5 & 2.27 \\
\hline 3 & 1 & B & 1 & 1 & 1 & 7 & 13 & 5.12 & 10 & 16 & 8.00 & 4 & 13 & 3.45 \\
\hline 3 & 1 & C & 0 & 0 & 0 & 5 & 9 & 3.52 & 6 & 13 & 4.83 & 4 & 8 & 2.29 \\
\hline 4 & 1 & A & 0 & 0 & 0 & 3 & 4 & 2.67 & 1 & 1 & 1.00 & 0 & 0 & 0.00 \\
\hline 4 & 1 & B & 0 & 0 & 0 & 2 & 3 & 1.80 & 4 & 6 & 3.00 & 4 & 4 & 4.00 \\
\hline 4 & 1 & C & 0 & 0 & 0 & 3 & 3 & 3.00 & 4 & 7 & 3.27 & 2 & 3 & 1.80 \\
\hline 5 & 1 & A & 0 & 0 & 0 & 4 & 19 & 1.97 & 9 & 23 & 4.17 & 8 & 19 & 4.95 \\
\hline 5 & 1 & B & 0 & 0 & 0 & 3 & 9 & 2.45 & 5 & 10 & 4.17 & 3 & 5 & 2.27 \\
\hline 5 & 1 & C & 1 & 1 & 1 & 4 & 7 & 3.77 & 5 & 11 & 3.46 & 2 & 4 & 2.00 \\
\hline 6 & 1 & A & 0 & 0 & 0 & 2 & 5 & 1.47 & 3 & 4 & 2.67 & 4 & 4 & 4.00 \\
\hline 6 & 1 & B & 1 & 1 & 1 & 3 & 3 & 3.00 & 5 & 9 & 3.52 & 3 & 3 & 3.00 \\
\hline 6 & 1 & C & 0 & 0 & 0 & 3 & 13 & 2.09 & 3 & 6 & 2.00 & 4 & 7 & 3.27 \\
\hline 7 & 1 & A & 0 & 0 & 0 & 8 & 16 & 2.91 & 5 & 5 & 5.00 & 6 & 15 & 4.59 \\
\hline 7 & 1 & B & 0 & 0 & 0 & 2 & 2 & 2.00 & 3 & 6 & 2.00 & 6 & 11 & 4.48 \\
\hline 7 & 1 & C & 0 & 0 & 0 & 3 & 7 & 2.33 & 5 & 6 & 4.50 & 4 & 8 & 2.29 \\
\hline 8 & 1 & A & 0 & 0 & 0 & 4 & 14 & 3.92 & 11 & 37 & 5.50 & 7 & 14 & 3.38 \\
\hline 8 & 1 & B & 0 & 0 & 0 & 8 & 23 & 5.04 & 12 & 19 & 8.02 & 9 & 22 & 6.37 \\
\hline 8 & 1 & C & 0 & 0 & 0 & 5 & 8 & 4.57 & 9 & 27 & 4.70 & 8 & 12 & 5.54 \\
\hline 10 & 1 & A & 1 & 1 & 1 & 3 & 6 & 2.57 & 4 & 10 & 1.92 & 0 & 0 & 0.00 \\
\hline 10 & 1 & B & 0 & 0 & 0 & 4 & 7 & 2.58 & 5 & 10 & 4.17 & 2 & 13 & 1.17 \\
\hline 10 & 1 & C & 0 & 0 & 0 & 5 & 7 & 3.77 & 8 & 26 & 4.51 & 4 & 19 & 2.19 \\
\hline 1 & 2 & A & 0 & 0 & 0 & 6 & 11 & 4.17 & 9 & 21 & 6.21 & 6 & 16 & 4.57 \\
\hline 1 & 2 & B & 0 & 0 & 0 & 9 & 14 & 6.53 & 8 & 10 & 7.14 & 2 & 2 & 2.00 \\
\hline 1 & 2 & C & 0 & 0 & 0 & 2 & 4 & 1.60 & 1 & 1 & 1.00 & 1 & 1 & 1.00 \\
\hline 2 & 2 & A & 0 & 0 & 0 & 2 & 2 & 2.00 & 2 & 2 & 2.00 & 0 & 0 & 0.00 \\
\hline
\end{tabular}




\begin{tabular}{rrrrrrrrrrrrrrr}
\hline Frag & Year & Site & $\begin{array}{c}\mathrm{S} \\
\text { small }\end{array}$ & $\begin{array}{r}\mathrm{N} \\
\text { small }\end{array}$ & $\begin{array}{c}1 / D \\
\text { small }\end{array}$ & $\begin{array}{r}\mathrm{S} \\
\text { Msmal }\end{array}$ & $\begin{array}{r}\mathrm{N} \\
\text { Msmal }\end{array}$ & $\begin{array}{c}1 / D \\
\text { Msmal }\end{array}$ & $\begin{array}{c}\mathrm{S} \\
\text { MLarg }\end{array}$ & $\begin{array}{c}\mathrm{N} \\
\text { MLarg }\end{array}$ & $\begin{array}{c}1 / D \\
\text { MLarg }\end{array}$ & $\begin{array}{c}\mathrm{S} \\
\mathrm{Lg}\end{array}$ & $\begin{array}{c}\mathrm{N} \\
\mathrm{Lg}\end{array}$ & $\begin{array}{c}1 / D \\
\mathrm{Lg}\end{array}$ \\
\hline 2 & 2 & $\mathrm{~B}$ & 0 & 0 & 0 & 5 & 6 & 4.50 & 4 & 4 & 4.00 & 0 & 0 & 0.00 \\
2 & 2 & $\mathrm{C}$ & 0 & 0 & 0 & 6 & 13 & 4.33 & 5 & 13 & 3.60 & 5 & 10 & 4.17 \\
3 & 2 & $\mathrm{~A}$ & 0 & 0 & 0 & 3 & 4 & 2.67 & 2 & 4 & 1.60 & 4 & 6 & 3.00 \\
3 & 2 & $\mathrm{~B}$ & 0 & 0 & 0 & 4 & 5 & 3.57 & 4 & 4 & 4.00 & 2 & 9 & 1.53 \\
3 & 2 & $\mathrm{C}$ & 0 & 0 & 0 & 2 & 2 & 2.00 & 5 & 10 & 3.13 & 3 & 6 & 2.00 \\
4 & 2 & $\mathrm{~A}$ & 0 & 0 & 0 & 3 & 5 & 2.78 & 10 & 15 & 7.76 & 2 & 2 & 2.00 \\
4 & 2 & $\mathrm{~B}$ & 0 & 0 & 0 & 4 & 4 & 4.00 & 4 & 5 & 3.57 & 4 & 5 & 3.57 \\
4 & 2 & $\mathrm{C}$ & 0 & 0 & 0 & 5 & 6 & 4.50 & 2 & 3 & 1.80 & 4 & 12 & 2.40 \\
5 & 2 & $\mathrm{~A}$ & 1 & 1 & 1 & 4 & 10 & 3.33 & 10 & 21 & 8.32 & 9 & 19 & 7.37 \\
5 & 2 & $\mathrm{~B}$ & 1 & 1 & 1 & 4 & 6 & 3.60 & 5 & 7 & 4.45 & 4 & 7 & 3.27 \\
5 & 2 & $\mathrm{C}$ & 0 & 0 & 0 & 5 & 6 & 4.50 & 4 & 4 & 4.00 & 3 & 3 & 3.00 \\
6 & 2 & $\mathrm{~A}$ & 0 & 0 & 0 & 2 & 3 & 1.80 & 6 & 8 & 5.33 & 2 & 4 & 1.60 \\
6 & 2 & $\mathrm{~B}$ & 1 & 1 & 1 & 2 & 3 & 1.80 & 3 & 4 & 2.67 & 3 & 3 & 3.00 \\
6 & 2 & $\mathrm{C}$ & 0 & 0 & 0 & 6 & 10 & 4.17 & 4 & 4 & 4.00 & 3 & 9 & 2.45 \\
7 & 2 & $\mathrm{~A}$ & 0 & 0 & 0 & 6 & 14 & 3.77 & 3 & 4 & 2.67 & 2 & 2 & 2.00 \\
7 & 2 & $\mathrm{~B}$ & 0 & 0 & 0 & 2 & 4 & 2.00 & 2 & 2 & 2.00 & 4 & 8 & 2.91 \\
7 & 2 & $\mathrm{C}$ & 0 & 0 & 0 & 8 & 11 & 6.37 & 10 & 22 & 6.54 & 4 & 14 & 2.39 \\
8 & 2 & $\mathrm{~A}$ & 0 & 0 & 0 & 2 & 3 & 1.80 & 7 & 10 & 6.25 & 5 & 19 & 2.93 \\
8 & 2 & $\mathrm{~B}$ & 0 & 0 & 0 & 4 & 16 & 2.84 & 11 & 16 & 7.53 & 4 & 10 & 1.92 \\
8 & 2 & $\mathrm{C}$ & 0 & 0 & 0 & 3 & 5 & 2.27 & 7 & 17 & 3.57 & 6 & 11 & 4.48 \\
10 & 2 & $\mathrm{~A}$ & 1 & 1 & 1 & 2 & 2 & 2.00 & 2 & 4 & 1.60 & 1 & 1 & 1.00 \\
10 & 2 & $\mathrm{~B}$ & 0 & 0 & 0 & 3 & 4 & 2.67 & 1 & 2 & 1.00 & 3 & 7 & 2.88 \\
10 & 2 & $\mathrm{C}$ & 0 & 0 & 0 & 4 & 5 & 3.57 & 2 & 3 & 1.80 & 2 & 2 & 2.00 \\
\hline
\end{tabular}


Appendix 2.4: Pooled species richness per fragment and year.

\begin{tabular}{llr} 
Table 2.4.1: & $\begin{array}{r}\text { Species } \\
\text { richness of the total species }\end{array}$ \\
assemblage per & fragment \\
\multicolumn{4}{l}{ S $_{\text {frag }}$ ) and Year. } \\
\hline Frag ID & Year & $\mathrm{S}_{\text {frag }}$ \\
\hline 1 & 1 & 25 \\
2 & 1 & 30 \\
3 & 1 & 25 \\
4 & 1 & 25 \\
5 & 1 & 35 \\
6 & 1 & 19 \\
7 & 1 & 14 \\
8 & 1 & 28 \\
10 & 1 & 30 \\
1 & 2 & 34 \\
2 & 2 & 21 \\
3 & 2 & 25 \\
4 & 2 & 25 \\
5 & 2 & 28 \\
6 & 2 & 44 \\
7 & 2 & 32 \\
8 & 2 & 27 \\
10 & 2 & 15 \\
\hline
\end{tabular}


Appendix 2.5: Parasitoids isolated from Malaise trap catches.

Table 2.5.1: Parasitoid taxa used in the analysis collected from nine native forest fragments during southern hemisphere summers 2002-2003 and 2003-2004.

\begin{tabular}{|c|c|c|c|c|c|c|c|c|c|c|c|}
\hline \multirow[b]{2}{*}{ Taxa } & \multirow[b]{2}{*}{1} & \multirow[b]{2}{*}{2} & \multirow[b]{2}{*}{3} & \multirow[b]{2}{*}{4} & \multicolumn{4}{|c|}{ Fragment } & \multirow[b]{2}{*}{10} & \multirow[b]{2}{*}{$\begin{array}{c}\text { Total } \\
\mathbf{N}\end{array}$} & \multirow[b]{2}{*}{$\begin{array}{l}\text { No. of } \\
\text { fragments }\end{array}$} \\
\hline & & & & & 5 & 6 & 7 & 8 & & & \\
\hline \multicolumn{12}{|l|}{ Ichneumonidae } \\
\hline \multicolumn{12}{|l|}{ Banchinae } \\
\hline Lissonoto albopicta & & 1 & & & & & & 8 & 1 & 10 & 3 \\
\hline Lissonoto fulva & & & 4 & 1 & 1 & & & 4 & & 10 & 4 \\
\hline \multicolumn{12}{|l|}{ Campopleginae } \\
\hline Campoletis sp. 1 & 5 & 4 & 12 & 4 & 8 & 3 & 5 & 1 & & 42 & 8 \\
\hline Campoletis sp. 2 & & & & & & & & 1 & & 1 & 1 \\
\hline Campopleginae sp. 1 & & & & & 1 & & & & & 1 & 1 \\
\hline Casinaria sp. 1 & & & & & 1 & & & 2 & & 3 & 2 \\
\hline Casinaria sp. 2 & 1 & & 1 & & 5 & 3 & 1 & 3 & 1 & 15 & 7 \\
\hline Diadegma sp 01 & & & & & & 1 & & & & 1 & 1 \\
\hline Diadegma sp. 02 & & 1 & & & & & & & & 1 & 1 \\
\hline Diadegma sp. 03 & & & & & & & & & 1 & 1 & 1 \\
\hline Diadegma sp. 04 & & 1 & & & & & & & & 1 & 1 \\
\hline Diadegma sp. 05 & & & & & & 1 & & & & 1 & 1 \\
\hline Diadegma sp. 07 & 1 & & & & & & & & & 1 & 1 \\
\hline Diadegma sp. 08 & & & & & & & & & 1 & 1 & 1 \\
\hline Diadegma sp. 09 & & & & & & & & 1 & & 1 & 1 \\
\hline Diadegma sp. 10 & & & 1 & & & & 1 & 3 & 2 & 7 & 4 \\
\hline Diadegma sp. 11 & 2 & 1 & 1 & & & & & 1 & 2 & 7 & 5 \\
\hline Dusona destructor & & & 2 & & & & & 4 & & 6 & 2 \\
\hline Dusona stramineipes & 2 & 4 & 1 & 2 & 3 & & & 3 & & 15 & 6 \\
\hline \multicolumn{12}{|l|}{ Eucerotinae } \\
\hline Euceros coxalis & & & & & & & 1 & & & 1 & 1 \\
\hline \multicolumn{12}{|l|}{ Ichneumoninae } \\
\hline Aucklandella sp. 03 & & & & & 1 & & & & & 1 & 1 \\
\hline Aucklandella sp. 04 & & & & & 1 & & & & & 1 & 1 \\
\hline Aucklandella sp. 05 & & & & & & & 1 & & & 1 & 1 \\
\hline Aucklandella sp. 06 & & & & & & 1 & & & & 1 & 1 \\
\hline Aucklandella sp. 07 & & & 1 & & 3 & 1 & & & 1 & 6 & 4 \\
\hline Aucklandella sp. 09 & 3 & & & & & & & & & 3 & 1 \\
\hline Aucklandella sp. 11 & & & & & 2 & & 1 & 2 & & 5 & 3 \\
\hline Aucklandella sp. 12 & 1 & 1 & 1 & 3 & & 1 & & 1 & & 8 & 6 \\
\hline Aucklandella sp. 13 & & & & & 1 & & & & & 1 & 1 \\
\hline Aucklandella sp. 15 & & & 2 & & 1 & & & 3 & 5 & 11 & 4 \\
\hline Aucklandella sp. 16 & 3 & 3 & 2 & 1 & 3 & 1 & 6 & 7 & 4 & 30 & 9 \\
\hline Aucklandella sp. 17 & 11 & 1 & 2 & 3 & 4 & & 2 & 3 & 2 & 28 & 8 \\
\hline Aucklandella sp. 18 & 2 & & & 1 & & & & 2 & & 5 & 3 \\
\hline Aucklandella sp. 19 & & & & & & & 1 & & & 1 & 1 \\
\hline Aucklandella sp. 20 & 5 & 10 & 2 & 1 & 1 & 3 & 9 & 5 & 3 & 39 & 9 \\
\hline Aucklandella sp. 21 & 6 & 4 & 2 & 3 & 8 & 3 & 6 & 18 & 5 & 55 & 9 \\
\hline Aucklandella sp. 22 & & & 1 & & 1 & & & 2 & & 4 & 2 \\
\hline Aucklandella sp. 23 & & & & 1 & & 1 & & 1 & & 3 & 3 \\
\hline
\end{tabular}




\begin{tabular}{|c|c|c|c|c|c|c|c|c|c|c|c|}
\hline \multirow[b]{2}{*}{ Taxa } & \multirow[b]{2}{*}{1} & \multirow[b]{2}{*}{2} & \multirow[b]{2}{*}{3} & \multirow[b]{2}{*}{4} & \multicolumn{5}{|c|}{ Fragment } & \multirow{2}{*}{$\begin{array}{c}\text { Total } \\
\mathbf{N}\end{array}$} & \multirow[b]{2}{*}{$\begin{array}{l}\text { No. of } \\
\text { fragments }\end{array}$} \\
\hline & & & & & 5 & 6 & 7 & 8 & 10 & & \\
\hline Aucklandella sp. 24 & 4 & 10 & 7 & 3 & 11 & 11 & 5 & 22 & 12 & 85 & 9 \\
\hline Degithina sp. 1 & & & & & & 1 & & & & 1 & 1 \\
\hline Degithina sp. 2 & & & & & & & & 3 & & 3 & 1 \\
\hline Degithina sp. 3 & 1 & & 2 & 3 & 4 & 2 & 5 & 6 & 2 & 25 & 8 \\
\hline Degithina sp. 4 & & & 2 & 1 & 8 & & 4 & 6 & 1 & 22 & 6 \\
\hline Ichneumon lotatorius & & 1 & & & 3 & & 1 & & & 5 & 2 \\
\hline Levansa sp. 1 & & 6 & 1 & 3 & 3 & & 3 & 7 & & 23 & 6 \\
\hline Lusius sp. & & 2 & & & & 1 & & & & 3 & 2 \\
\hline \multicolumn{12}{|l|}{ Mesochorinae } \\
\hline Mesochorus sp. & & 1 & 2 & 4 & & 3 & 2 & & 1 & 13 & 6 \\
\hline \multicolumn{12}{|l|}{ Metopiinae } \\
\hline Carria fortipes & & & & 3 & 1 & & 1 & 5 & 1 & 11 & 5 \\
\hline \multicolumn{12}{|l|}{ Orthocentrinae } \\
\hline Megastylus sp. & 3 & 2 & 1 & 1 & & 1 & 2 & 1 & 1 & 12 & 8 \\
\hline \multicolumn{12}{|l|}{ Phygadeuontinae } \\
\hline Aclastus sp. 01 & 6 & 2 & 3 & 4 & 4 & 4 & 14 & 7 & 1 & 45 & 9 \\
\hline Aclastus sp. 02 & 11 & 3 & 11 & 10 & & 5 & 5 & 3 & 22 & 70 & 8 \\
\hline Aclastus sp. 03 & 4 & & 9 & 5 & 6 & 12 & 4 & 1 & 10 & 51 & 8 \\
\hline Amblyaclastus sp. & & 1 & & & & & & & & 1 & 1 \\
\hline Phygadeuontinae sp. 01 & & & & 1 & 1 & & 1 & 2 & 2 & 7 & 5 \\
\hline Phygadeuontinae sp. 03 & & 1 & & & & 2 & 2 & & & 5 & 3 \\
\hline Phygadeuontinae sp. 04 & 1 & & & & 3 & & 2 & & & 6 & 3 \\
\hline Phygadeuontinae sp. 05 & & & & & & & & & 1 & 1 & 1 \\
\hline Phygadeuontinae sp. 06 & & & 1 & & & & & 2 & & 3 & 2 \\
\hline Phygadeuontinae sp. 07 & & & 3 & & 8 & & 1 & 2 & & 14 & 4 \\
\hline Phygadeuontinae sp. 08 & & 6 & 1 & & 1 & & & & & 8 & 3 \\
\hline Phygadeuontinae sp. 09 & & & & & 1 & & & 1 & & 2 & 2 \\
\hline Phygadeuontinae sp. 10 & & & & & 1 & & & & & 1 & 1 \\
\hline Phygadeuontinae sp. 11 & & & & & & & & & 1 & 1 & 1 \\
\hline Phygadeuontinae sp. 14 & 7 & 1 & 5 & & & 1 & 1 & 10 & 2 & 27 & 7 \\
\hline Phygadeuontinae sp. 15 & 8 & 11 & 5 & 8 & 25 & 11 & 8 & 16 & 7 & 99 & 9 \\
\hline Phygadeuontinae sp. 16 & & & & & & & & & 1 & 1 & 1 \\
\hline Phygadeuontinae sp. 17 & & & & & & & 1 & & & 1 & 1 \\
\hline Phygadeuontinae sp. 18 & 1 & & & & & 2 & & & & 3 & 2 \\
\hline Phygadeuontinae sp. 21 & & & 1 & & & & & 1 & & 2 & 2 \\
\hline Phygadeuontinae sp. 22 & & & & & & & 1 & & & 1 & 1 \\
\hline Xanthocryptus novozealandicus & & & & & 7 & & & 2 & & 9 & 2 \\
\hline Xenolytus bitinctus & 1 & & & & & & & & & 1 & 1 \\
\hline \multicolumn{12}{|l|}{ Tersilochinae } \\
\hline Tersilochinae sp. 1 & & 3 & & & & & & & & 3 & 1 \\
\hline Tersilochinae sp. 2 & 1 & & & & & & & & & 1 & 1 \\
\hline Tersilochinae sp. 3 & 1 & & & & & & & & & 1 & 1 \\
\hline Tersilochinae sp. 4 & & & & & 1 & & & & 1 & 2 & 2 \\
\hline Tersilochinae sp. 5 & 1 & 1 & 1 & & & & & & & 3 & 3 \\
\hline Tersilochinae sp. 6 & & & 1 & & & 3 & & & 1 & 5 & 3 \\
\hline Tersilochinae sp. 7 & 1 & & & & 2 & 2 & & & & 5 & 3 \\
\hline Tersilochinae sp. 8 & & & 2 & & 1 & & 14 & 1 & & 18 & 4 \\
\hline Tersilochinae sp. 9 & & 1 & & & & & & & & 1 & 1 \\
\hline \multicolumn{12}{|l|}{ Tryphoninae } \\
\hline Netelia ephippiata & & & & & 1 & & & & & 1 & 1 \\
\hline
\end{tabular}




\begin{tabular}{|c|c|c|c|c|c|c|c|c|c|c|c|}
\hline \multirow[b]{2}{*}{ Taxa } & \multicolumn{9}{|c|}{ Fragment } & \multirow[b]{2}{*}{$\begin{array}{c}\text { Total } \\
\mathbf{N}\end{array}$} & \multirow[b]{2}{*}{$\begin{array}{l}\text { No. of } \\
\text { fragments }\end{array}$} \\
\hline & 1 & 2 & 3 & 4 & 5 & 6 & 7 & 8 & 10 & & \\
\hline $\begin{array}{l}\text { Phytodietus zealandicus } \\
\text { Pompilidae }\end{array}$ & & & & 1 & 1 & & & 2 & 1 & 5 & 4 \\
\hline \multicolumn{12}{|l|}{ Pepsinae } \\
\hline Priocnemis conformis & 3 & & & & 1 & & & & 1 & 5 & 3 \\
\hline Priocnemis monachus & & & 1 & & & 2 & & & & 3 & 2 \\
\hline Sphictostethus fugax & 11 & 4 & 11 & 4 & 11 & 7 & 17 & 34 & 27 & 126 & 9 \\
\hline Sphictostethus nitidus & 7 & 6 & 24 & 13 & 13 & 13 & 15 & 16 & 3 & 110 & 9 \\
\hline \multicolumn{12}{|l|}{ Pompilinae } \\
\hline $\begin{array}{l}\text { Epipompilus insularis } \\
\text { Proctotrupidae }\end{array}$ & 2 & 2 & 7 & 1 & 15 & 1 & 10 & 31 & 1 & 70 & 9 \\
\hline \multicolumn{12}{|l|}{ Proctotrupinae } \\
\hline Fustiserphus longiceps & 2 & 2 & 2 & 2 & 8 & & 1 & 15 & 2 & 34 & 8 \\
\hline Fustiserphus sp. 1 & & 1 & & & & & 3 & & & 4 & 2 \\
\hline Fustiserphus sp. 2 & 7 & 2 & 1 & & 6 & & & 1 & & 17 & 5 \\
\hline Fustiserphus sp. 3 & & & & & & 1 & & & & 1 & 1 \\
\hline Fustiserphus sp. 4 & 12 & & 1 & & & & & 4 & & 17 & 3 \\
\hline Fustiserphus sp. 5 & & & & & & & & 4 & & 4 & 1 \\
\hline Oxyserphus sp. 1 & 1 & 3 & 1 & & 1 & & & & & 6 & 4 \\
\hline Oxyserphus sp. 2 & 2 & & & 1 & & & & 3 & & 6 & 3 \\
\hline Oxyserphus sp. 3 & & 1 & & & & & & & & 1 & 1 \\
\hline Oxyserphus sp. 4 & 1 & & & & & & & & & 1 & 1 \\
\hline Oxyserphus sp. 5 & 1 & & & & & & & & & 1 & 1 \\
\hline Proctotrupidae sp. 1 & & & 1 & & & & & & & 1 & 1 \\
\hline Grand Total & 142 & 104 & 142 & 88 & 193 & 104 & 157 & 283 & 130 & 1343 & 9 \\
\hline
\end{tabular}




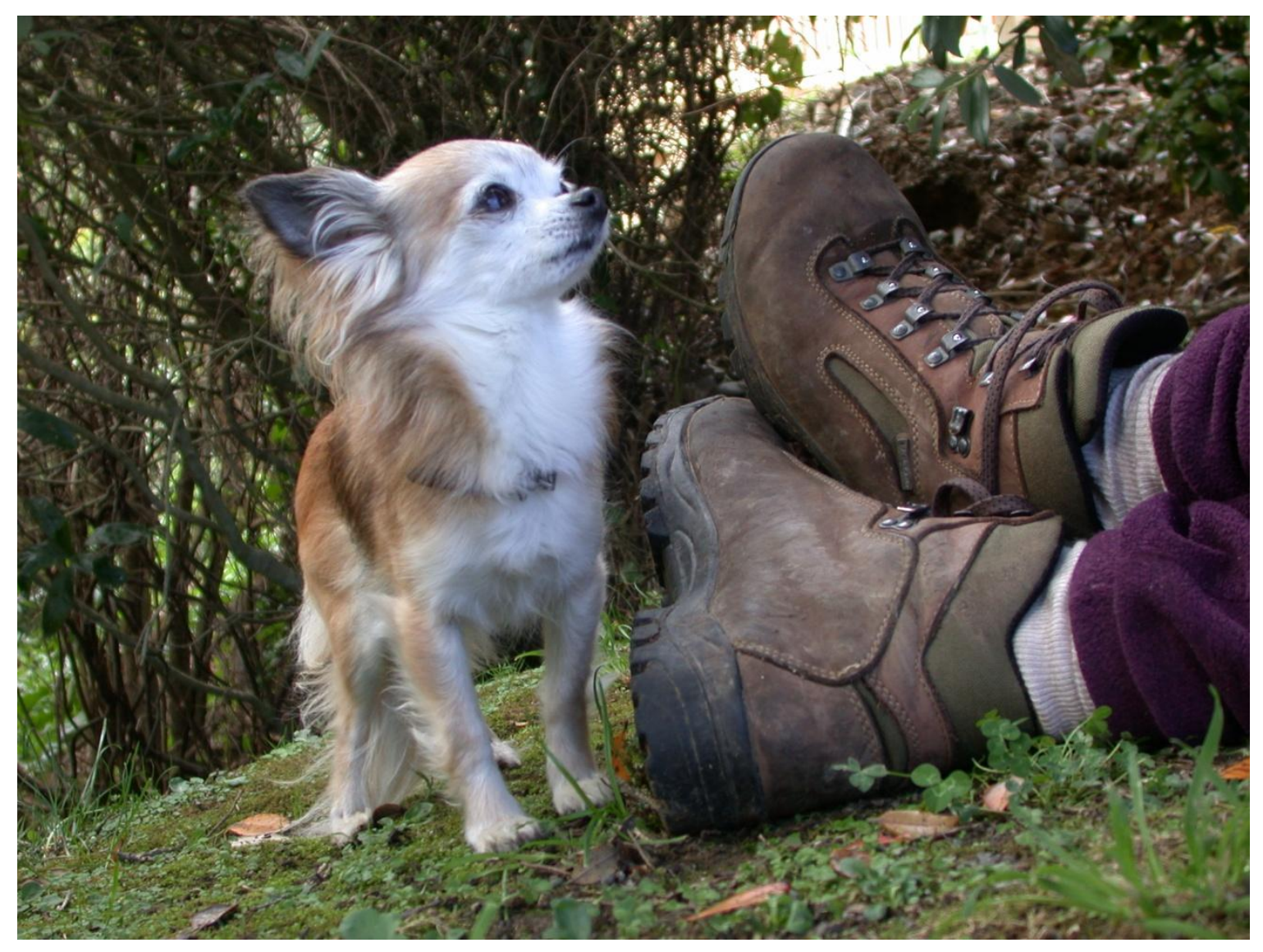

My faithful field companion Poppy 


\section{On the relationship between plant and parasitoid community structure: Do plant communities predict structure at higher trophic levels across a fragmented forest landscape? ${ }^{1}$}

\subsection{Abstract}

1. Species extinctions have been attributed particularly to habitat loss with increasing fragmentation of the landscape matrix. Specifically, organisms at the higher trophic levels are thought to be confounded by habitat fragmentation. Effects of habitat fragmentation however, do not always adequately explain the parasitoid community patterns. Parasitoids may be correlated with plant species richness, because plants host a variety of phytophagous insects acting as hosts for parasitoids, or plants provide food or act as shelter for parasitoids. To investigate this we assessed the plant and parasitoid communities of 10 fragments of native forest within the Wellington and Hutt Valley regions of the North Island of New Zealand.

2. Insects were sampled from each fragment during the southern summer months December and February 2002/2003 and 2003/2004. A total of 103 parasitoid species from the families Ichneumonidae, Pompilidae and Proctotrupidae were selected for this study. Plant surveys resulted in a total of 116 plant species.

3. The plant and parasitoid community composition was examined in relation to fragment area and isolation. Correlations between beta diversity of the plant

\footnotetext{
${ }^{1}$ Co-authors: Hartley, S., and Lester, P. J.
} 
community and the parasitoid community were analysed and we investigated whether individual parasitoid occurrences can be predicted by the range of their host's host plants.

4. Plant richness was positively affected by the combination of area and a reduction in isolation whereas parasitoid abundance and richness responded negatively to an increase in area and connectivity. Correlations between plant and parasitoid community structures were not significant. Individual parasitoidplant associations were weak and inconclusive.

5. The current study clearly shows that fragment area and isolation on their own are not always sufficient predictors to explain community structure for parasitoids. Despite strong variations between research sites, the plant community provided weak explanations for the parasitoid community as a whole and for some individual species. This study provided evidence for and strongly supports the general idea that there are many aspects that contribute to the persistence and viability of parasitoid populations.

Keywords: Parasitoids, Ichneumonidae, habitat fragmentation, community structure, parasitoid-plant relationship, trophic interactions 


\subsection{Introduction}

In general, habitat fragmentation is recognised as a driver for the loss of local biodiversity (Fahrig, 2003; Wiegand, Revilla \& Moloney, 2005). Arthropods, in particular those at the higher trophic levels, such as parasitoids, are thought to respond negatively to fragmentation at a much stronger rate than their herbivorous hosts, which again respond more strongly than their own host plants (Kruess, 2003; Kruess \& Tscharntke, 1994, 2000). However, van Nouhuys (2005) concluded that there is no consensus on parasitoid responses to fragmentation. In her review she showed that parasitoid species abundance, richness and diversity, for example, had been found to be lower in smaller and more isolated fragments than in larger and connected fragments. Other studies showed that parasitoid species richness as well as diversity were unresponsive to habitat fragmentation, yet species composition differed between fragments of different area and degree of isolation (van Nouhuys, 2005 and references therein). One study even found that parasitoid abundance was positively related with a loss of forest cover of below approximately 40\% (Chust, Garbin \& Pujade-Villar, 2007).

Loss of habitat quality as a result of fragmentation might be of more importance to species extinction than the fragmentation of the landscape itself (Fahrig, 2003; Wiegand, Revilla \& Moloney, 2005). In a fragmented landscape matrix the proportional availability of suitable habitat is therefore the most important factor for populations to persist (Andrén, 1994). For example, differences in beetle and wasp species richness, abundance and composition were attributed to differences in habitat complexity (Lassau \& Hochuli, 2005; Lassau et al., 2005). Parasitoid communities differed between broadleaved and coniferous woodlands (Fraser, Dytham \& Mayhew, 2007) and between fragments of heath and woodland (Gibb \& Hochuli, 2002). 
The study from Chapter 2 concluded that fragmentation effects such as fragment area, isolation, percent of residential area in the surrounding matrix and the overall number of plant species per fragment alone could not adequately explain the parasitoid community patterns observed in urban native forest fragments of the Wellington and Hutt Valley regions.

A comparison of species compositions between islands has shown a significant correlation between the avifauna and the floral species richness on the Galapagos Islands (Power, 1975). Similarly, habitat quality for parasitoids may be correlated with plant species richness because plants host a variety of phytophagous insects acting as hosts for parasitoids, or plants provide food or act as shelter for parasitoids to roost (Shaw, 2006). Variation in parasitoid communities might therefore be related to plant species richness of a habitat fragment. Plant species richness, for example, was found to predict butterfly richness (Steffan-Dewenter \& Tscharntke, 2000) and number of arthropod pest species (Raupp et al., 2001).

For the majority of New Zealand's parasitoids the hosts are unknown. However, since the parasitoid distribution depends on the distribution of the herbivore's host plants, we might expect to find a significant correlation in species composition between parasitoid and plant communities. This study examines whether beta diversity of the plant community can predict beta diversity patterns of the parasitoid community. Beta diversity, often referred to as the spatial turnover or change in species assemblages, measures the difference in species composition between two or more species assemblages from different localities (Koleff, Gaston \& Lennon, 2003). Beta diversity is a more direct measure of between-habitat diversity also referred to as "differentiation diversity", 
whereas alpha-diversity measures the diversity at a given point in time, hence "inventory diversity" (Magurran, 2004). We therefore analyse the multivariate relationship between plant and parasitoid community composition across a set of fragments differing in their area and isolation. We also examine whether beta diversity of the plant community is correlated to the beta diversity of the parasitoid community. Finally, we wanted to know whether individual parasitoid occurrences can be predicted by the range of their host's host plants.

In this study the following hypotheses were tested:

1. plant and parasitoid community compositions are independent of one another and unaffected by fragment area and isolation;

2. parasitoid beta diversity between sites is independent of plant beta diversity;

3. individual parasitoid absence/presence is independent of the absence/presence of their host's host plants.

\subsection{Methods}

\subsubsection{Study sites and sampling}

Ten fragments of native forest were studied within the Wellington and Hutt Valley region in the North Island (New Zealand) (Fig. 3.1). The area of the study fragments ranged from 12 to 1068 ha (see Appendix 3.1, Table 3.1.1 for fragment indices). The area and isolation of fragments were quantified using ESRI®ArcGISTM 9.0 Build 560 (ESRI, 
2004). Within a range of $1 \mathrm{~km}$ distance from the edge of each research fragment we calculated an isolation index for each fragment, based on the commonly-used formula proposed by Hanski, Kuussaari and Nieminen (1994):

$$
I_{j}=\sum_{j=1}^{n} \exp \left(-d_{i j}\right) A_{j}, \quad j \neq i
$$

where, $d_{i j}$ is the minimum distance (in $\mathrm{km}$ ) from the focal fragment $i$ to the neighbouring native fragment $j, n$ is the number of neighbouring fragments, and $A_{j}$ is the area (in $\mathrm{m}^{2}$ ) of the neighbouring native fragments. A lower value of $I$ indicates a more isolated fragment in comparison to less isolated fragments with larger $I$ values. Fragment area and isolation were $\log _{10}$ transformed prior to analysis

Three randomly selected collection sites ( 20 x 20 m sample quadrates) per fragment were placed inside each fragment at a consistent distance of $30 \pm 5$ meters from the fragment edge. Due to logistical difficulties the Stokes Valley fragment only contained two collecting sites instead of three randomly selected collection sites. The plant communities (absence/presence and relative abundance data) from the 10 fragments were described using Reconnaissance (RECCE) description procedure (Allen, 1992). Relative abundance for each plant species was calculated as mean percentage canopy cover from different tiers.

To collect parasitoids, Malaise traps were set during December and February of the 2002/2003 and 2003/2004 summer periods (Appendix 3.1, Table 3.1.2). Logistical constraints meant we could not sample all 27 sites concurrently. Consequently, traps were 
set for a period of four to five days within the month, and rotated across fragments following a randomly determined sequence. For the purpose of this study we isolated female wasps of the families Ichneumonidae, Pompilidae and Proctotrupidae from Malaise trap collections. The collected specimens were stored in $70 \%$ ethanol and reference material was sorted, mounted and identified to subfamily and where possible to genus or species using available keys (Gauld, 1984; Harris, 1987; Townes \& Townes, 1981; Wahl, 1993). Ichneumonidae are sexually dimorphic and assignment of males to corresponding females in this family is almost impossible without a key or species knowledge. To prevent inflated species richness all males are therefore excluded from this study. Where identification to genus or species level was not possible, specimens were sorted to morpho-species, which will be referred to as species from here on. In addition, we compared our ichneumonid and proctotrupid specimens with collections held at the Auckland Museum, the New Zealand Arthropod Collection at Landcare Research (Manaaki Whenua) and the Museum of New Zealand, Wellington (Te Papa Tongarewa). Some voucher specimens were deposited at the Museum of New Zealand (Te Papa Tongarewa), Wellington.

For the following analyses, beta-diversity for parasitoids and plant communities was calculated between all possible pairs of sites. For this Bray-Curtis dissimilarity coefficient matrices were established from non-standardised and non-transformed plant as well as parasitoid absence/presence and abundance data. The Bray-Curtis distance measure ignores species jointly absent from sites and therefore is well suited for species abundance data (Quinn \& Keough, 2002) and is highly commended by Magurran (2004). A parasitoid absence/presence matrix was also established transforming parasitoid abundance data. 


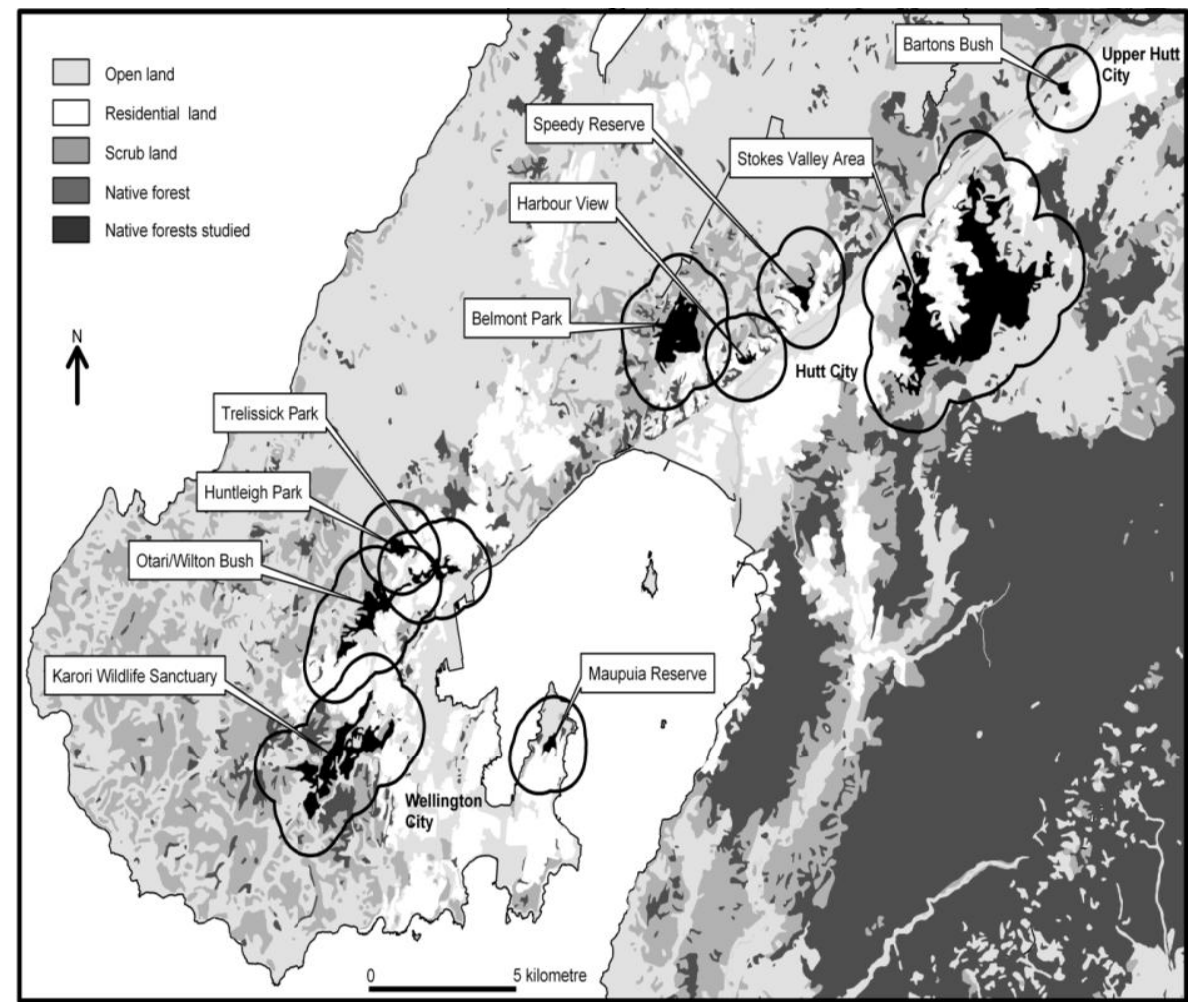

Figure 3.1: The Wellington and Hutt Valley region with the location of 10 native forest research fragments and the surrounding $1 \mathrm{~km}$ range included in the study. (Data and land cover shape files courtesy of New Zealand Department of Conservation http://extranet.doc.govt.nz/bip).

\subsubsection{Community responses to fragment area and isolation}

We analysed alpha diversity of species at a site level between fragments of the plant and parasitoid composition as a multivariate community response to fragment area and isolation (as predictors). We examined plant and parasitoid absence/presence as well as parasitoid abundance data using a non-parametric multivariate analysis of variance with the software "PERMANOVA6" (Anderson, 2001; McArdle \& Anderson, 2001). This method can test one or more continuous variables for their response to one or more factors and covariates in a balanced ANOVA experimental design using permutation methods to calculate a p-value and has the advantage of good power coupled with an 
absence of assumptions of normality of the errors, a constant variance, and independent errors (Anderson, 2005). Any distance measure may be used for the response variable (we used Bray-Curtis dissimilarity), which makes this method particularly useful for ecological data where the assumption of a multivariate normal distribution of the data is unrealistic (Anderson, 2001). We treated sites within fragments as replicates, with fragment as a fixed factor (totalling 27 observations) in a one-way crossed MANCOVA design (the Stokes Valley fragment was excluded). We used 4999 permutations in order to obtain reliable results at an $\alpha$-level of 0.01 . We used ' 3 ' as the seed integer for randomisations. This integer needs to be the same in a repeat analysis to achieve the exact same result (Anderson, 2005).

We also used a two-factor crossed ANCOVA design, where "year" and "fragment" were the factors and properties of the fragment ("area" and "isolation") were entered as covariates. We calculated the influence of the covariates in combination with factor effects, but due to the nesting of sites within fragments, the p-values for the factors and factor interactions had to be determined from a separate ANOVA without covariates. For these latter analyses we used the program's option of "unrestricted permutations of raw data". This option was not available for the analyses with the covariates and we used "permutation of the raw data". We do not report the $F$-statistics produced in our analyses as they are pseudo $F$-statistics and do not represent Fisher's traditional $F$-ratio (Anderson, 2005). To investigate the explanatory power of the "best" models we calculated the $R^{2}$ values for the fragment and covariate terms:

$R_{\text {term }}^{2}=\mathrm{SS}_{\text {term }} / \mathrm{SS}_{\text {total }}$

eqn. 3.2 
The PERMANOVA method used in this study fits a linear model that is additive (Type I sums of squares) and can only calculate a single $\mathrm{p}$-value for the combined effect of all the covariates in the model (Anderson, 2005). Similarly to Chapter 2 where we discussed caveats associated with correlated covariates we retained, despite correlations between our covariates, all covariates in our initial model (correlations were not absolute). Since our primary interest was to discover which of the two covariates fragment area or isolation or both in combination were important to community structure we analysed a model with both covariates included and reduced models with each covariate individually included in the model. The model with the lowest p-value was considered the "best approximate model". We felt this to be an appropriate basis for model comparison and selection, because the significance of each model was determined from a permutation test that implicitly accounts for the number of terms in the model. Many of the statistics commonly used for this purpose, such as the Akaike Information Criterion (AIC), are only applicable within a likelihood or quasi-likelihood framework.

\subsubsection{Plant-parasitoid relationships}

Using RELATE with the software PRIMER (PRIMER version 5.0, Clarke \& Warwick, 2001), we correlated beta-diversity between sites using per site plant richness, plant relative abundances, parasitoid richness and abundances and the geographic distances between sites. RELATE is Spearman rank correlation calculating the correlation coefficient $\rho$ between two similarity matrices. Beta-diversity matrices were established in PRIMER for non-transformed and non-standardised data using Bray-Curtis similarity and the geographic distance matrix was established using Euclidian distances. All correlations were computed using PRIMER's default setting of 999 permutations. 
Where there was a significant correlation between the plant and parasitoid communities, PRIMER BVSTEP analyses were used to find the subset of parasitoid and plant species that contribute most to the correlation. BVSTEP is a stepwise method with several random starts to find the "best" minimal species set accounting for a correlation of about $\rho=0.95$ (Clarke, 1993; Clarke \& Warwick, 2001). For this analysis we used the following BVSTEP parameters. The plant absence/presence and parasitoid abundance dissimilarity matrices respectively, were fixed and the similarity matrix parameter was Bray-Curtis similarity for non-transformed and non-standardised data. All variables were made "available" to the analyses. The Spearman rank correlation method was used as well as the programmes default stopping criteria of $\rho>0.95$ and a change in $\rho$ of less than 0.001 .

\subsubsection{Responses of individual parasitoid species}

For this part of the study, we worked solely on those ichneumonid species which we were able to identify to their known taxonomic species level and with known herbivorous hosts with known host plant feeding relationships. We were especially interested in any of those identified parasitoid species that were also present in the species list obtained from the BVSTEP analysis. We compiled the known relationships into an interaction web to compare the presence/absence of parasitoids in relation to the presence/absence of the corresponding herbivore plants in the 10 fragments. We analysed correlations between the most abundant ( $\geq 10$ individuals) parasitoid species and the plant species known to be associated with the parasitoid's hosts using PRIMER RELATE. 


\subsection{Results}

Species richness in the 10 fragments was 116 species of plants (Appendix 3.2, Tables 3.2.1 \& 3.2.2) and 103 species of parasitoids (Appendix 2.3, Table 2.3.1 \& 2.3.2; Appendix 3.3, Table 3.3.1) (Fig. 3.2). Average species richness per fragment was slightly higher for plants $(40.8 \pm 7.8)$ than for parasitoids $(36.8 \pm 6.9)$ (mean \pm S.D.). Mean beta diversity between all sites was similar between plants (Bray-Curtis dissimilarity $56.9 \% \pm$ $11.7 \%$ ) and parasitoids (Bray-Curtis dissimilarity $57.6 \% \pm 11.3 \%$ ).

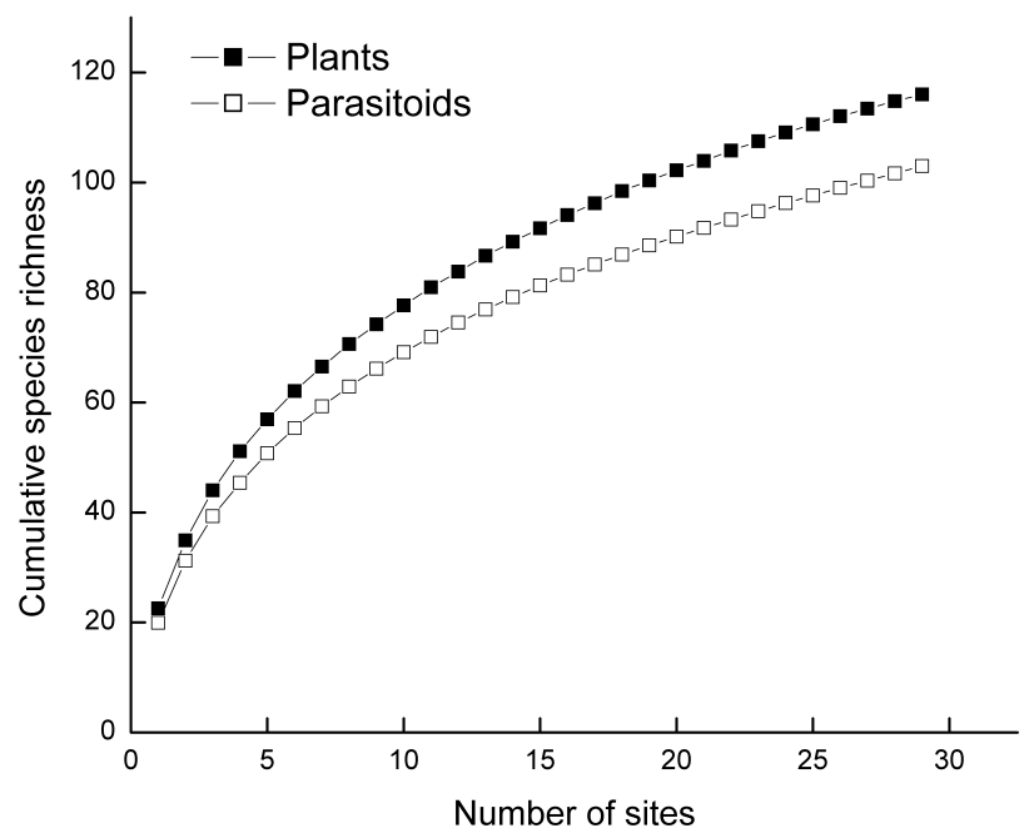

Figure 3.2: Cumulative rarefaction curve for the 116 plant and 103 parasitoid species found in 29 research sites from 10 native urban forest fragments. Plants represented $72 \%$ and parasitoids $62 \%$ of the total species richness estimated using EstimateS version 7.5.0 (Colwell, 2005). 
Table 3.1: PERMANOVA results of the parasitoid and plant community responses to the covariates area and isolation combined and alone using a MANCOVA analysis design. P-values for the factor fragment were established in a separate MANOVA design analysis. Best models are shown in bold. *p $<0.05$, $* * \mathrm{p}<0.01$.

\begin{tabular}{|c|c|c|c|c|c|c|}
\hline \multirow[b]{2}{*}{ Communities } & \multicolumn{2}{|c|}{ Covariates } & \multirow[b]{2}{*}{$\begin{array}{c}\text { P-value } \\
\text { covariate }\end{array}$} & \multirow[b]{2}{*}{$\begin{array}{c}R^{2} \\
\text { covariate }\end{array}$} & \multirow[b]{2}{*}{$\begin{array}{l}\mathrm{p} \text {-value } \\
\text { factor }\end{array}$} & \multirow[b]{2}{*}{$R^{2}$ facto } \\
\hline & 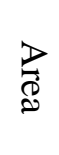 & $\begin{array}{l}\vec{\nabla} \\
0 \\
\stackrel{0}{0} \\
\stackrel{0}{0}\end{array}$ & & & & \\
\hline \multirow{3}{*}{ Plant richness } & $\checkmark$ & $\checkmark$ & 0.029* & 0.102 & \multirow{3}{*}{$0.001^{* *}$} & 0.333 \\
\hline & $\checkmark$ & & 0.234 & 0.039 & & 0.376 \\
\hline & & $\checkmark$ & 0.498 & 0.030 & & 0.395 \\
\hline \multirow{3}{*}{$\begin{array}{l}\text { Relative plant } \\
\text { abundance }\end{array}$} & $\checkmark$ & $\checkmark$ & 0.401 & 0.067 & \multirow{3}{*}{$0.001^{* *}$} & 0.352 \\
\hline & $\checkmark$ & & 0.663 & 0.026 & & 0.398 \\
\hline & & $\checkmark$ & 0.717 & 0.024 & & 0.401 \\
\hline \multirow{3}{*}{$\begin{array}{l}\text { Parasitoid } \\
\text { richness }\end{array}$} & $\checkmark$ & $\checkmark$ & 0.013* & 0.107 & \multirow{3}{*}{$0.002 * *$} & 0.293 \\
\hline & $\checkmark$ & & $0.028 *$ & 0.057 & & 0.355 \\
\hline & & $\checkmark$ & $0.021^{*}$ & 0.061 & & 0.310 \\
\hline \multirow{3}{*}{$\begin{array}{l}\text { Parasitoid } \\
\text { abundance }\end{array}$} & $\checkmark$ & $\checkmark$ & 0.056 & 0.094 & \multirow{3}{*}{$0.001^{* *}$} & 0.297 \\
\hline & $\checkmark$ & & $0.038^{*}$ & 0.056 & & 0.343 \\
\hline & & $\checkmark$ & $0.030 *$ & 0.058 & & 0.308 \\
\hline
\end{tabular}

\subsubsection{Community responses to fragment area and isolation}

Plant richness changed significantly with area and isolation of the fragment (combined effect, $\mathrm{p}=0.029$ ) and increased with increasing area and decreasing isolation, whereas plant abundance was not affected by either area or isolation (Fig. 3.3). Similarly, the combination of area and isolation explained a significant amount of the variation in parasitoid richness $(\mathrm{p}=0.013)$ and isolation alone best described the changes in parasitoid abundances $(\mathrm{p}=0.03)$ (Table 3.1). Both parasitoid abundance and richness were negatively affected by increasing area and decreasing isolation (Fig. 3.3). However, 
there were always significant responses to the factor fragment, and the plant and parasitoid community varied on average by $32 \%$ between fragments independent of fragment area and isolation, whereas on average only $6 \%$ of the variation was explained by fragment area and isolation (Table 3.1). The low $R^{2}$ values for area and isolation indicate that the variation of the communities might be due to properties of the fragments other than the measured covariates. In addition, examination of both the plant and parasitoid community MDS ordinations showed that even though responding significantly, changes in plant and parasitoid richness and parasitoid abundances are rarely dependent on area or isolation (Fig. 3.4). High stress levels however mean that these MDS plots are difficult to interpret in two dimensions. 

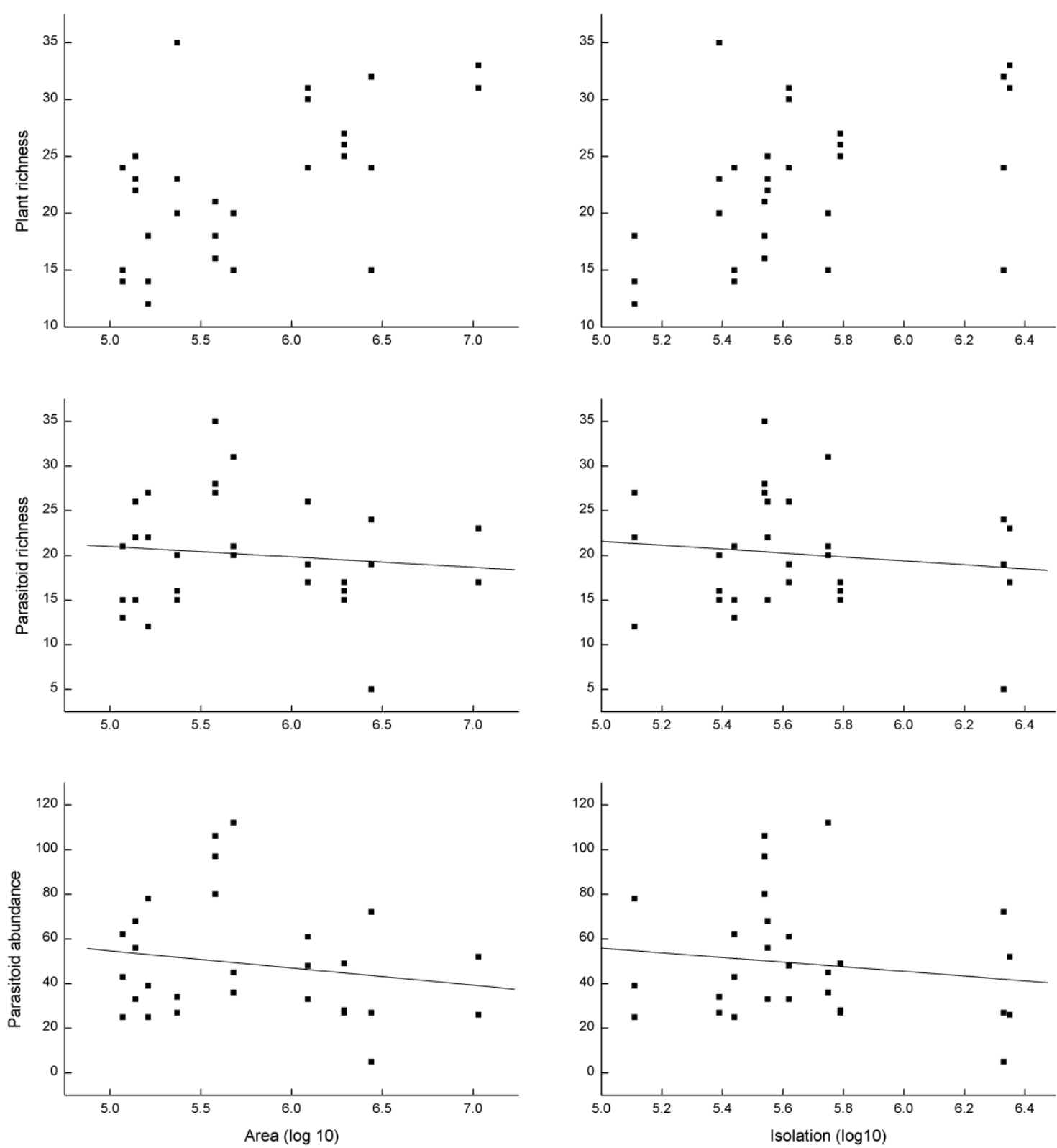

Figure 3.3: Plant and parasitoid species richness and parasitoid abundance for each site in relation to fragment area and isolation. Where $\mathrm{p}<0.05$ linear regression lines are fitted to indicate trends in the response variables. 

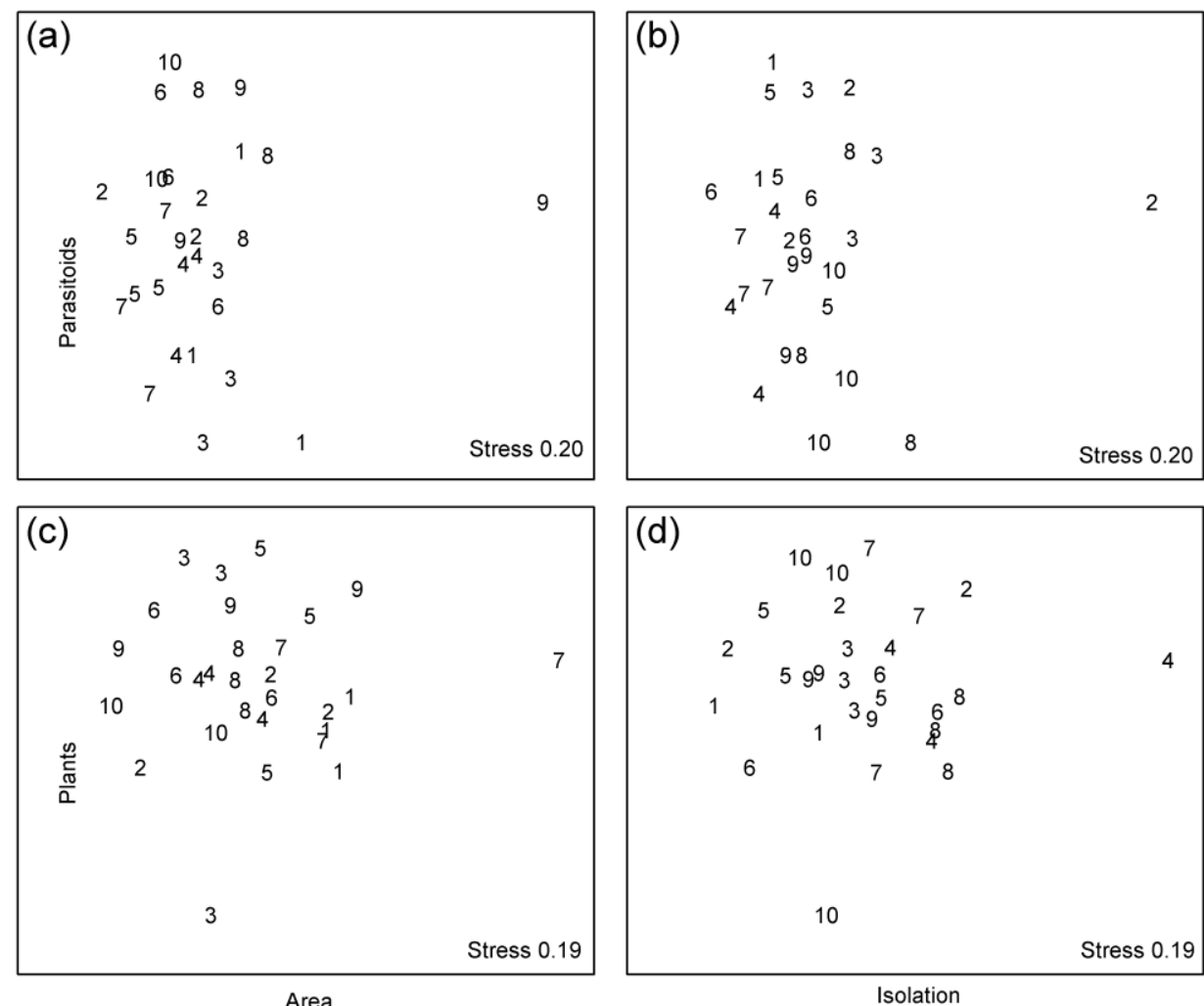

Figure 3.4: MDS ordination showing the extent to which sites in 10 fragments have similar parasitoid (a \& b) and plant (c \& d) composition in relation to area (a \& c) and isolation $(\mathrm{b} \& \mathrm{~d})$. Area and isolation superimposed increasing from 1-10. MDS were created using default settings in PRIMER version 5.0 (Clarke, 1993).

\subsubsection{Plant-parasitoid relationships}

Beta diversity of the parasitoid abundance between research sites increased significantly with beta diversity of plant richness between sites, whereas correlations between beta diversity of plant richness with parasitoid richness as well as plant abundance with parasitoid richness and abundance were not significant (Fig. 3.5).

Beta diversity in parasitoid abundance and richness as well as in plant richness increased significantly with increasing distances between research sites (Fig. 3.6). However, the 
low correlation coefficients are far from being high enough to suggest that species dissimilarities are solely or principally a function of distances between localities.
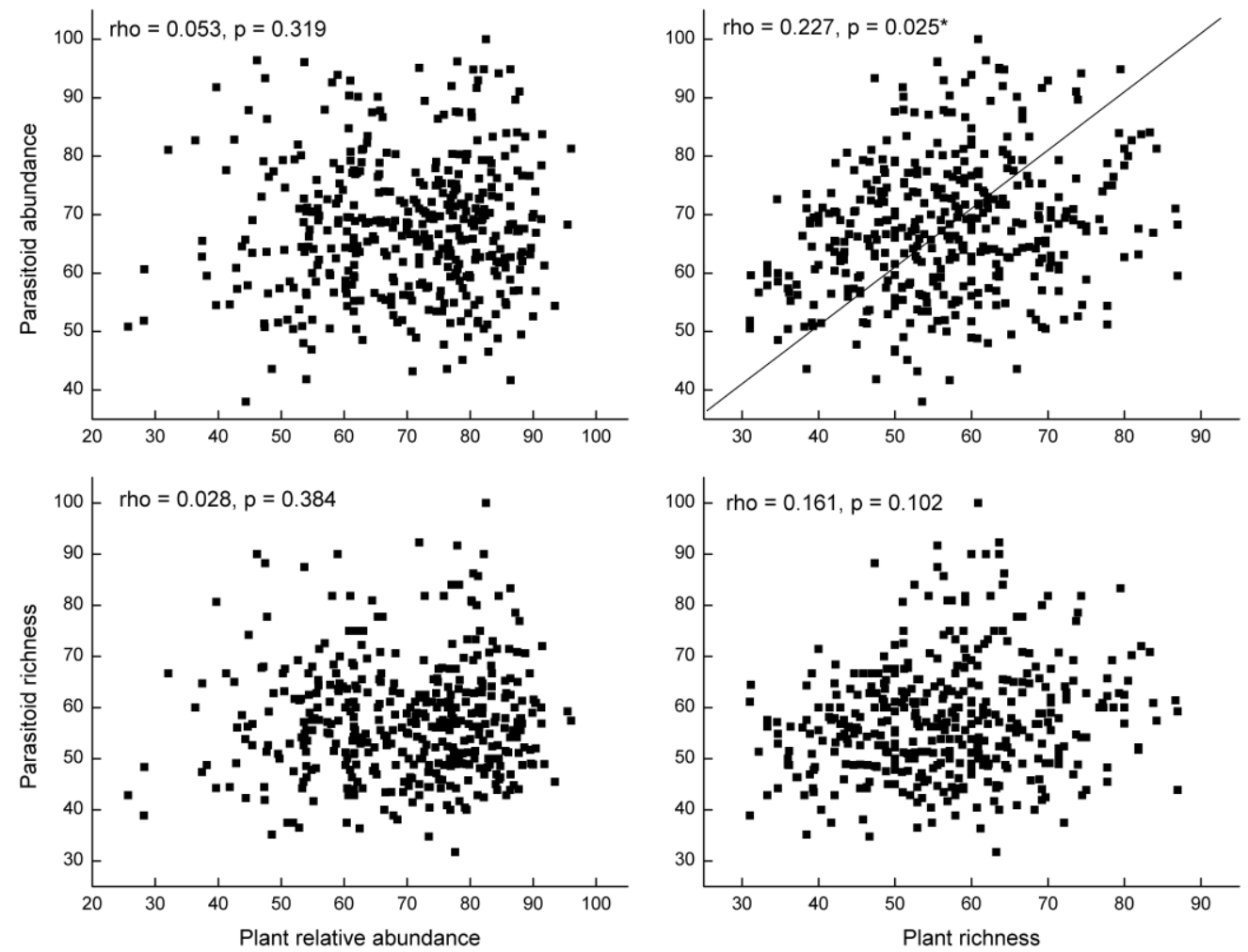

Figure 3.5: Correlations between Bray-Curtis dissimilarity matrices for each of the parasitoid and plant community measures between pairs of sites for relative plant species abundance, plant richness, parasitoid species abundance and parasitoid richness. The lines fitted represent the "major axis" for significant correlations (Sokal \& Rohlf, 1995). Coefficients and their p-values where calculated with PRIMER's RELATE (Clarke, 1993) ${ }^{*} \mathrm{p}<0.05$.

The PRIMER BVSTP routine found a selection of 16 parasitoid species $(\rho=0.485)$ and 26 plant species $(\rho=0.560)$ that best describe the relationship between parasitoid abundance patterns and the plant community composition (Appendix 3.4, Table 3.4.1). Of these 16 parasitoid species two were from the family Proctotrupidae and the remainder were Ichneumonidae. 

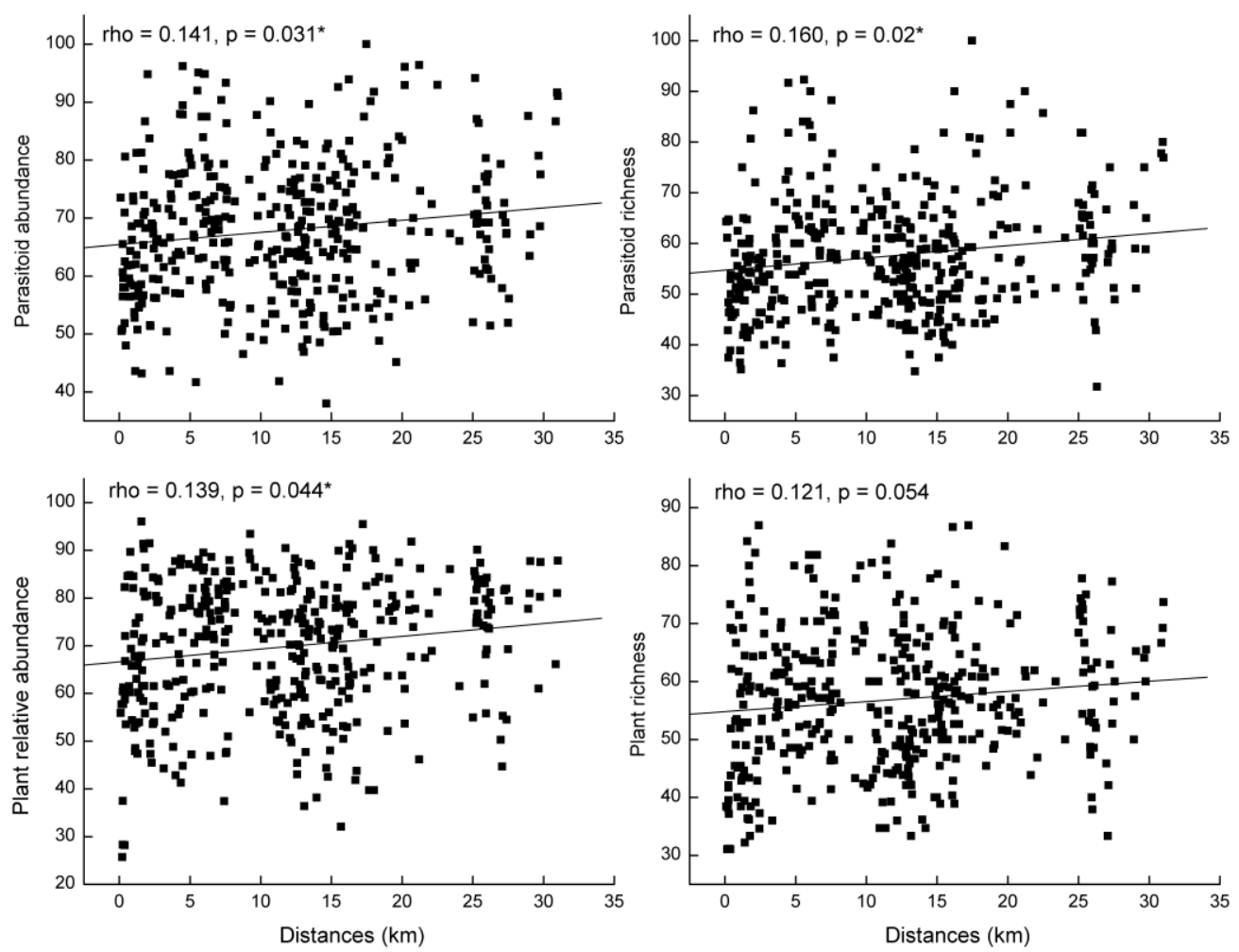

Figure 3.6: Beta diversity between pairs of sites regressed against their geographical separation. Both plants and parasitoids are well distributed across the Wellington and Hutt Valley regions indicating weak associations. Linear regression lines are fitted to show overall trends. Coefficients and their p-values where calculated with PRIMER's RELATE (Clarke, 1993). ${ }^{*} \mathrm{p}<0.05$.

\subsubsection{Responses of individual parasitoid species}

Ichneumonids are poorly described in New Zealand. We were able to identify 11 Ichneumonidae to their taxonomic species level. From six of these we were able to locate information on their herbivorous hosts and their host plants from the literature (Anonymous, 2004; Clunie, 2004; Dumbleton, 1957; Munro \& Henderson, 2002; Spiller \& Wise 1982; Valentine \& Walker, 1991) (Fig. 3.7, Table 3.2). The two ichneumonid parasitoids Euceros coxalis Barron (Eucerotinae) and Carria fortipes Cameron (Metopiinae) parasitise the common generalist moths Ctenopseustis obliquana Walker 
(Tortricidae), Epalxifora axenana Meyrick (Tortricidae) and Planotortrix sp. (Lepidoptera: Tortricidae). These moths feed on a wide variety of plants, including $20 \%$ (23 species) of the 116 plant species recorded from the study sites (Spiller \& Wise 1982).

Table 3.2: Names of hosts and plants from Figure 3.7.

\begin{tabular}{|c|c|}
\hline Host species & 7 Coprosma grandifolia (Rubiaceae) \\
\hline Coleoptera & 8 Corynocarpus laevigatus (Corynocarpaceae) \\
\hline A Oemona hirta (Fabricius) (Cerambycidae) & 9 Cytisus scoparius (Fabaceae) \\
\hline B Didymocantha sp. (Cerambycidae) & 10Dysoxylum spectabile (Meliiaceae) \\
\hline C Eburilla sericea (White) (Cerambycidae) & 11 Fuchsia exorticata (Onagraceae) \\
\hline D Hexatricha pulverulenta (Westwood) (Cerambycidae) & 12 Fuchsia sp. (Onagraceae) \\
\hline E Liogramma zealandica (Blanchard) (Cerambycidae) & 13 Griselinia sp. (Cornaceae) \\
\hline F Navomorpha sulcata (Fabricius) (Cerambycidae) & 14 Hedycarya arborea (Monimiaceae) \\
\hline Lepidoptera & 15 Hoheria sp. (Malvaceae) \\
\hline G Ctenopseustis obliquana Walker (Tortricidae) & 16Laurelia novae-zelandiae (Monimiaceae) \\
\hline H Epalxifora axenana Meyrick (Tortricidae) & 17 Myrsine australis (Myrsinaceae) \\
\hline I Planotortrix sp. (Tortricidae) & 18 Nothofagus sp. (Fagaceae) \\
\hline J Orthoclydon praefactata Walker (Geometridae) & 19Olearia rani (Compositea) \\
\hline K Xyridacma alectoraria Walker (Geometridae) & 20 Parsonsia heterophylla (Apocynaceae) \\
\hline L Xyridacma veronicae Prout (Geometridae) & 21 Pinus radiate (Pinaceae) \\
\hline M Wiseana cervinata Walker (Hepialidae) & 22 Macropiper excelsum (Piperaceae) \\
\hline Plant species & 23 Pittosporum eugenioides (Pittosporaceae) \\
\hline 1 Alectryon excelsus (Sapindaceae) & 24 Pittosporum tenuifolium (Pittosporaceae) \\
\hline 2 Aristotelia serrata (Elaeocarpaceae) & 25 Pseudopanax arboreum (Araliaceae) \\
\hline 3 Beilschmiedia tawa (Lauraceae) & 26Ripogonum scandens (Liliaceae) \\
\hline 4 Berberis glaucocarpa (Berberidaceae) & 27 Rubus fructicosus (Rosaceae) \\
\hline 5 Brachyglottis repanda (Compositae) & 28Rubus sp. (Rosaceae) \\
\hline 6 Carpodetus serratus (Escalloniaceae) & 29Rumex sp. (Polygonaceae) \\
\hline
\end{tabular}

However, only one individual of Euceros coxalis was found. Abundances for Carria fortipes ranged from 1-5 individuals in five fragments and for the ichneumonid Dusona stramineipes Cameron from 1-4 individuals found in six fragments and corresponded with its known host's host plant in three fragments. Correlations between abundance and 
absence/presence data of these latter two parasitoids and the host plants associated with the parasitoid's hosts were all non-significant (Appendix 3.5, Table 3.5.1). The ichneumonid Xanthocryptus novozealandicus (Dalla Torre) parasitises several cerambycid beetles; it was found in two fragments, neither of which had records of the associated host plants. Xenolytus bitinctus (Gmelin) (Ichneumonidae: Phygadeuontinae) is a parasitoid of pests found in stored food products, and was found only once. None of the plants associated with Ichneumon lotatorius Fabricius (Ichneumonidae: Ichneumoninae) as well as Netelia ephippiata (Smith) (Ichneumonidae: Tryphoninae) were present in any of the fragments and we could not find any host records for four of the identified ichneumonids. Euceros coxalis was also the only species identified from the 16 selected parasitoid species in the PRIMER BVSTP routine analysing the plantparasitoid relationships.

\subsection{Discussion}

The results of our study do not follow general patterns observed that responses to fragmentation at the higher trophic level are stronger than they are at the lower trophic level (Kruess, 2003; Kruess \& Tscharntke, 1994, 2000). However, compositional differences at the site level affected by fragment area and isolation were most apparent for parasitoids, rather than for plants. Both parasitoid richness and abundance at the site level changed significantly with fragment area or isolation, whereas plant richness responded significantly to only a combined effect of area and isolation. The overall contribution of area and isolation to the variation in the data of the plant and parasitoid communities was very low. In fact, the results of this study are very similar to our findings in Chapter 2, where we found changes in parasitoid communities to be strongly 
influenced by fragment factors other than area and isolation measured. However the study in Chapter 2 also showed differential responses to area and isolation as well as to the plant community by different parasitoid families. Similarly to Chapter 2 the results and their interpretation need to be seen within the capacity of the analysis of this work and are subject to the partitioning of variance between the factor "fragment" and their covariates.

Differences in parasitoid abundance increased with increasing differences of plant species between research sites, possibly indicating the dependency of parasitoid distribution on the distribution of the herbivore's host plants. Despite the parasitoids' dependency on plants for food, shelter and finding hosts, we were not able, at the site level, to associate changes in plant species abundance with changes in parasitoid richness and abundance nor plant species richness with changes in parasitoid richness. Elsewhere, parasitoid colonisation of a patch, for example, depended not only on presence of a host insect, but also, on which plant species the host was using (Van Nouhuys \& Hanski, 1999). This result means a herbivore feeding on two different plant species will influence parasitoid abundance or persistence in a patch differentially, depending on which of the two plants is absent/present or dominates a patch. Influences that could act individually or in combination on such processes are discussed by Van Nouhuys and Hanski (1999) with several examples. These are: plant structural differences or differences in plant spatial aggregation, both providing different habitats for the herbivorous host; or plant volatiles released are not equally attractive for the parasitoid; or herbivore larval physiology and growth differ between the host plant species. All these attributes have been found to influence a parasitoid's population dynamics. 


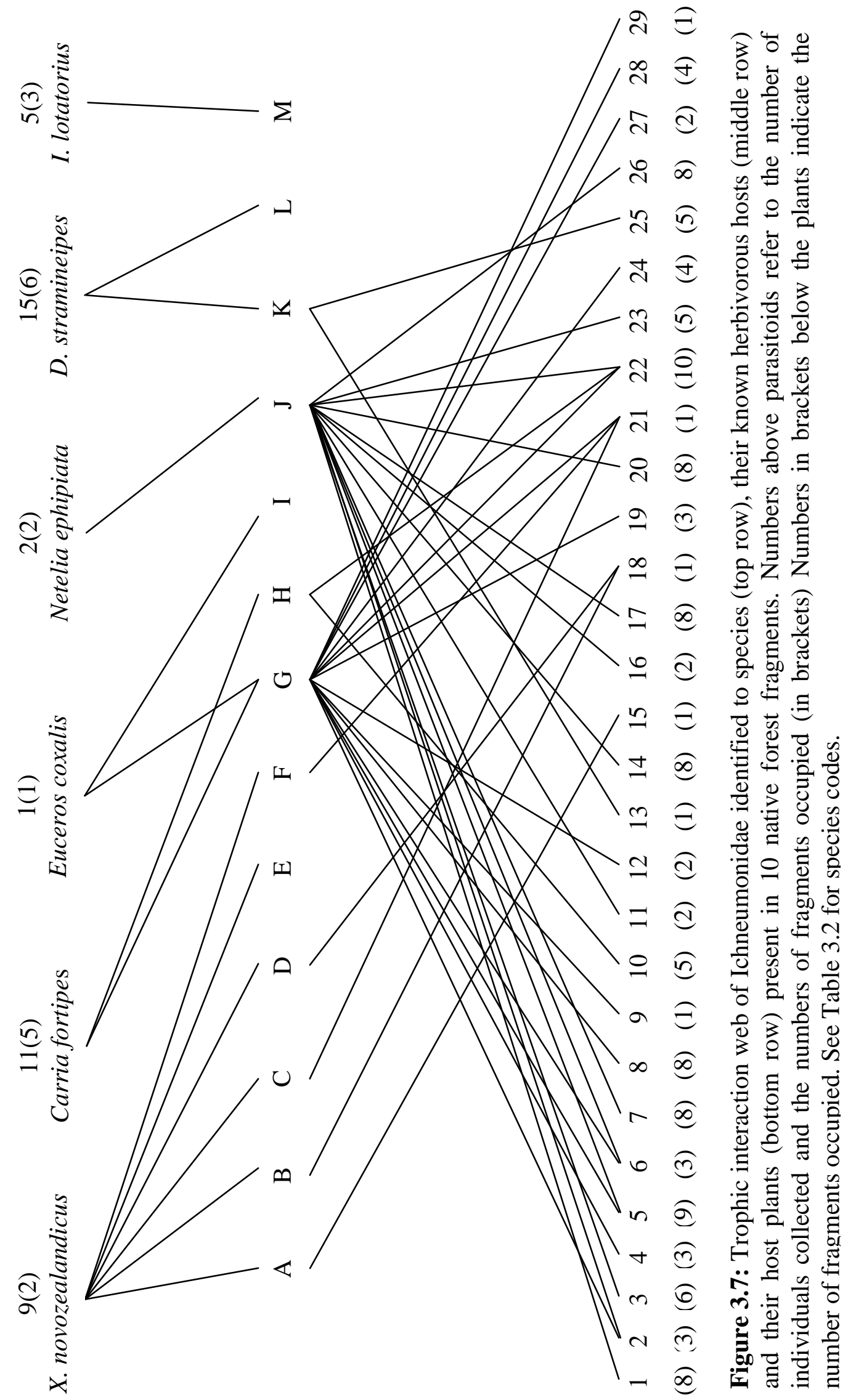


Elsewhere, the distribution of a parasitoid was found to be reflected by the geographical range of its host insects and their host plants (Van Nouhuys \& Hanski, 1999). Plant richness in our study changed only marginally with increasing distances between research sites, whereas parasitoid richness as well as parasitoid and plant richness significantly changed with increasing distances between research sites. This pattern, in combination with the significant changes in parasitoid abundances with increasing changes in plant richness, indicates some parasitoid dependency on plant richness in general. However, community structures are influenced by not only one part of the species' biology. For example, habitat can be determined for butterflies depending on their life stages, for which the habitat requirements differ for larval and adult stages (Dennis, Shreeve \& Van Dyck, 2003). Food resources are in the form of suitable host plants for larvae, whereas adults are dependent on food sources in the form of flowering plants. If these resources do not overlap then resource-free areas lie within the area of occurrence of the species (Vanreusel \& Van Dyck, 2007). Similarly, we might infer that parasitoids have different habitat requirements depending on their life stage requirements. Some parasitoids parasitise adults while others parasitise egg, larval or pupal stages of their hosts. The foraging habitat for the parasitoid therefore will depend on the hosts' requirements for each life stage. In addition, as with the presence of resources for butterfly larvae or adults the resources for adult parasitoids and their larvae might not overlap. Adult hymenoptera are often dependent on nectar resources while their larvae are dependent on the presence of the host larvae.

Somewhat related to plant communities in a habitat might be habitat complexity. In general, parasitoids of herbivores partition the environment between low plants and trees or bushes and rarely forage in both environments regardless of host range (Shaw, 2006). 
It was somewhat surprising, therefore, that habitat complexity was an important predictor only for hymenoptera (Lassau \& Hochuli, 2005) and beetle (Lassau et al., 2005) communities sampled in pitfall traps and not from Malaise trap samples. Because we used flight-intercept traps in our study similar to these latter two studies, we would not expect significant influences of habitat complexity on the parasitoid communities. Pompilidae might be most affected by habitat complexity because they parasitise spiders. Plant structure is generally recognised as an important factor in determining spider diversity (for example see Halaj, Ross \& Moldenke, 2000; Jimenez-Valverde \& Lobo, 2007). In Chapter 2, we found Pompilidae to be solely affected by plant species richness. New Zealand's pompilids are generalists, each parasitising a wide variety of spider species and they are known to partition their foraging by habitat (Harris, 1987).

The relatively weak responses to fragment area and isolation in relation to the factor 'fragment' as well as the generally weak correlations between the parasitoid and plant communities in our study could be the result of the landscape matrix surrounding the study fragments. The surrounding landscape matrix can be a confounding factor, making it difficult to detect the effects of fragmentation on biodiversity of insects (Ewers \& Didham, 2006). It is generally accepted that urbanisation leads to the homogenisation in diversity of a variety of plants, mammals and birds in addition to an increase in plant species richness through introduction of alien plants into the urban environment (Kühn, Brandl \& Klotz, 2004; Kühn \& Klotz, 2006; McKinney, 2006; Wania, Kühn \& Klotz, 2006). While we did not find strong responses by the plant community to fragment area and isolation, we did find significant differences by the plant community between the fragments. The weak parasitoid-plant relationships encountered in our study might therefore be a result of parasitoid responses to the surrounding landscape matrix. This 
matrix is composed of native bush fragments, scrubland and residential garden. If the surrounding matrix contains sufficient host populations as well as food plants for parasitoids, then parasitoids encountered in our study sites could be immigrating individuals.

Of the sixteen species that contributed most to the parasitoid-plant relationship in our study, the endemic parasitoid E. coxalis is unfortunately the only species for which we could establish host relationships from the literature. We collected only one individual for this parasitoid, which is known to parasitise two common generalist hosts. The rarity of this parasitoid, however, does not seem to be attributable to the urban environment, since it was also very rare in a study involving several native New Zealand forests (Munro \& Henderson, 2002). We were unable to establish neither statistically significant (for the two most abundant species Carria fortipes and Dusona stramineipes) nor any conclusive relationships between individual parasitoids and the known host plants of the parasitoid's herbivorous hosts. Netelia ephippiata, for example, was present in one fragment despite the absence of flax, Phormium tenax (Agavaceae), its (N. ephippiata) host's host plant. But flax, even though not recorded in our sample sites, was observed within several hundred metres of study sites in the fragments. In other studies $N$. ephippiata had been found in high numbers in the absence of its host and it has been suggested that this parasitoid might parasitise some other Noctuidae similar to $N$. producta (Brullé) (Mc Gregor, Watts \& Esson, 1987).

Tri-trophic relationships are complex and to establish mechanisms that influence community structure in relation to fragmentation it would be beneficial to know the relationships across the different trophic levels. In our studies these relationships are not 
well known, which makes it difficult to draw any general conclusions. This is a common problem because host records for parasitoids are difficult to assess (Shaw, 2006), and there are differences between realised and potential host ranges or host specificity of parasitoids might even differ between habitats (Fraser, Dytham \& Mayhew, 2007; Shaw, 2006 and references therein).

Therefore, to detect tri-trophic responses to fragmentation in urban native forest fragments, a study concentrating on one plant species, its herbivore and the herbivore parasitoids could be of advantage. For example parasitism rate rather than parasitoid diversity could well be a measure best suited to describe parasitoid responses to habitat fragmentation. A study analysing parasitism rates from parasitoid rearing experiments is described in the next chapter.

The current study clearly shows that fragment area and isolation on their own are not always sufficient predictors to explain community structure for parasitoids. Despite strong variations between research sites, the plant community provided weak explanations for the parasitoid community as a whole and for some individual species. Native forest fragments encountered in the Wellington and Upper Hutt regions may act as a resource or refuge for many herbivore and parasitic insects. There is an increasing call worldwide to provide a range of different habitats to preserve biodiversity in cities and suburbs (Miller, 2006; Snep et al., 2006) and this study provided evidence for and strongly supports the general idea that there are many aspects that contribute to the persistence and viability of parasitoid populations (Shaw, 2006). 


\subsection{Acknowledgements}

We thank the bug-club members of the School of Biological Sciences, Victoria University of Wellington for valuable comments on this manuscript and Adrian Pike, John Brightwell, Megan Sarty, Nick Rawlence and Travis Chellman for the assistance in sorting insects. Many thanks go to Cleland Wallace for surveying the plant communities. We also thank the different park managements for permission to establish traps in their native bush fragments. We thank the NZ Department of Conservation for the loan of traps. This research was funded by the 21 st Anniversary Fund from the Entomological Society of NZ and the Victoria University of Wellington, NZ.

\subsection{Literature cited}

Allen, R.B. (1992). RECCE - an inventory method for describing New Zealand vegetation. In Forest Research Institute Bulletin (ed F.R. Institute), Vol. 176, Christchurch, N. Z.

Anderson, M.J. (2001) A new method for non-parametric multivariate analysis of variance. Austral Ecology, 26(1), 32-46.

Anderson, M.J. (2005). PERMANOVA: a FORTRAN computer program for permutational multivariate analysis of variance. In. Department of Statistics, University of Auckland, New Zealand.

Andrén, H. (1994) Effects of habitat fragmentation on birds and mammals in landscapes with different proportions of suitable habitat: A review. Oikos, 71(3), 355-66.

Anonymous. (2004) Import Risk Analysis for Sawn Coniferous Timber from Canada, New Zealand and the United States. Deparment of Agriculture, Fisheries and 
Forestry. Australian Government.

http://www.daffa.gov.au/_data/assets/pdf_file/24522/timber_pestcat.pdf.

Chust, G., Garbin, L. \& Pujade-Villar, J. (2007) Gall wasps and their parasitoids in cork oak fragmented forests. Ecological Entomology, 32(1), 82-91.

Clarke, K.R. (1993) Non-parametric multivariate analyses of changes in community structure. Australian Journal of Ecology, 18(1), 117-43.

Clarke, K.R. \& Warwick, R.M. (2001) Change in marine communities: an approach to statistical analysis and interpretation, 2. edn. PRIMER-E, Plymouth.

Clunie, L. (2004) What is this bug? A guide to common invertebrates of New Zealand., www.landcareresearch.co.nz/research/biosystematics/invertebrates/invertid/.

Colwell, R.K. (2005). EstimateS: Statistical estimation of species richness and shared species from samples. Version 7.5. User's Guide and application published at: http://pulr.oclc.org/estimates. In.

Dennis, R.L.H., Shreeve, T.G. \& Van Dyck, H. (2003) Towards a functional resourcebased concept for habitat: a butterfly biology viewpoint. Oikos, 102(2), 417-26.

Dumbleton, L.J. (1957) The immature stages of some New Zealand longhorn beetles (Coleoptera-Cerambycidae). Transactions of the Royal Society of New Zealand, 84, $611-28$.

ESRI. (2004). ESRI®ArcMap ${ }^{\mathrm{TM}} 9.0$ Build 560. In. ESRI, Redlands, CA, USA.

Ewers, R.M. \& Didham, R.K. (2006) Confounding factors in the detection of species responses to habitat fragmentation. Biological Reviews, 81(1), 117-42.

Fahrig, L. (2003) Effects of habitat fragmentation on biodiversity. Annual Review of Ecology, Evolution, and, 34, 487-515. 
Fraser, S.E.M., Dytham, C. \& Mayhew, P.J. (2007) Determinants of parasitoid abundance and diversity in woodland habitats. Journal of Applied Ecology, 44(2), $352-61$.

Gauld, I.D. (1984) An Introduction to the Ichneumonidae of Australia. British Museum (Natural History), London.

Gibb, H. \& Hochuli, D.F. (2002) Habitat fragmentation in an urban environment: large and small fragments support different arthropod assemblages. Biological Conservation, 106(1), 91-100.

Halaj, J., Ross, D.W. \& Moldenke, A.R. (2000) Importance of habitat structure to the arthropod food-web in Douglas-fir canopies. Oikos, 90(1), 139-52.

Hanski, I., Kuussaari, M. \& Nieminen, M. (1994) Metapopulation structure and migration in the butterfly Melitaea cinxia. Ecology, 75(3), 747-62.

Harris, A.C. (1987) Pompilidae (Insecta: Hymenoptera). Fauna of New Zealand, 12. Jimenez-Valverde, A. \& Lobo, J.M. (2007) Determinants of local spider (Araneidae and Thomisidae) species richness on a regional scale: climate and altitude vs. habitat structure. Ecological Entomology, 32(1), 113-22.

Koleff, P., Gaston, K.J. \& Lennon, J.J. (2003) Measuring beta diversity for presenceabsence data. Journal of Animal Ecology, 72(3), 367-82.

Kruess, A. (2003) Effects of landscape structure and habitat type on a plant-herbivoreparasitoid community. Ecography, 26(3), 283-90.

Kruess, A. \& Tscharntke, T. (1994) Habitat fragmentation, species loss, and biological control. Science, 264(5165), 1581-84.

Kruess, A. \& Tscharntke, T. (2000) Species richness and parasitism in a fragmented landscape: experiments and field studies with insects on Vicia sepium. Oecologia, 122(1), 129-37. 
Kühn, I., Brandl, R. \& Klotz, S. (2004) The flora of German cities is naturally species rich. Evolutionary Ecology Research, 6(5), 749-64.

Kühn, I. \& Klotz, S. (2006) Urbanization and homogenization - Comparing the floras of urban and rural areas in Germany. Biological Conservation, 127(3), 292-300.

Lassau, S.A. \& Hochuli, D.F. (2005) Wasp community responses to habitat complexity in Sydney sandstone forests. Austral Ecology, 30(2), 179-87.

Lassau, S.A., Hochuli, D.F., Cassis, G. \& Reid, C.A.M. (2005) Effects of habitat complexity on forest beetle diversity: do functional groups respond consistently? Diversity and Distributions, 11(1), 73-82.

Magurran. (2004) Measuring Biological Diversity. Blackwell Science Ltd, Oxford.

Mc Gregor, P.G., Watts, P.J. \& Esson, M.J. (1987) Light trap records from southern North Island hill country. New Zealand Entomologist, 10, 104-21.

McArdle, B.H. \& Anderson, M.J. (2001) Fitting multivariate models to community data: A comment on distance-based redundancy analysis. Ecology, 82(1), 290-97.

McKinney, M.L. (2006) Urbanization as a major cause of biotic homogenization. Biological Conservation, 127(3), 247-60.

Miller, J.R. (2006) Restoration, reconciliation, and reconnecting with nature nearby. Biological Conservation, 127(3), 356-61.

Munro, V.M.W. \& Henderson, I.M. (2002) Nontarget Effect of Entomophagous Biocontrol: Shared Parasitism Between Native Lepidopteran Parasitoids and the Biocontrol Agent Trigonospila brevifacies (Diptera: Tachinidae) in Forest Habitats. Environmental Entomology, 31, 388-96.

Power, D.M. (1975) Similarity among Avifaunas of the Galapagos Islands. Ecology, 56(3), 616-26. 
Quinn, G.P. \& Keough, M.J. (2002) Experimental design and data analysis for biologists. Cambridge University Press, Cambridge, UK.

Raupp, M.J., Shrewsbury, P.M., Holmes, J.J. \& Davidson, J.A. (2001) Plant species diversity and abundance affects the number of arthropod pests in residential landscapes. Journal of Arboriculture, 27(4), 222-29.

Shaw, M.R. (2006) Habitat considerations for parasitic wasps (Hymenoptera). Journal of Insect Conservation, 10(2), 117-27.

Snep, R.P.H., Opdam, P.F.M., Baveco, J.M., WallisDeVries, M.F., Timmermans, W., Kwak, R.G.M. \& Kuypers, V. (2006) How peri-urban areas can strengthen animal populations within cities: A modeling approach. Biological Conservation, 127(3), $345-55$.

Sokal, R.S. \& Rohlf, F.J. (1995) Biometry: The principles and practice of statistics in biological research, 3. edn. W. H. Freeman and Company, New York.

Spiller, D.M. \& Wise , K.A.J. (1982). A catalogue (1860-1960) of New Zealand insects and their host plants. DSIR Science Information Division Bulletin. In, Vol. 231. DSIR, Wellington.

Steffan-Dewenter, I. \& Tscharntke, T. (2000) Butterfly community structure in fragmented habitats. Ecology Letters, 3(5), 449-56.

Townes, H.K. \& Townes, M. (1981) A revision of the Sirphidae (Hymenoptera). Memoirs of the American Entomological Institute, 32, 1-541.

Valentine, E.W. \& Walker, A.K. (1991) Annotated catalogue of New Zealand Hymenoptera. DSIR Plant Protection Report No. 4. DSIR Plant Protection. van Nouhuys, S. (2005) Effects of habitat fragmentation at different trophic levels in insect communities. Annales Zoologici Fennici, 42(4), 433-47. 
Van Nouhuys, S. \& Hanski, I. (1999) Host diet affects extinctions and colonizations in a parasitoid metapopulation. Journal of Animal Ecology, 68(6), 1248-58.

Vanreusel, W. \& Van Dyck, H. (2007) When functional habitat does not match vegetation types: A resource-based approach to map butterfly habitat. Biological Conservation, 135(2), 202-11.

Wahl, D.B. (1993). Family Ichneumonidae. In Hymenoptera of the World: An Identification Guide to Families. (eds H. Goulet \& J.T. Huber), pp. 395-448. Agriculture Canada Research Branch Monograph No. 1894E, Ottawa.

Wania, A., Kühn, I. \& Klotz, S. (2006) Plant richness patterns in agricultural and urban landscapes in Central Germany - spatial gradients of species richness. Landscape and Urban Planning, 75(1-2), 97-110.

Wiegand, T., Revilla, E. \& Moloney, K.A. (2005) Effects of habitat loss and fragmentation on population dynamics. Conservation Biology, 19(1), 108-21. 
Appendix 3.1: Fragment indices and insect collection schedule.

Table 3.1.1: Fragment area, isolation index, percentage of residential area in $1000 \mathrm{~m}$ buffer around fragments, and number of plant species of 10 native urban bush fragments.

\begin{tabular}{lrrrrr}
\hline \multicolumn{1}{c}{ Fragment } & $\begin{array}{c}\text { Fragment } \\
\text { ID }\end{array}$ & Area m $^{2}$ & $\begin{array}{c}\text { Isolation } \\
\text { index }\end{array}$ & $\begin{array}{c}\text { Residential } \\
\text { area (\%) }\end{array}$ & $\begin{array}{l}\text { Number of } \\
\text { Plant } \\
\text { Species }\end{array}$ \\
\hline Maupuia Reserve & 1 & 1635 & 130008 & 25.2 & 30 \\
Karori Sanctuary & 2 & 27616 & 2126344 & 22.4 & 51 \\
Otari/Wilton Bush & 3 & 12190 & 414122 & 36.1 & 47 \\
Huntleigh Park & 4 & 2319 & 247604 & 28.8 & 41 \\
Trelissick Park & 5 & 4738 & 565475 & 47.3 & 34 \\
Belmont Park & 6 & 19525 & 616690 & 9.1 & 43 \\
Harbour View & 7 & 1386 & 353955 & 23.1 & 45 \\
Speedy Reserve & 8 & 3804 & 350115 & 19.5 & 39 \\
Stokes Valley & 9 & 106852 & 2230408 & 18.4 & 48 \\
Bartons Bush & 10 & 1180 & 274226 & 31.9 & 29 \\
\hline
\end{tabular}

Table 3.1.2: Malaise trapping schedule for each fragment over a period of two summers.

\begin{tabular}{lcccc}
\hline \multicolumn{1}{c}{ Fragment } & $\begin{array}{c}\text { December } \\
\text { Frand }\end{array}$ & $\begin{array}{c}\text { February } \\
2003\end{array}$ & $\begin{array}{c}\text { December } \\
2003\end{array}$ & $\begin{array}{c}\text { February } \\
2004\end{array}$ \\
\hline Maupuia Reserve & $09-13$ & $19-23$ & $09-13$ & $10-14$ \\
Karori Sanctuary & $18-23$ & $10-14$ & $11-15$ & $04-08$ \\
Otari/Wilton Bush & $05-10$ & $04-09$ & $17-21$ & $02-06$ \\
Huntleigh Park & $10-14$ & $12-16$ & $10-14$ & $20-24$ \\
Trelissick Park & $10-14$ & $13-17$ & $19-23$ & $18-22$ \\
Belmont Park & $27-31$ & $18-22$ & $03-07$ & $09-13$ \\
Harbour View & $03-08$ & $07-11$ & $18-22$ & $03-07$ \\
Speedy Reserve & $16-20$ & 26 Feb-02 Mar & $08-12$ & $19-23$ \\
Stokes Valley & $17-23$ & $19-24$ & $02-06$ & $11-15$ \\
Bartons Bush & $19-23$ & $20-25$ & $04-08$ & $05-09$ \\
\hline
\end{tabular}


Appendix 3.2: Plant species and their relative abundance for each research site.

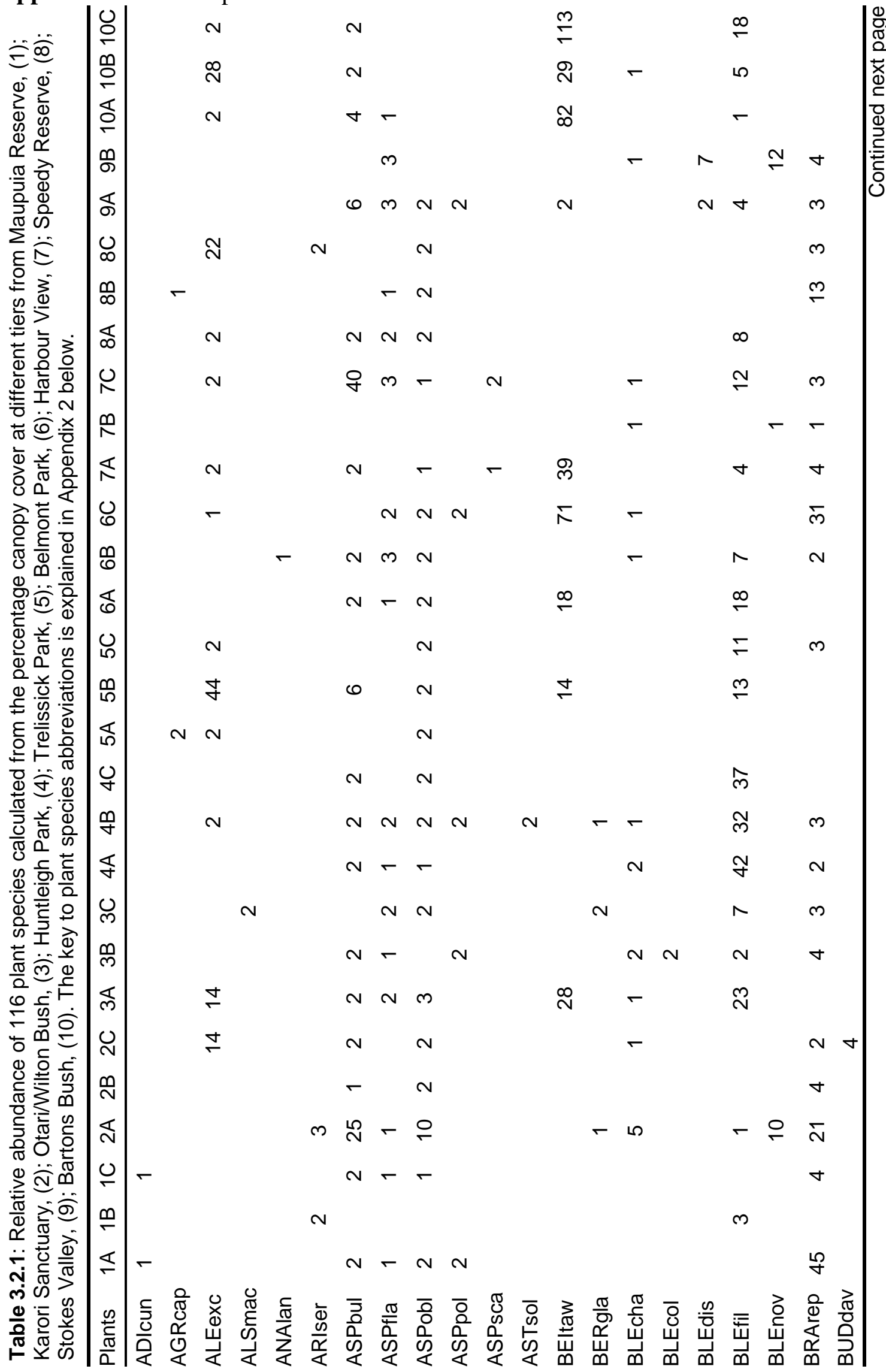




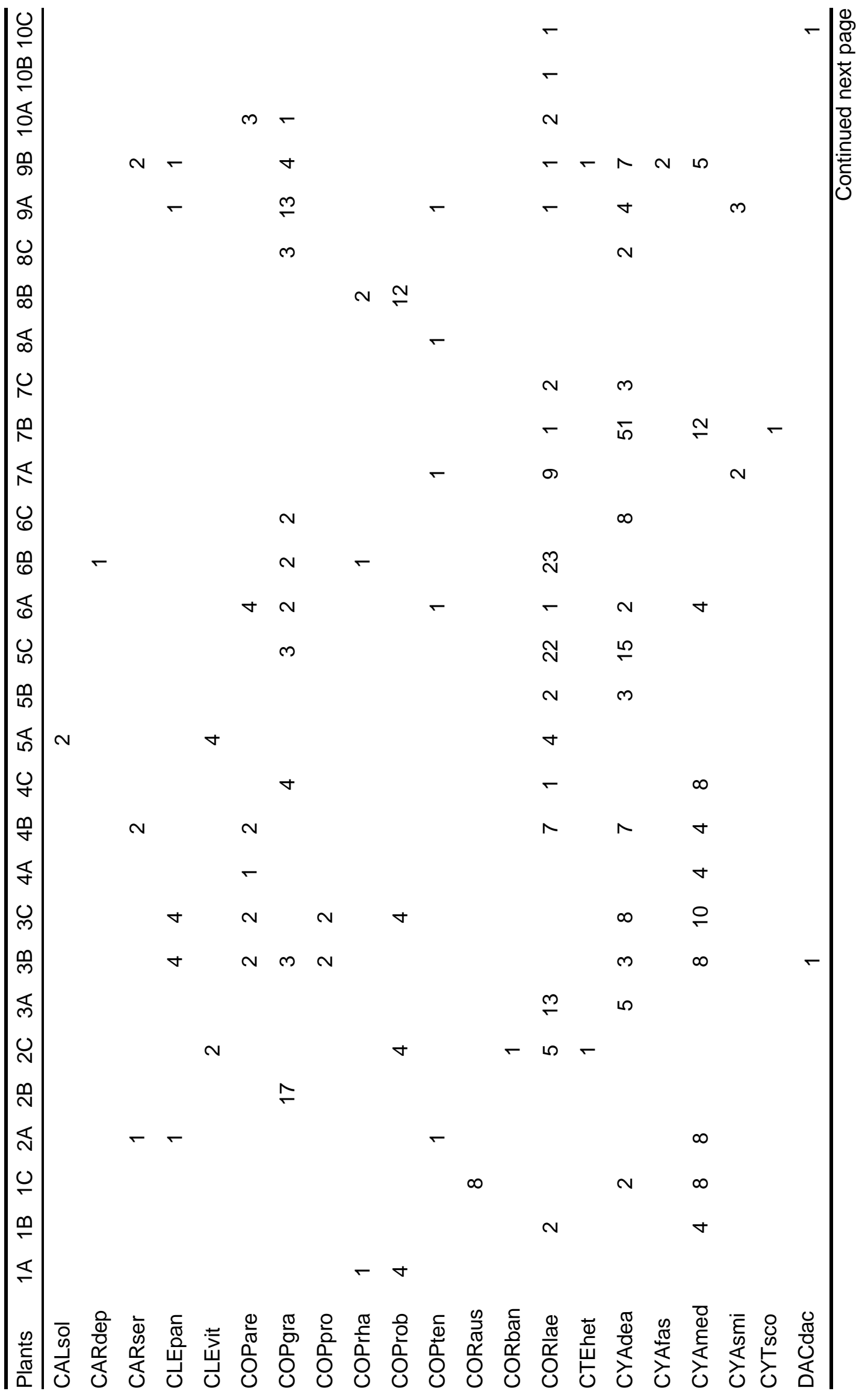




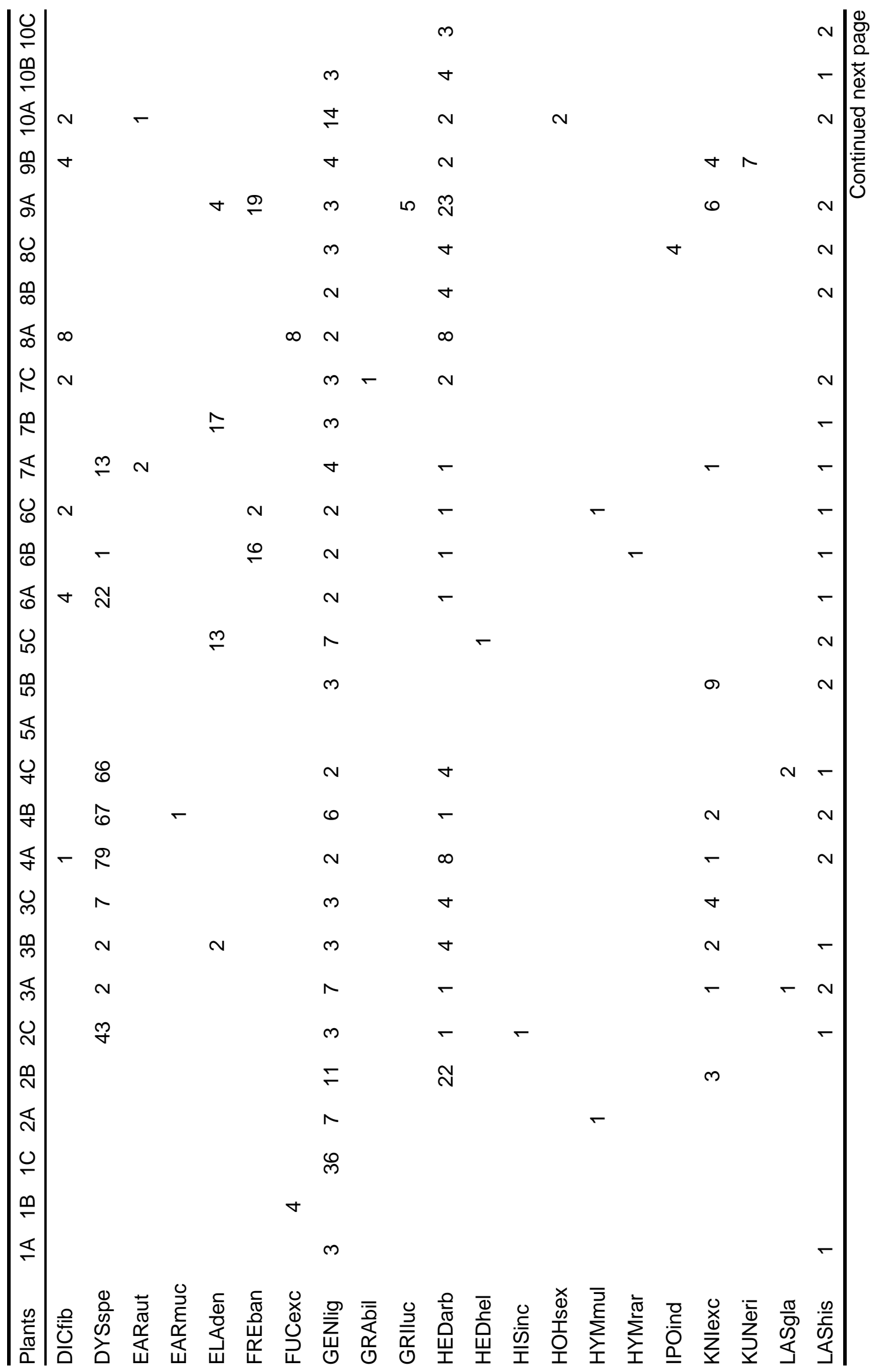




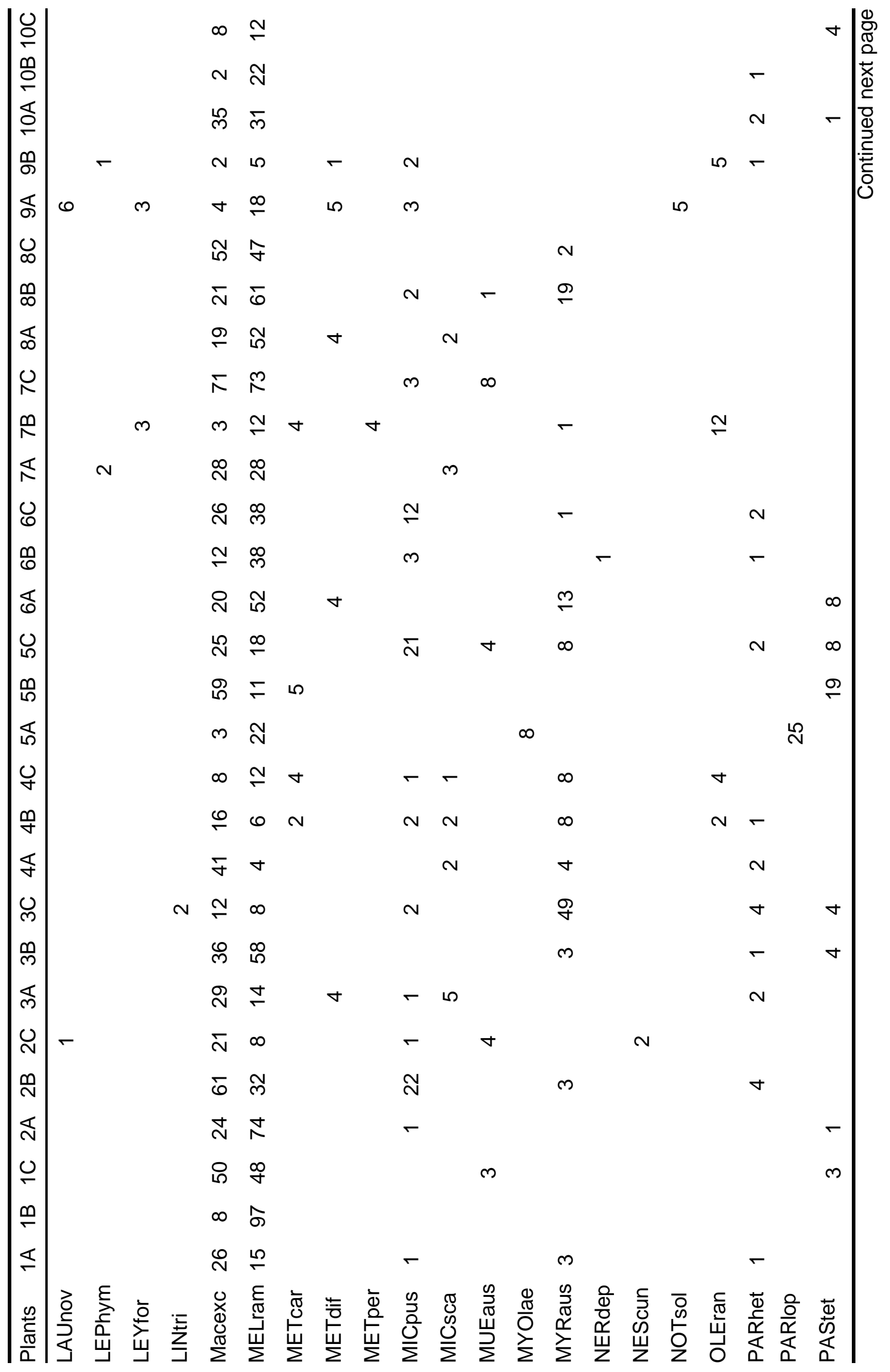




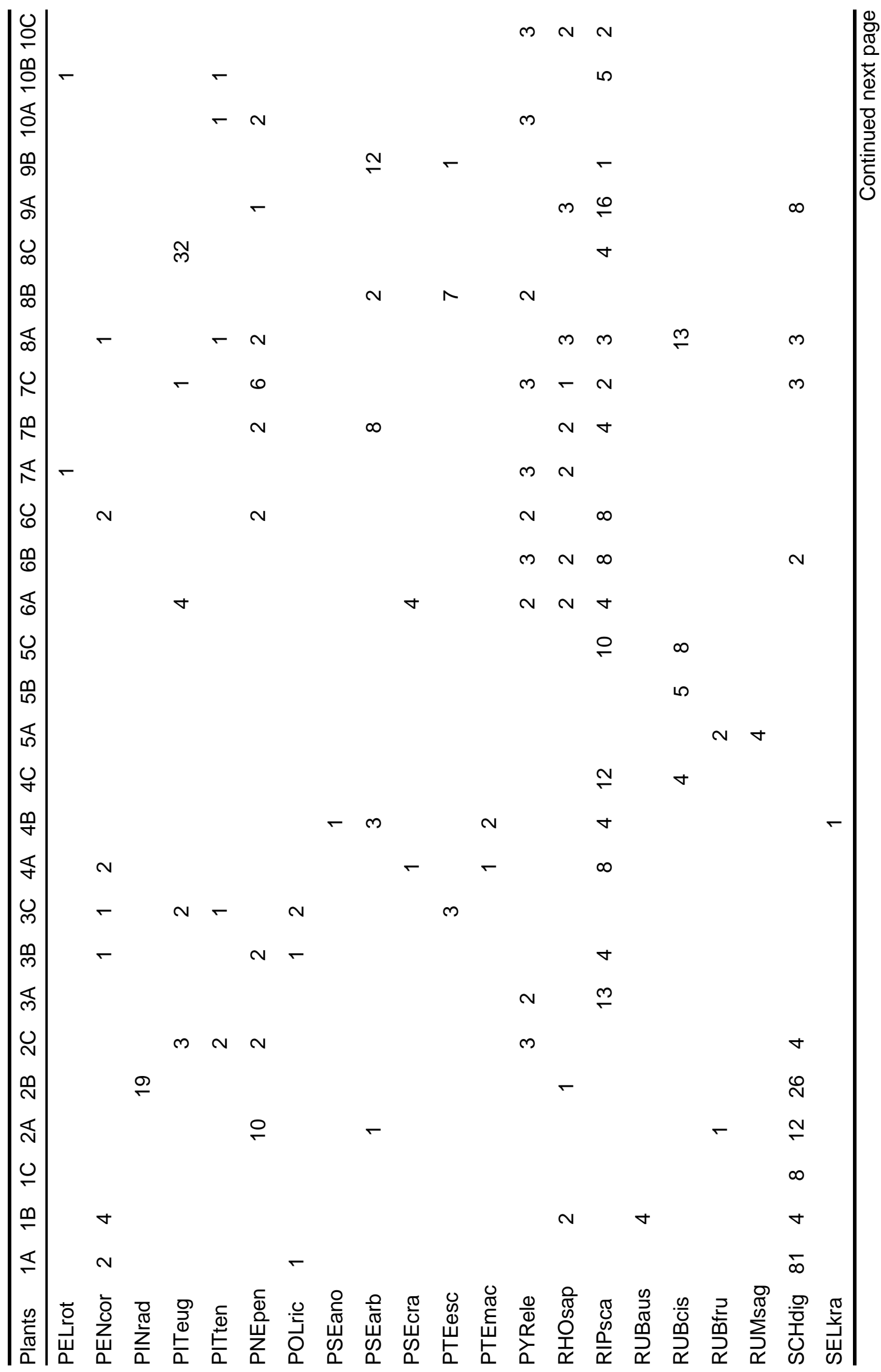




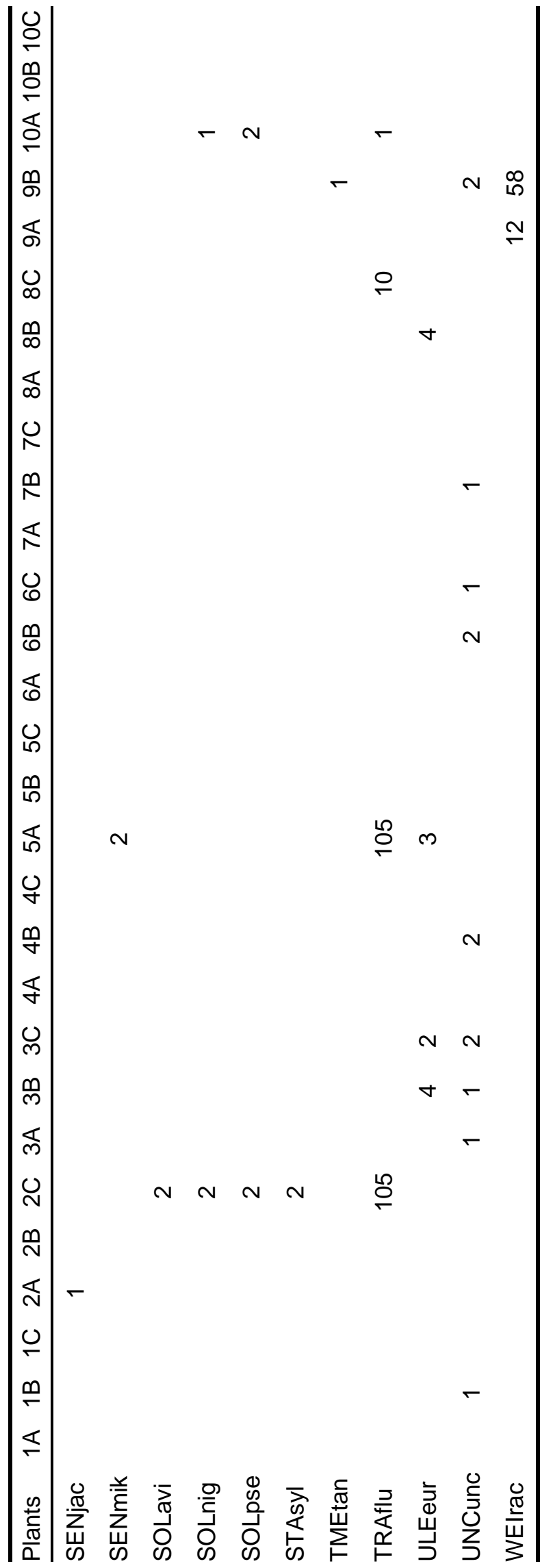


Table 3.2.2: Plant species abbreviations from Appendix 1 and their corresponding scientific and common names.

\begin{tabular}{|c|c|c|c|}
\hline Abbreviation & Scientific name & Family & Common name \\
\hline ADIcun & Adiantum cunninghamii & Pteridaceae & Maidenhair fern \\
\hline AGRcap & Agrostis capillaris & & Browntop (grass) \\
\hline ALEexc & Alectryon excelsus & Sapindaceae & Tītoki \\
\hline ALSmac & Alseuosmia macrophylla & Alseuosmiaceae & Toropapa \\
\hline ANAlan & Anarthropteris lanceolata & Polypodiaceae & Lance fern \\
\hline ARIser & Aristotelia serrata & Elaeocarpaceae & Makomako \\
\hline ASPbul & Asplenium bulbiferum & Aspleniaceae & Pikopiko, Hen \& chicken fern \\
\hline ASPfla & Asplenium flaccidum & Aspleniaceae & Hanging spleenwort \\
\hline ASPobl & Asplenium oblongifolium & Aspleniaceae & Shining spleenwort \\
\hline ASPpol & Asplenium polyodon & Aspleniaceae & Peretao, Sickle spleenwort \\
\hline ASPsca & Asparagus scandens & Liliaceae & Climbing asparagus \\
\hline ASTsol & Astelia solandri & Liliaceae & Kaiwharawhara, Perching lily \\
\hline BEItaw & Beilschmiedia tawa & Lauraceae & Tawa \\
\hline BERgla & Berberis glaucocarpa & Berberidaceae & Barbery \\
\hline BLEcha & Blechnum chambersii & Blechnaceae & Nini, Rereti, Lance fern, \\
\hline BLEcol & Blechnum colensoi & Blechnaceae & Peretao, Petako, Colensos hard fern \\
\hline BLEdis & Blechnum discolor & Blechnaceae & Petipeti, Piupiu, Crown fern \\
\hline BLEfil & Blechnum filiforme & Blechnaceae & Climbing hard fern \\
\hline BLEnov & Blechnum novaezelandiae & Blechnaceae & Kiokio, Gully Fern \\
\hline BRArep & Brachyglottis repanda & Compositae & Rangiora, Raurēkau \\
\hline BUDdav & Buddleja davidii & Buddlejaceae & Butterfly bush \\
\hline CALsol & Calystegia soldanella & Convolvulaceae & Bind weed \\
\hline CARdep & Cardamine debilis & Brassicaceae & Bitter cress \\
\hline CARser & Carpodetus serratus & Escalloniaceae & Putaputaweta, Marbleleaf \\
\hline CLEpan & Clematis paniculata & Ranunculaceae & Puawānaga \\
\hline CLEvit & Clematis vitalba & Ranunculaceae & Old Mans beard \\
\hline COPare & Coprosma areolata & Rubiaceae & Thin-leaved Coprosma \\
\hline COPgra & Coprosma grandifolia & Rubiaceae & Kanono, large-leaved coprosma \\
\hline COPpro & Coprosma propinqua & Rubiaceae & Mingimingi \\
\hline COPrha & Coprosma rhamnoides & Rubiaceae & \\
\hline COProb & Coprosma robusta & Rubiaceae & Karamū \\
\hline COPten & Coprosma tenuifolia & Rubiaceae & Wavy-leaved coprosma \\
\hline CORaus & Cordyline australis & Agavaceae & Kanono, Cabbage tree \\
\hline CORban & Cordyline banksii & Agavaceae & $\mathrm{T} \overline{1}$, Cabbage tree \\
\hline CORlae & Corynocarpus laevigatus & Corynocarpaceae & Karaka \\
\hline CTEhet & Ctenopteris heterophylla & Grammitidaceae & Comb fern \\
\hline CYAdea & Cyathea dealbata & Cyatheaeae & Ponga, Silver fern \\
\hline CYAfas & Cyathodes fasiculata & Epacridaceae & Mingimingi \\
\hline CYAmed & Cyathea medullaris & Cyatheaeae & Mamaku \\
\hline CYAsmi & Cyathea smithii & Cyatheaeae & Ponga, Soft tree fern \\
\hline
\end{tabular}




\begin{tabular}{|c|c|c|c|}
\hline CYTsco & Cytisus scoparius & Fabaceae & Broom \\
\hline DACdac & Podocarpus dacrydioides & Podocarpaceae & Kahikatea, white pine \\
\hline DICfib & Dicksonia fibrosa & Dicksoniaceae & Whekī-ponga, golden tree fern \\
\hline DYSspe & Dysoxylum spectabile & Meliiaceae & Kohekohe \\
\hline EARmuc & Earina mucronata & Orchidaceae & Peka-a-waka, Bamboo orchid, \\
\hline EARaut & Earina autumnalis & Orchidaceae & Raupeka, Autumn (Easter) orchid \\
\hline ELAden & Elaeocarpus dentatus & Elaeocarpaceae & Hīnau \\
\hline FREban & Freycinetia banksii & Pandanaceae & Kiekie \\
\hline FUCexc & Fuchsia excorticata & Onagraceae & Kōtukutuku, Tree fuchsia \\
\hline GENlig & Geniostoma ligustrifolium & Loganiaceae & Hangehange, NZ Privet \\
\hline GRAbil & Grammitis billardierei & Grammitidaceae & Common strap fern \\
\hline GRIluc & Griselinia lucida & Cornaceae & Puka \\
\hline HEDarb & Hedycarya arborea & Monimiaceae & Kaiwhiri, Pigeonwood \\
\hline HEDhel & Hedera helix & Araliaceae & Ivy \\
\hline HISinc & Histiopteris incisa & Pteridaceae & Mātā, Water fern \\
\hline HOHsex & Hoheria sexstylosa & Malvaceae & Ribbonwood \\
\hline HYMmul & $\begin{array}{l}\text { Hymenophyllum } \\
\text { multifidum }\end{array}$ & Hymenophyllaceae & Much divided filmy fern \\
\hline HYMrar & Hymenophyllum rarum & Hymenophyllaceae & Filmy fern \\
\hline IPOind & Ipomoea indica & Convolvulaceae & Blue morning glory \\
\hline KNIexc & Knightia excelsa & Proteaceae & Rewarewa, NZ honeysuckle \\
\hline KUNeri & Kunzea ericoides & Myrtaceae & Mānuka, Kānuka \\
\hline LASgla & Lastreopsis glabella & Dryopteridaceae & Smooth shield fern \\
\hline LAShis & Lastreopsis hispida & Dryopteridaceae & Hairy fern \\
\hline LAUnov & Laurelia novae-zelandiae & Monimiaceae & Pukatea \\
\hline LEPhym & $\begin{array}{l}\text { Leptopteris } \\
\text { hymenophylloides }\end{array}$ & Osmundaceae & Lesser Prince of Wales feather \\
\hline LEYfor & Leycesteria formosa & Caprifoliaceae & Himalayan honeysuckle \\
\hline LINtri & Lindsaea trichomanoides & Lindsaeaceae & \\
\hline MACexc & Piper excelsum & Piperaceae & Kawakawa, Pepper tree \\
\hline MELram & Melicytus ramiflorus & Violaceae & Māhoe, whitey wood \\
\hline METcar & Melicope ternata & Rutaceae & Wharangi \\
\hline METdif & Metrosideros diffusa & Myrtaceae & Rātā \\
\hline METper & Metrosideros perforata & Myrtaceae & White Rātā \\
\hline MICpus & Microsorium pustulatum & Polypodiaceae & Kōwaowao, Hounds tounge \\
\hline MICsca & Microsorium scandens & Polypodiaceae & Mokimoki, Fragrant fern \\
\hline MUEaus & Muehlenbeckia australis & Polygonaceae & Pōhuehue, Muehlenbeckia \\
\hline MYOlae & Myoporum laetum & Myoporaceae & Ngaio \\
\hline MYRaus & Myrsine australis & Myrsinaceae & Red Matipou, Red Māpou \\
\hline NERdep & Nertera depressa & Rubiaceae & Nertera \\
\hline NEScun & Nestegis cunninghamii & Oleaceae & Black Maire \\
\hline NOTsol & $\begin{array}{l}\text { Nothofagus solandri var. } \\
\text { solandri }\end{array}$ & Fagaceae & Black Beech \\
\hline OLEran & Olearia rani & Compositae & Heketara \\
\hline PARhet & Parsonsia heterophylla & Apocynaceae & NZ Jasmine \\
\hline
\end{tabular}




\begin{tabular}{|c|c|c|c|}
\hline PARlop & Paraserianthes lophantha & Mimosoideae & Brush wattle \\
\hline PAStet & Passiflora tetrandra & Passifloraceae & Kōhia, NZ passion fruit \\
\hline PELrot & Pellaea rotundifolia & Adiantaceae & Round-leaved fern \\
\hline PENcor & Pennantia corymbosa & Icacinaceae & Kaikōmako \\
\hline PINrad & Pinus radiata & Pinaceae & Monterey pine \\
\hline PITeug & Pittosporum eugenioides & Pittosporaceae & Tarata, Lemonwood \\
\hline PITten & Pittosporum tenuifolium & Pittosporaceae & Kōhūhū, black Matipou \\
\hline PNEpen & Pneumatopteris pennigera & Thelypteridaceae & Piupiu, Gully fern \\
\hline POLric & Polystichum richardii & Dryopteridaceae & Pikopiko mauku, Shield fern \\
\hline PSEano & Neopanax anomalum & Araliaceae & Raukawa \\
\hline PSEarb & Pseudopanax arboreus & Araliaceae & Whauwhau, Five finger \\
\hline PSEcra & Pseudopanax crassifolius & Araliaceae & Horoeka, Lancewood \\
\hline PTEesc & Pteridium esculentum & Pteridaceae & Rarauhe, Bracken \\
\hline PTEmac & Pteris macilenta & Pteridaceae & Sweet fern \\
\hline PYRele & Pyrrosia eleagnifolia & Polypodiaceae & Leather leaf fern \\
\hline RHOsap & Rhopalostylis sapida & Palmae & Nīkau palm \\
\hline RIPsca & Ripogonum scandens & Liliaceae & Kareao, Supplejack \\
\hline RUBaus & Rubus australis & Rosaceae & Tātarāmoa, Bush Lawyer \\
\hline RUBcis & Rubus cissoides & Rosaceae & Tātarāmoa, Bush Lawyer \\
\hline RUBfru & Rubus fruticosus & Rosaceae & Blackberry \\
\hline RUMsag & Rumex sagittatus & Polygonaceae & Rambling Dock \\
\hline SCHdig & Schefflera digitata & Araliaceae & Patē, Seven-finger \\
\hline SELkra & Selaginella kraussiana & Selaginellaceae & Selaginella \\
\hline SENjac & Senecio jacobaea & Senecionaceae & Ragwort \\
\hline SENmik & Delairea odorata & Asteraceae & Cape ivy \\
\hline SOLavi & Solanum aviculare & Solanaceae & Poroporo \\
\hline SOLnig & Solanum nigrum & Solanaceae & Black nightshade \\
\hline SOLpse & Solanum pseudocapsicum & Solanaceae & Jerusalem cherry \\
\hline STAsyl & Stachys sylvatica & Lamiaceae & Hedge woundwort \\
\hline TMEtan & Tmesipteris tannensis & Psilotaceae & \\
\hline TRAflu & Tradescantia fluminensis & Commelinaceae & Wondering Jew / Willie \\
\hline ULEeur & Ulex europaeus & Fabaceae & Gorse \\
\hline UNCunc & Uncinia uncinata & Cyperaceae & Hook grass \\
\hline WEIrac & Weinmannia racemosa & Cunoniaceae & Kāmahi \\
\hline
\end{tabular}


Appendix 3.3: Parasitoids from Stokes Valley.

Table 3.3.1: Additional parasitoid taxa included in this study from the native forest fragment of the Stokes Valley area.

\begin{tabular}{|c|c|}
\hline Taxa & Abundance \\
\hline \multicolumn{2}{|l|}{ Ichneumonidae } \\
\hline \multicolumn{2}{|l|}{ Banchinae } \\
\hline Lissonata albopicta & 4 \\
\hline Lissonata fulva & 3 \\
\hline \multicolumn{2}{|l|}{ Campopleginae } \\
\hline Campoletis sp. 1 & 2 \\
\hline Dusona destructor & 1 \\
\hline \multicolumn{2}{|l|}{ Ichneumoninae } \\
\hline Aucklandella sp. 01 & 3 \\
\hline Aucklandella sp. 09 & 1 \\
\hline Aucklandella sp. 16 & 3 \\
\hline Aucklandella sp. 17 & 1 \\
\hline Aucklandella sp. 20 & 3 \\
\hline Aucklandella sp. 23 & 1 \\
\hline Aucklandella sp. 24 & 5 \\
\hline Degithina sp. 2 & 2 \\
\hline Degithina sp. 3 & 1 \\
\hline Degithina sp. 4 & 1 \\
\hline Levansa sp. 2 & 1 \\
\hline \multicolumn{2}{|l|}{ Mesochorinae } \\
\hline Mesochorus sp. & 2 \\
\hline \multicolumn{2}{|l|}{ Phygadeuontinae } \\
\hline Aclastus sp. 01 & 3 \\
\hline Aclastus sp. 02 & 2 \\
\hline Aclastus sp. 03 & 6 \\
\hline Phygadeuontinae sp. 05 & 1 \\
\hline Phygadeuontinae sp. 15 & 5 \\
\hline \multicolumn{2}{|l|}{ Tersilochinae } \\
\hline $\begin{array}{l}\text { Tersilochinae sp. } 8 \\
\text { Pompilidae }\end{array}$ & 1 \\
\hline \multicolumn{2}{|l|}{ Pepsinae } \\
\hline Priocnemis conformis & 1 \\
\hline Sphictostethus calvus & 2 \\
\hline Sphictostethus fugax & 9 \\
\hline Sphictostethus nitidus & 9 \\
\hline \multicolumn{2}{|l|}{ Pompilinae } \\
\hline $\begin{array}{l}\text { Epipompilus insularis } \\
\text { Proctotrupidae }\end{array}$ & 3 \\
\hline \multicolumn{2}{|l|}{ Proctotrupinae } \\
\hline Fustiserphus longiceps & 1 \\
\hline Fustiserphus sp. 5 & 1 \\
\hline Grand Total & 78 \\
\hline
\end{tabular}


Appendix 3.4: Parasitoid species and plant species that best describe the relationship between parasitoid abundance patterns and the plant community composition.

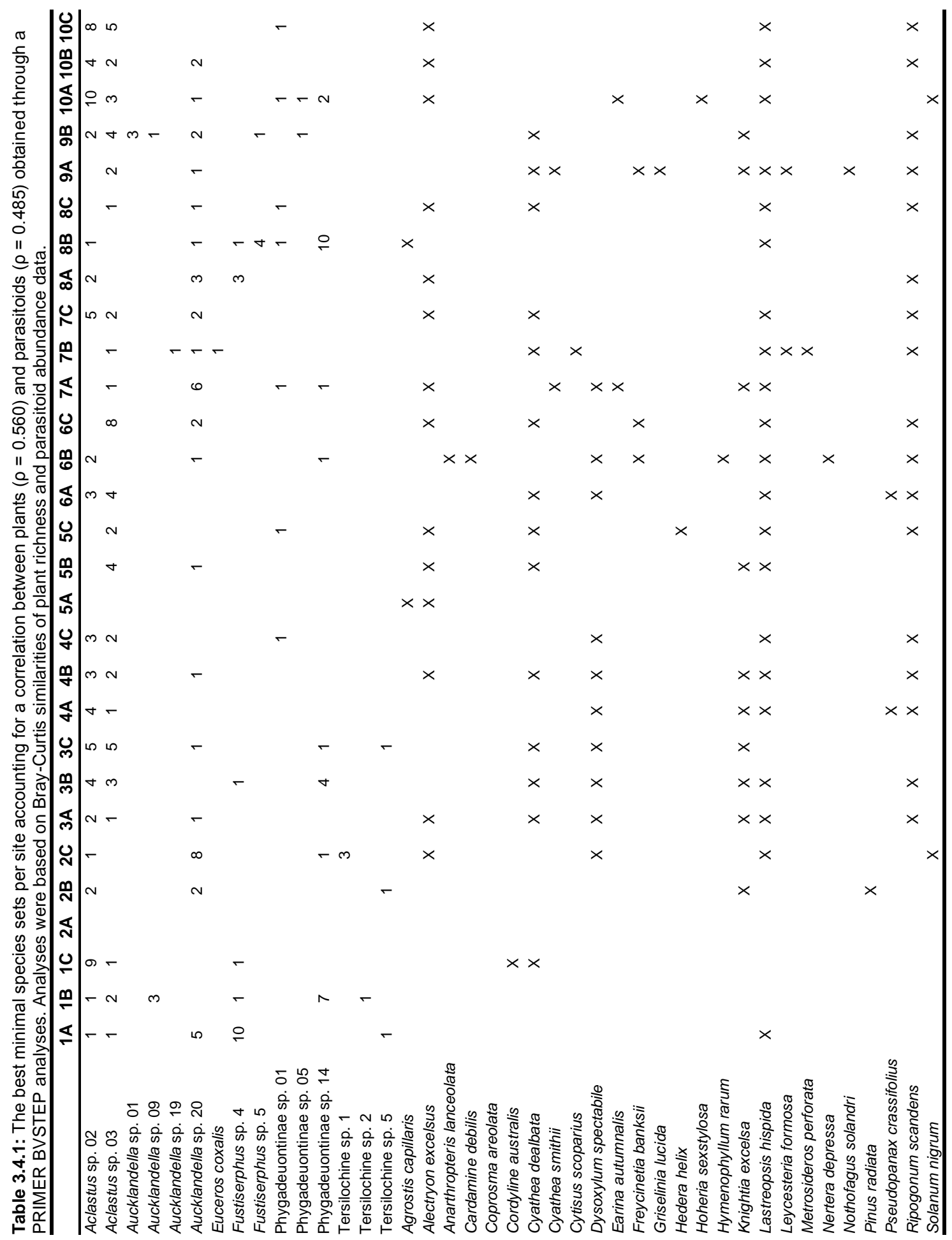


Appendix 3.5: Correlations between parasitoids and the host plants associated with the parasitoids' hosts.

Table 3.5.1: Spearman rank correlations (rho) and their p-values for the parasitoids Carria fortipes and Dusona stramineipes with their known herbivorous hosts' host plants from 29 samples. Relationships are for the parasitoid as well as the plant abundances and species richness.

\begin{tabular}{|c|c|c|c|c|c|}
\hline \multirow[b]{3}{*}{ Plant species } & \multirow[b]{3}{*}{ Statistics } & \multicolumn{4}{|c|}{ Carria fortipes } \\
\hline & & \multicolumn{2}{|c|}{ abundance } & \multicolumn{2}{|c|}{ richness } \\
\hline & & Plant N & Plant S & Plant $\mathrm{N}$ & Plant S \\
\hline \multirow[t]{2}{*}{ Aristotelia serrata } & rho & .089 & .099 & .064 & .073 \\
\hline & $p$ & .645 & .608 & .742 & .707 \\
\hline \multirow[t]{2}{*}{ Berberis glaucocarpa } & rho & .037 & .045 & .064 & .073 \\
\hline & $\mathrm{p}$ & .849 & .816 & .742 & .707 \\
\hline \multirow[t]{2}{*}{ Brachyglottis repanda } & rho & 118 & .255 & .094 & .240 \\
\hline & $p$ & .542 & 182 & .627 & .210 \\
\hline \multirow[t]{2}{*}{ Carpodetus serratus } & rho & .053 & .045 & .082 & .073 \\
\hline & $\mathrm{p}$ & .784 & .816 & .672 & .707 \\
\hline \multirow[t]{2}{*}{ Corynocarpus laevigatus } & rho & -.051 & -.125 & .015 & -.057 \\
\hline & $\mathrm{p}$ & .792 & .519 & .939 & .768 \\
\hline \multirow[t]{2}{*}{ Cytisus scoparius } & rho & -.106 & -.106 & -.107 & -.107 \\
\hline & $\mathrm{p}$ & .586 & .586 & .582 & .582 \\
\hline \multirow[t]{2}{*}{ Dysoxylum spectabile } & rho & .024 & -.069 & .023 & -.070 \\
\hline & $\mathrm{p}$ & .903 & .720 & .907 & .718 \\
\hline \multirow[t]{2}{*}{ Fuchsia excorticata } & rho & -.152 & -.152 & -.153 & -.154 \\
\hline & $\mathrm{p}$ & .432 & .431 & .427 & .427 \\
\hline \multirow[t]{2}{*}{ Piper excelsum } & rho & 192 & & 174 & \\
\hline & $\mathrm{p}$ & .318 & & .368 & \\
\hline \multirow[t]{2}{*}{ Olearia rani } & rho & -.037 & -.016 & -.016 & .008 \\
\hline & $\mathrm{p}$ & .848 & .935 & .934 & .967 \\
\hline \multirow[t]{2}{*}{ Pinus radiata } & rho & -.106 & -.106 & -.107 & -.107 \\
\hline & $\mathrm{p}$ & .586 & .586 & .582 & .582 \\
\hline \multirow[t]{2}{*}{ Pittosporum tenuifolium } & rho & -.072 & -.066 & -.051 & -.044 \\
\hline & $\mathrm{p}$ & .711 & .735 & .791 & .820 \\
\hline \multirow[t]{2}{*}{ Rubus australis } & rho & -.106 & -.106 & -.107 & -.107 \\
\hline & $\mathrm{p}$ & .586 & .586 & .582 & .582 \\
\hline \multirow[t]{2}{*}{ Rubus cissoides } & rho & -.009 & -.016 & .016 & .008 \\
\hline & $\mathrm{p}$ & .964 & .935 & .934 & .967 \\
\hline \multirow[t]{2}{*}{ Rubus fruticosus } & rho & -.152 & -.152 & -.153 & -.154 \\
\hline & $p$ & .432 & .431 & .427 & .427 \\
\hline \multirow[t]{3}{*}{ Rumex sagittatus } & rho & -.106 & -.106 & -.107 & -.107 \\
\hline & $\mathrm{p}$ & .586 & .586 & .582 & .582 \\
\hline & & \multicolumn{4}{|c|}{ Dusona stramineipes } \\
\hline \multirow{2}{*}{ Griselinia lucida } & rho & -.145 & -.145 & -.148 & -.148 \\
\hline & $\mathrm{p}$ & .452 & .452 & .444 & .444 \\
\hline \multirow[t]{2}{*}{ Pseudopanax arboreum } & rho & -.018 & -.006 & -.006 & -.019 \\
\hline & $\mathrm{p}$ & .926 & .974 & .974 & .920 \\
\hline
\end{tabular}




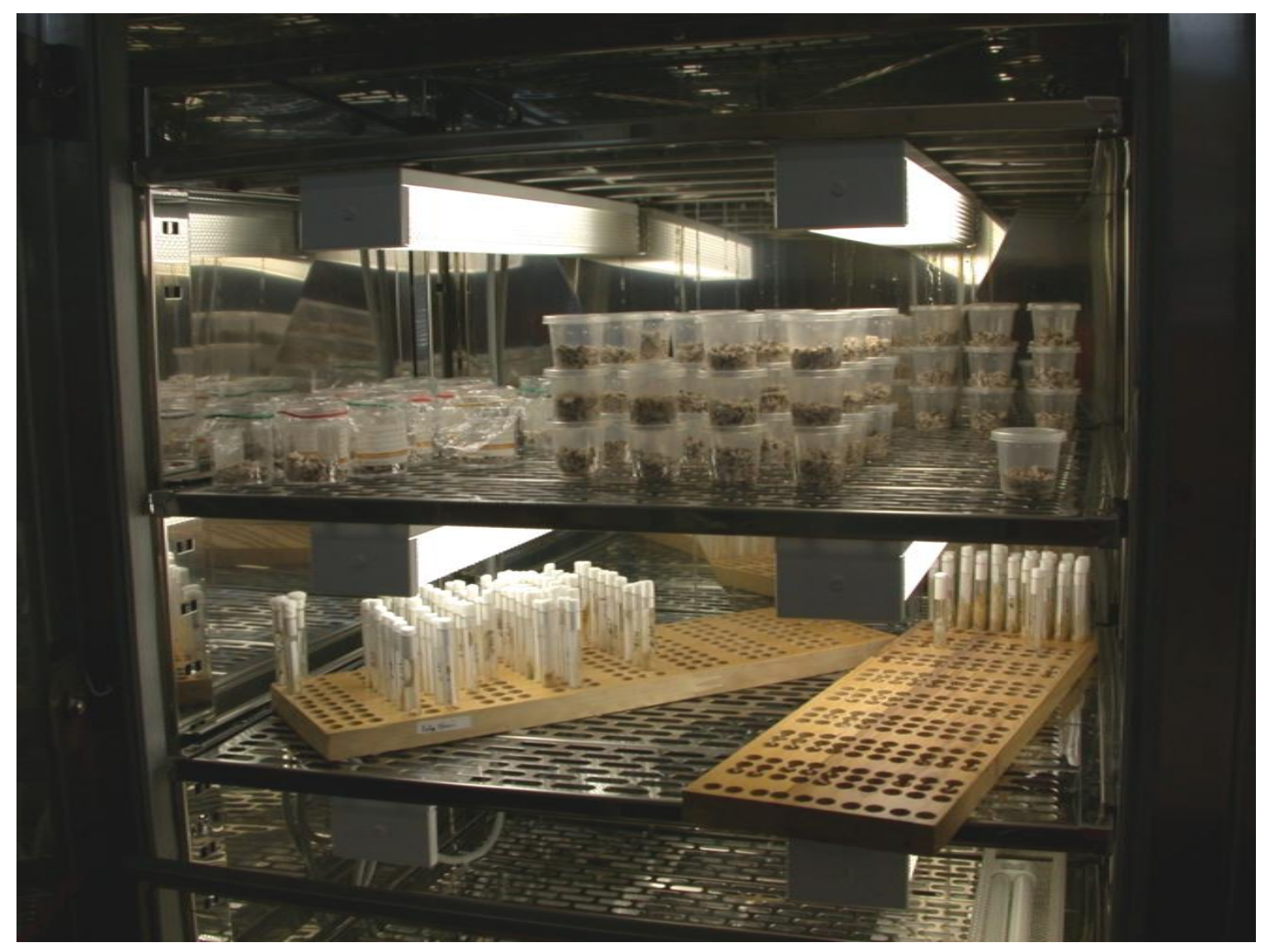

Rearing Cleora scriptaria larvae 


\section{Hierarchical influences on tri-trophic interactions: Parasitism of Cleora scriptaria (Lepidoptera: Geometridae) larvae and herbivory of Macropiper excelsum (Piperaceae) -plant, plot and fragment effects $^{1}$}

\subsection{Abstract}

1. Habitat fragmentation and the resulting decline in biodiversity through the loss of habitat are thought to be the main threat to insect extinctions, particularly at higher trophic levels. According to the trophic level hypothesis habitat fragmentation should affect parasitoids more severely than herbivores, however, herbivore and parasitoid responses to fragmentation have been found to be consistently inconsistent. This study examines the effects of habitat loss on a tritrophic system between plant, herbivore and parasitoids in 10 urban native forest fragments within the Wellington and Hutt Valley regions of the North Island of New Zealand.

2. The study system consisted of the generalist herbivore, the kawakawa moth larva Cleora scriptaria, and its primary host plant Macropiper excelsum. In total, we investigated 1170 individual trees. We collected and reared 2049 kawakawa moth larvae from 718 trees. Parasitism rates by the two parasitoids Aleiodes declanae (an endemic species) and Meteorus pulchricornis (an exotic species) as well as herbivory caused by $C$. scriptaria larvae were investigated in response to properties of the fragment, plot level and individual plant. These

\footnotetext{
${ }^{1}$ Co-authors: Hartley, S., and Lester, P. J.
} 
properties were fragment area, isolation and percentage residential area surrounding fragments; relative $M$. excelsum abundance and plant richness at the plot level; and C. scriptaria larval densities, herbivory, tree size and overall parasitism rate at the plant level.

3. Parasitism rates for $A$. declanae were significantly higher in more isolated fragments with smaller trees, and were negatively affected by overall parasitism rates but more so in isolated fragments. Parasitism rates by $M$. pulchricornis responded positively to larval densities and declined with increasing plant richness. Herbivory was positively related to the abundance of $M$. excelsum, tree size and larval density. The different parasitoid responses possibly reflect the biological differences related to host searching strategies rather than different dispersal abilities.

4. In conclusion, one parasitoid was affected by isolation, but opposite to what was expected according to the trophic level hypothesis. Neither the parasitism rate by the other parasitoid nor herbivory was responding to any fragment level properties. However plot level elements as well as properties associated with individual plants showed that mechanisms other than fragmentation alone influence tri-trophic interactions, which we also concluded in a related study.

Keywords: Tri-trophic interaction, habitat fragmentation, parasitoids, herbivory, Geometridae, Braconidae, insect conservation, invasive species, urban forest fragmentation, conservation management. 


\subsection{Introduction}

Habitat fragmentation, involving both the loss of habitat area and the subsequent isolation of remnant fragments (Fahrig 2003), is one of the major threats to the maintenance of biodiversity (Henle et al. 2004). Loss of habitat, in particular, is thought to be the main driver for insect extinctions, possibly threatening insects more than many other organisms (Warren et al. 2001; Thomas et al. 2004; Samways 2007). Furthermore, it has been suggested that insects at higher trophic levels (such as parasitoids) are more sensitive to the effects of habitat fragmentation than those at lower trophic levels (Kruess and Tscharntke 1994; Komonen et al. 2000). Despite their importance, trophic interactions in relation to habitat loss have been studied relatively rarely and often the focus has been on insect-plant interactions in agricultural or forest situations (e.g. Kruess and Tscharntke 1994; Roland and Taylor 1997; Cappuccino et al. 1998; Zabel and Tscharntke 1998; Komonen et al. 2000; Roth et al. 2006; Valladares et al. 2006; Chust et al. 2007). Few studies have measured species richness, abundances and composition in urban settings that included parasitoids (e.g. Gibb and Hochuli 2002; Lassau and Hochuli 2005). In the previous chapters we examined how forest fragmentation affected different parasitoid families and the relationships between plant diversity to those parasitoid communities within an urban area. To our knowledge no study has addressed the effects of habitat fragmentation on the trophic processes between a plant, its herbivore and the herbivore's parasitoids in an urban setting.

In this study we concentrate on tri-trophic interactions in native forest fragments, examining herbivory and parasitism in relation to forest fragmentation within the urbanised area of the Wellington and Upper Hutt regions in North Island, New Zealand. According to the trophic level hypothesis parasitism rates should be more negatively 
affected than herbivory by habitat fragmentation and lower parasitism rates are expected in smaller and more isolated habitat fragments than in larger and more connected habitat fragments (Kruess and Tscharntke 1994; Komonen et al. 2000). In contrast smaller or more isolated patches of host plants were found to have a higher parasitism rate (Doak 2000; Cronin 2003; Roth et al. 2006), whereas others have found distance has no effects on parasitism rates (Amarasekare 2000b; Esch et al. 2005).

Negative effects of habitat fragmentation on biodiversity are most apparent with the loss of habitat rather than the breaking apart of habitat per se (Fahrig 2003). Here we examined the potential effects of fragment size, isolation and percentage of residential area as a measure of habitat loss on herbivory and parasitism. Our study systems were the kawakawa tree Macropiper excelsum (G.Forst.) Miq. (1843) (Piperaceae) and its primary herbivore the common kawakawa moth larvae Cleora scriptaria Walker (Lepidoptera: Geometridae) and parasitoids reared from the larvae. Kawakawa (also commonly known as the New Zealand pepper tree) is a small forest tree, usually found in the sub-canopy of native New Zealand forest, mixed bush and scrub (Smith 1975). Kawakawa is the primary host plant of the kawakawa moth larvae (Hudson 1928), which is the predominant herbivore on kawakawa. Kawakawa moth larvae, however, also feed on some other host plants (Spiller and Wise 1982) and this species therefore could be considered a generalist feeder. However, the kawakawa moth is known typically to inhabit forested areas (Dugdale pers. comm., Hassell 1986) and herbivory might therefore show some negative responses to the loss of forested habitat in our study system, in spite of kawakawa moth larvae being generalist feeders. Not only are herbivores predicted to be less sensitive to fragmentation than parasitoids, herbivores also have been found to respond to changes in habitat area whereas predators were affected predominantly by 
isolation (Zabel and Tscharntke 1998). We would therefore expect herbivory to be less affected by fragmentation, and respond to different properties of the forest fragment compared to parasitism. However, such a response may depend on whether a parasitoid is a generalist or a specialist (Zabel and Tscharntke 1998; Steffan-Dewenter and Tscharntke 2000) and we would predict parasitism rates of a specialist parasitoid to decrease faster than those of a generalist parasitoid.

Naturally, organisms may respond to many environmental factors and also interact with each other. For example, herbivore densities are dependent on the distribution of their host plants, which can determine parasitoid assemblages (Doak 2000; Umbanhowar et al. 2003; Vanbergen et al. 2007). Changes in plant species composition as well as spatial distribution of the host plant Cirsium palustre (L.) Scop. (Asteraceae) affected interactions between the herbivore Tephritis conura Loew (Diptera: Tephritidae) and its parasitoid Pteromalus elevatus (Walker) (Hymenoptera: Pteromalidae), whereby the herbivore was unaffected by host-plant distribution, but parasitism rates were higher in patches where host plants were aggregated (Vanbergen et al. 2006). The absence of parasitoids and low parasitism rates in a patch or habitat fragment could be a response to low herbivore or host plant densities (Doak 2000; Esch et al. 2005). We therefore examined herbivory and parasitism rate in relation to larval densities per plant, the size of individual kawakawa trees, and the relative kawakawa abundance and plant richness. As mentioned before, $C$. scriptaria is known to feed on alternative food plants and availability of these resources and the densities of the larvae might determine availability of larvae for parasitoids. Our studies in Chapters 2 and 3, for example, showed that factors other than those relating to habitat fragmentation may have had important influences on parasitoid diversity and possible plant-herbivore-parasitoid interactions. 
Tri-trophic interactions are determined by the attributes of each member in a system, and forest fragmentation effects alone do not always sufficiently explain how organisms respond (Chapter 2). Here we investigate additional mechanisms of fragmentation effects that might influence our study system at the individual plant-herbivore-parasitoid level.

We also examine whether herbivory has any influence on parasitism rates. Parasitoids of some species are known to be attracted to plant volatiles released through leaf damage caused by feeding larvae and some parasitoids parasitising the same host on the same plants respond to the cues more than others (e.g. Turlings et al. 2002). We might therefore expect to find different parasitism rates for different parasitoids, dependent on the amount of herbivory. As discussed by Hawkins (1994), parasitoids have some form of control over host densities, which we might expect to be reflected in the degree of herbivory on a tree. The degree of herbivory might also be related to the extent of parasitism by different parasitoids, because not every parasitoid will affect its host populations equally (Hawkins 1994). Similarly, if parasitoids that interfere with each other are less likely to exploit their host effectively (Amarasekare 2000a) and parasitoids respond differently to habitat area and isolation (Kruess and Tscharntke 2000a), due to dispersal ability of each parasitoid competing for the same host (Roland and Taylor 1997; Amarasekare 2000b), we would expect parasitism rates of individual species to vary among habitat patches, depending on parasitism rates of the other species.

In summary, we would expect parasitoids to respond to attributes such as the abundance of the host larvae, overall parasitism on the host larvae, herbivory and plant size as well as to the abundance of their host's host plant and local plant richness. Such responses might differ between plants, research plots and habitat fragments with different areas, 
degrees of isolation or the degree of residential build up surrounding a fragment. We examine the hierarchy of environmental influences on herbivory and parasitism at the following three-levels:

4. at the fragment level by habitat area, habitat isolation, percentage residential area;

5. at the plot level by host plant abundance and plant richness;

6. at the plant level by host larval abundances, overall parasitism rate, and degree of herbivory on an individual tree and individual tree size.

\subsection{Methods}

\subsubsection{Study sites}

We studied 10 fragments of native forest within the Wellington and Hutt Valley regions in North Island, New Zealand (Fig. 4.1). Prior to European settlement towards the end of $18^{\text {th }}$ century this region had extensive native forest cover, most of which has been cleared to make way for European settlements. Generally, the trees in the fragments we surveyed are between 50 - 100 years old (Gabites 1993; Shepherd 2000). Native forest covers around $15 \%$ of this region, $20 \%$ is covered by regenerating scrub, $25 \%$ is urban and $40 \%$ is open grassland in the form of parks or pasture. The area of the study fragments ranged from 12 to 1078 ha (Appendix 4.1, Table 4.1.1). The location of fragments, their area, and the distances from the edge of the fragment to the edges of neighbouring native fragments were established using ESRI®ArcGISTM 9.0 (ESRI 2004). Within a range of 1 $\mathrm{km}$ distance from the edge of each research fragment we calculated an isolation index for each fragment, based on the commonly used formula proposed by Hanski, Kuussaari \& Nieminen (1994): 


$$
I_{j}=\sum_{j=1}^{n} \exp \left(-d_{i j}\right) A_{j}, \quad j \neq i
$$

where $d_{i j}$ is the minimum distance (in $\mathrm{km}$ ) from the focal fragment $i$ to the neighbouring native fragment $j, n$ is the number of neighbouring fragments, and $A_{j}$ is the area (in $\mathrm{m}^{2}$ ) of the neighbouring native fragments. A lower value of $I$ indicates a more isolated fragment in comparison to less isolated fragments with larger $I$ values (Appendix 4.1, Table 4.1.1). Fragment area and isolation were $\log _{10}$ transformed prior to analysis. Within the same 1 $\mathrm{km}$ range around each fragment, we calculated the relative cover of residential area as a measure of matrix quality that may be related to functional isolation (Appendix 4.1, Table 4.1.1).

Edge effects, such as differences in light, wind and humidity often meant that forest fragments contained different faunal compositions or species in the centre compared to the fragment edges (Turner 1996; Didham et al. 1998; Carvalho and Vasconcelos 1999; Munro 1999; Gibb and Hochuli 2002). To control for this possibility, three randomly selected collection sites were placed inside each fragment at a consistent distance of 30 \pm 5 metres from the fragment edge. For each research site we estimated the abundance of M. excelsum and measured the plant richness within a $20 \times 20$ metre plot using the Reconnaissance (RECCE) description procedure (Allen 1992). 


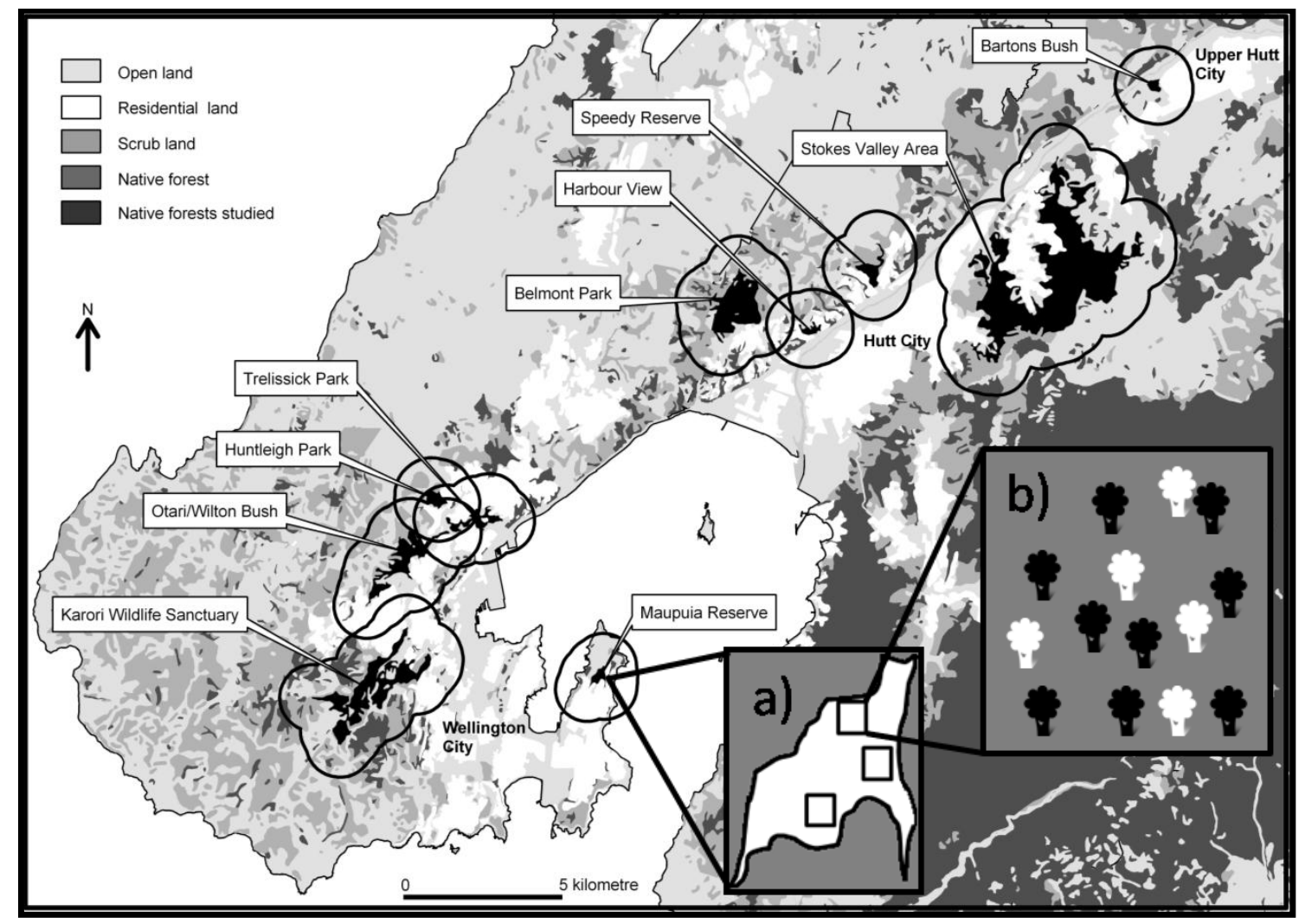

Figure 4.1: The Wellington and Hutt Valley regions: Location of 10 native forest research fragments and the surrounding $1 \mathrm{~km}$ range included in the study. Inserts: a) individual fragment with three plots; b) individual plot with individual trees investigated (white). (Data and land cover shape files courtesy of New Zealand Department of Conservation http://extranet.doc.govt.nz/bip).

\subsubsection{Study species: plant, herbivore and parasitoids}

At each research site we counted and labelled all kawakawa trees within the central $10 \times$ $10 \mathrm{~m}$ area. From five randomly selected trees we counted the number of kawakawa moth larvae $C$. scriptaria. For this we placed a $1 \times 1 \mathrm{~m}$ white beating sheet under a tree and shook each tree vigorously until no more larvae fell onto the sheet. Beating as a method to quantify geometrid larval abundances has been used and described previously (White 1975). Every fourth larvae encountered was collected for rearing in the laboratory. If less than 10 larvae were collected from the five randomly chosen trees, than additional larva 
were collected from adjacent trees within the $10 \times 10 \mathrm{~m}$ plot, and if necessary from trees in the wider $20 \times 20 \mathrm{~m}$ research site. The number of leaves was estimated visually to determine the tree size for each tree that larvae were collected from. A herbivory index was estimated for each tree ranging from no herbivory (0) to almost total loss of leaves (5). Collection of larvae took place during the summer months of December, February and April 2002/2003 and of December, February, and April 2003/2004, whereas kawakawa moth abundances and herbivory were recorded for February and April 2003 and December, February, and April 2003/2004 (Appendix 4.1, Table 4.1.2). The collected larvae were raised in individual containers in incubators on a general-purpose diet (Singh 1983) until lepidopteran or parasitoid adults emerged. The rearing method and the parasitoids reared are explained in more detail by Schnitzler et al. (2004) (see Appendix 4.7). No dead larvae or pupae dissected were found to be parasitised and were therefore all treated as such. In this paper we focus on the two hymenopteran parasitoids most frequently reared in this study: Aleiodes declanae van Achterberg 2004 (Braconidae), an endemic parasitoid and Meteorus pulchricornis (Wesmael 1835) (Braconidae), an exotic parasitoid. Both species are solitary endoparasitic koinobiont parasitoids. Voucher specimens for parasitoids reared were deposited at the Museum of New Zealand (Te Papa Tongarewa), Wellington and with the New Zealand Arthropod Collection at LandCare, Auckland.

\subsubsection{Statistical analysis}

We investigated whether the probability of a kawakawa moth larva being parasitised, by either parasitoid, varied in response to a hierarchy of predictors. These predictors were measured at the scale of individual plants, local sites and forest fragment. At the individual plant level the factors were: kawakawa tree size, the number of kawakawa 
moth larvae encountered on a tree, and the amount of herbivory on a tree. As an additional predictor at this level we used the rate of 'overall parasitism' minus the parasitism rate by $A$. declanae or $M$. pulchricornis respectively. 'Overall parasitism' might reduce the potential number of host larvae available and thus influence parasitism rates by $A$. declanae or $M$. pulchricornis. 'Overall parasitism' included all parasitoids reared from kawakawa moth larvae in this study and described by Schnitzler et al. (2004). At the site level (referred to as plot level from here on) the predictors were kawakawa abundance and plant species richness. At the third level the predictors associated with fragment were: area, isolation, and percentage of urban or residential land within $1 \mathrm{~km}$ of the fragment. Similarly, we wanted to know whether herbivory on a plant could be related to kawakawa moth larval abundance, tree size, the rate of parasitism by $A$. declanae and M. pulchricornis, and the level 2 and level 3 predictors as described above (responses for each level and their corresponding predictors are summarised in Table 4.1).

We pooled data at the individual plant level across February and April 2003 and December, February, and April 2003/2004. In addition, the number of ordinal categories for herbivory were reduced to three, combining categories 1 and 2 into low herbivory, category 3 into medium herbivory and categories 4 and 5 into high herbivory (HERBCOM). The herbivory category 0 did not occur in the data and the categories 1 and 5 were rarely observed. 
Table 4.1: Three-level model showing the possible predictors at each level for the responses of parasitism by A. declanae and M. pulchricornis as well as for herbivory. Abbreviations for each variable as they are used throughout this study are shown in brackets.

\begin{tabular}{|c|c|c|c|}
\hline \multirow[b]{2}{*}{ Response } & \multicolumn{3}{|c|}{ Predictors } \\
\hline & Level 1 (plant) & Level 2 (plot) & Level 3 (fragment) \\
\hline \multirow{4}{*}{$\begin{array}{l}\text { Probability of a } \\
\text { kawakawa moth } \\
\text { larva being } \\
\text { parasitised (AL, } \\
\text { MET) }\end{array}$} & $\begin{array}{l}\text { Tree size } \\
\text { (LEAVES) }\end{array}$ & $\begin{array}{l}\text { Kawakawa } \\
\text { abundance } \\
\text { (KAWAABUN) }\end{array}$ & $\begin{array}{l}\text { Area } \\
(\text { LOG_AREA) }\end{array}$ \\
\hline & $\begin{array}{l}\text { Herbivory } \\
\text { (HERB12, } \\
\text { HERB3, } \\
\text { HERB45) }\end{array}$ & $\begin{array}{l}\text { Plant richness } \\
\text { (PLANTS) }\end{array}$ & $\begin{array}{l}\text { Isolation } \\
\text { (LOG_ISO) }\end{array}$ \\
\hline & $\begin{array}{l}\text { Geometrid } \\
\text { abundance } \\
\text { (GEO) }\end{array}$ & & $\begin{array}{l}\text { Percentage } \\
\text { residential area } \\
\text { (PERC_RES) }\end{array}$ \\
\hline & $\begin{array}{l}\text { Parasitism rate } \\
\text { by all other } \\
\text { parasitoids } \\
\text { (TOTRAT_A, } \\
\text { TOTRAT_B) }\end{array}$ & & \\
\hline \multirow[b]{3}{*}{$\begin{array}{l}\text { Herbivory } \\
\text { (HERBCOM) }\end{array}$} & Tree size & $\begin{array}{l}\text { Kawakawa } \\
\text { abundance }\end{array}$ & Area \\
\hline & $\begin{array}{l}\text { Geometrid } \\
\text { abundance }\end{array}$ & Plant richness & Isolation \\
\hline & $\begin{array}{l}\text { parasitism rate } \\
\text { by either of the } \\
\text { two parasitoids } \\
\text { (AL_RAT, } \\
\text { MET_RAT) }\end{array}$ & & $\begin{array}{l}\text { percentage } \\
\text { residential area }\end{array}$ \\
\hline
\end{tabular}

We used a hierarchical linear modelling (HLM) approach (Raudenbush and Bryk 2002; McMahon and Diez 2007), also sometimes known as mixed effect multi-level models. As described above, the three-levels were individual plants surveyed nested within plots, which were nested within a fragment. Hierarchical organisation in ecological systems has long been the focus of ecological studies (Müller 1992) and the benefits of an HLM approach to ecological studies were recently reviewed (e.g. Beever et al. 2006; Kristan 
and Scott 2006; van de Pol and Verhulst 2006; McMahon and Diez 2007) and were demonstrated in various applications (e.g. Gering and Crist 2002; Storch et al. 2005; Anadon et al. 2007; Clark et al. 2007; Diez 2007; Thogmartin and Knutson 2007). For example, a two-level linear model explaining variation in individual leaf herbivory according to initial plant height and species richness per patch was explained by McMahon and Diez (2007). Our data were collected across three different levels with different characteristics (covariates) measured at each level.

Parasitism was treated as a binomial response variable (number of parasitised larvae out of the total number of larvae reared). Herbivory was treated as an ordinal response variable and had three possible ordered response categories $1=$ low herbivory, $2=$ medium herbivory, and 3 = high herbivory. We used a hierarchical generalised linear modelling (HGLM) approach with the software HLM 6.02, which allows for a non-linear analysis appropriate for binomial and ordinal data (Raudenbush et al. 2000). The underlying principle behind the models used in this study is summarised in Appendix 4.2.

\subsubsection{Model building}

The fragments (level 3 in the model) in this study were selected by stratified sampling (see above for detailed sampling method) and fragment predictors were treated as fixed. For ease of interpretation, and to maintain a parsimonious model appropriate to the quantity of available data, individual plant predictors (level-1 in the model) and the level 2 (plot level) predictors were also treated as fixed. All predictors are included un-centred in the model. Fragment area and isolation were important factors in the choice of fragments therefore, except for the 'unconditional (null, intercepts only) model', area and 
isolation were included by default in all the possible models as potential predictors of interest.

The program HLM uses full Penalised Quasi-Likelihood estimation (PQL) for three-level models with binary outcomes with a logit link. In contrast, restricted PQL was chosen for the analysis of the two-level herbivory models (ordinal data). Restricted PQL applies the principle of likelihood estimates to the least-squares residuals by removing the fixedeffects of the variables. The distribution of the residuals becomes independent from the fixed effects and in this way depends only on the variance components. This is in contrast to full PQL estimates where the distribution of the dependent variable is assumed to be normal, with a mean depending on the regression coefficients and the dispersion depending on the variance components. A restricted likelihood estimate is especially recommended when the number of level 2 units is small (Raudenbush et al. 2000), as is the case with the herbivory model. All models were fitted using the default iteration control settings and the frequency of the iteration accelerator set to 10 .

First we examined the unconditional model for each response variable to investigate the partitioning of variation across levels. Following on from the unconditional model, we introduced the covariates area and isolation at level 3 into each model and started the model building process by including the covariates at the individual level to explain the level 1 variance. We dropped level 1 predictors that had a $\mathrm{P}$ value greater than 0.1 , and proceeded to include covariates at level 2. We retained the level 2 terms with a $\mathrm{P}$ value less than 0.1 and proceeded to introduce the remaining level 3 predictor: percentage of residential area. For the level 1 predictor herbivory, dummy variables were created for the medium and high herbivory levels (HERB3 and HERB45 respectively), which were 
both introduced as predictors into the model. The full potential mixed regression model with all level predictors included for the outcome of parasitism by A. declanae is given as an example in Appendix 4.2, eqn. 4.2.12. Because of missing values in some predictor variables run-time deletion in each analysis reduced the number of level 1 units accordingly. The appropriate number of available units for each model is given in the respective result tables below.

For the binomial three-level models HLM provides unit-specific as well as populationaverage coefficient estimates. We were interested in unit-specific changes, which are changes between plots and between fragments, but we also wanted to know whether influences by the predictors are relevant for the wider Wellington and Upper Hutt region. We therefore report the results for the unit-specific as well as the population-average models.

\subsection{Results}

In total we investigated 1170 individual trees and collected and reared 2049 kawakawa moth larvae from 718 trees. From those we reared 209 A. declanae, 62 M. pulchricornis and 59 parasitoids of a combination of six to seven species; the latter are discussed in more detail by Schnitzler et al. (2004) (Fig 4.2). Insect dynamics observed differed between years; however, datasets from both years were combined for the model analysis. 

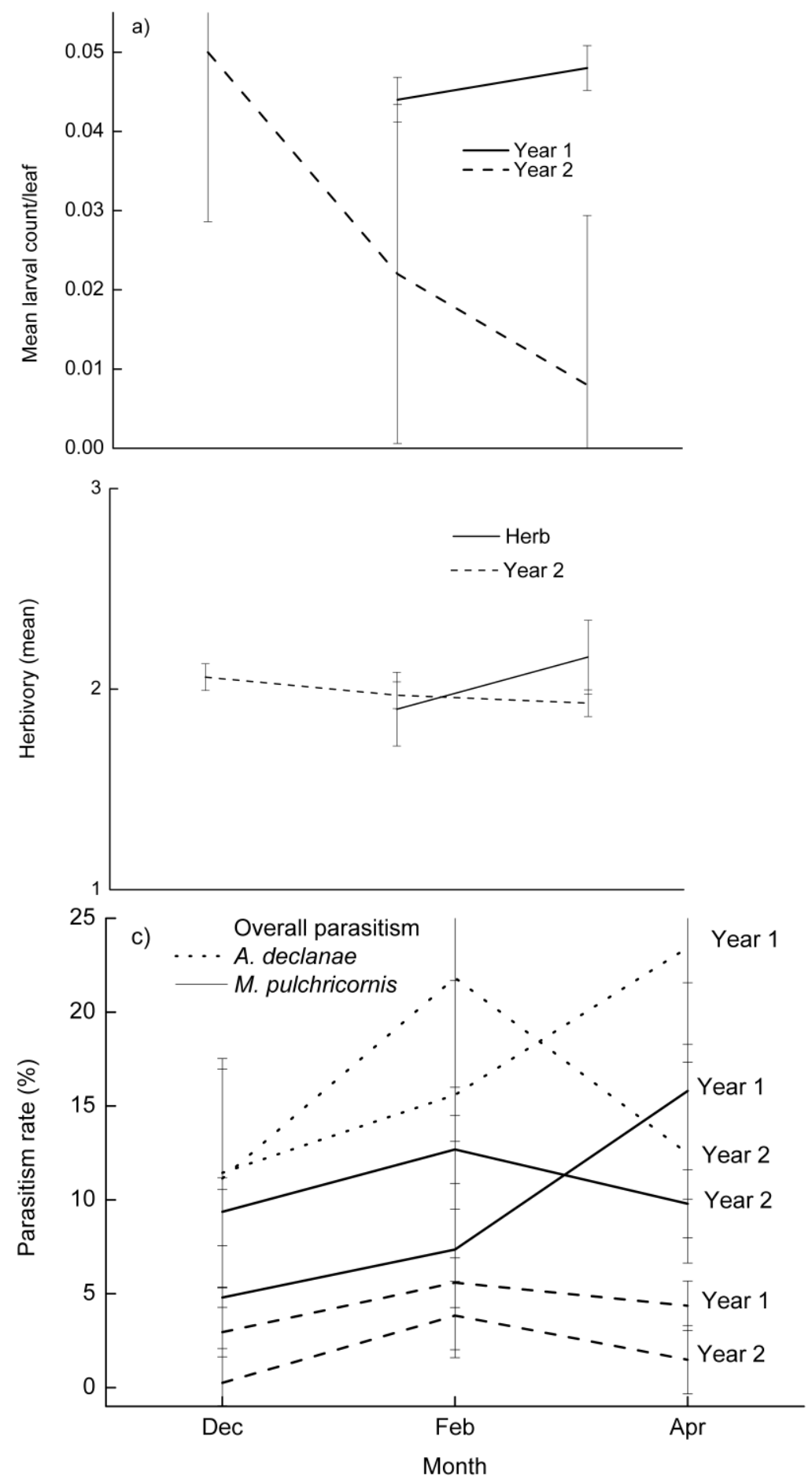

Figure 4.2: a) Mean kawakawa moth abundance per kawakawa leaf; b) mean kawakawa tree herbivory low (1), medium (2) and high (3) herbivory; and c) parasitism rate for A. declanae and M. pulchricornis and for overall parasitism summarised over two southern hemisphere summer periods in 2002/2003 and $2003 / 2004$. 
Table 4.2: Summary of variables and their abbreviations for each level used in this study. For example, LARCOL (larvae reared) is the mean number of larvae reared per plant within each plot.

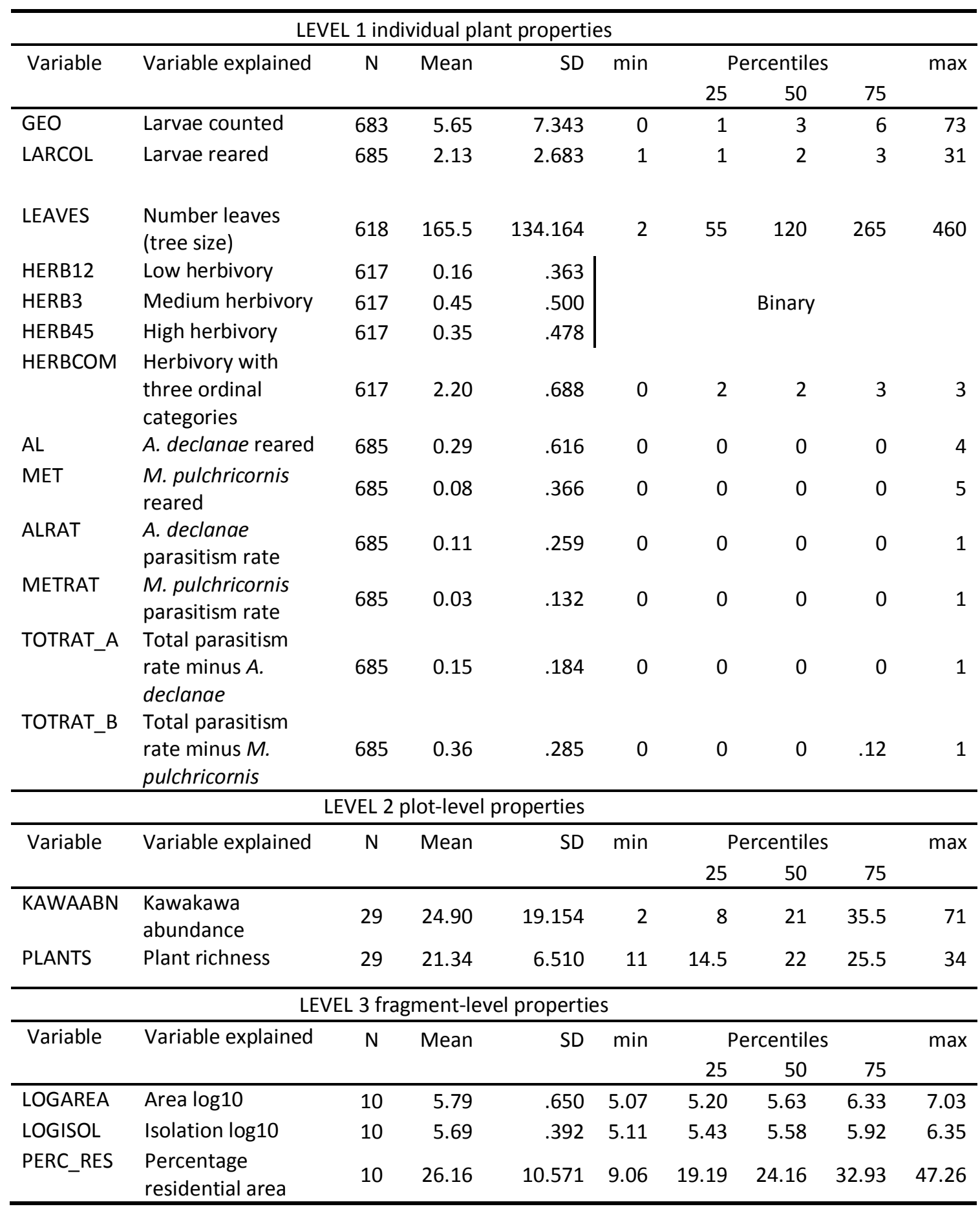

Due to missing data for larval counts and herbivory for December 2002, the analysis of this study includes 685 samples from the time period, February and April 2003 and 
December, February, and April 2003/2004. These samples included 3857 counted larvae with a mean of 5.65 larvae per tree (Fig. 4.2) and 1759 reared larvae with 196 larvae parasitised by A. declanae, 54 larvae by $M$. pulchricornis and 49 larvae by a combination of parasitoids. The mean herbivory per tree was in the 'low herbivory' category (Fig 4.2) and tree size ranged from $2-460$ leaves.

The variables used in this study, their median, range and quartiles are summarised in Table 4.2. Correlations between covariates at level 1 were generally weak but were statistically significant, between larval abundance and low and high herbivory as well as tree size $(\mathrm{P}<0.01)$ (Table 4.3). Correlations between kawakawa abundance and plant richness were non-significant $(\mathrm{P}>0.05)$. Area and isolation were highly correlated $(\mathrm{r}=$ $0.878, \mathrm{P}<0.01)$, but we report results for both because responses vary to these two level 3 predictors (Table 4.4 ).

Table 4.3: Pearson's correlation coefficients between relevant covariates at the individual tree level from $\mathrm{N}(561-685)$ trees. *P $<0.05$ level (2-tailed); **P $<0.01$ (2-tailed).

\begin{tabular}{lccccc}
\hline & GEO & LEAVES & HERB12 & HERB3 & HERB45 \\
\hline LEAVES & $0.376^{* *}$ & & & & \\
HERB12 & $-0.131^{* *}$ & -0.040 & & & \\
HERB3 & -0.074 & $0.103^{*}$ & & & \\
HERB45 & $0.178^{* *}$ & -0.077 & & & \\
TOTRAT_A & 0.019 & 0.060 & -0.036 & 0.069 & -0.044 \\
TOTRAT_B & 0.023 & 0.078 & -0.037 & 0.032 & -0.006 \\
ALRATE & 0.024 & 0.074 & & & \\
METRATE & 0.023 & 0.060 & & & \\
\hline
\end{tabular}


Table 4.4: Pearson's correlation coefficients between plot level covatiates, $\mathrm{N}=29$; and fragment level covariates, $\mathrm{N}=10 ; * * \mathrm{P}<0.01$ (2-tailed).

\begin{tabular}{cccccc}
\hline \multicolumn{2}{c}{ Plot level } & & \multicolumn{3}{c}{ Fragment level } \\
\cline { 1 - 2 } \cline { 5 - 6 } PLANTS & KAWAABN & & & LOG_AREA & LOG_ISOL \\
& -0.194 & & LOG_ISOL & $0.878^{* *}$ & \\
& & & PERC_RES & -0.347 & -0.240 \\
\hline
\end{tabular}

Table 4.5: Proportion of the total variation $(\rho)$ accounted for by the variation of the responses in parasitism of A. declanae and M. pulchricornis and final estimation of fixed effects of the unconditional three-level model $(\mathrm{N}=685)$. For levels 2 and 3 , the variance components $\left(\sigma_{\text {plots }}^{2}\right.$ and $\sigma_{\text {fragments }}^{2}$ are tested for differences from zero; chisquare tests are given for the degrees of freedom (d.f.) shown with probability $P$.

\begin{tabular}{lcc}
\hline \multicolumn{3}{c}{ Level 1 variance components } \\
\hline$\sigma_{\text {plants }}^{2}$ & A. declanae & M. pulchricornis \\
$\rho_{\text {plants }}$ & 0.992 & 0.476 \\
\hline \multicolumn{3}{c}{ Level 2 variance components } \\
\hline$\sigma_{\text {plots }}^{2}$ & 0.248 & 0.155 \\
d.f. & 19 & 1.641 \\
$\chi_{\text {plots }}^{2}$ & 44.580 & 19 \\
$P_{\text {plots }}$ & 0.001 & 58.623 \\
$\rho_{\text {plots }}$ & 0.162 & 0.000 \\
\hline \multicolumn{3}{c}{ Level 3 variance components } \\
\hline$\sigma_{\text {fragments }}^{2}$ & 0.289 & 0.535 \\
d.f. & 9 & 0.951 \\
$\chi_{\text {fragments }}^{2}$ & 27.711 & 9 \\
$P_{\text {fragments }}$ & 0.001 & 21.834 \\
$\rho_{\text {fragments }}$ & 0.189 & 0.010 \\
\hline
\end{tabular}




\subsubsection{Parasitism}

The algorithm for each model converged in fewer than 15 iterations. The coefficients estimated in the unconditional model were all statistically significant (Table 4.5), indicating sufficient variation in parasitism by $A$. declanae and $M$. pulchricornis at the plot and fragment level to justify the introduction of the level covariates into each model.

\subsubsection{Aleiodes declanae}

The partitioning of variation for the unconditional model showed that $65 \%$ of the variation occurred at the individual plant level within plots (Table 4.5). After sequential introduction and deletion of the predictors, as explained above, the final mixed regression model is given below (eqn. 4.2). The model at each level for A. declanae is summarised in Appendix 4.3, Table 4.3.1.

$$
\begin{array}{cc}
\eta_{i j k}=\gamma_{000}+\gamma_{001} * \text { LOGAREA }_{k}+\gamma_{002} * \text { LOGISOL }_{k}+\gamma_{100} * \text { LEAV }_{i j k}+\gamma_{200} * \text { TOTRAT_A } & \\
r_{0 j k}+u_{00 k}+e_{i j k} & \text { eqn. } 4.2
\end{array}
$$

Where $\eta_{i j k}$ is the probability of a larva being parasitised by A. declanae on the $i$ th plant of the $j$ th plot of the $k$ th fragment; $r_{0 j k}$ represents a plot-level error term, $u_{00 k}$ a fragment level error term and $e_{i j k}$ an individual-level error term.

The final unit-specified as well as the population-average model (Table 4.6) suggest that individual tree size expressed as the number of leaves per tree, may negatively affect the probability of a larvae being parasitised $(0.05<\mathrm{P}<0.1)$. The parasitism of larvae by other species of parasitoids negatively influenced parasitism by A. declanae $(\mathrm{P}<0.05)$ indicating that the fewer larvae there are available to be parasitised, the less likely $A$. 
declanae might be able to find a suitable host. At the fragment level, an increase in isolation was significantly related to the likelihood of parasitism by A. declanae ( $\mathrm{P}<$ 0.05). Parasitism by this parasitoid was highest on small trees with few other parasitoids present (Figure 4.3). The abundance of geometrid larvae and herbivory at the tree level, the abundance of kawakawa and plant richness at the plot level, and area as well as percentage of residential area at the fragment level, all appeared to have no influence on the likelihood of a kawakawa moth larva being parasitised (all P > 0.1) (Appendix 4.4).

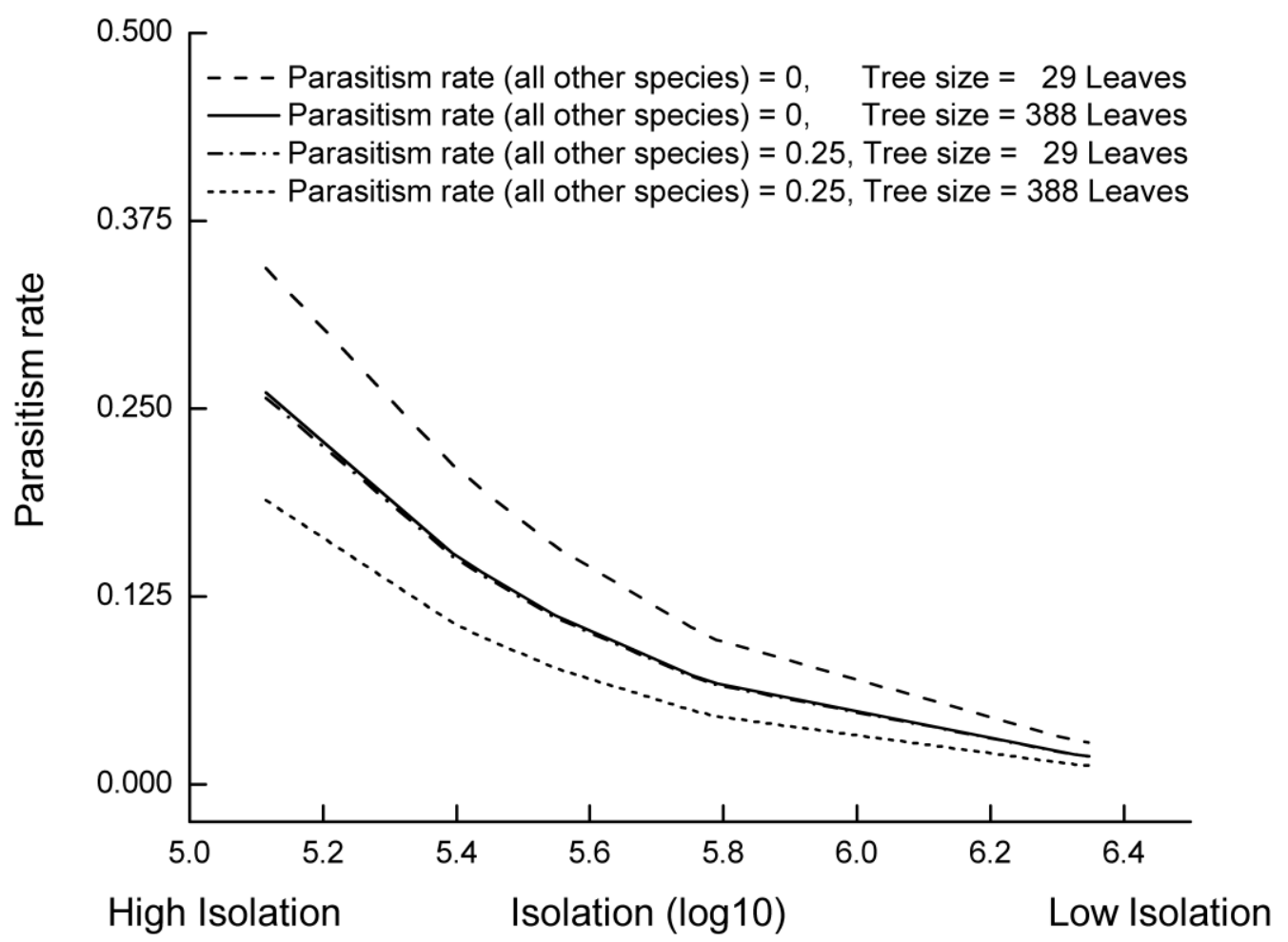

Figure 4.3: Parasitism rate by $A$. declanae as a function of fragment isolation (index). The probability of a larva being parasitised by A. declanae is in relation to the upper and lower quartiles respectively for parasitism by A. declanae at: an average of zero parasitism rate by all other parasitoids on small tress (dashed line) and large trees (solid line); an average of 0.25 parasitism rate by all other parasitoids on small tress (dash-dotted line) and large trees (dotted line). 
Table 4.6: Parameter estimates for the final fixed effect three-level regression model for the $\log$ likelihood of parasitism by A. declanae. Runtime deletion reduced the number of available units to $\mathrm{N}=618$.

\begin{tabular}{|c|c|c|c|c|c|}
\hline Parameter & Estimate & $\mathrm{SE}$ & T-ratio & d.f. & $P$-value \\
\hline$\sigma_{\text {plants }}^{2}$ & 0.946 & 0.055 & & & \\
\hline$\sigma_{\text {plots }}^{2}$ & 0.191 & 0.128 & & & \\
\hline$\sigma_{\text {fragments }}^{2}$ & 0.083 & 0.110 & & & \\
\hline \multicolumn{6}{|c|}{ Unit-specified model } \\
\hline \multicolumn{6}{|l|}{ Level 1} \\
\hline$\gamma_{\text {Leaves }}$ & 0.001 & 0.001 & 1.862 & 613 & 0.063 \\
\hline$\gamma_{\text {Totrat_Al }}$ & -1.673 & 0.800 & -2.091 & 613 & 0.037 \\
\hline \multicolumn{6}{|l|}{ Level 3} \\
\hline$\gamma_{\text {Area }}$ & 0.678 & 0.507 & 1.337 & 7 & 0.223 \\
\hline$\gamma_{\text {Isolation }}$ & -2.355 & 0.850 & -2.772 & 7 & 0.028 \\
\hline \multicolumn{6}{|c|}{ Population-average model } \\
\hline$\sigma_{\text {plants }}^{2}$ & 1.002 & 0.058 & & & \\
\hline \multicolumn{6}{|l|}{ Level 1} \\
\hline$\gamma_{\text {Leaves }}$ & 0.001 & 0.001 & 1.816 & 613 & 0.069 \\
\hline$\gamma_{\text {Totrat_Al }}$ & -1.655 & 0.777 & -2.129 & 613 & 0.033 \\
\hline \multicolumn{6}{|l|}{ Level 3} \\
\hline$\gamma_{\text {Area }}$ & 0.689 & 0.511 & 1.348 & 7 & 0.220 \\
\hline$\gamma_{\text {Isolation }}$ & -2.330 & 0.832 & -2.801 & 7 & 0.027 \\
\hline
\end{tabular}

\subsubsection{Meteorus pulchricornis}

The unconditional model showed that over $50 \%$ of the variation exists between plots and over $30 \%$ between fragments (Table 4.7 ). The predictors summarised in the final mixed regression model (eqn. 4.3) for M. pulchricornis where kawakawa moth larval abundance (GEO) at the level 1, plant richness (PLANTS) at level 2, and fragment area 
(LOGAREA) and isolation (LOGISOL) at level 3. The models at each level for $M$. pulchricornis are summarised in Appendix 4.3, Table 4.3.1.

$\eta_{i j k}=\gamma_{000}+\gamma_{001} *$ LOGAREA $_{k}+\gamma_{002} * \mathrm{LOGISOL}_{k}+\gamma_{010} * \mathrm{PLANTS}_{j k}+\gamma_{100} * \mathrm{GEO}_{i j k}+r_{0 j k}+$ $u_{00 k}+e_{i j k}$ eqn. 4.3

Where $\eta_{i j k}$ is the probability of a larva being parasitised by $M$. pulchricornis on the $i$ th plant of the $j$ th plot of the $k$ th fragment; $r_{0 j k}$ represents a plot level error term, $u_{00 k}$ a fragment level error term and $e_{i j k}$ an individual level error term. Kawakawa moth larval abundance alone was significantly positively related to parasitism by the parasitoid $M$. pulchricornis at the plant level across plots as well as across the entire population $(\mathrm{P}<$ 0.01), whereas at the plot level plant richness negatively influenced parasitism $(\mathrm{P}<0.05)$. The latter appeared to be less influential at the population level $(\mathrm{P}>0.05)$ (Table 4.7, Figure 4.4). In the initial level 1 model herbivory appeared to have a positive effect (HERB3, $\mathrm{P}=0.051$ and HERB45, $\mathrm{P}=0.117$ ) and overall parasitism a negative effect on parasitism by $M$. pulchricornis $(\mathrm{P}=0.038)$. This influence was largely reduced after introduction of kawakawa abundance and plant richness at the level 2 model $(\mathrm{P}>0.10)$. The non-significant response to herbivory and overall parasitism did not change even after the exclusion of the non-significant effect of kawakawa abundance. In addition, these two-level 2 analyses did not converge until after 98006 iterations: therefore herbivory as well as overall parasitism were treated as non-informative and were excluded from the subsequent level 3 model. In all other models the algorithms converged in fewer than 24 iterations. Neither overall parasitism nor herbivory at the plant level, nor kawakawa abundance at the plot level, and none of the fragment level predictors had any significant influence on this parasitoid $(\mathrm{P}>0.1)$ (Appendix 4.5). 


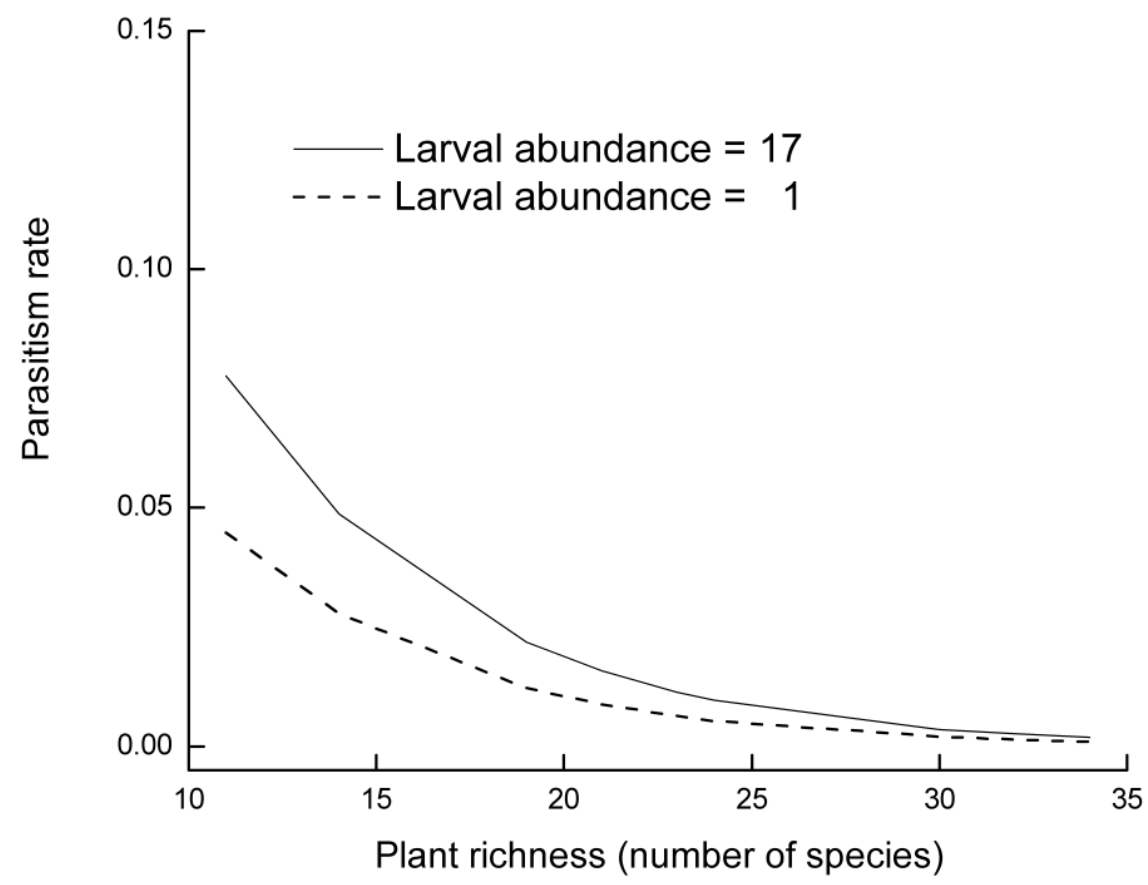

Figure 4.4: Parasitism rate by $M$. pulchricornis as a function of plant richness. The probability of a larva being parasitised by $M$. pulchricornis is in relation to the upper and lower quartiles respectively for parasitism by M. pulchricornis at an average of 17 larvae C. scriptaria per tree (solid line) and at an average of 1 C. scriptaria larva per tree (dashed line). 
Table 4.7: Parameter estimates for the final fixed effects three-level regression model for the log likelihood of parasitism by M. pulchricornis $(\mathrm{N}$ $=683$ ).

\begin{tabular}{|c|c|c|c|c|c|}
\hline Parameter & Estimate & $\mathrm{SE}$ & T-ratio & d.f. & $P$-value \\
\hline$\sigma_{\text {plants }}^{2}$ & 0.494 & 0.027 & & & \\
\hline$\sigma_{\text {plots }}^{2}$ & 2.078 & 0.943 & & & \\
\hline$\sigma_{\text {fragments }}^{2}$ & 0.062 & 0.581 & & & \\
\hline \multicolumn{6}{|c|}{ Unit-specified model } \\
\hline \multicolumn{6}{|l|}{ Level 1} \\
\hline$\gamma_{\mathrm{Geo}}$ & 0.037 & 0.012 & 3.192 & 678 & 0.002 \\
\hline \multicolumn{6}{|l|}{ Level 2} \\
\hline$\gamma_{\text {Plants }}$ & -0.166 & 0.068 & -2.423 & 27 & 0.023 \\
\hline \multicolumn{6}{|l|}{ Level 3} \\
\hline$\gamma_{\text {Area }}$ & -0.892 & 1.308 & -0.682 & 7 & 0.517 \\
\hline$\gamma_{\text {Isolation }}$ & 0.925 & 1.867 & 0.496 & 7 & 0.635 \\
\hline \multicolumn{6}{|c|}{ Population-average model } \\
\hline$\sigma_{\text {plants }}^{2}$ & 0.730 & 0.040 & & & \\
\hline \multicolumn{6}{|l|}{ Level 1} \\
\hline$\gamma_{\mathrm{Geo}}$ & 0.031 & 0.010 & 3.227 & 678 & 0.002 \\
\hline \multicolumn{6}{|l|}{ Level-2 } \\
\hline$\gamma_{\text {Plants }}$ & -0.112 & 0.059 & -1.899 & 27 & 0.068 \\
\hline \multicolumn{6}{|l|}{ Level 3} \\
\hline$\gamma_{\text {Area }}$ & -1.183 & 1.141 & -1.037 & 7 & 0.335 \\
\hline$\gamma_{\text {Isolation }}$ & 2.054 & 1.698 & 1.210 & 7 & 0.266 \\
\hline
\end{tabular}

\subsubsection{Herbivory}

The partitioning of variation for the unconditional model showed that about $51 \%$ of the variation in herbivory occurred at the plot level and $<1 \%$ at the fragment level. Subsequent models with inclusions of predictors were found not to converge. Due to the extremely low variation at the third level and the convergence problems the third level 
was removed from the model and herbivory was analysed with a two-level model. (The inclusion of level 3 predictors was not found to be more or less informative than a twolevel model. Therefore only results for the more parsimonious two-level model are reported in this study). The models for herbivory are summarised for each level in Appendix 4.3, Table 4.3.2. The final mixed regression model with the predictors retained after excluding predictors with $\mathrm{P}>0.1$ is summarised as:

$\eta_{i j}=\gamma_{00}+\gamma_{01} * \mathrm{KAWAABUN}_{j}+\gamma_{10} * \mathrm{GEO}_{i j}+\gamma_{20} * \mathrm{LEAVES}_{j j}+\delta_{(2)}+u_{0 j} \quad$ eqn. 4.4

Where $\eta_{i j k}$ is the probability of herbivory on the $i$ th plant of the $j$ th plot; $\delta_{(2)}$ is the difference in log-odds between the two cumulative logits for the herbivory categories $m$ $(m=1)$ and $m-1(m=2)$, and $u_{0 j}$ a plot level error term. In all two-level models the algorithm converged in fewer than 15 iterations. The results summarised in Table 4.8 indicate that within plots, abundance of kawakawa moth larvae $\left(\gamma_{\mathrm{Geo}}\right)$ had a strong positive effect on levels of herbivory $(\mathrm{P}<0.01)$, as one might expect, while larger trees suffered significantly lower levels of herbivory $(\mathrm{P}<0.05)$. Increasing kawakawa abundance increases the incidence of herbivory at a relatively constant rate $\left(\gamma_{\text {Kawaabun }}\right)(\mathrm{P}$ $<0.05)$. The interaction between these three effects is summarised in Figure 4.5. The highest herbivory coincides with high larval abundance on small trees, whereas the lowest herbivory corresponds with low larval abundance on large trees. These relationships are influenced by the per leaf larval abundances and herbivory, which are strongly correlated and are higher on smaller trees than larger trees $(\mathrm{P}<0.000)$ (Figure 4.6). At the individual tree level, parasitism by neither A. declanae nor M. pulchricornis significantly influenced herbivory $(\mathrm{P}>0.1)$, nor did herbivory change significantly with a change in plant richness at the plot level $(\mathrm{P}>0.1)$ (Appendix 4.6). 


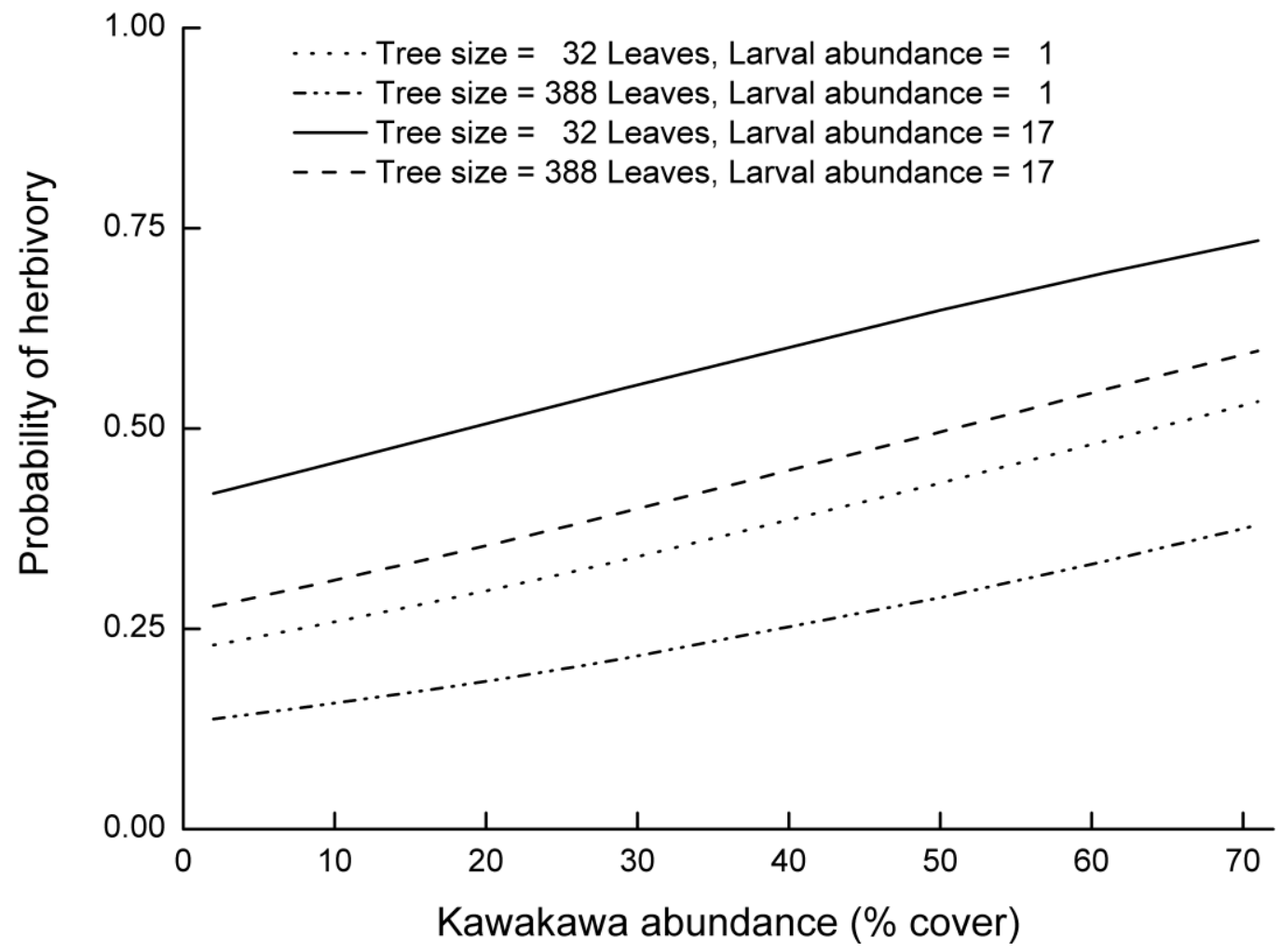

Figure 4.5: Herbivory as a function of kawakawa abundance. The probability of herbivory is shown in relation to the upper and lower quartiles respectively for the average abundance of one kawakawa moth on small trees (dotted line) and large trees (dashed-dotted line) and for the average abundance of 17 kawakawa moths on small trees (solid line) and large trees (dashed line).

Table 4.8: Parameter estimates for the final fixed effects two-level regression model with robust standard errors for herbivory $(\mathrm{N}=617)$.

\begin{tabular}{|c|c|c|c|c|c|}
\hline Parameter & Estimate & SE & T-ratio & d.f. & $P$-value \\
\hline$\sigma_{\text {plants }}^{2}$ & constant & & & & \\
\hline$\sigma_{\text {plots }}^{2}$ & 0.702 & & & & \\
\hline \multicolumn{6}{|l|}{ Level 1} \\
\hline$\gamma_{\mathrm{Geo}}$ & 0.057 & 0.017 & 3.350 & 555 & 0.001 \\
\hline$\gamma_{\text {Leaves }}$ & -0.002 & 0.001 & -2.185 & 555 & 0.029 \\
\hline \multicolumn{6}{|l|}{ Level 2} \\
\hline$\gamma_{\text {Kawaabun }}$ & 0.019 & 0.009 & 2.194 & 27 & 0.037 \\
\hline
\end{tabular}




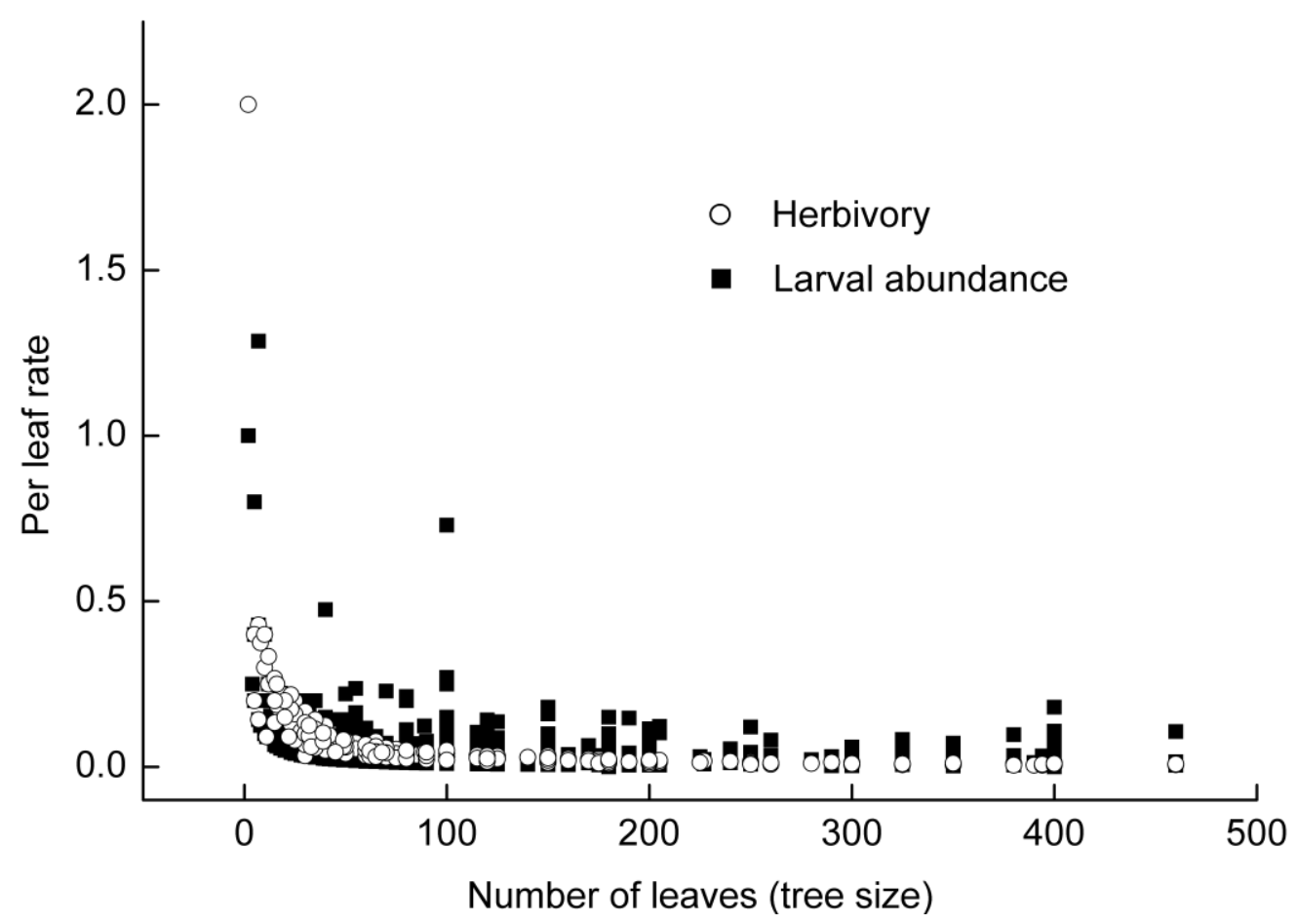

Figure 4.6: Relationship between number of leaves per tree and per leaf rate for: larval abundance (Pearson $r=-0.288^{* *}, \mathrm{~N}=617$ ) and herbivory (Pearson $r=0.374 * *, \mathrm{~N}=$ 561). Per leaf herbivory is significantly dependent on per leaf larval abundance $(R=$ $0.869 * *, \mathrm{SE}=0.041, t=21.264) . * * \mathrm{P}<0.000$ (2-tailed).

\subsection{Discussion}

\subsubsection{Hierarchy of fragment, plot and plant level influences}

Isolation was the only property at the scale of fragments to significantly influence parasitism of $C$. scriptaria by the braconid parasitoid A. declanae. The likelihood of a larva being parasitised by this parasitoid increased with increasing isolation. In contrast, parasitism by $M$. pulchricornis and herbivory were not significantly related to any of the fragment level properties. These responses support our first hypothesis that parasitism by individual parasitoids and herbivory show different responses to fragmentation. At the level of plots, parasitism by the braconid parasitoid $M$. pulchricornis declined with increasing plant richness, herbivory was dependent on kawakawa abundance, and $A$. 
declanae showed no significant responses to plant richness or kawakawa abundance, supporting our second hypothesis of different responses at the plot level. At the level of individual trees, A. declanae responded significantly to tree size and the frequency of parasitism by all other parasitoids; $M$. pulchricornis was affected by the abundance of C. scriptaria larvae, while levels of herbivory were significantly related to tree size and larval abundance. The degree of herbivory on the plant had no influence on parasitism by either parasitoid. Our study therefore showed that parasitoid and herbivore abundances respond individually to a hierarchy of influences, operating at different scales from the location of the habitat fragment within the landscape, via habitat quality, down to characteristics of the individual plant.

\subsubsection{Effects of isolation on parasitism rates and herbivory}

Herbivore and parasitoid responses to fragmentation have been found to be consistently inconsistent (Hunter 2002; van Nouhuys 2005). Here we found different responses by the two parasitoids A. declanae and $M$. pulchricornis. Parasitism rates by both parasitoids as well as the degree of herbivory did not confirm that increasing isolation negatively influences parasitoids and herbivores, with parasitoids responding more strongly than their herbivorous hosts, (Kruess and Tscharntke 1994; Kruess and Tscharntke 2000b). However, increased parasitism rates by A. declanae and no response by $M$. pulchricornis are in accordance with similar findings of differing responses by parasitoids to habitat fragmentation (Roland and Taylor 1997; Doak 2000; Roland 2000; Roth et al. 2006). Likewise, in our study parasitism rates by two Aleiodes species were found to be higher in smaller and isolated patches (Doak 2000; Roland 2000). It is interesting to note that we found a third species in this genus namely A. declanae being significantly negatively affected by reduction in isolation. Since a negative response to increasing isolation has 
been found in parasitic fly species as well as in parasitic wasp species, these parasitoids may have common attributes causing such a response. These attributes could be similarities in host searching behaviour, whether parasitoids are specialists or generalists, or attributes that are related to the parasitoid's host's food plant range or availability.

Higher parasitism rates in isolated fragments were explained by parasitoids following an optimal foraging strategy (Roland and Taylor 1997; Doak 2000; Roth et al. 2006). Time and energy invested in travelling to an isolated patch might determine search time and oviposition effort within the patch. This has been shown to be the case by a small egg parasitoid (Cronin and Strong 1999; Cronin 2003). If movement-capability and a related foraging strategy would determine parasitism rates by A. declanae then we would expect parasitism rates by this parasitoid to be higher in more isolated fragments. However, parasitism rates by $M$. pulchricornis were not determined by isolation and we would expect dispersal abilities to be very similar between $A$. declanae and $M$. pulchricornis because they are about equal size. Therefore movement-capability might not determine the parasitism rates of $A$. declanae observed within this study.

\subsubsection{Responses to forest edges and landscape matrix}

Roth et al. (2006) also observed elevated parasitism rates at fragment edges. A parasitoid might be less likely to leave a forest fragment than an equivalent area of continuous forest (Roth et al. 2006). As far as we can ascertain A. declanae is primarily a forest dweller, whereas $M$. declanae has been found primarily in environments modified by humans (Berry and Walker 2004). This would suggest that M. pulchricornis is more likely to be in high abundance in small isolated fragments which have a high edge to area ratio. This might explain the different responses between the two parasitoids to isolation. 
However, this does not quite explain what determines differences in parasitism of the two parasitoids or what determines search behaviour by A. declanae.

\subsubsection{Aleiodes declanae responses to host densities}

Increased parasitism in isolated patches could be driven by increased host densities in these fragments. For example, consistently higher prey densities of the aphid Uroleucon nigrotuberculatum (Olive) (Homoptera: Aphidae) were found in patchy environments, and determined the aggregation of its predator the ladybird beetle Coccinella septempunctata Linnaeus (Coccinellidae: Coleoptera) (Kareiva 1987). In our study, however, herbivory, which was positively related to kawakawa larval abundances, did not seem to play an important factor on parasitism rates by A. declanae. This finding is in line with other studies (Doak 2000; Cronin 2003; Esch et al. 2005). Esch et al. (2005) for example, showed neither dispersal rate nor the percentage parasitism by the specialist parasitoid Cotesia (Apanteles) popularis L. (Braconidae) was affected by larval densities of its herbivorous host Tyria jacobaeae L. (Lepidoptera: Arctiidae).

\subsubsection{Influence of larval densities on $M$. pulchricornis and influences of plant species} richness

In contrast, parasitism by $M$. pulchricornis was higher where host larval densities were high and in plots with relatively low plant richness. The responses to kawakawa moth larval densities appear to be less pronounced in plots with higher plant richness, indicated by the converging lines in Figure 4.4. This response may indicate the generalist nature of this parasitoid displaying frequency-dependent prey searching behaviour. We have shown a significant positive relationship between plant richness and area and plant richness and isolation (Chapter 2, Table 2.2). Because, M. pulchricornis is the second most common 
parasitoid reared in this study, there could be significant competition with A. declanae in isolated fragments that show reduced plant richness. Meteorus pulchricornis is an exotic species widely distributed throughout Western Europe, North Africa, China, and Japan, and has been accidentally introduced into New Zealand (Berry 1997). Presently, $M$. pulchricornis is known to parasitise around 21 host species from eight families with the potential of parasitizing many more species with the potential to displace many endemic parasitoid species (Berry and Walker 2004).

\subsubsection{Influences of tree size on herbivory and parasitism rates}

Because lower herbivore abundances are frequently found with increasing habitat fragmentation (Kruess and Tscharntke 2000a; Hunter 2002), we would have expected some response in herbivory to at least one of the fragment level elements. Variation in abundance at the fragment level, however, was less than one percent in spite of the kawakawa moth being primarily a forest inhabitant. Larger trees displayed proportionally higher herbivory than smaller trees and $C$. scripataria larval densities were positively correlated with tree size in our study. If optimal foraging would explain elevated parasitism in isolated fragments, then we would expect higher parasitism rates in trees with higher host abundance. Indeed, parasitism by A. declanae was on average higher on smaller trees that displayed high herbivory than on larger trees with a lower herbivory. This difference becomes less influential in less isolated fragments indicated by the converging trend lines in less isolated fragments (Fig. 4.3). In addition, overall parasitism rate and tree size are less effective on the parasitism rates of $A$. declanae in less isolated fragments. Fewer larvae on smaller trees however, may be easier to find because we found the number of larvae per leaf to be higher on smaller trees than on larger trees. Also per leaf herbivory was higher on smaller trees than on larger trees. Even though 
these relationships are relatively weak, this might indicate that $A$. declanae is either more attracted by herbivory or stays longer in trees with higher larval densities. Such a result also indicates that host searching strategies differ between $A$. declanae and $M$. pulchricornis. Meteorus pulchricornis might depend on larval densities in general and $A$. declanae on higher larval per leaf densities causing higher per leaf herbivory. Yet there seems to be a diluting effect of tree size on parasitism by A. declanae in less isolated fragments.

\subsubsection{Info-chemicals}

Aleiodes declanae might use chemical cues released by damaged plants to home in on its host. Kawakawa is known to possess chemical compounds that might attract natural enemies or deter herbivorous insects (Russel and Fenemore 1973; Russel and Lane 1993; Reddy and Guerrero 2004). The kawakawa compounds are thought to be antifeedants and are even considered to be insecticidal (Russel and Fenemore 1973; Russel and Lane 1993); however, the compounds were not found to deter $C$. scriptaria from feeding off kawakawa (Hodge et al. 2000). Such herbivore-induced defence responses are also known to cause the release of volatiles that are used by parasitoids to locate their hosts (Turlings et al. 2002; Reddy and Guerrero 2004). Since A. declanae is a specialist parasitoid it might well be using such cues to find its hosts. Higher herbivory on smaller trees might mean higher concentrations of such volatiles released, resulting in higher parasitism rates by $A$. declanae in smaller trees than in larger trees with lower herbivory. However, A. declanae has been reared also from Declana and Selidosema larvae (both Geometridae) collected from rewarewa trees (Knightia excelsa R. Br.: Proteaceae), of which we found no records in regards to this plant containing volatiles. Furthermore, rewarewa does not appear, at least to humans, to have strong-smelling properties, which 
might indicate the absence of such defences in rewarewa. Interestingly, Oppenheim and Gould (2002) found that parasitoids were most attracted by plants that were infested by generalist herbivores feeding on their most preferred host plant in comparison to plants that were infested by a specialist herbivore.

\subsubsection{Parthenogenesis}

The endemic A. declanae and the exotic M. pulchricornis are both multi-voltine parasitoids with several generations during the summer months. One large difference between the two species is that for $A$. declanae we reared both females and males (females are arrhenotokous), whereas we only reared females without males of $M$. pulchricornis (females are thelytokus). The latter is bi-parental in its European home range, but only females are known in New Zealand (Berry and Walker 2004). This difference between the two species leads to the interesting and potential research question of whether the difference between the two species in their reproductive mode has any affect on parasitism rates influenced by isolation as we observed in our study. Nothing is known about the mating biology or foraging strategy of $A$. declanae that would indicate a predictable response to fragmentation effects. An interesting study by Thiel et al. (2006) found such differences to affect foraging strategies in the parasitic wasp Venturia canescens (Gravenhorst) (Hymenoptera: Ichneumonidae) in response to habitat quality. This wasp has the arrhenotokous as well as the obligatory thelytokous reproductive mode. Increased patch encounter, which we might view as being equivalent to connected habitats, resulted in decreased parasitism by arrhenotokous females, whereas thelytokous (e.g. parthenogenetic) types were found to maximise their parasitism efficiency. This behaviour by the arrhenotokous females might lead to a spreading of offspring reducing the risk of sib-mating (Thiel et al. 2006). Perhaps such a mechanism is operating and 
influences differential oviposition behaviour in habitats with differing degrees of isolation for A. declanae.

\subsubsection{Implications for invasive species biology and habitat fragmentation}

Given the different effects of habitat fragmentation in this study on an endemic, specialist and an exotic, generalist, parthenogenetic parasitoid future studies and experiments might reveal mechanisms operating on these differences. Displacement of endemic organisms by exotic invaders has been demonstrated many times over (Mooney and Cleland 2001). The potential displacement of endemic parasitoids by $M$. pulchricornis through competitive sharing of hosts was discussed by Berry and Walker (2004). If lower parasitism rates in less isolated fragments mean spreading of offspring to avoid inbreeding as has been suggested for arrhenotokous females (Thiel et al. 2006) then the response to isolation by $A$. declanae can be explained by the energy invested in travelling to an isolated fragment maximising the number of offspring but at the same time increasing the risk of inbreeding. If inbreeding poses a risk for population viability for $A$. declanae, then $M$. pulchricornis might place additional strain on those populations in a landscape with isolated habitat fragments. Habitat fragmentation and species invasions are not independent of each other and both are driving native species decline (Didham et al. 2007). Because M. pulchricornis is a generalist invader in New Zealand, similar interactions might be found with a variety of native and introduced parasitoids that have female/male populations. Persistence of native parasitic wasp populations that have both males and females and are specialist parasitoids might therefore be especially at risk from loss of habitat as well as from introduced generalist parasitoids that only have females. This risk from introduced parasitoids should therefore be considered in any risk management plans considering invasive species as well as the deliberate introduction of 
parasitoids for bio-control. Additionally, future experimental and field studies might show that elevated parasitism rates in relation to habitat fragmentation could prove to be an important indicator of habitat quality. This could become a valuable tool in general as well as providing directions for urban planners for conservation management and the maintenance of communities depending on each trophic level.

\subsubsection{Summary}

With this study we have shown that the two main parasitoids reared from C. scriptaria respond differently to habitat fragmentation at the landscape level. This result is in agreement with Chapter 2, where individual parasitoids were shown to respond in different ways to forest fragmentation. But also plot level properties as well as properties at the individual plant level influenced parasitism significantly. Our study is also in agreement with other studies that showed elevated parasitism rates in more isolated fragments. From this we conclude that it is not possible to generalise distribution or parasitism patterns at the higher trophic levels in response to habitat fragmentation from the trophic level hypothesis, and species responses to fragmentation might be dependent on a species' biology and/or a variety of environmental factors.

\subsection{Acknowledgements}

We would like to thank the bug-club members of the School of Biological Sciences, Victoria University of Wellington for valuable comments on this manuscript and Adrian Pike, John Brightwell, Megan Sarty, for the assistance in rearing insects. We are grateful to Cleland Wallace for surveying the plant communities and to Clare Salmond for statistical advice. We also thank the different park managements for the permission to 
establish plots in their native bush fragments. This research was funded by the $21 \mathrm{st}$ Anniversary Fund from the Entomological Society of NZ and the Victoria University of Wellington, NZ.

\section{Literature cited}

Allen, R. B. (1992) RECCE - an inventory method for describing New Zealand vegetation. Forest Research Institute Bulletin (ed. F. R. Institute). Christchurch, N. Z.

Amarasekare, P. (2000a) Coexistence of competing parasitoids on a patchily distributed host: Local vs. spatial mechanisms. Ecology, 81, 1286-1296.

Amarasekare, P. (2000b) Spatial dynamics in a host-multiparasitoid community. Journal of Animal Ecology, 69, 201-213.

Anadon, J. D., Gimenez, A., Martinez, M., Palazon, J. A. \& Esteve, M. A. (2007) Assessing changes in habitat quality due to land use changes in the spur-thighed tortoise Testudo graeca using hierarchical predictive habitat models. Diversity and Distributions, 13, 324-331.

Beever, E. A., Swihart, R. K. \& Bestelmeyer, B. T. (2006) Linking the concept of scale to studies of biological diversity: evolving approaches and tools. Diversity and Distributions, 12, 229-235.

Berry, J. A. (1997) Meteorus pulchricornis Wesmael (Hymenoptera: Braconidae: Euphorinae), a new record for New Zealand. New Zealand Entomologist, 20, 45-48.

Berry, J. A. \& Walker, G. P. (2004) Meteorus pulchricornis (Wesmael) (Hymenoptera : Braconidae : Euphorinae): an exotic polyphagous parasitoid in New Zealand. New Zealand Journal of Zoology, 31, 33-44. 
Cappuccino, N., Lavertu, D., Bergeron, Y. \& Regniere, J. (1998) Spruce budworm impact, abundance and parasitism rate in a patchy landscape. Oecologia, 114, 236242.

Carvalho, K. S. \& Vasconcelos, H. L. (1999) Forest fragmentation in central Amazonia and its effects on litter-dwelling ants. Biological Conservation, 91, 151-157.

Chust, G., Garbin, L. \& Pujade-Villar, J. (2007) Gall wasps and their parasitoids in cork oak fragmented forests. Ecological Entomology, 32, 82-91.

Clark, J. S., Dietze, M., Chakraborty, S., Agarwal, P. K., Ibanez, I., LaDeau, S. \& Wolosin, M. (2007) Resolving the biodiversity paradox. Ecology Letters, 10, 647659.

Cronin, J. T. (2003) Patch structure, oviposition behavior, and the distribution of parasitism risk. Ecological Monographs, 73, 283-300.

Cronin, J. T. \& Strong, D. R. (1999) Dispersal-Dependent Oviposition and the Aggregation of Parasitism. The American Naturalist, 154, 23-36.

Didham, R. K., Hammond, P. M., Lawton, J. H., Eggleton, P. \& Stork, N. E. (1998) Beetle species responses to tropical forest fragmentation. Ecological Monographs, 68 , 295-323.

Didham, R. K., Tylianakis, J. M., Gemmell, N. J., Rand, T. A. \& Ewers, R. M. (2007) Interactive effects of habitat modification and species invasion on native species decline. Trends in Ecology \& Evolution, 22, 489-496.

Diez, J. M. (2007) Hierarchical patterns of symbiotic orchid germination linked to adult proximity and environmental gradients. Journal of Ecology, 95, 159-170.

Doak, P. (2000) The effects of plant dispersion and prey density on parasitism rates in a naturally patchy habitat. Oecologia, 122, 556-567. 
Esch, S., Klinkhamer, P. G. L. \& van der Meijden, E. (2005) Do distances among host patches and host density affect the distribution of a specialist parasitoid? Oecologia, 146, 218-226.

ESRI (2004) ESRI®ArcMap ${ }^{\mathrm{TM}} 9.0$ Build 560. (ed. ESRI, Redlands, CA, USA.

Fahrig, L. (2003) Effects of habiat fragmentation on biodiversity. Annual Review of Ecology, Evolution, and, 34, 487-515.

Gabites, I. (1993) Wellington's Living Cloak: A Guide to the Natural Plant Communities. Wellington Botanical Society, Wellington.

Gering, J. C. \& Crist, T. O. (2002) The alpha-beta-regional relationship: providing new insights into local-regional patterns of species richness and scale dependence of diversity components. Ecology Letters, 5, 433-444.

Gibb, H. \& Hochuli, D. F. (2002) Habitat fragmentation in an urban environment: large and small fragments support different arthropod assemblages. Biological Conservation, 106, 91-100.

Hanski, I., Kuussaari, M. \& Nieminen, M. (1994) Metapopulation structure and migration in the butterfly Melitaea cinxia. Ecology, 75, 747-762.

Hassell, M. P. (1986) Parasiotids and population regulation. Insect Parasitoids. (ed. J. Waage \& D. Greathead), pp. 201-224. Academic Press, London.

Hawkins, B. A. (1994) Pattern and Process in Host-Parasitoid Interactions. Cambridge University Press, Cambridge.

Henle, K., Lindenmayer, D. B., Margules, C. R., Saunders, D. A. \& Wissel, C. (2004) Species Survival in Fragmented Landscapes: Where are We Now? Biodiversity and Conservation, 13, 1-8. 
Hodge, S., Barron, M. \& Wratten, S. D. (2000) Induced defences in kawakawa (Macropiper excelsum): do caterpillars avoid previous leaf damage? New Zealand Journal of Ecology, 24, 91-95.

Hudson, G. V. (1928) The butterflies and moths of New Zealand. Ferguson and Osborne, New Zealand.

Hunter, M. D. (2002) Landscape structure, habitat fragmentation, and the ecology of insects. Agricultural and Forest Entomology, 4, 159-166.

Kareiva, P. (1987) Habitat Fragmentation and the Stability of Predator Prey Interactions. Nature, 326, 388-390.

Komonen, A., Penttila, R., Lindgren, M. \& Hanski, I. (2000) Forest fragmentation truncates a food chain based on an old-growth forest bracket fungus. Oikos, 90, 119126.

Kristan, W. B. \& Scott, J. M. (2006) Hierarchical models for avian ecologists. Condor, 108, $1-4$.

Kruess, A. \& Tscharntke, T. (1994) Habitat fragmentation, species loss, and biological control. Science, 264, 1581-1584.

Kruess, A. \& Tscharntke, T. (2000a) Effects of habitat fragmentation on plant-insect communities. Interchanges of Insects between Agriculture and surrounding Landscapes. (ed. B. Eckboom, M. Irwin \& Y. Robert), pp. 53-70. Kluwer, Dordrecht.

Kruess, A. \& Tscharntke, T. (2000b) Species richness and parasitism in a fragmented landscape: experiments and field studies with insects on Vicia sepium. Oecologia, 122, 129-137.

Lassau, S. A. \& Hochuli, D. F. (2005) Wasp community responses to habitat complexity in Sydney sandstone forests. Austral Ecology, 30, 179-187. 
McMahon, S. M. \& Diez, J. M. (2007) Scales of association: hierarchical linear models and the measurement of ecological systems. Ecology Letters, 10, 437-452.

Mooney, H. A. \& Cleland, E. E. (2001) The evolutionary impact of invasive species. Proceedings of the National Academy of Sciences of the United States of America, 98, $5446-5451$.

Müller, F. (1992) Hierarchical approaches to ecosystem theory. Ecological Modelling, 63, 215-242.

Munro, V. M. W. (1999) The non-target effects of the introduced parasitoid Trigonospila brevifacies (Hardy) (Diptera: Tachinidae) on the native fauna of New Zealand., Massey University.

Oppenheim, S. J. \& Gould, F. (2002) Is attraction fatal? The effects of herbivore-induced plant volatiles on herbivore parasitism. Ecology, 83, 3416-3425.

Raudenbush, S. W. \& Bryk, A. S. (2002) Hierarchical Linear Models: Applications and Data Analysis Methods, 2 edn. Sage Publications, London.

Raudenbush, S. W., Bryk, A. S. \& Congdon, R. (2000) HLM: Hierarchical linear and nonlinear modeling (Version 6.02). (ed. Scientific Software International, Lincolnwood, IL.

Reddy, G. V. P. \& Guerrero, A. (2004) Interactions of insect pheromones and plant semiochemicals. Trends in Plant Science, 9, 253-261.

Roland, J. (2000) Landscape ecology of parasitism. Parasitoid population biology. (ed. M. E. Hochberg \& A. R. Ives), pp. 83-99. Princeton University Press, Princeton.

Roland, J. \& Taylor, P. D. (1997) Insect parasitoid species respond to forest structure at different spatial scales. Nature, 386, 710-713.

Roth, D., Roland, J. \& Roslin, T. (2006) Parasitoids on the loose - experimental lack of support of the parasitoid movement hypothesis. Oikos, 115, 277-285. 
Russel, G. B. \& Fenemore, P. G. (1973) New ligans from leaves of Macropiper excelsum. Phytochemistry, 12, 1799-1803.

Russel, G. B. \& Lane, G. A. (1993) Insect antifeedants - A New Zealand perspective. Proceedings of the 46th New Zealand Plant Protection Conference. (ed., pp. 179-186.

Samways, M. J. (2007) Insect conservation: A synthetic management approach. Annual Review of Entomology, 52, 465-487.

Schnitzler, F.-R., Sarty, M. \& Lester, P. J. (2004) Larval parasitoids reared from Cleora scriptaria (Geometridae: Ennominae). The Weta, 28, 13-18.

Shepherd, W. (2000) Wellington's Heritage: Plants, Gardens, and Landscape. Te Papa Press, Wellington.

Singh, P. (1983) A general purpose laboratory diet mixture for rearing insects. Insect Science and its Application, 4, 357-362.

Smith, A. C. (1975) Genus Macropiper (Piperaceae). Botanical Journal of the Linnean Society, 71, 1-\&.

Spiller, D. M. \& Wise , K. A. J. (1982) A catalogue (1860-1960) of New Zealand insects and their host plants. DSIR Science Information Division Bulletin. (ed. DSIR, Wellington.

Steffan-Dewenter, I. \& Tscharntke, T. (2000) Butterfly community structure in fragmented habitats. Ecology Letters, 3, 449-456.

Storch, D., Evans, K. L. \& Gaston, K. J. (2005) The species-area-energy relationship. Ecology Letters, 8, 487-492.

Thiel, A., Driessen, G. \& Hoffmeister, T. S. (2006) Different habitats, different habits? Response to foraging information in the parasitic wasp Venturia canescens. Behavioral Ecology and Sociobiology, 59, 614-623. 
Thogmartin, W. E. \& Knutson, M. G. (2007) Scaling local species-habitat relations to the larger landscape with a hierarchical spatial count model. Landscape Ecology, 22, 6175.

Thomas, J. A., Telfer, M. G., Roy, D. B., Preston, C. D., Greenwood, J. J. D., Asher, J., Fox, R., Clarke, R. T. \& Lawton, J. H. (2004) Comparative losses of British butterflies, birds, and plants and the global extinction crisis. Science, 303, 1879-1881.

Turlings, T. C., Sandrine, G., Degen, T. \& Fritzsche-Hoballah, M. E. (2002) The chemical ecology of plant-caterpillar interactions. Multitrophic Level Interactions (ed. T. Tscharntke \& B. A. Hawkins), pp. 148-173. Cambridge University Press, Cambridge, UK.

Turner, I. M. (1996) Species loss in fragments of tropical rain forest - a review of the evidence. Journal of Applied Ecology, 33, 200-209.

Umbanhowar, J., Maron, J. \& Harrison, S. (2003) Density-dependent foraging behaviors in a parasitoid lead to density-dependent parasitism of its host. Oecologia, 137, 123130.

Valladares, G., Salvo, A. \& Cagnolo, L. (2006) Habitat fragmentation effects on trophic processes of insect-plant food webs. Conservation Biology, 20, 212-217.

van de Pol, M. \& Verhulst, S. (2006) Age-dependent traits: A new statistical model to separate within- and between-individual effects. American Naturalist, 167, 766-773.

van Nouhuys, S. (2005) Effects of habitat fragmentation at different trophic levels in insect communities. Annales Zoologici Fennici, 42, 433-447.

Vanbergen, A. J., Hails, R. S., Watt, A. D. \& Jones, T. H. (2006) Consequences for hostparasitoid interactions of grazing-dependent habitat heterogeneity. Journal of Animal Ecology, 75, 789-801. 
Vanbergen, A. J., Jones, T. H., Hails, R. S., Watt, A. D. \& Elston, D. A. (2007) Consequences for a host-parasitoid interaction of host-plant aggregation, isolation, and phenology. Ecological Entomology, 32, 419-427.

Warren, M. S., Hill, J. K., Thomas, J. A., Asher, J., Fox, R., Huntley, B., Roy, D. B., Telfer, M. G., Jeffcoate, S., Harding, P., Jeffcoate, G., Willis, S. G., GreatorexDavies, J. N., Moss, D. \& Thomas, C. D. (2001) Rapid responses of British butterflies to opposing forces of climate and habitat change. Nature, $\mathbf{4 1 4 , 6 5 - 6 9 .}$

White, T. C. R. (1975) A quantitative method of beating for sampling larvae of Selidosema suavis (Lepidoptera: Geometridae) in plantations in New Zealand. Canadian Entomologist, 107, 403-412.

Zabel, J. \& Tscharntke, T. (1998) Does fragmentation of Urtica habitats affect phytophagous and predatory insects differentially? Oecologia, 116, 419-425 


\section{Appendix 4.1}

Table 4.1.1: Fragment area, isolation index, percentage of residential area in $1000 \mathrm{~m}$ buffer around fragments and number of plant species of 10 native urban bush fragments.

\begin{tabular}{lrrrr}
\hline \multicolumn{1}{c}{ Fragment } & $\begin{array}{c}\text { Fragment } \\
\text { ID }\end{array}$ & Area $\mathrm{m}^{2}$ & $\begin{array}{c}\text { Isolation } \\
\text { index }\end{array}$ & $\begin{array}{c}\text { Residential } \\
\text { area }(\%)\end{array}$ \\
\hline Maupuia Reserve & 1 & 1635 & 130008 & 25.2 \\
Karori Sanctuary & 2 & 27616 & 2126344 & 22.4 \\
Otari/Wilton Bush & 3 & 12190 & 414122 & 36.1 \\
Huntleigh Park & 4 & 2319 & 247604 & 28.8 \\
Trelissick Park & 5 & 4738 & 565475 & 47.3 \\
Belmont Park & 6 & 19525 & 616690 & 9.1 \\
Harbour View & 7 & 1386 & 353955 & 23.1 \\
Speedy Reserve & 8 & 3804 & 350115 & 19.5 \\
Stokes Valley & 9 & 106852 & 2230408 & 18.4 \\
Bartons Bush & 10 & 1180 & 274226 & 31.9 \\
\hline
\end{tabular}

Table 4.1.2: Dates kawakawa moth larvae were collected for each fragment over a period of two summers.

\begin{tabular}{lcccccc}
\hline \multicolumn{1}{c}{ Fragment } & $\begin{array}{c}\text { December } \\
2002\end{array}$ & $\begin{array}{c}\text { February } \\
2003\end{array}$ & $\begin{array}{c}\text { April } \\
2003\end{array}$ & $\begin{array}{c}\text { December } \\
2003\end{array}$ & $\begin{array}{c}\text { February } \\
2004\end{array}$ & $\begin{array}{c}\text { April } \\
2004\end{array}$ \\
\hline Maupuia Reserve & 09 & 19 & 19 & 09 & 10 & 10 \\
Karori Sanctuary & 18 & 14 & $01 \& 02$ & 11 & 04 & 11 \\
Otari/Wilton & $05 \& 06$ & $04 \& 05$ & 03 & 26 & 06 & 16 \\
Bush & 12 & 16 & 05 & 10 & 20 & 05 \\
Huntleigh Park & 10 & 17 & 23 & 19 & 18 & 08 \\
Trelissick Park & 27 & $18 \& 22$ & 20 & 03 & 09 & 20 \\
Belmont Park & $03 \& 04$ & $07 \& 11$ & 04 & 18 & $03 \& 07$ & 13 \\
Harbour View & 16 & $02 \mathrm{Mar}$ & 22 & 08 & 19 & 12 \\
Speedy Reserve & 17 & 24 & 08 & 02 & 22 & 17 \\
Stokes Valley & 19 & 25 & 26 & 04 & 05 & 14 \\
Bartons Bush & & & & & & \\
\hline
\end{tabular}




\section{Appendix 4.2: Model rational}

The 'unconditional' three-level model in the following description is equivalent to a oneway ANOVA with random effects model, where the levels of the hierarchy are the treatments of the single factor variance decomposition models estimating the baseline of the variation in the response variable on the different levels of the hierarchy (Raudenbush and Bryk 2002). The analysis for the response of parasitism (binomial) and herbivory (ordinal) differ somewhat in the equation of the outcome variable. The decomposition of the models used in the analyses is as follows.

\subsubsection{Parasitism}

For the level 1 model of the parasitism analysis we used a binary outcome model at the individual plant level using a binomial sampling model for parasitism and a logit link. The response variable $Y_{i j k}$ is the number of successes in an individual sampling unit $(i)$ within a group of units $(j)$ within a unit of groups $(k)$ out of $m_{i j k}$ number of trials, and $\varphi_{i j k}$ is the probability of each trial being successful, so that:

$Y_{i j k} \mid \varphi_{i j k} \sim B\left(m_{i j k}, \varphi_{i j k}\right)$.

Where the expected outcome and variance of $Y_{i j k}$ are:

$\mathrm{E}\left(Y_{i j k} \mid \varphi_{i j k}\right)=m_{i j k} \varphi_{i j k}$ and $\operatorname{Var}\left(Y_{i j k} \mid \varphi_{i j k}\right)=\sigma^{2} /\left(m_{i j k} \varphi_{i j k}\left(1-\varphi_{i j k}\right)\right)$ respectively.

eqn. 4.2.2

With a binomial response, a logit link function is used: 
$Y_{i j k}=\log \left(\varphi_{i j k} / 1-\varphi_{i j k}\right)=\pi_{0 j k}+e_{i j k}$,

eqn. 4.2 .3

where $Y_{i j k}$ is the log of the odds of a trial being successful, with the level 1 coefficient $\left(\pi_{0 j k}\right)$ indicating the mean outcome over level 1 units and a normally distributed random level 1 unit effect $\left(e_{i j k}\right)$ with a mean of zero and a scalar variance $\left(\sigma^{2}\right)$. Because we were not sure whether to expect more, or less, dispersion of the level 1 variance than expected under a binomial model, we allowed for estimation of a scalar variance for any over or under-dispersion that may exist (Raudenbush et al. 2000).

The level 1 coefficient $\left(\pi_{0 j k}\right)$ becomes the outcome variable in the level 2 model where $\beta_{00 k}$ represents the mean outcome over level 2 units with $r_{0 j k}$ assumed to be a random term $\sim N\left(0, \tau_{00}\right):$

$\pi_{0 j k}=\beta_{00 k}+r_{0 j k}$

eqn. 4.2 .4

For the level 3 model the level 2 coefficient $\left(\beta_{00 k}\right)$ becomes the outcome variable where $\gamma_{000}$ represents the mean outcome over level 3 units with the random term $u_{00 k}$ assumed to be $\sim N\left(0, \tau_{000}\right)$ :

$\beta_{00 k}=\gamma_{000}+u_{00 k}$

eqn. 4.2 .5

The unconditional mixed-model representing the combined three-level model (eqn. 4.2.6) describes the overall average of the probability of the log odds of success in every level 1 
unit across every level 2 unit within each level 3 unit (the grand mean $\gamma_{000}$ ), the effects of level 2 units within level 3 units on the probability of the log odds of success in every level 1 unit $\left(r_{0 j k}\right)$, plus the effects of the level 3 units on the probability of the log odds of success across level 2 units $\left(u_{00 k}\right)$, taking into account individual variation on the probability of the log odds of success in every level 1 unit $\left(e_{i j k}\right)$.

$Y_{i j k}=\gamma_{000}+r_{0 j k}+u_{00 k}+e_{i j k}$.

eqn. 4.2 .6

The unconditional model permits one to estimate the proportion of the total variation that is accounted for by the variation between level 2 units $\left(\rho_{1}\right)$ and between level 3 units $\left(\rho_{2}\right)$

$\rho_{1}=\tau_{00} / \sigma^{2}+\tau_{00}+\tau_{000} \quad$ and $\quad \rho_{2}=\tau_{000} / \sigma^{2}+\tau_{00}+\tau_{000} \quad$ respectively

eqn. 4.2 .7

The variance component $\tau_{00}\left(=\sigma_{\text {plots }}^{2}\right.$ in the main text $)$ refers to the variation of the means over the level 2 units in the data set and $\tau_{000}\left(=\sigma_{\text {fragments }}^{2}\right.$ in the main text $)$ denotes the variation in the mean over level 3 units. If a level variance component differs significantly from zero than it may be worthwhile to include predictor variables to explain the larger variation or, if not found significant, to even reduce the number of levels within a model.

\subsubsection{Herbivory}

The outcome variable herbivory $\left(\eta_{i j}\right)$ (Chapter 4 , eqn. 4.4) at the individual plant level was treated as an ordinal response variable with three possible ordered response 
categories $1=$ high herbivory, $2=$ medium herbivory and $3=$ low herbivory $(m=1,2,3)$, where herbivory takes on the value of $m$ with probability:

$\varphi_{m i j}=\operatorname{prob}\left(H E R B C O M_{i j}=m\right)$

where each category has the probability of :

$\varphi_{1 i j}=\operatorname{prob}\left(\operatorname{HERBCOM}_{i j}=1\right)=\operatorname{prob}($ low herbivory $)$

$\varphi_{2 i j}=\operatorname{prob}\left(H E R B C O M_{i j}=2\right)=\operatorname{prob}($ medium herbivory $)$

$\varphi_{3 i j}=\operatorname{prob}\left(H E R B C O M_{i j}=3\right)=\operatorname{prob}($ high herbivory $)$

eqn. 4.2 .9

The program HLM works with cumulative probabilities rather than the probabilities themselves and constructs dummy variables $\left(Y_{m i j}\right)$ so that the probabilities $\operatorname{Prob}\left(Y_{m i j}=1\right)$ are cumulative probabilities for the three categories with $M=3$ :

$\operatorname{Prob}\left(Y_{1 i j}=1\right)=\operatorname{Prob}\left(\operatorname{HERBCOM} M_{i j}=1\right)=\varphi_{1 i j}$

$\operatorname{Prob}\left(Y_{2 i j}=1\right)=\operatorname{Prob}\left(\operatorname{HERBCOM}_{i j}=1\right)+\operatorname{Prob}\left(\operatorname{HERBCOM}_{i j}=2\right)=\varphi_{2 i j}$

$\operatorname{Prob}\left(Y_{3 i j}=1\right)=\operatorname{Prob}\left(\operatorname{HERBCOM}_{i j}=1\right)+\operatorname{Prob}\left(\operatorname{HERBCOM}_{i j}=2\right)+\operatorname{Prob}\left(\operatorname{HERBCOM}_{i j}=\right.$ 3) $=1$

eqn. 4.2 .10

Given that $Y_{3 i j}=1-Y_{2 i j}, Y_{3 i j}$ is actually redundant and only $M-1=2$ dummy variables are included in the model. The level 1 structural models assume 'proportional odds' where the cumulative probabilities are associated with the cumulative logits. The unconditional level 1 structural model therefore is: 
$\eta_{i j(1)}=\log \left(\varphi_{i j(1)} / 1-\varphi_{i j(1)}\right)=\beta_{0 j}$

$\eta_{i j(2)}=\log \left(\varphi_{i j(2)} / 1-\varphi_{i j(2)}\right)=\beta_{0 j}+\delta_{(2)}$

eqn. 4.2.11

where $\delta_{(2)}$ is the difference in log-odds between the two cumulative logits for the categories $m(m=1)$ and $m-1(m=2)$ depending only on the difference in the respective intercepts $\beta_{0 j}$ and not on any level 1 predictors. The level 2 and level 3 model follow the same form as described in the binomial model above. As an example, eqn. 4.2.12 below shows the potential full mixed regression model with all level predictors included for the outcome of parasitism by A. declanae:

$$
\begin{aligned}
& \eta_{i j k}=\gamma_{000}+\gamma_{001} * \text { LOGAREA }_{k}+\gamma_{002} * \text { LOGISOL }_{k}+\gamma_{003} * \text { PERC_RES }_{k}+\gamma_{010} * \text { KWAABUN }_{j k} \\
& +\gamma_{020} * \text { PLANTS }_{j k}+\gamma_{100} * \mathrm{GEO}_{i j k}+\gamma_{100} * \text { LEAVES }_{i j k}+\gamma_{100} * \mathrm{HERB}_{i j k}+\gamma_{100} * \mathrm{HERB} 5_{i j k}+ \\
& \gamma_{200} * \text { TOTRAT_A } \\
& i j k
\end{aligned}
$$




\section{Appendix 4.3:}

Table 4.3.1: Final three-level models for the responses of parasitism by A. declanae and M. pulchricornis with fixed effects. Shown are the models with predictor variables included for each level model.

\section{Parasitism by A. declanae}

\section{LEVEL 1 MODEL}

$$
\begin{aligned}
& \mathrm{E}\left(\mathrm{AL}_{i j k}=1 \mid \pi_{j k}\right)=\varphi_{i j k} * \mathrm{LARCOL} \\
& \log \left[\varphi_{i j k} /\left(1-\varphi_{i j k}\right)\right]=\eta_{i j k} \\
& \eta_{i j k}=\pi_{0 j k}+\pi_{1 j k}\left(\text { LEAVES }_{i j k}\right)+\pi_{2 j k}(\text { TOTRAT_A } i j k \\
& )+e_{i j k}
\end{aligned}
$$

\section{LEVEL 2 MODEL}

$$
\begin{aligned}
\pi_{0 j k} & =\beta_{00 k}+r_{0 j k} \\
\pi_{1 j k} & =\beta_{10 k} \\
\pi_{2 j k} & =\beta_{20 k}
\end{aligned}
$$

\section{LEVEL 3 MODEL}

$$
\begin{aligned}
& \beta_{00 k}=\gamma_{000}+\gamma_{001}\left(\text { LOGAREA }_{k}\right)+\gamma_{002}\left(\text { LOGISOL }_{k}\right)+u_{00 k} \\
& \beta_{10 k}=\gamma_{100} \\
& \beta_{20 k}=\gamma_{200}
\end{aligned}
$$

Parasitism by M. pulchricornis

\section{LEVEL 1 MODEL}

$$
\begin{aligned}
& \mathrm{E}\left(\mathrm{MET}_{i j k}=1 \mid \pi_{j k}\right)=\varphi_{i j k} * \mathrm{LARCOL} \\
& \log \left[\varphi_{i j k} /\left(1-\varphi_{i j k}\right)\right]=\eta_{i j k} \\
& \eta_{i j k}=\pi_{0 j k}+\pi_{1 j k}\left(\mathrm{GEO}_{i j k}\right)+\epsilon_{i j k}
\end{aligned}
$$

\section{LEVEL 2 MODEL}

$$
\begin{aligned}
& \pi_{0 j k}=\beta_{00 k}+\beta_{01 k}\left(\text { PLANTS }_{j k}\right)+r_{0 j k} \\
& \pi_{1 j k}=\beta_{10 k}
\end{aligned}
$$

\section{LEVEL 3 MODEL}

$$
\begin{aligned}
& \beta_{00 k}=\gamma_{000}+\gamma_{001}\left(\text { LOGAREA }_{k}\right)+\gamma_{002}\left(\text { LOGISOL }_{k}\right)+u_{00 k} \\
& \beta_{01 k}=\gamma_{010} \\
& \beta_{10 k}=\gamma_{100}
\end{aligned}
$$


Table 4.3.2: Final the two-level model for herbivory with fixed effects. Shown are the models with predictor variables included for each level model.

\section{LEVEL 1 MODEL}

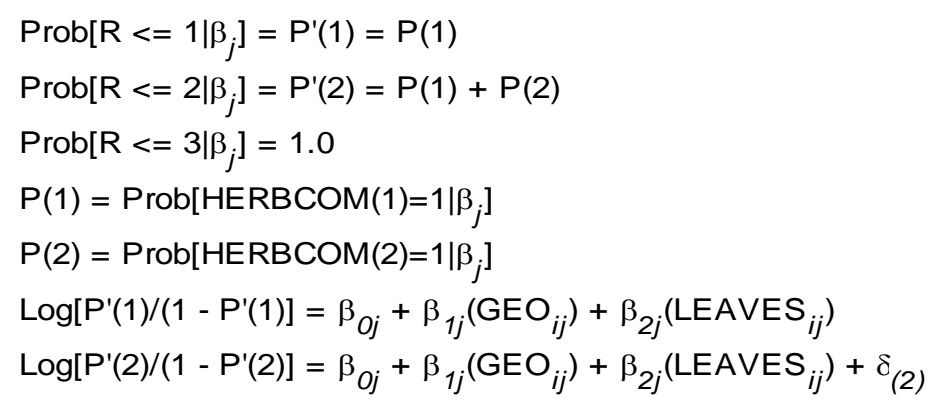

\section{LEVEL 2 MODEL}

$$
\begin{aligned}
& \beta_{0 j}=\gamma_{00}+\gamma_{01}\left(\text { KAWAABN }_{j}\right)+u_{O j} \\
& \beta_{1 j}=\gamma_{10} \\
& \beta_{2 j}=\gamma_{20} \\
& \delta_{(2)}
\end{aligned}
$$


Appendix 4.4: Summary of results for A. declanae at each level of model building process.

\section{Unconditional three-level model for A. declanae}

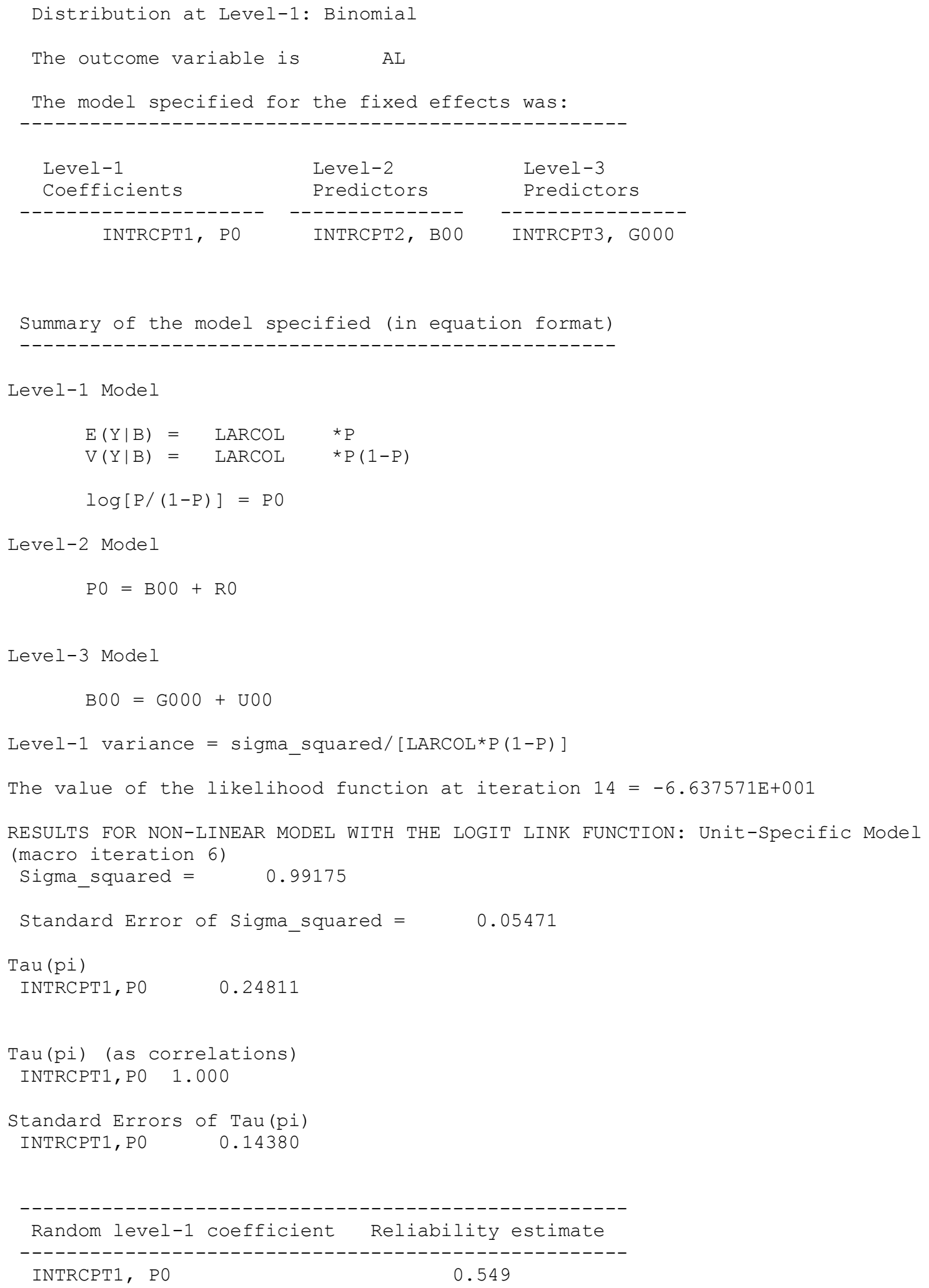




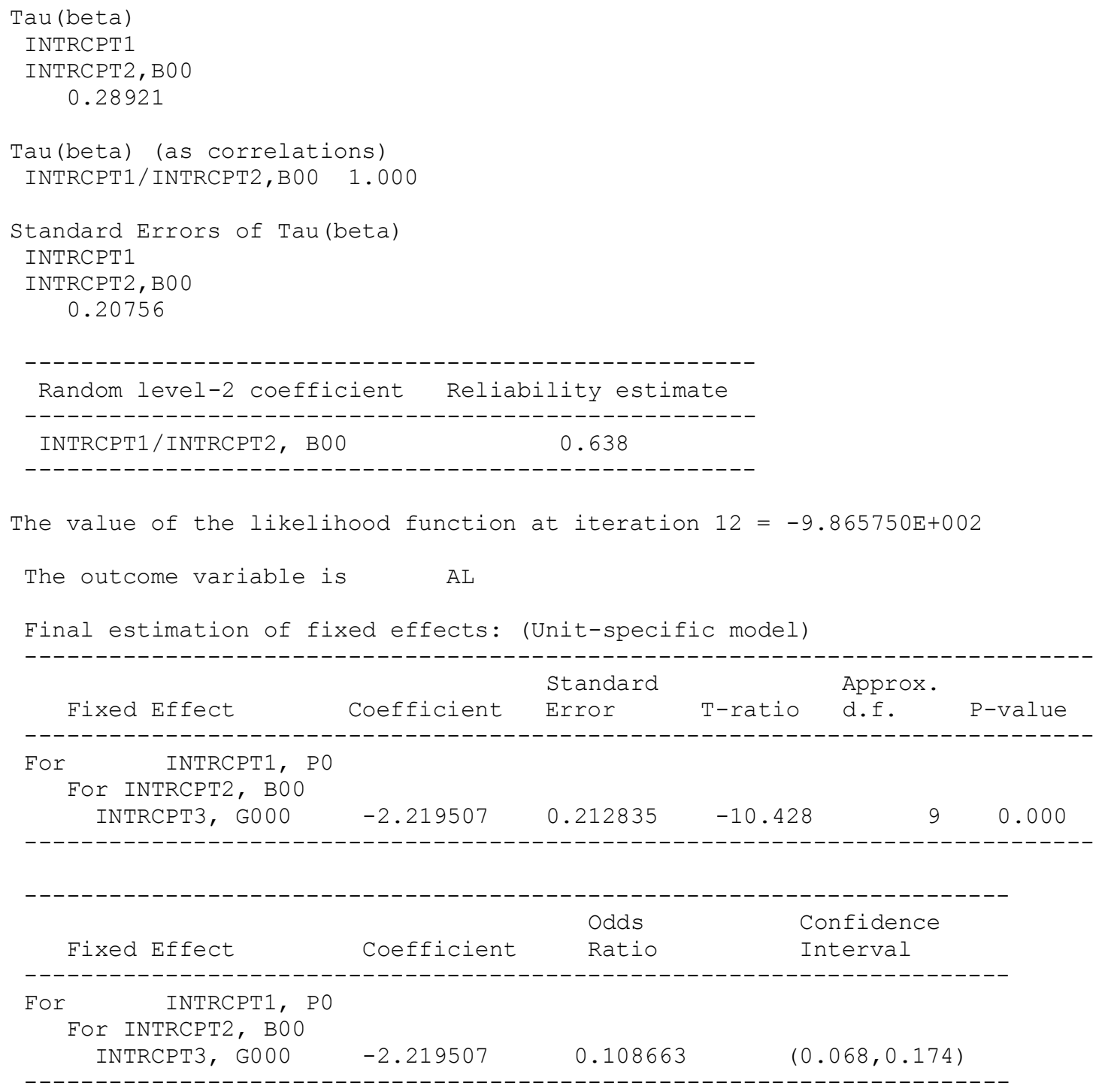

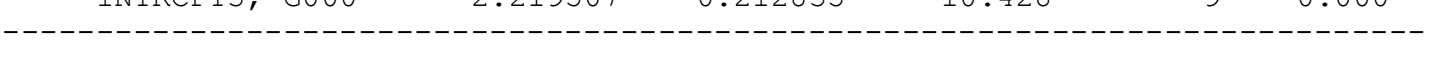

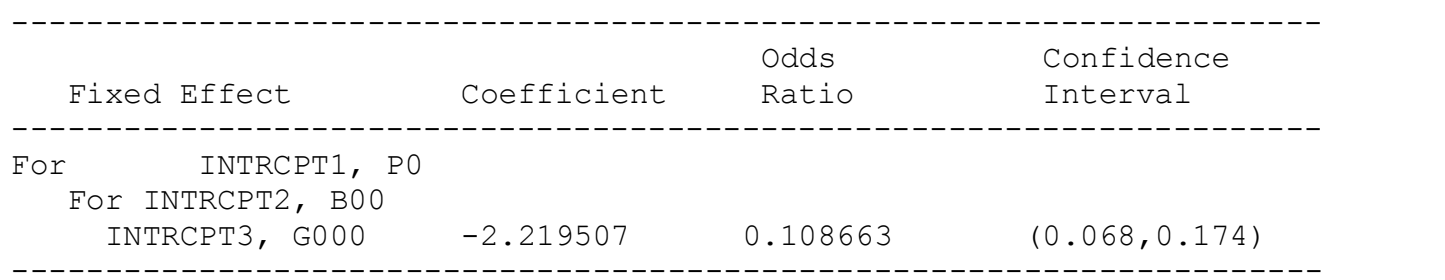

Final estimation of level-1 and level-2 variance components:

\begin{tabular}{|c|c|c|c|c|c|c|}
\hline Random Effect & & $\begin{array}{l}\text { Standard } \\
\text { Deviation }\end{array}$ & $\begin{array}{l}\text { Variance } \\
\text { Component }\end{array}$ & $d f$ & Chi-square & P-value \\
\hline $\begin{array}{l}\text { INTRCPT1, } \\
\text { level-1, }\end{array}$ & $\begin{array}{l}\text { R0 } \\
\mathrm{E}\end{array}$ & $\begin{array}{l}0.49810 \\
0.99587\end{array}$ & $\begin{array}{l}0.24811 \\
0.99175\end{array}$ & 19 & 44.67965 & 0.001 \\
\hline
\end{tabular}

Final estimation of level-3 variance components:

\begin{tabular}{|c|c|c|c|c|c|}
\hline Random Effect & $\begin{array}{l}\text { Standard } \\
\text { Deviation }\end{array}$ & $\begin{array}{l}\text { Variance } \\
\text { Component }\end{array}$ & df & Chi-square & P-value \\
\hline JTRCPT1/INTRCPT2, U00 & 0.53778 & 0.28921 & 9 & 27.71542 & 0.001 \\
\hline
\end{tabular}

RESULTS FOR NON-LINEAR MODEL WITH THE LOGIT LINK FUNCTION:

Population Average Model
Sigma_squared $=$
1.02461
Standard Error of Sigma_squared =
0.05656 
The value of the likelihood function at iteration $4=-9.964392 \mathrm{E}+002$

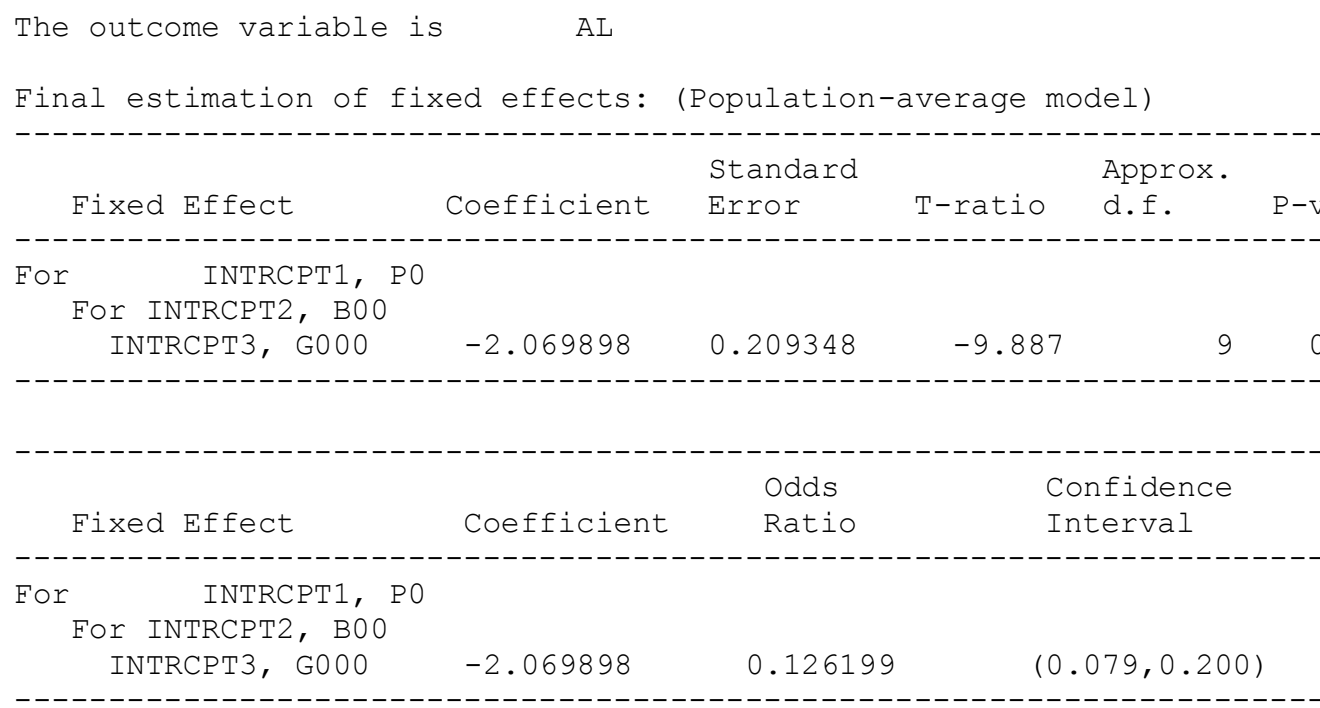

\section{Level 2 model for the three-level model of $A$. declanae}

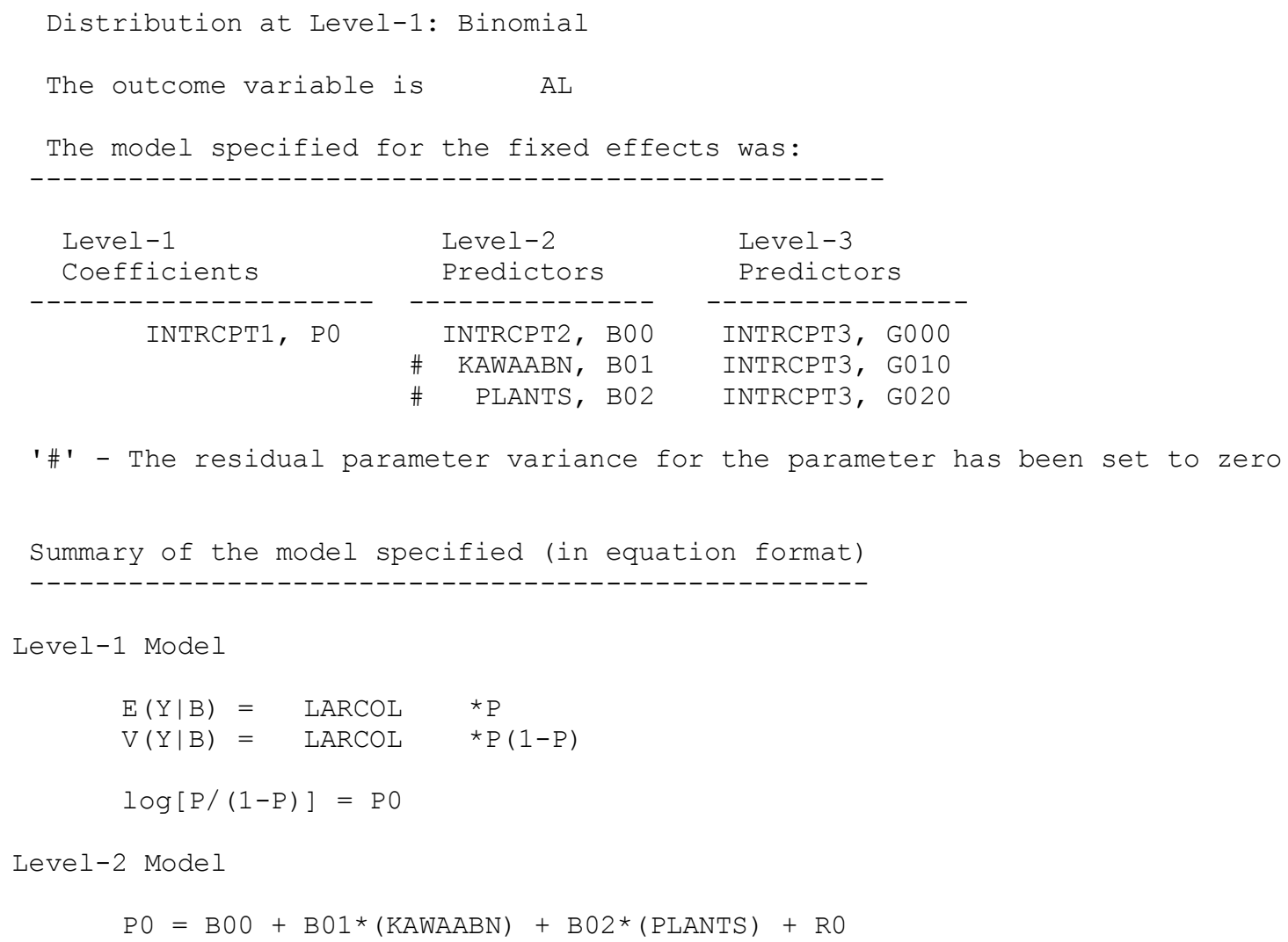




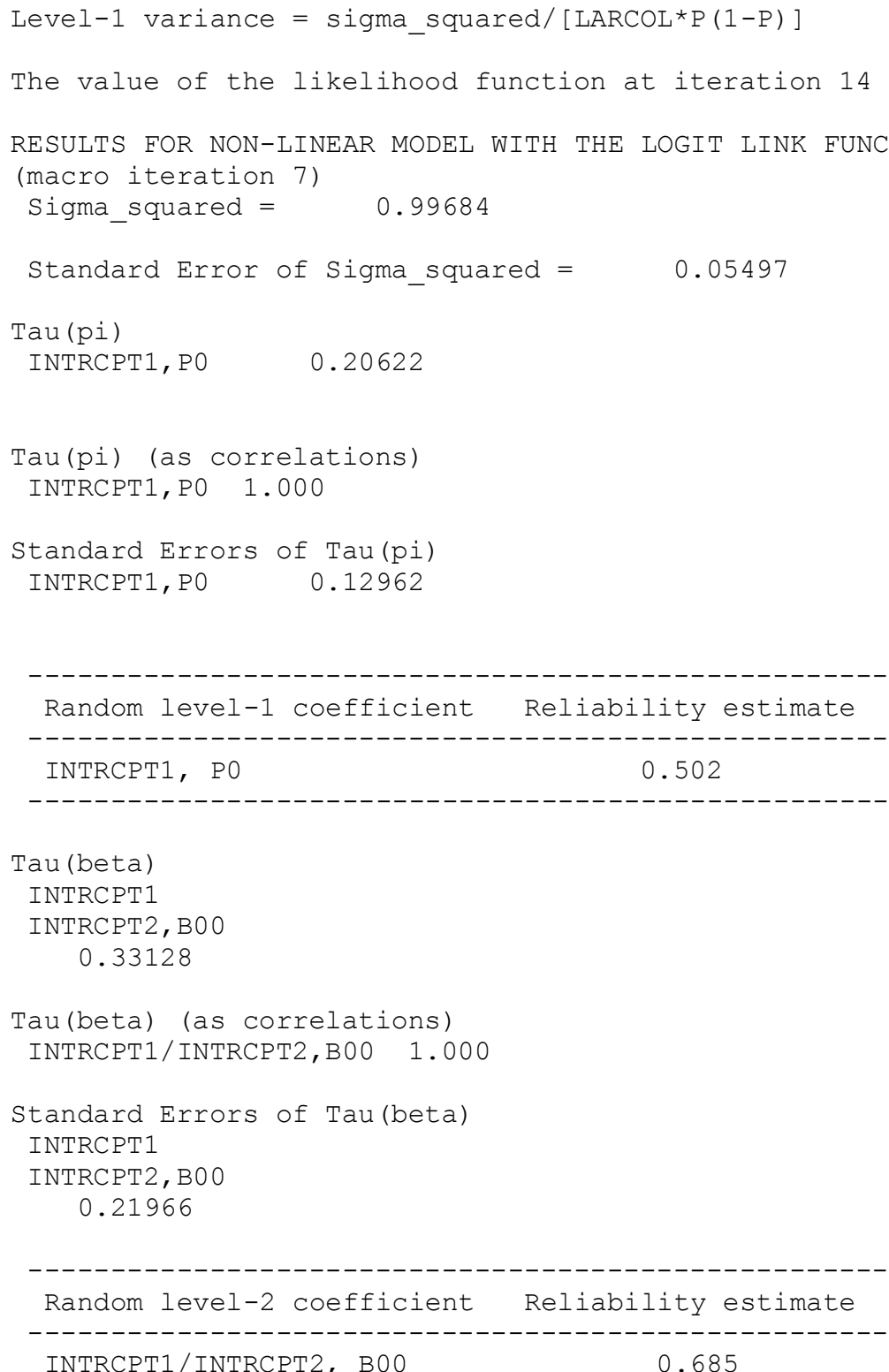

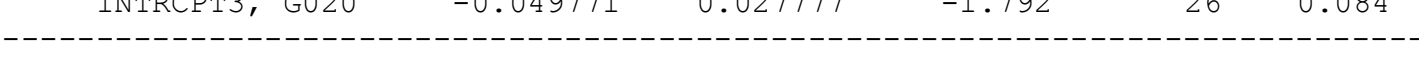




Fixed Effect
$\begin{aligned} & \text { Coefficient } \\ & \text { INTRCPT1, P0 }\end{aligned}$

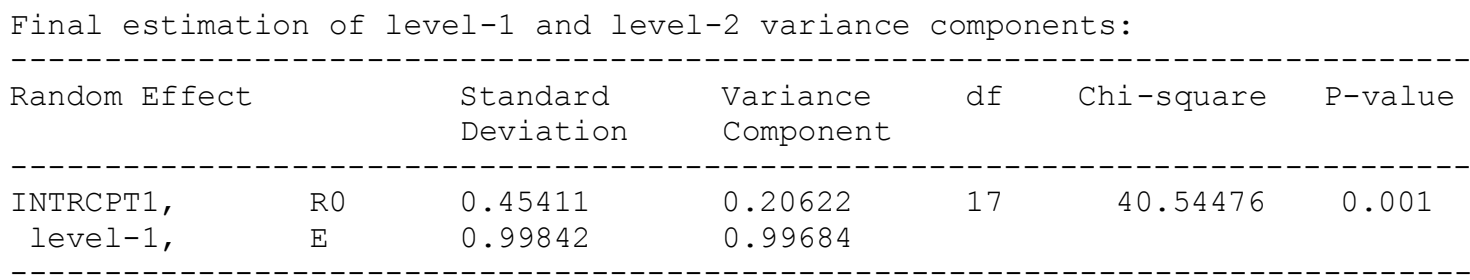

Final estimation of level-3 variance components:

\begin{tabular}{|c|c|c|c|c|c|}
\hline Random Effect & $\begin{array}{l}\text { Standard } \\
\text { Deviation }\end{array}$ & $\begin{array}{l}\text { Variance } \\
\text { Component }\end{array}$ & $d f$ & Chi-square & P-value \\
\hline INTRCPT1/INTRCPT2, U00 & 0.57557 & 0.33128 & 9 & 32.60781 & 0.000 \\
\hline
\end{tabular}

RESULTS FOR NON-LINEAR MODEL WITH THE LOGIT LINK FUNCTION:

Population Average Model
Sigma_squared $=$
1.01701
Standard Error of Sigma_squared =
0.05612

The value of the likelihood function at iteration $4=-9.945155 \mathrm{E}+002$

The outcome variable is AL

Final estimation of fixed effects: (Population-average model)

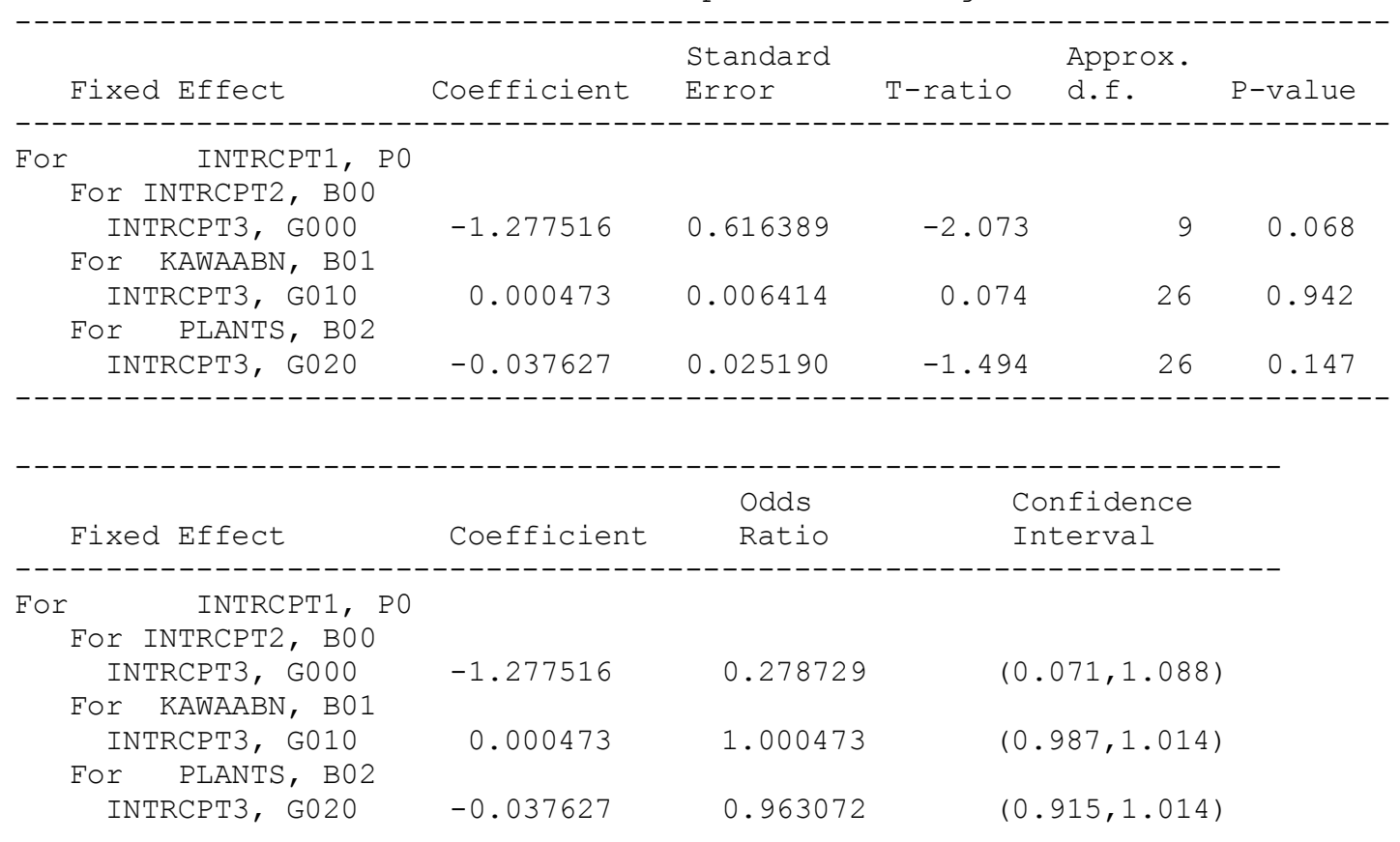




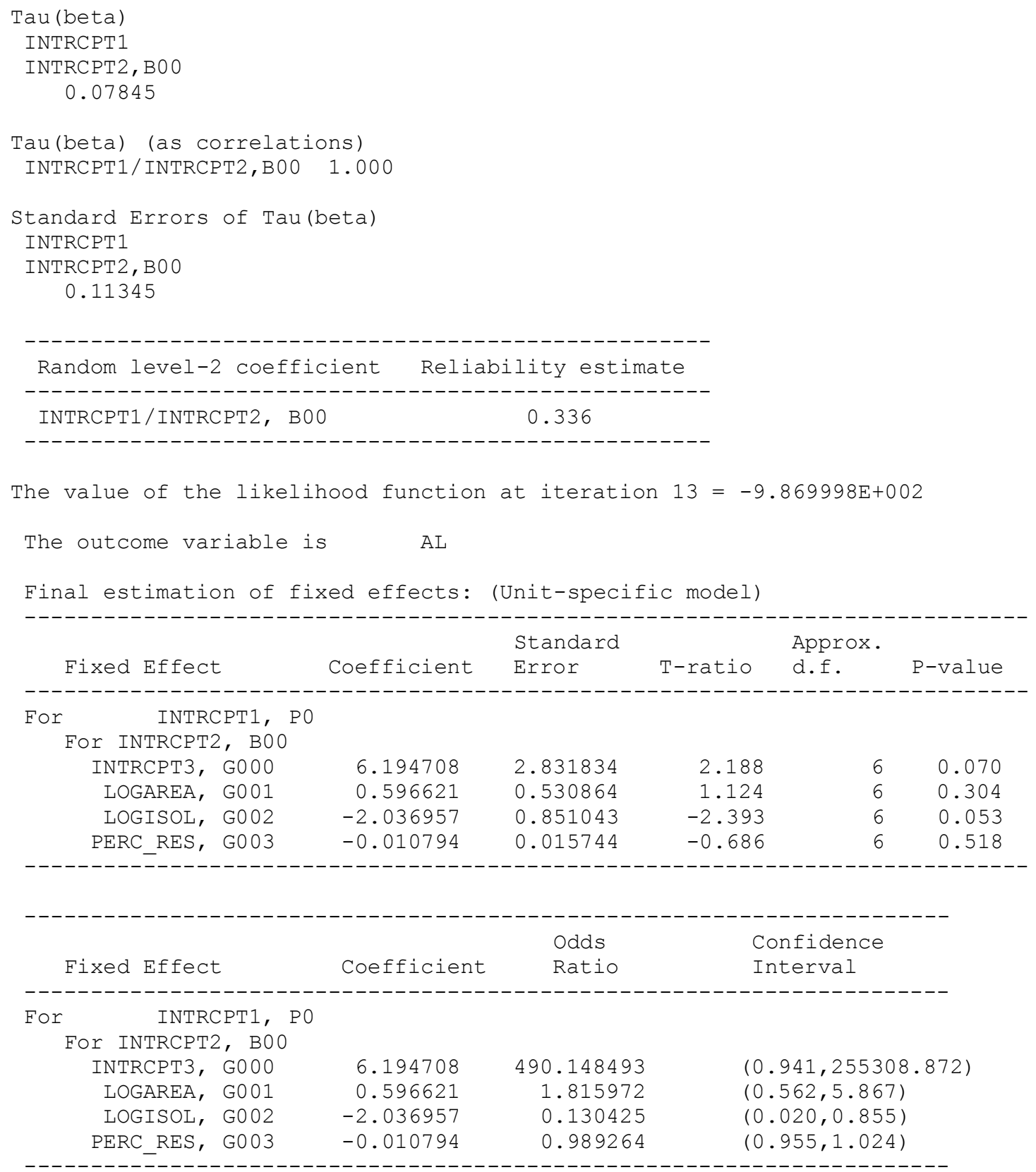

Final estimation of level-1 and level-2 variance components:

\begin{tabular}{|c|c|c|c|c|c|c|}
\hline Random Effect & & $\begin{array}{l}\text { Standard } \\
\text { Deviation }\end{array}$ & $\begin{array}{l}\text { Variance } \\
\text { Component }\end{array}$ & $d f$ & Chi-square & P-value \\
\hline $\begin{array}{l}\text { INTRCPT1, } \\
\text { level-1, }\end{array}$ & $\begin{array}{l}\mathrm{RO} \\
\mathrm{E}\end{array}$ & $\begin{array}{l}0.48417 \\
1.00178\end{array}$ & $\begin{array}{l}0.23442 \\
1.00356\end{array}$ & 19 & 43.59028 & 0.001 \\
\hline
\end{tabular}

Final estimation of level-3 variance components:

\begin{tabular}{|c|c|c|c|c|c|}
\hline Random Effect & $\begin{array}{l}\text { Standard } \\
\text { Deviation }\end{array}$ & $\begin{array}{l}\text { Variance } \\
\text { Component }\end{array}$ & $d f$ & Chi-square & P-value \\
\hline NTRCPT1/INTRCPT2, U00 & 0.28009 & 0.07845 & 6 & 15.40599 & 0.017 \\
\hline
\end{tabular}


RESULTS FOR NON-LINEAR MODEL WITH THE LOGIT LINK FUNCTION: Population Average Model
Sigma_squared $=$
1.05256
Standard Error of Sigma_squared $=$
0.05808

The value of the likelihood function at iteration $4=-1.002379 \mathrm{E}+003$

$\mathrm{AL}$

Final estimation of fixed effects: (Population-average model)

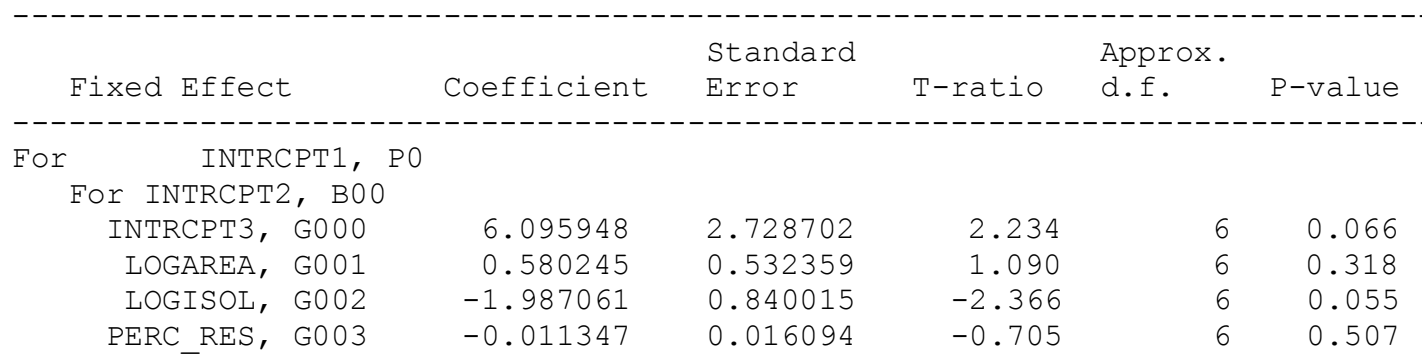

\begin{tabular}{|c|c|c|c|}
\hline Fixed Effect & Coefficient & $\begin{array}{l}\text { Odds } \\
\text { Ratio }\end{array}$ & $\begin{array}{l}\text { Confidence } \\
\text { Interval }\end{array}$ \\
\hline $\begin{array}{l}\text { For INTRCPT1, P0 } \\
\text { For INTRCPT2, B00 }\end{array}$ & & & \\
\hline INTRCPT3, G000 & 6.095948 & 444.054713 & $(1.071,184176.481)$ \\
\hline LOGAREA， G001 & 0.580245 & 1.786476 & $(0.551,5.791)$ \\
\hline LOGISOL, G002 & -1.987061 & 0.137098 & $(0.021,0.877)$ \\
\hline PERC_RES， G003 & -0.011347 & 0.988717 & $(0.954,1.024)$ \\
\hline
\end{tabular}


Appendix 4.5: Summary of results for $M$. pulchricornis at each level of model building process.

\section{Unconditional model for the three-level model of $M$. pulchricornis}

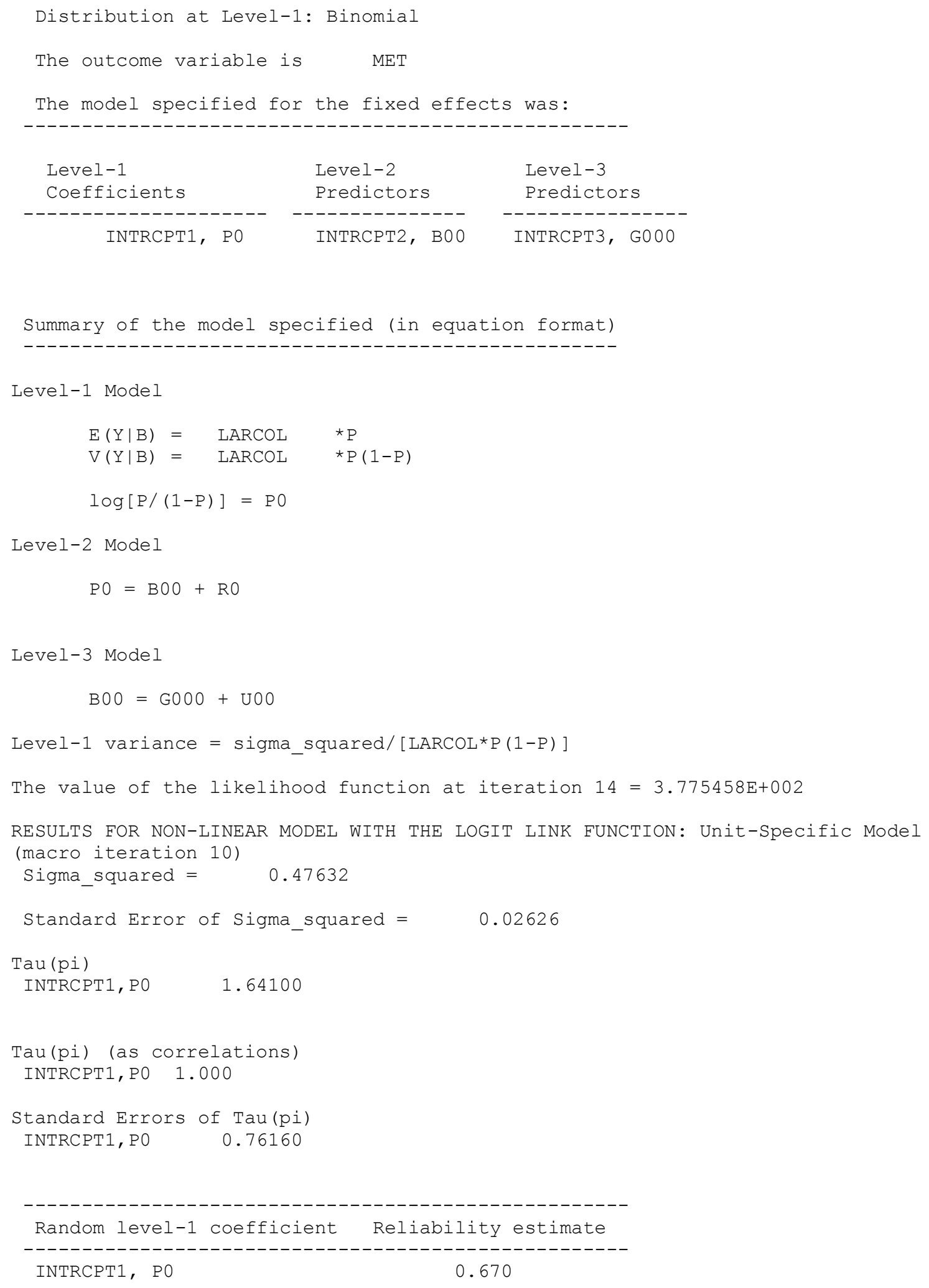




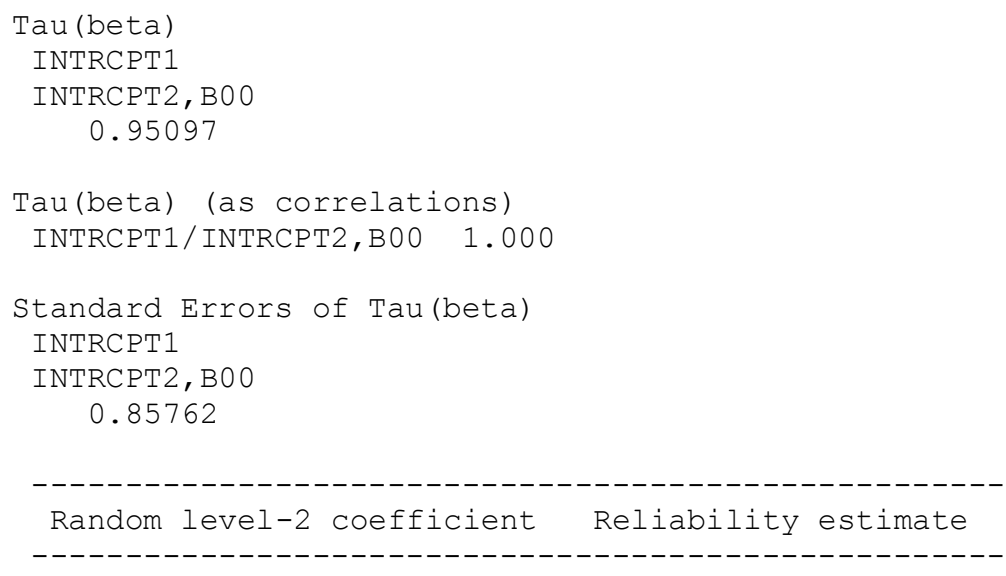

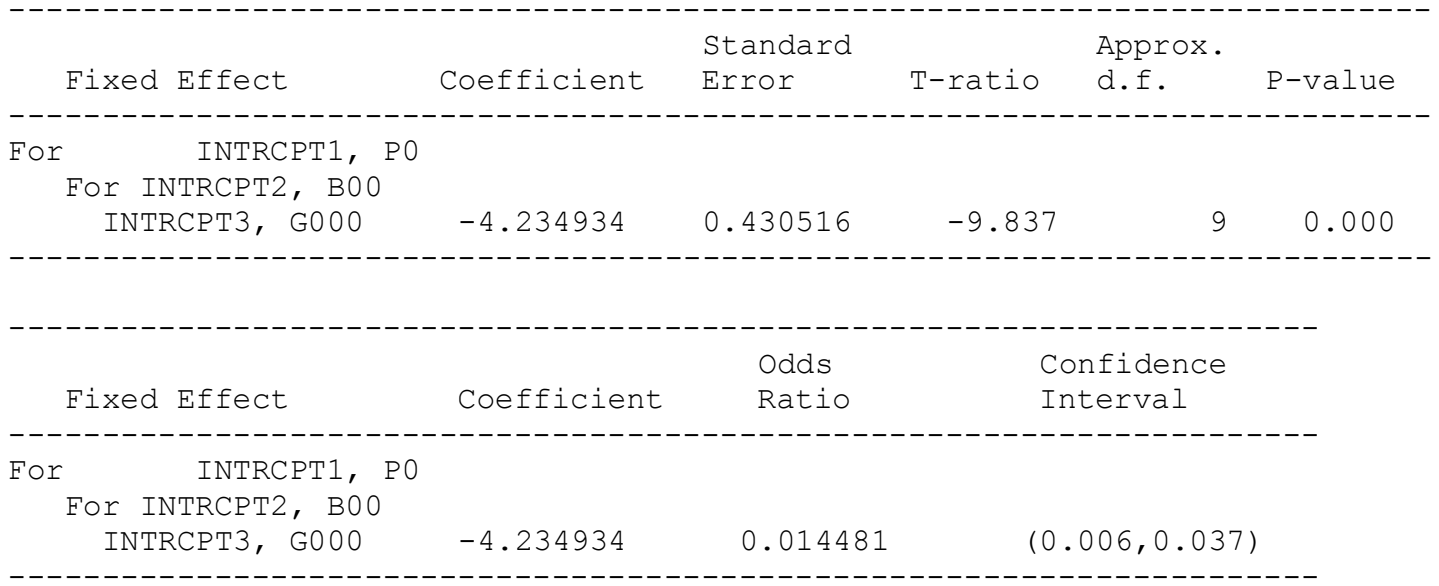

Final estimation of level-1 and level-2 variance components:

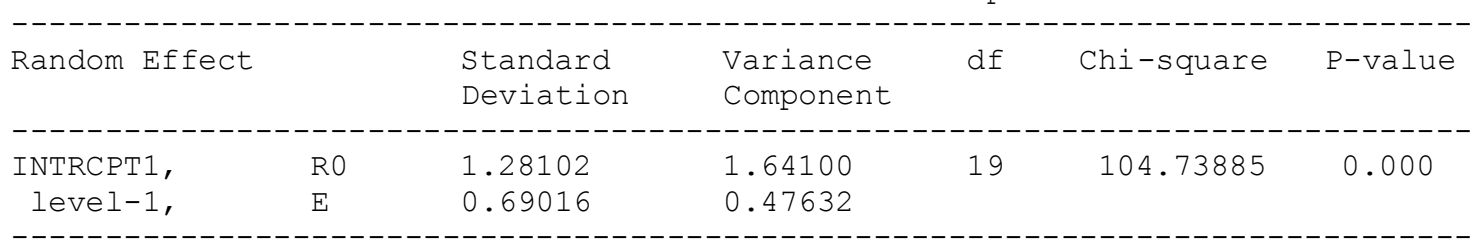

Final estimation of level-3 variance components:

\begin{tabular}{|c|c|c|c|c|c|}
\hline Random Effect & $\begin{array}{l}\text { Standard } \\
\text { Deviation }\end{array}$ & $\begin{array}{l}\text { Variance } \\
\text { Component }\end{array}$ & $d f$ & Chi-square & P-value \\
\hline INTRCPT1/INTRCPT2, U00 & 0.97518 & 0.95097 & 9 & 21.83091 & 0.010 \\
\hline
\end{tabular}

RESULTS FOR NON-LINEAR MODEL WITH THE LOGIT LINK FUNCTION:

Population Average Model
Sigma_squared =
0.63640 


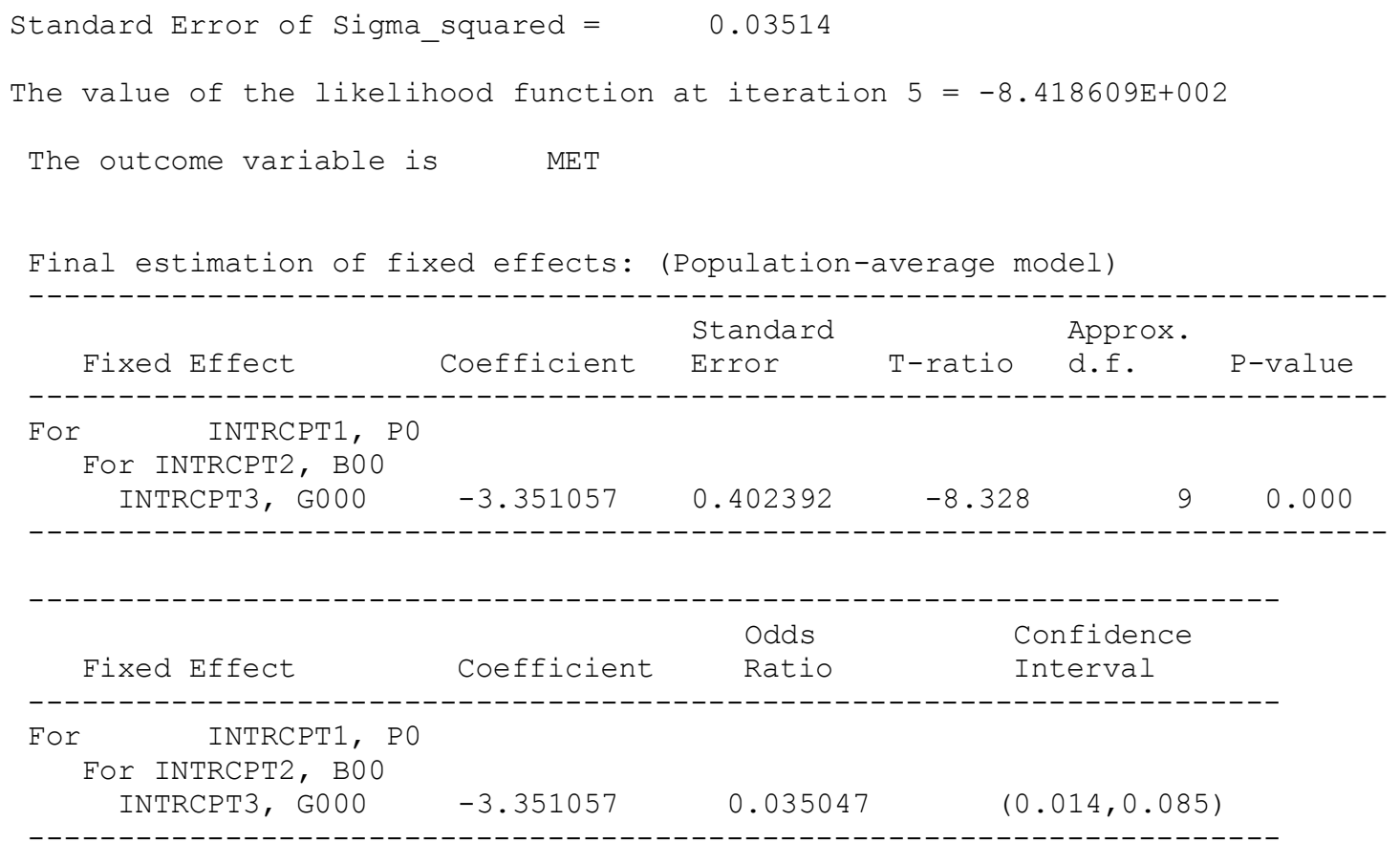

\section{Level 2 of the three-level model for M. pulchricornis}

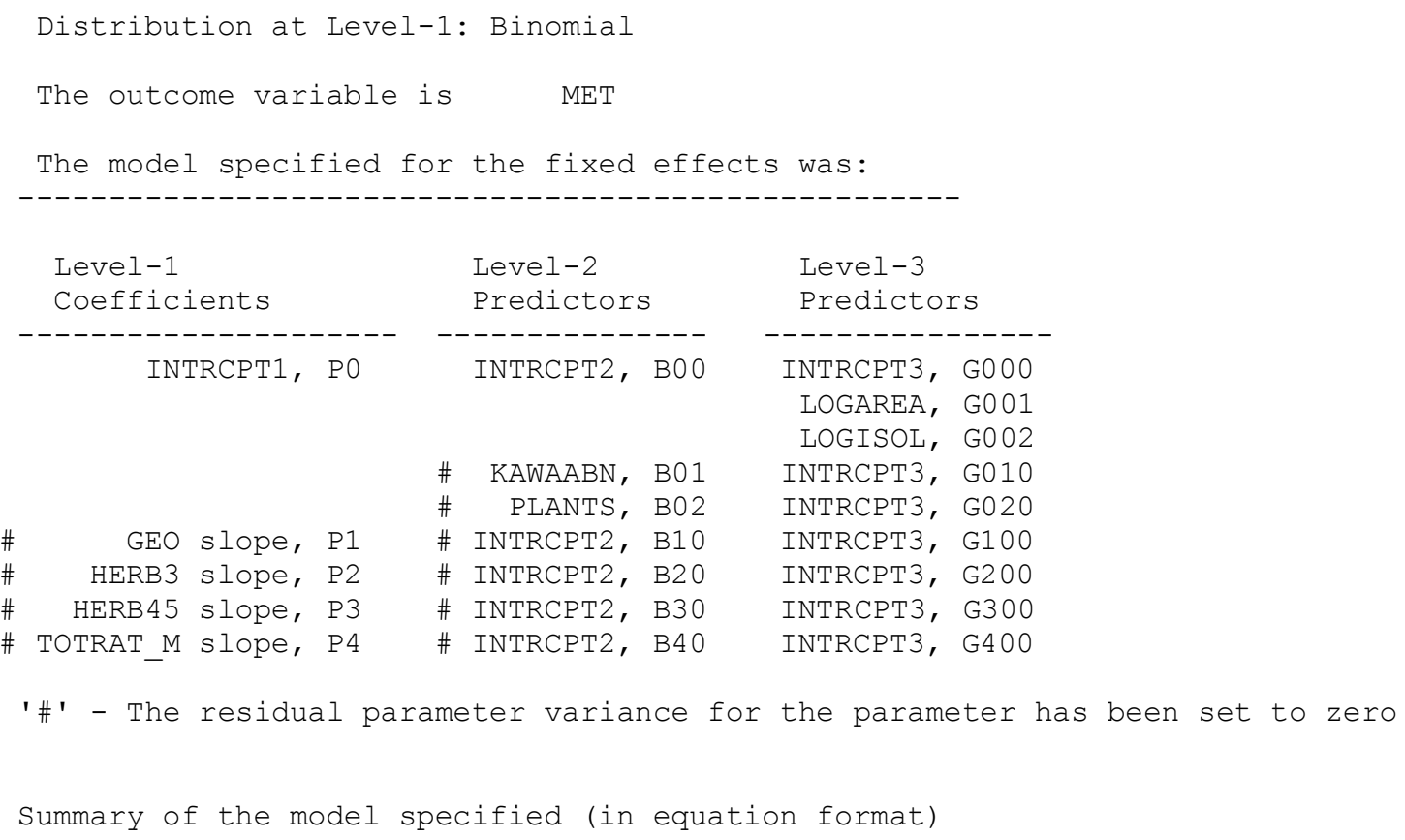




$$
\begin{aligned}
& \mathrm{P} 2=\mathrm{B} 20 \\
& \mathrm{P} 3=\mathrm{B} 30 \\
& \mathrm{P} 4=\mathrm{B} 40
\end{aligned}
$$

Level-3 Model

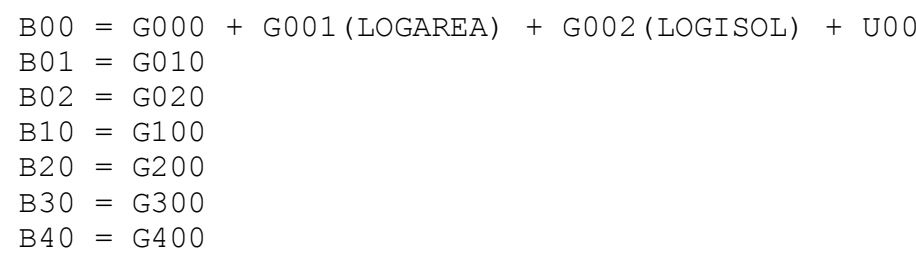

Random level-2 coefficient Reliability estimate
------1230
INTRCPT1/INTRCPT2, B00


The value of the likelihood function at iteration $14=-8.798375 \mathrm{E}+002$

The outcome variable is MET

Final estimation of fixed effects: (Unit-specific model)

\begin{tabular}{|c|c|c|c|c|c|}
\hline Fixed Effect & Coefficient & $\begin{array}{l}\text { Standard } \\
\text { Error }\end{array}$ & T-ratio & $\begin{array}{l}\text { Approx. } \\
\text { d.f. }\end{array}$ & P-value \\
\hline \multirow{2}{*}{\multicolumn{6}{|c|}{ For INTRCPT1, P0 }} \\
\hline & & & & & \\
\hline \multicolumn{6}{|l|}{ For INTRCPT2, B00 } \\
\hline INTRCPT3, G000 & 1.457823 & 3.702230 & 0.394 & 7 & 0.705 \\
\hline LOGAREA, G001 & -0.746906 & 0.939808 & -0.795 & 7 & 0.453 \\
\hline LOGISOL, G002 & 0.484491 & 1.197247 & 0.405 & 7 & 0.697 \\
\hline \multicolumn{6}{|l|}{ For KAWAABN, B01 } \\
\hline INTRCPT3, G010 & -0.005404 & 0.008554 & -0.632 & 26 & 0.533 \\
\hline For PLANTS, $\mathrm{B} 02$ & & & & & \\
\hline INTRCPT3, G020 & -0.211579 & 0.047320 & -4.471 & 26 & 0.000 \\
\hline \multicolumn{6}{|l|}{ For GEO slope, P1 } \\
\hline INTRCPT3, G100 & 0.027622 & 0.014635 & 1.887 & 607 & 0.059 \\
\hline \multicolumn{6}{|l|}{ For HERB3 slope, P2 } \\
\hline \multicolumn{6}{|l|}{ For INTRCPT2, B20 } \\
\hline INTRCPT3, G200 & 0.391672 & 0.487710 & 0.803 & 607 & 0.422 \\
\hline \multicolumn{6}{|l|}{ For HERB45 slope, P3 } \\
\hline \multicolumn{6}{|l|}{ For INTRCPT2, B30 } \\
\hline INTRCPT3, G300 & 0.054517 & 0.542903 & 0.100 & 607 & 0.921 \\
\hline \multicolumn{6}{|l|}{ For TOTRAT_M slope, P4 } \\
\hline \multicolumn{6}{|l|}{ For INTR $\bar{R} C P T 2$, B40 } \\
\hline INTRCPT3, G400 & -1.749923 & 1.072987 & -1.631 & 607 & 0.103 \\
\hline
\end{tabular}

\begin{tabular}{|c|c|c|c|}
\hline Fixed Effect & Coefficient & $\begin{array}{l}\text { Odds } \\
\text { Ratio }\end{array}$ & $\begin{array}{l}\text { Confidence } \\
\text { Interval }\end{array}$ \\
\hline For INTRCPT1, P0 & & & \\
\hline $\begin{array}{r}\text { For INTRCPT2, B00 } \\
\text { INTRCPT3, G000 } \\
\text { LOGAREA, G001 } \\
\text { LOGISOL, G002 }\end{array}$ & $\begin{array}{r}1.457823 \\
-0.746906 \\
0.484491\end{array}$ & $\begin{array}{l}4.296596 \\
0.473831 \\
1.623349\end{array}$ & $\begin{array}{l}(0.001,15306.757) \\
(0.059,3.778) \\
(0.115,22.856)\end{array}$ \\
\hline For KAWAABN, B01 & & & \\
\hline $\begin{array}{l}\text { INTRCPT3, G010 } \\
\text { For PLANTS, B02 }\end{array}$ & -0.005404 & 0.994610 & $(0.977,1.012)$ \\
\hline INTRCPT3, G020 & -0.211579 & 0.809305 & $(0.734,0.892)$ \\
\hline $\begin{array}{c}\text { For GEO slope, P1 } \\
\text { For INTRCPT2, B10 }\end{array}$ & & & \\
\hline $\begin{array}{cc} & \text { INTRCPT3, G100 } \\
\text { For } & \text { HERB3 slope, P2 }\end{array}$ & 0.027622 & 1.028007 & $(0.999,1.058)$ \\
\hline For INTRCPT2, B20 & & & \\
\hline INTRCPT3, G200 & 0.391672 & 1.479452 & $(0.569,3.850)$ \\
\hline $\begin{array}{l}\text { For HERB4S SLOpe, } \\
\text { For INTRCPT2, B30 }\end{array}$ & & & \\
\hline $\begin{array}{l}\text { INTRCPT3, G300 } \\
\text { For TOTRAT_M slope, P4 } \\
\text { For INTRCPT2, B40 }\end{array}$ & 0.054517 & 1.056030 & $(0.364,3.062)$ \\
\hline INTRCPT3, G400 & -1.749923 & 0.173787 & $(0.021,1.425)$ \\
\hline
\end{tabular}


Final estimation of level-1 and level-2 variance components:

\begin{tabular}{|c|c|c|c|c|c|c|}
\hline Random Effect & & $\begin{array}{l}\text { Standard } \\
\text { Deviation }\end{array}$ & $\begin{array}{l}\text { Variance } \\
\text { Component }\end{array}$ & $d f$ & Chi-square & P-value \\
\hline $\begin{array}{l}\text { INTRCPT1, } \\
\text { level-1, }\end{array}$ & $\begin{array}{l}\text { RO } \\
\text { E }\end{array}$ & $\begin{array}{l}0.00641 \\
1.00698\end{array}$ & $\begin{array}{l}0.00004 \\
1.01401\end{array}$ & 17 & 54.13577 & 0.000 \\
\hline
\end{tabular}

Final estimation of level-3 variance components:

\begin{tabular}{|c|c|c|c|c|c|}
\hline Random Effect & $\begin{array}{l}\text { Standard } \\
\text { Deviation }\end{array}$ & $\begin{array}{l}\text { Variance } \\
\text { Component }\end{array}$ & $d f$ & Chi-square & P-value \\
\hline INTRCPT1/INTRCPT2, U00 & 0.30885 & 0.09539 & 7 & 10.78593 & 0.148 \\
\hline
\end{tabular}

RESULTS FOR NON-LINEAR MODEL WITH THE LOGIT LINK FUNCTION:

Population Average Model
Sigma_squared $=$
0.97478
Standard Error of Sigma_squared =
0.05624

The value of the likelihood function at iteration $4=-8.678419 \mathrm{E}+002$

The outcome variable is MET

Final estimation of fixed effects: (Population-average model)

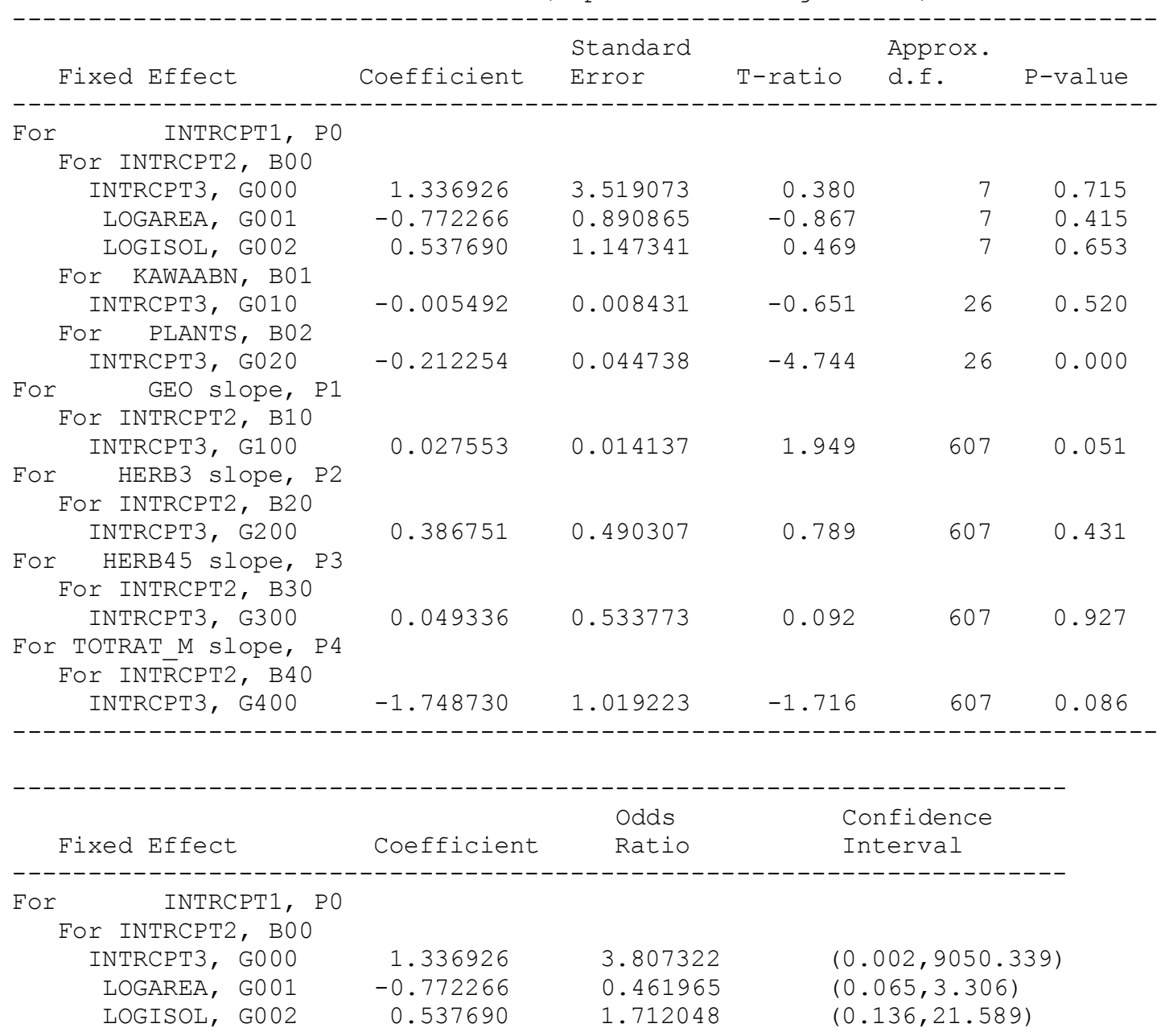




\begin{tabular}{|c|c|c|c|}
\hline $\begin{array}{l}\text { For KAWAABN, B01 } \\
\text { INTRCPT3, G010 }\end{array}$ & -0.005492 & 0.994523 & $(0.977,1.012)$ \\
\hline For PLANTS, B02 & & & \\
\hline $\begin{array}{l}\text { INTRCPT3, G020 } \\
\text { GEO slope, P1 }\end{array}$ & -0.212254 & 0.808759 & $(0.738,0.887)$ \\
\hline For INTRCPT2, B10 & & & \\
\hline $\begin{array}{l}\text { INTRCPT3, G100 } \\
\text { For HERB3 slope, P2 }\end{array}$ & 0.027553 & 1.027937 & $(1.000,1.057)$ \\
\hline For INTRCPT2, B20 & & & \\
\hline $\begin{array}{l}\text { INTRCPT3, G200 } \\
\text { HERB45 slope, P3 }\end{array}$ & 0.386751 & 1.472191 & $(0.563,3.851)$ \\
\hline For INTRCPT2, B30 & & & \\
\hline $\begin{array}{l}\text { INTRCPT3, G300 } \\
\text { For TOTRAT_M slope, P4 }\end{array}$ & 0.049336 & 1.050573 & $(0.369,2.992)$ \\
\hline $\begin{array}{c}\text { For INTRCPT2, B40 } \\
\text { INTRCPT3, G400 }\end{array}$ & -1.748730 & 0.173995 & $(0.024,1.284)$ \\
\hline
\end{tabular}

\section{Level 2 after removal of kawakawa abundance from the three-level model for $M$. pulchricornis}

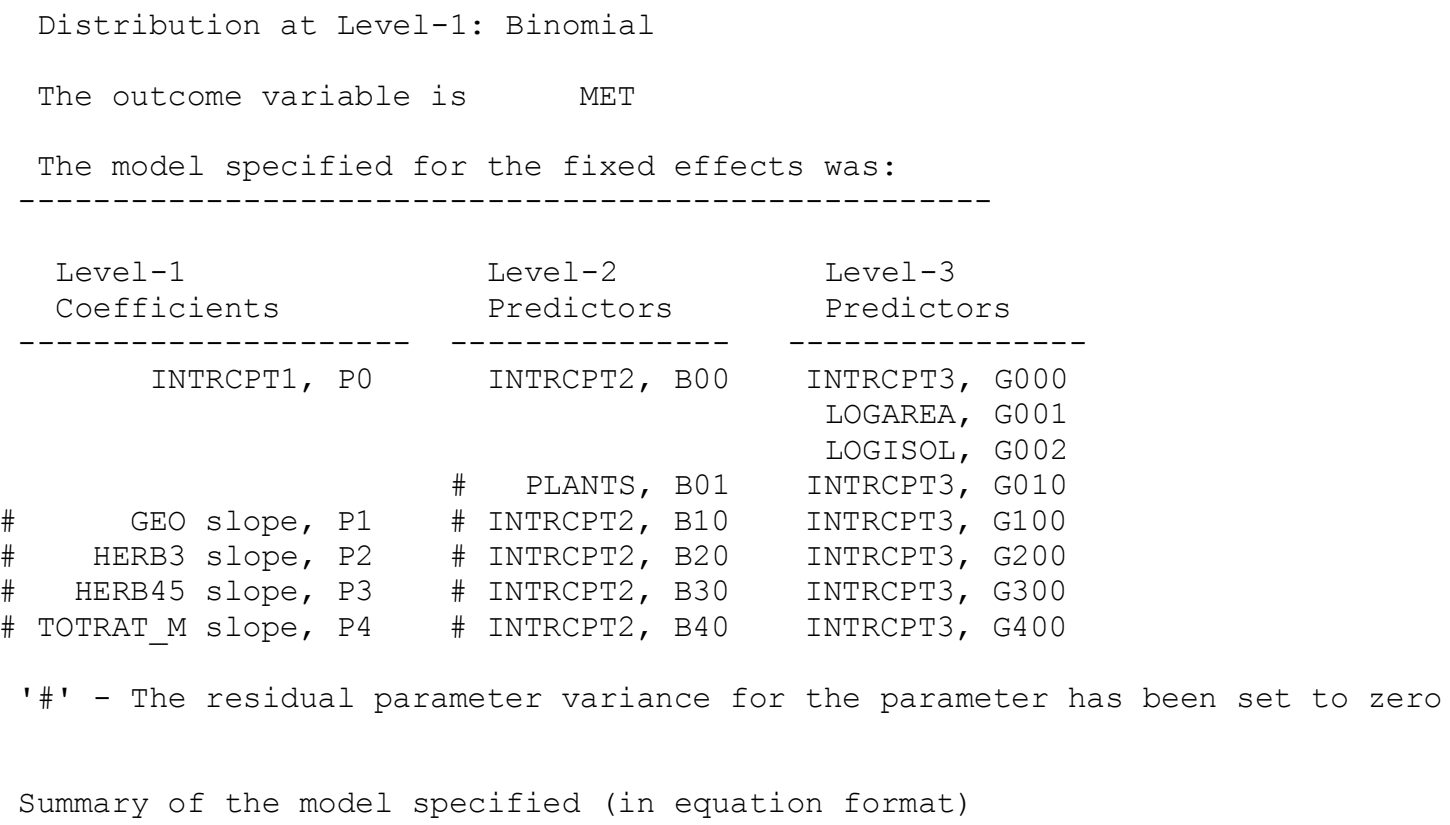


Level-3 Model

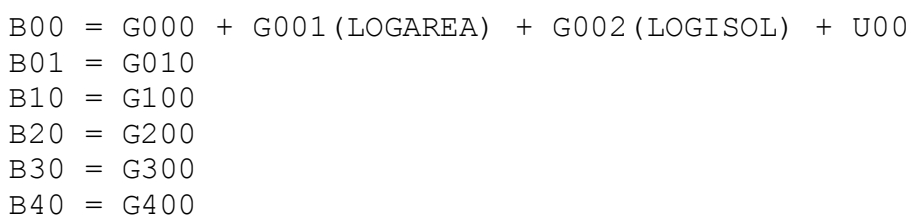


Final estimation of fixed effects: (Unit-specific model)

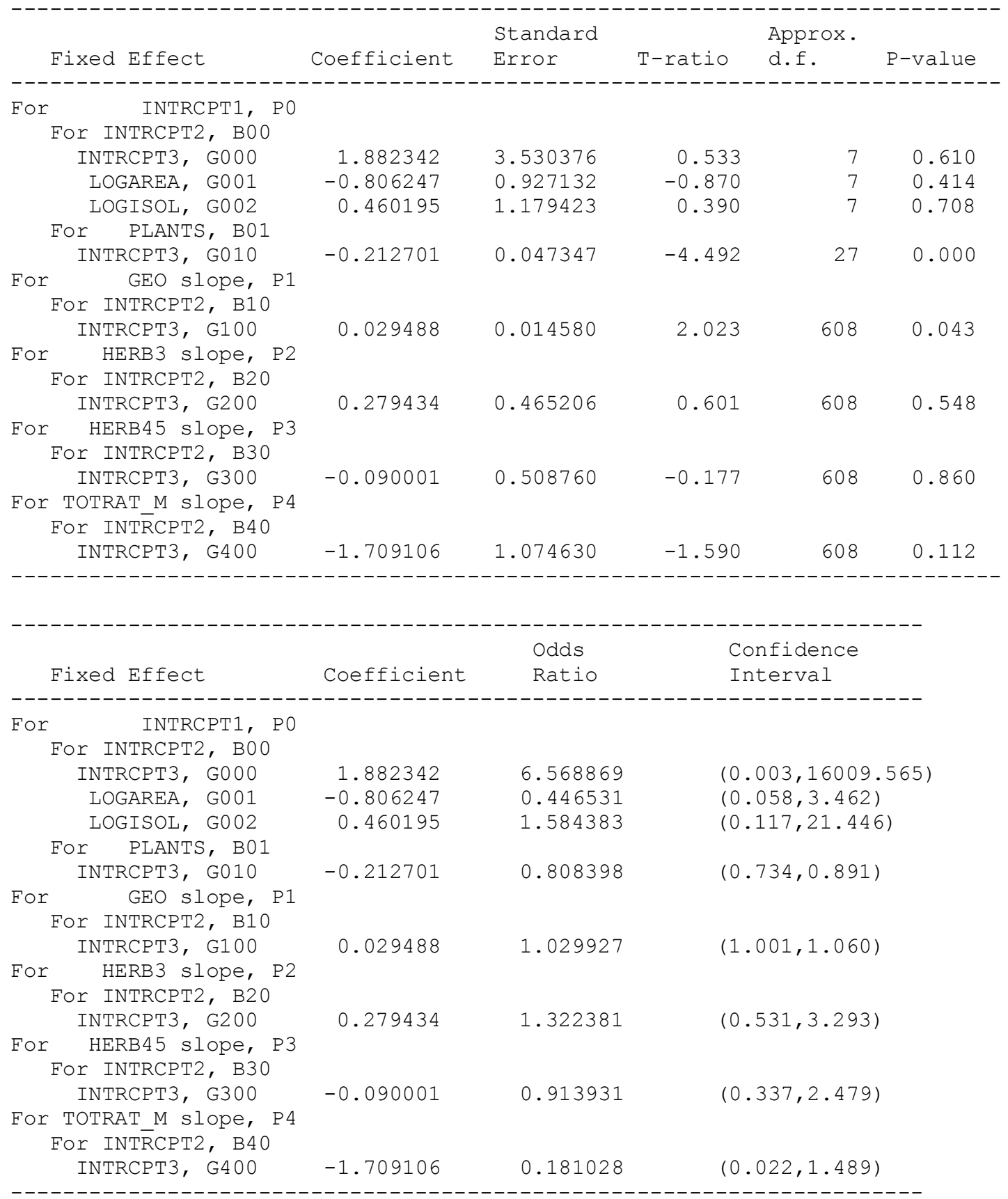

Final estimation of level-1 and level-2 variance components:

\begin{tabular}{|c|c|c|c|c|c|c|}
\hline Random Effect & & $\begin{array}{l}\text { Standard } \\
\text { Deviation }\end{array}$ & $\begin{array}{l}\text { Variance } \\
\text { Component }\end{array}$ & $d f$ & Chi-square & P-value \\
\hline $\begin{array}{l}\text { INTRCPT1, } \\
\text { level-1, }\end{array}$ & $\begin{array}{l}\text { R0 } \\
\text { E }\end{array}$ & $\begin{array}{l}0.00814 \\
1.01766\end{array}$ & $\begin{array}{l}0.00007 \\
1.03564\end{array}$ & 18 & 55.20767 & 0.000 \\
\hline
\end{tabular}


Final estimation of level-3 variance components:

\begin{tabular}{|c|c|c|c|c|c|}
\hline Random Effect & $\begin{array}{l}\text { Standard } \\
\text { Deviation }\end{array}$ & $\begin{array}{l}\text { Variance } \\
\text { Component }\end{array}$ & $d f$ & Chi-square & P-value \\
\hline INTRCPT1/INTRCPT2, U00 & 0.28707 & 0.08241 & 7 & 9.81405 & 0.199 \\
\hline
\end{tabular}

RESULTS FOR NON-LINEAR MODEL WITH THE LOGIT LINK FUNCTION:

Population Average Model
Sigma_squared $=$
0.99310
Standard Error of Sigma_squared =
0.05729

The value of the likelihood function at iteration $4=-8.733547 \mathrm{E}+002$

The outcome variable is MET

Final estimation of fixed effects: (Population-average model)

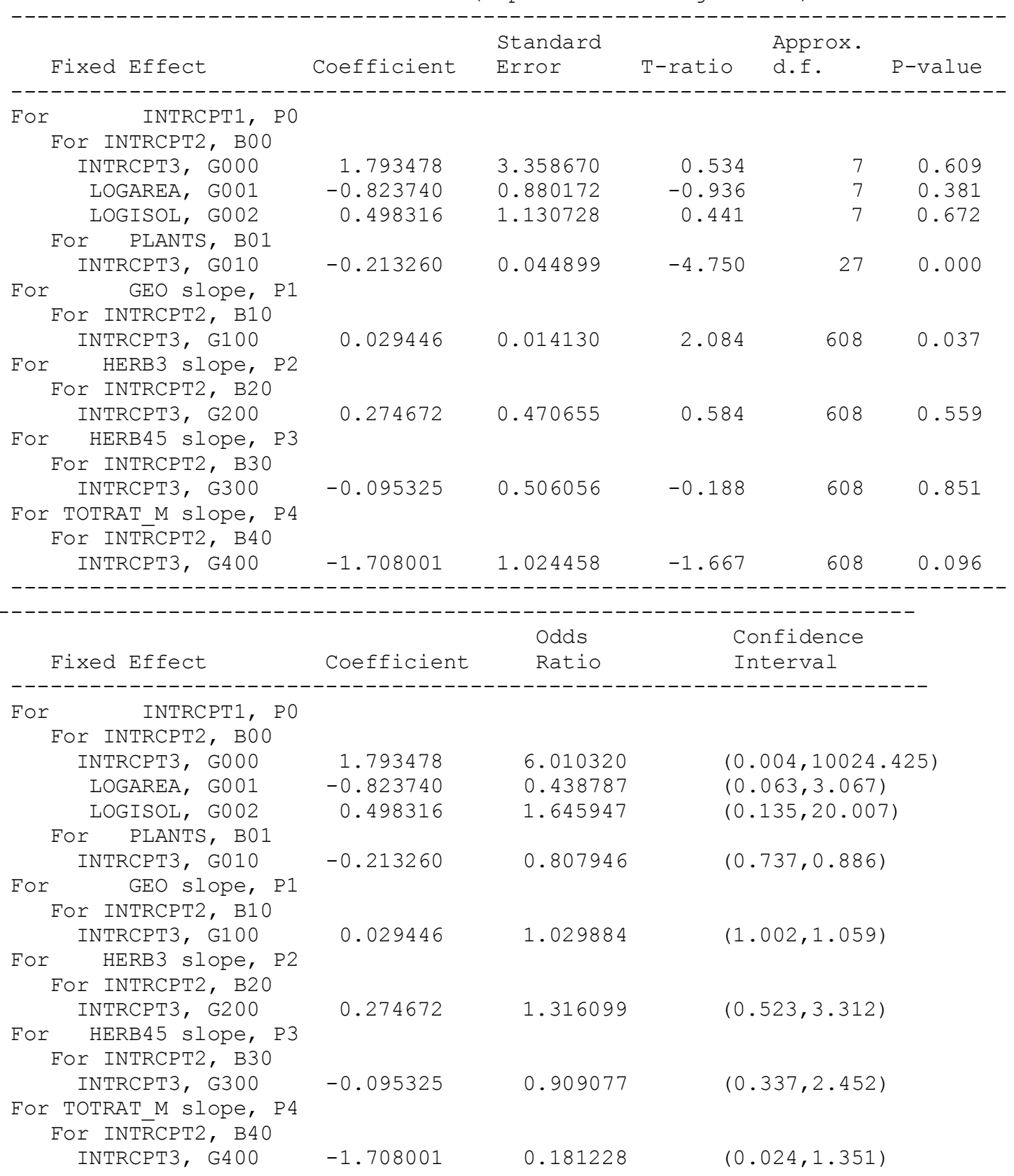




\section{Level 3 of the three-level model for M. pulchricornis}

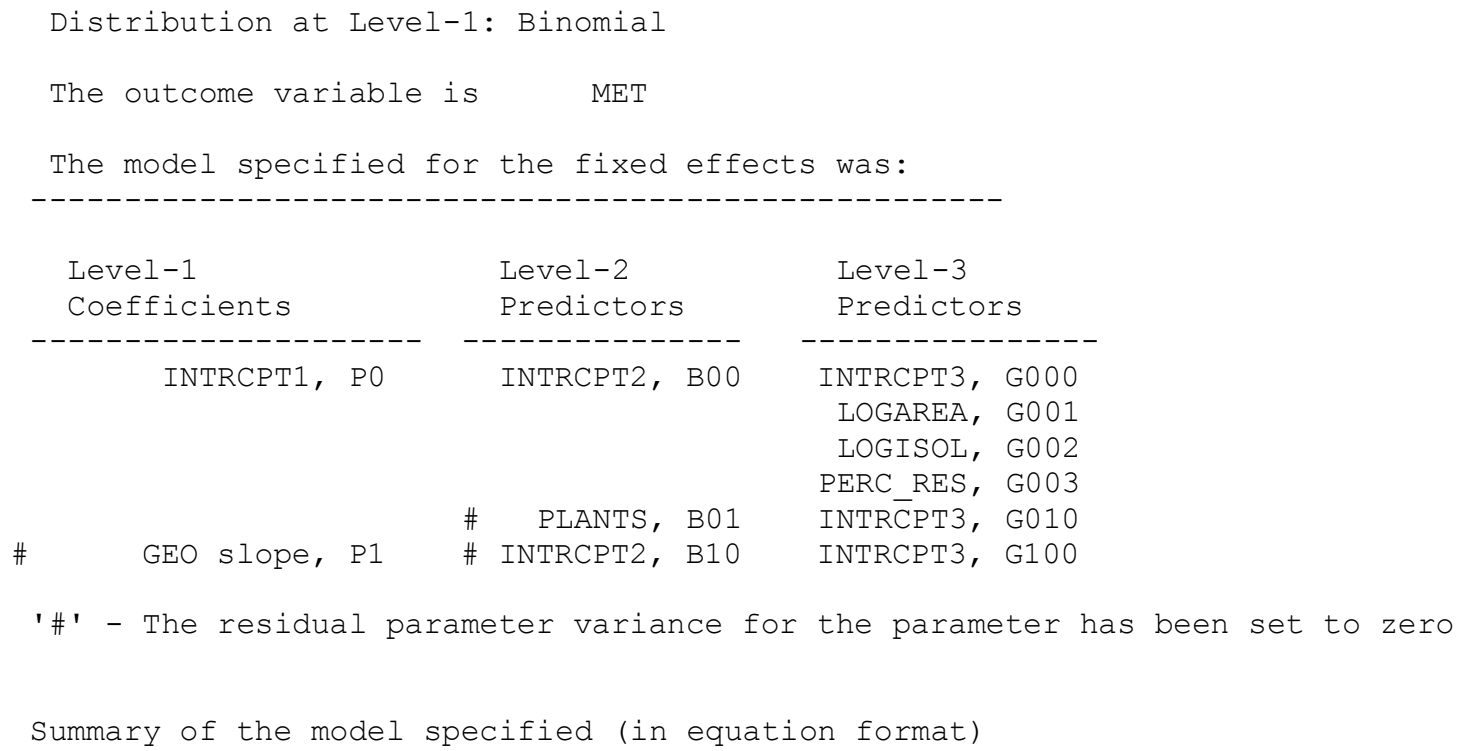




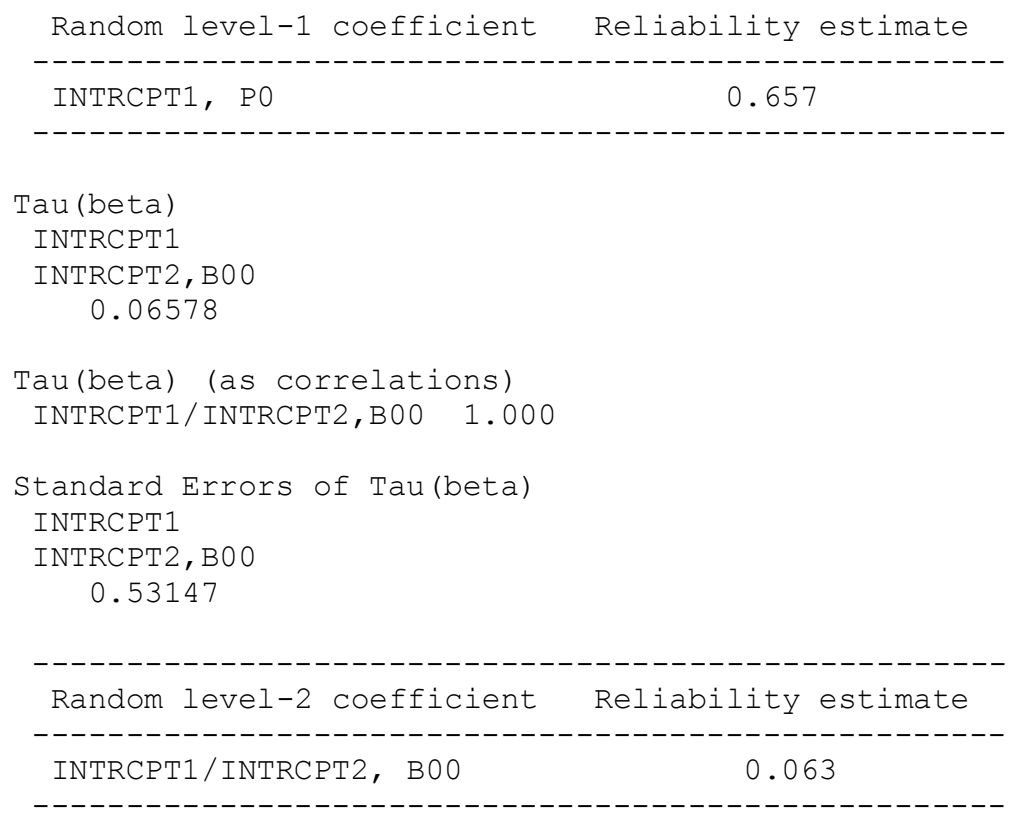

The value of the likelihood function at iteration $14=-7.539756 \mathrm{E}+002$

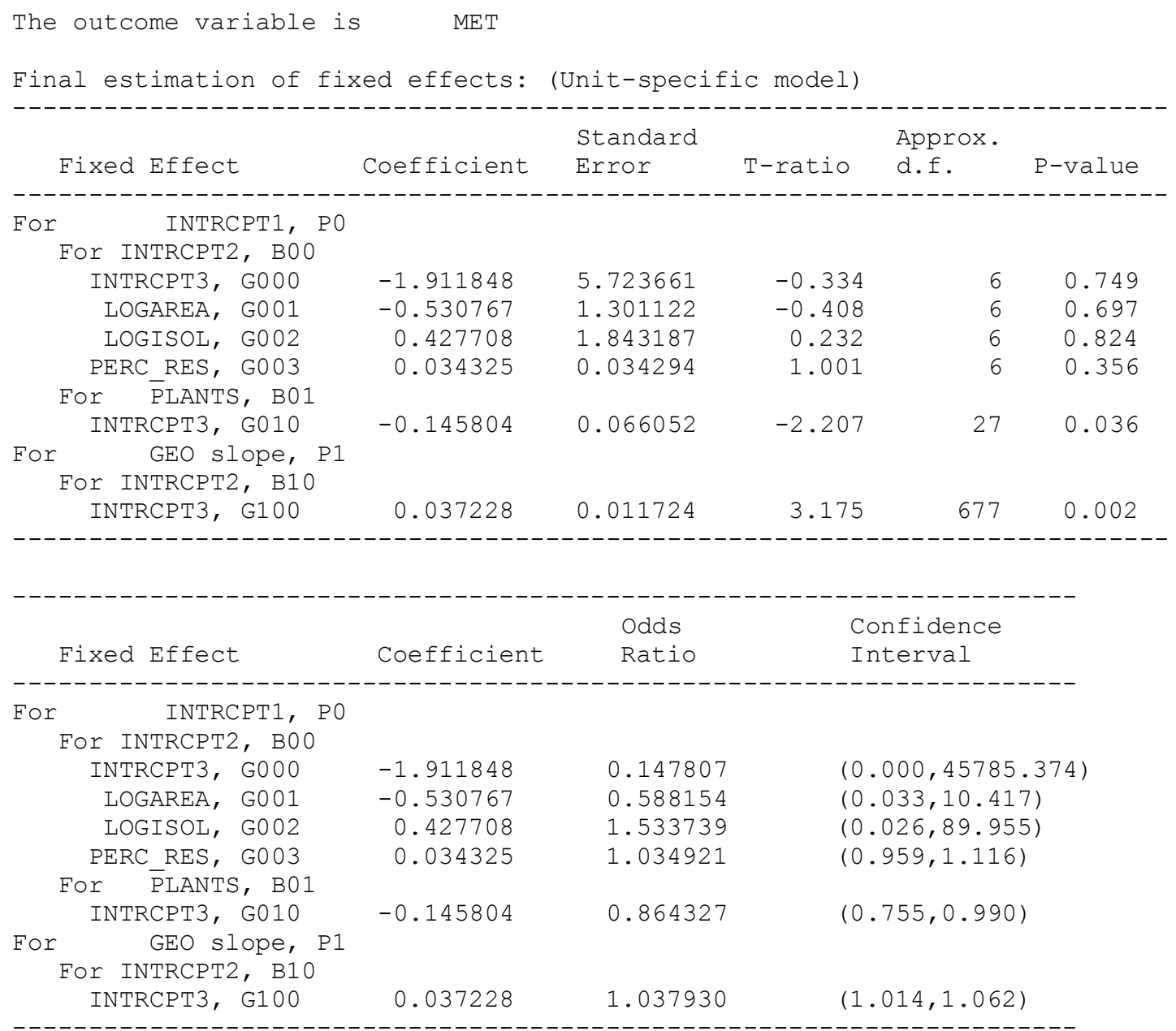


Final estimation of level-1 and level-2 variance components:

\begin{tabular}{|c|c|c|c|c|c|c|}
\hline Random Effect & & $\begin{array}{l}\text { Standard } \\
\text { Deviation }\end{array}$ & $\begin{array}{l}\text { Variance } \\
\text { Component }\end{array}$ & $d f$ & Chi-square & P-value \\
\hline -----ー-ー-ー-- & --- & ----------- & ----------- & ---1 r & --------- & ------ \\
\hline $\begin{array}{l}\text { INTRCPT1, } \\
\text { level-1, }\end{array}$ & $\begin{array}{l}\text { R0 } \\
\mathrm{E}\end{array}$ & $\begin{array}{l}1.36106 \\
0.70717\end{array}$ & $\begin{array}{l}1.85247 \\
0.50009\end{array}$ & 18 & 125.08183 & 0.000 \\
\hline
\end{tabular}

Final estimation of level-3 variance components:

\begin{tabular}{|c|c|c|c|c|c|}
\hline Random Effect & $\begin{array}{l}\text { Standard } \\
\text { Deviation }\end{array}$ & $\begin{array}{l}\text { Variance } \\
\text { Component }\end{array}$ & $d f$ & Chi-square & P-value \\
\hline NTRCPT1/INTRCPT2, U00 & 0.25648 & 0.06578 & 6 & 4.92217 & $>.500$ \\
\hline
\end{tabular}

RESULTS FOR NON-LINEAR MODEL WITH THE LOGIT LINK FUNCTION:

Population Average Model

Sigma_squared $=\quad 0.73074$

Standard Error of Sigma squared $=\quad 0.04037$

The value of the likelihood function at iteration $5=-8.847330 \mathrm{E}+002$

The outcome variable is MET

Final estimation of fixed effects: (Population-average model)

\begin{tabular}{|c|c|c|c|c|c|}
\hline Fixed Effect & Coefficient & $\begin{array}{l}\text { Standard } \\
\text { Error }\end{array}$ & T-ratio & $\begin{array}{l}\text { Approx. } \\
\text { d.f. }\end{array}$ & P-value \\
\hline \multicolumn{6}{|l|}{$\begin{array}{l}\text { For INTRCPT1, P0 } \\
\text { For INTRCPT2, B00 }\end{array}$} \\
\hline INTRCPT3, G000 & -6.210247 & 5.315444 & -1.168 & 6 & 0.287 \\
\hline LOGAREA, G001 & -0.863242 & 1.122692 & -0.769 & 6 & 0.471 \\
\hline LOGISOL, G002 & 1.521135 & 1.645262 & 0.925 & 6 & 0.391 \\
\hline PERC_RES， G003 & 0.023345 & 0.031528 & 0.740 & 6 & 0.487 \\
\hline \multicolumn{6}{|l|}{ For $\overline{\text { PLANTS, }}$ B01 } \\
\hline \multicolumn{6}{|l|}{ For GEO slope, P1 } \\
\hline \multicolumn{5}{|l|}{ For INTRCPT2, B10 } & 0.002 \\
\hline \multicolumn{6}{|c|}{----------------------------------------------------------------------} \\
\hline Fixed Effect & Coefficient & $\begin{array}{l}\text { Odds } \\
\text { Ratio }\end{array}$ & \multicolumn{3}{|c|}{$\begin{array}{l}\text { Confidence } \\
\text { Interval }\end{array}$} \\
\hline \multicolumn{6}{|l|}{$\begin{array}{l}\text { For INTRCPT1, P0 } \\
\text { For INTRCPT2, B00 }\end{array}$} \\
\hline INTRCPT3, G000 & -6.210247 & 0.002009 & \multicolumn{3}{|c|}{$(0.000,252.540)$} \\
\hline LOGAREA, G001 & -0.863242 & 0.421793 & \multicolumn{3}{|c|}{$(0.035,5.037)$} \\
\hline LOGISOL, G002 & 1.521135 & 4.577418 & \multicolumn{3}{|c|}{$(0.121,173.386)$} \\
\hline PERC_RES， G003 & 0.023345 & 1.023619 & \multicolumn{3}{|c|}{$(0.955,1.097)$} \\
\hline \multicolumn{6}{|l|}{ For $\overline{\text { PLANTS, }}$ B01 } \\
\hline INTRCPT3, G010 & -0.095109 & 0.909274 & \multicolumn{3}{|c|}{$(0.810,1.021)$} \\
\hline \multicolumn{6}{|l|}{ For GEO slope, P1 } \\
\hline INTRCPT3, G100 & 0.031596 & 1.032100 & & $012,1.053$ & \\
\hline
\end{tabular}


Appendix 4.6: Summary of results for herbivory at each level of model building process.

\section{Unconditional two-level model for herbivory}

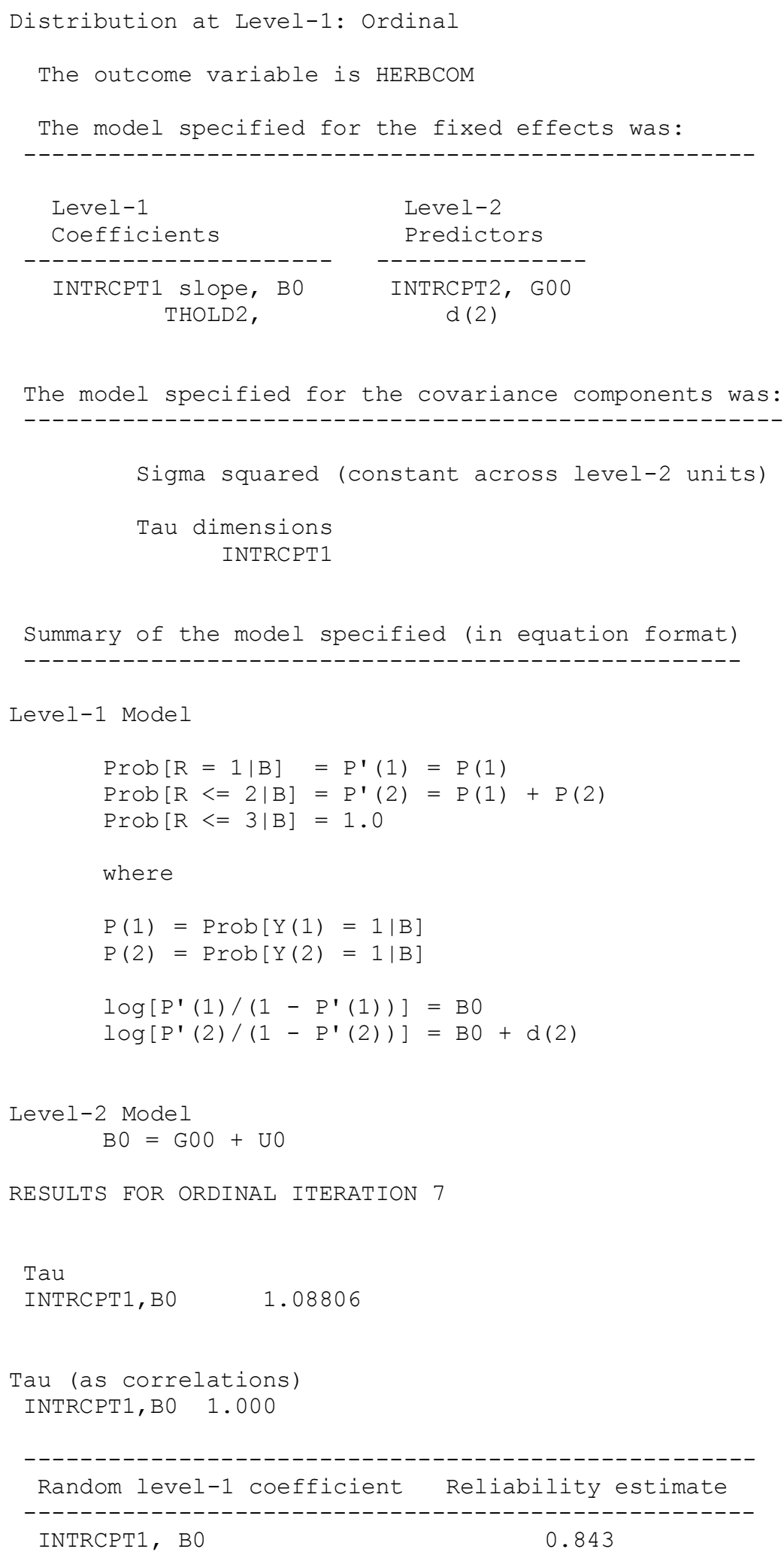

The value of the likelihood function at iteration $2=-1.161682 \mathrm{E}+003$ 


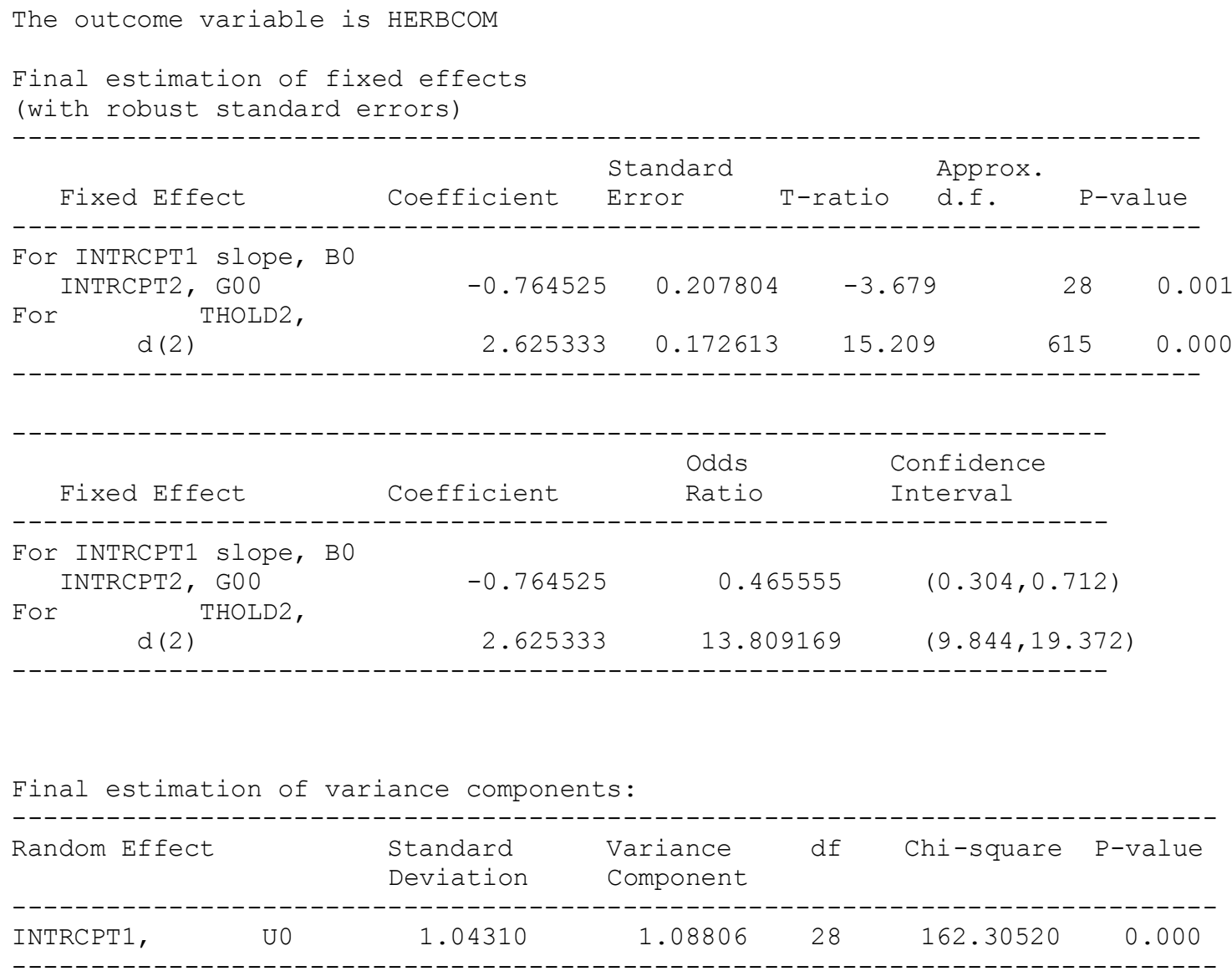

\section{Level 1 model for herbivory}

Distribution at Level-1: Ordinal

The outcome variable is HERBCOM

The model specified for the fixed effects was:

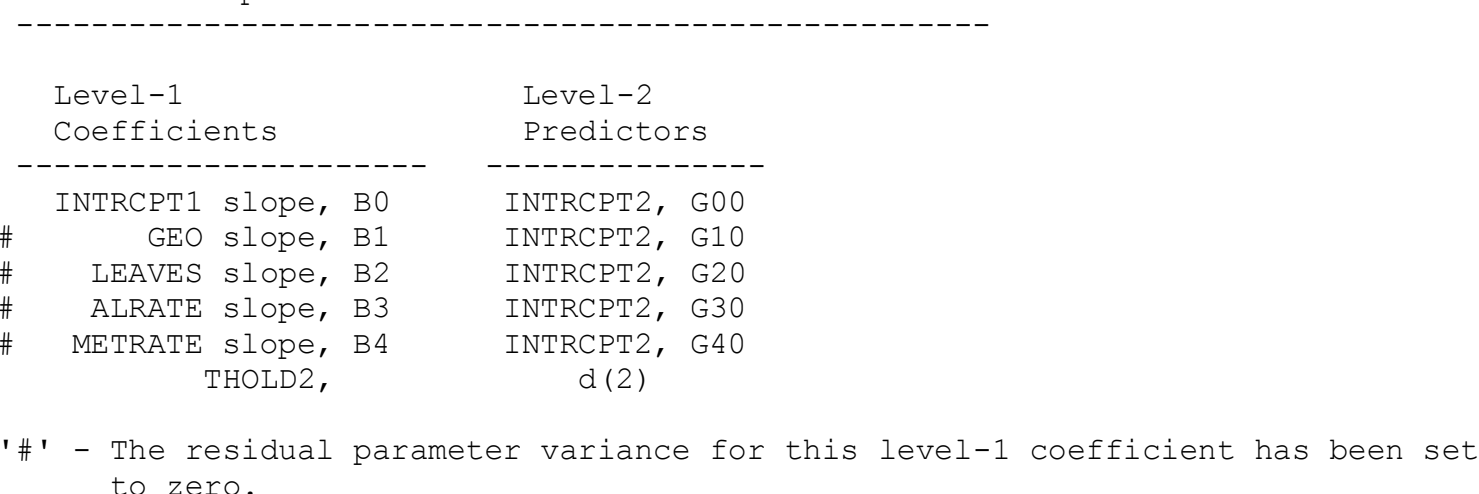

The model specified for the covariance components was:

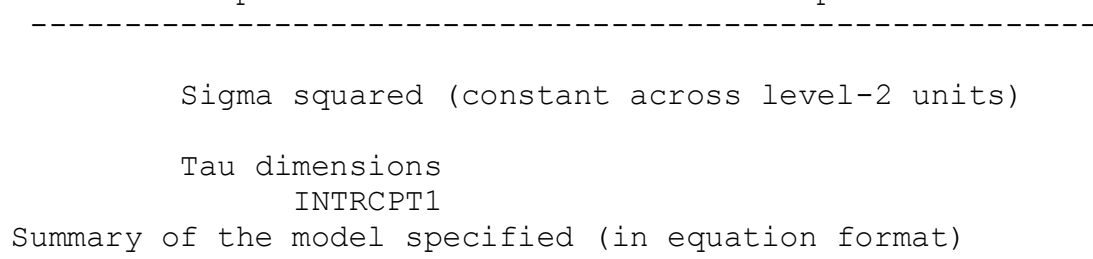


Level-1 Model

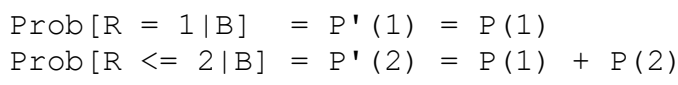

RESULTS FOR ORDINAL ITERATION 7

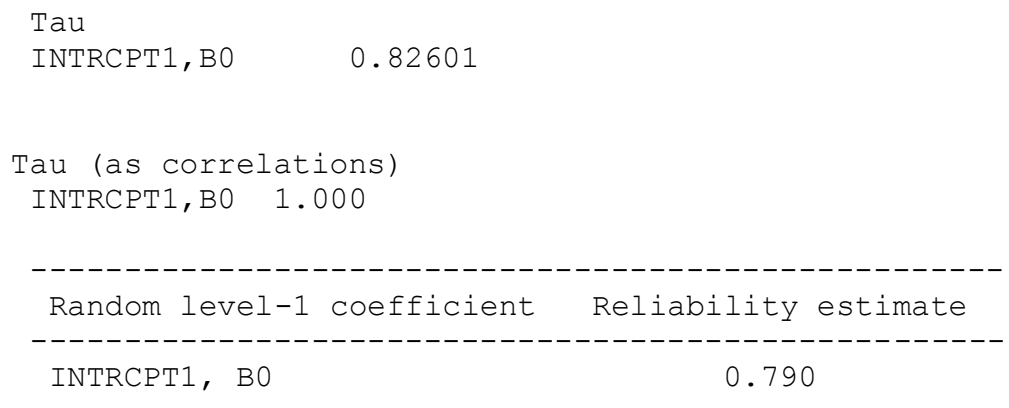




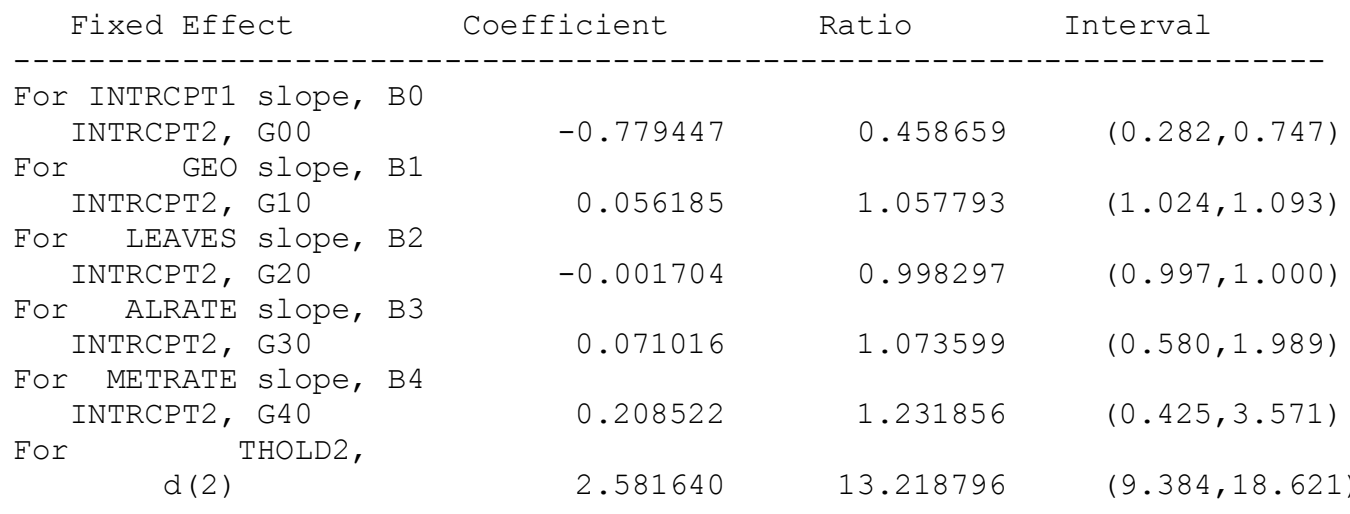

Final estimation of variance components:

\begin{tabular}{|c|c|c|c|c|c|c|}
\hline Random Effect & & $\begin{array}{l}\text { Standard } \\
\text { Deviation }\end{array}$ & $\begin{array}{l}\text { Variance } \\
\text { Component }\end{array}$ & $d f$ & Chi-square & P-value \\
\hline--1 & --- & ----------- & ---------- & -- & ----------1 & -------- \\
\hline INTRCPT1, & UO & 0.90885 & 0.82601 & 28 & 125.81802 & 0.000 \\
\hline
\end{tabular}

\section{Level 2 model for herbivory}

Distribution at Level-1: Ordinal

The outcome variable is HERBCOM

The model specified for the fixed effects was:

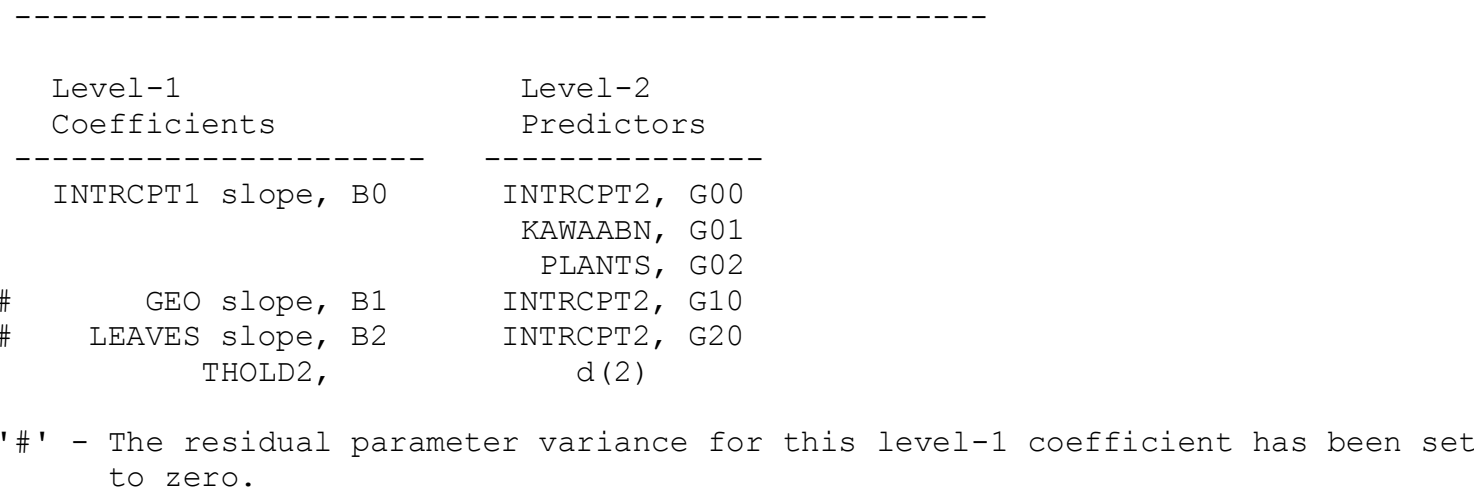

The model specified for the covariance components was:

Sigma squared (constant across level-2 units)

Tau dimensions INTRCPT1

Summary of the model specified (in equation format)

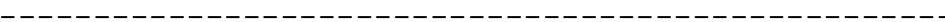

Level-1 Model

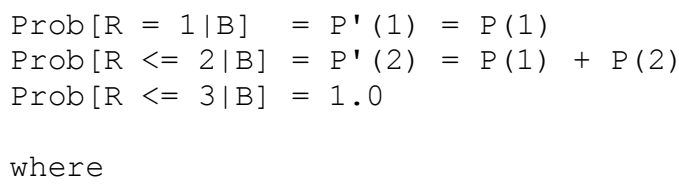




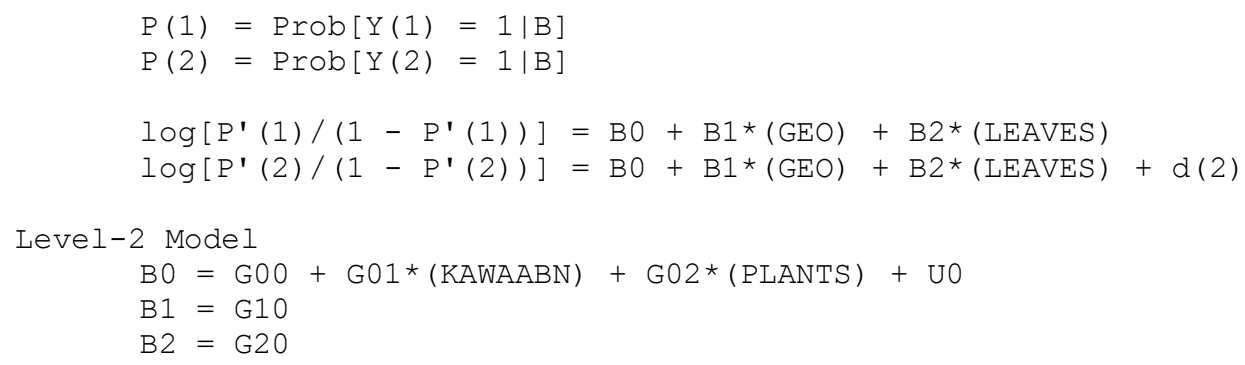

RESULTS FOR ORDINAL ITERATION 8

Tau
INTRCPT1, B0
0.73891

Tau (as correlations)

INTRCPT $1, \mathrm{~B} 01.000$

Random level-1 coefficient Reliability estimate
-1 INTRCPT1, B0

The value of the likelihood function at iteration $2=-1.064709 \mathrm{E}+003$

The outcome variable is HERBCOM

Final estimation of fixed effects

(with robust standard errors)

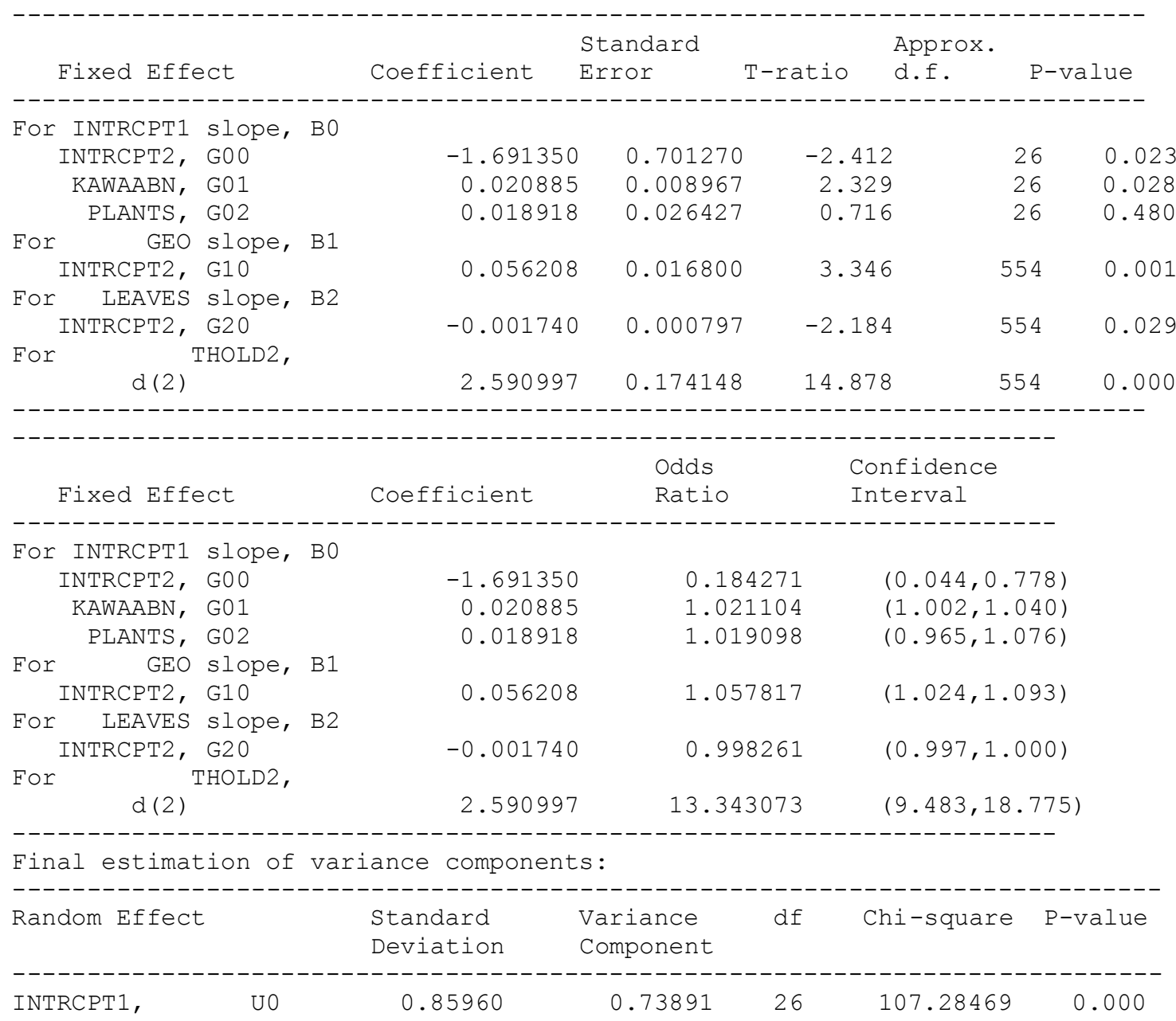




\section{Appendix 4.7}

\section{Larval parasitoids reared from Cleora scriptaria}

\section{(Geometridae: Ennominae) ${ }^{1}$}

The kawakawa moth, Cleora scriptaria (Walker 1860) (=Selidosema panagrata) is found throughout the North, South and Stewart Islands. The larvae of $C$. scriptaria are found predominantly on kawakawa, Macropiper excelsum Forst. f. and related species (Beever 1987, Hudson 1928, Spiller \& Wise 1982). It is the feeding behaviour of the larvae that causes the characteristic 'riddled' look of the kawakawa leaves. There are a number of other invertebrates that are also associated with kawakawa and some of these are mentioned by Hodge et al. (2001), Hodgson \& Henderson (2000) and Spiller et al. (1982). More details about the moth, its larval growth and relationship with the kawakawa plant are given by Baird (1983), who recorded some parasitoids reared from kawakawa moth larvae collected in the field.

Despite these studies there is very little known about the relationship and interactions of the kawakawa moth and its hosts, its competing herbivores, and the predators and parasitoids of the moth. In our studies, we collected 2133 kawakawa moth larvae from approximately 300 kawakawa trees in 10 fragments of native bush across the Wellington and Hutt Valley region during the summer months of 2002/03 and 2003/ 04. In addition, we collected 279 larvae from Otari-Wilton bush and 240 larvae from one small central city section in the gardens of the Kelburn campus of Victoria University of Wellington

${ }^{1}$ Based on: Schnitzler, F.-R., Sarty, M. \& Lester, P. J. (2004) Larval parasitoids reared from Cleora scriptaria (Geometridae: Ennominae). The Weta, 28, 13-18. 
during the summer months of 2003/04. Larvae were collected by beating kawakawa trees and brought into the laboratory for rearing. We reared the larvae at $20^{\circ} \mathrm{C}$ and $65 \%$ relative humidity, some on multi-purpose diet (Singh 1983) and some on kawakawa leaves in petri dishes. From these larvae we reared five species of solitary hymenopteran endoparasitoids, one tachinid and one nematode (Table 1) at differing rates (Fig. 1). By contrast, Baird (1983) reared two hymenopteran, one tachinid and one nematode species from C. scriptaria.

Table 1. Parasitoids reared from Cleora scriptaria larvae and associated rearing information.

\begin{tabular}{lccc}
\hline \multicolumn{1}{c}{ Parasitoid } & $\begin{array}{c}\text { Earliest } \\
\text { instar } \\
\text { parasitised }\end{array}$ & $\begin{array}{c}\text { Parasitoid } \\
\text { emerged at } \\
\text { host instars }\end{array}$ & $\begin{array}{c}\text { Average } \\
\text { emergence } \\
\text { time (days ) }\end{array}$ \\
\hline $\begin{array}{l}\text { Pales Robineau-Desvoidy sp. (Diptera: } \\
\text { Tachinidae: Goniinae) }\end{array}$ & 3 & pupae & 10 \\
$\begin{array}{l}\text { Meteorus pulchricornis (Wesmael) } \\
\text { (Hymenoptera: Braconidae: Euphorinae) }\end{array}$ & 1 & $3-5$ & 9 \\
$\begin{array}{l}\text { Rogas sp. (Hymenoptera: Braconidae: } \\
\text { Rogadinae) }\end{array}$ & 1 & $3-5$ & 11 \\
$\begin{array}{l}\text { Microgastrinae (Hymenoptera: } \\
\text { Braconidae) }\end{array}$ & 2 & $3-4$ & 14 \\
$\begin{array}{l}\text { Diadegma Förster sp. (Ichneumonidae: } \\
\text { Campopleginae) }\end{array}$ & 3 & 5 & 12 \\
Casinaria Holmgren (Ichneumonidae: & & & \\
Campopleginae) & 2 & 5 & 17 \\
(Mermithida: Nematoda: Mermithidae) & 2 & $2-5$ & \\
\hline
\end{tabular}

In addition we collected two Rogas sp. (Braconidae: Rogadinae) pupae from kawakawa, of which we found one case to be hyper-parasitised by the endemic species Zealachertus binarius Berry 1999 (Eulophidae: Eulophinae). This seems to be the first record of $Z$. 
binarius as a hyper-parasitoid (J. Berry, personal communication) and the biology of this species was previously unknown (Berry 1999).

The final larval instars of the two Campopleginae species, the unknown Microgastrinae species and Meteorus pulchricornis (Braconidae: Euphorinae) emerged from and pupated outside their host (Fig. 2). The Microgastrinae species we reared was unusual in that only one individual was reared from all the larvae collected, and only one further specimen was found but this subsequently died while trying to spin its cocoon. The reared specimen was a male and no further identification could be established.

Meteorus pulchricornis suspends its pupal cocoon from a thread attached to leaves or branchlets. This species is a relatively recent arrival to New Zealand and was first recorded as an accidental introduction in 1996 (Berry 1997). To our knowledge this is the first record of $M$. pulchricornis reared from $C$. scriptaria (see also Berry \& Walker 2004). Cleora scriptaria larvae collected from the Victoria University of Wellington garden had the highest rate of parasitism by M. pulchricornis (Fig. 1). 


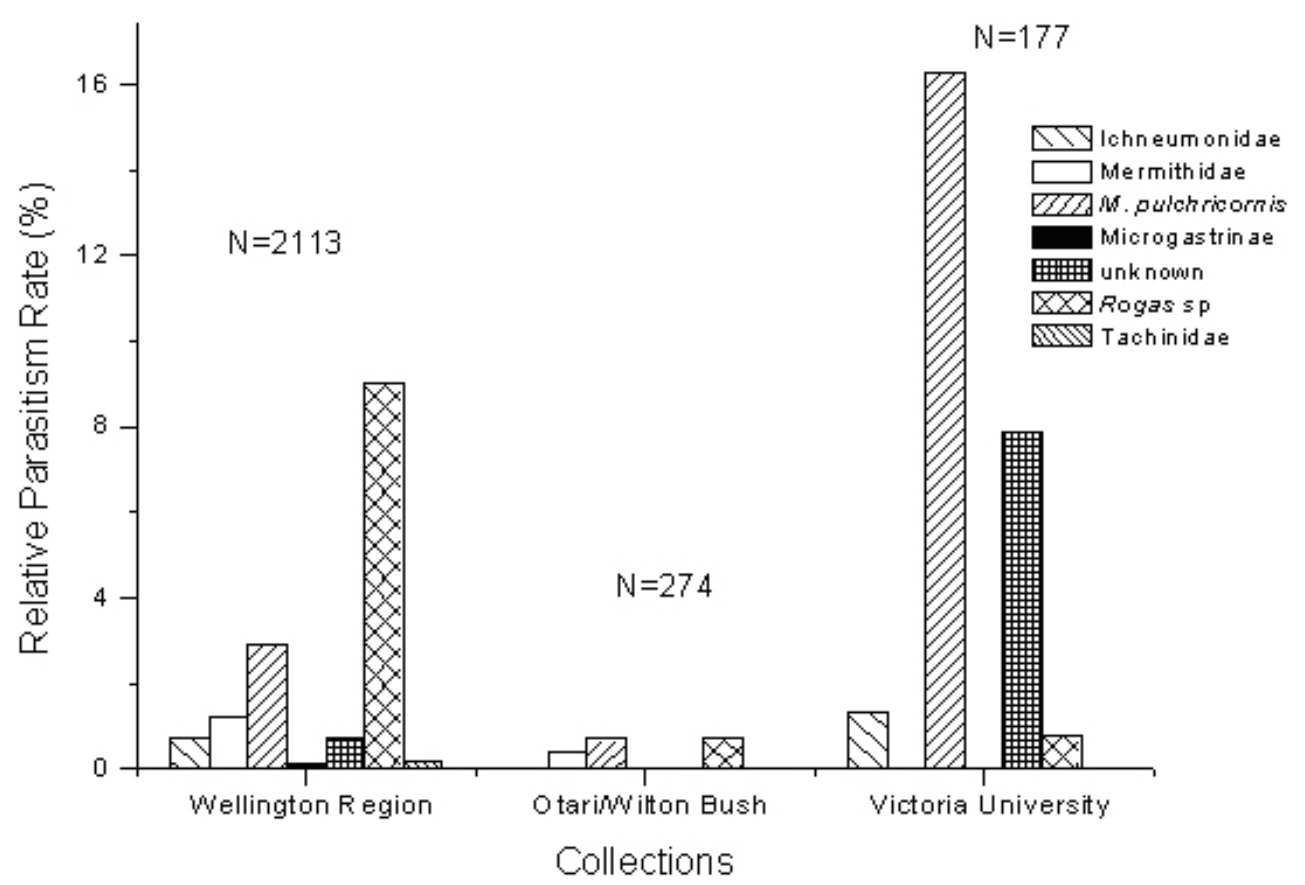

Figure 1. Relative parasitism rates of five parasitoids utilising Cleora scriptaria as a host at different collecting sites in urban Wellington, New Zealand.

These gardens represent a highly modified environment, and across the Wellington region, in general, parasitism rates were higher in the smaller native habitat fragments. Berry \& Walker (2004) state that all previous host records of M. pulchricornis are from modified habitats.

In contrast to the other Hymenoptera, the Rogas sp. larva secretes a gluey substance through the oral opening of the head when ready to pupate. That way the host larvae is glued to a leaf and mummifies as a cocoon in which the parasitoid pupates. Rogas sp. is also known to parasitise Pseudocoremia suavis Butler 1879 and Declana floccosa Walker 1858 (L. Berndt, personal communication). Like C. scriptaria, these two hosts also belong to the Ennominae. 
The Diadegma sp. is not the common introduced species and all specimens reared were females. Of the Casinaria sp. we reared both males and females. In New Zealand there are three undetermined species of Casinaria and around 50 undescribed species of Diadegma, with very few described species in either genus (J. Berry, personal communication).

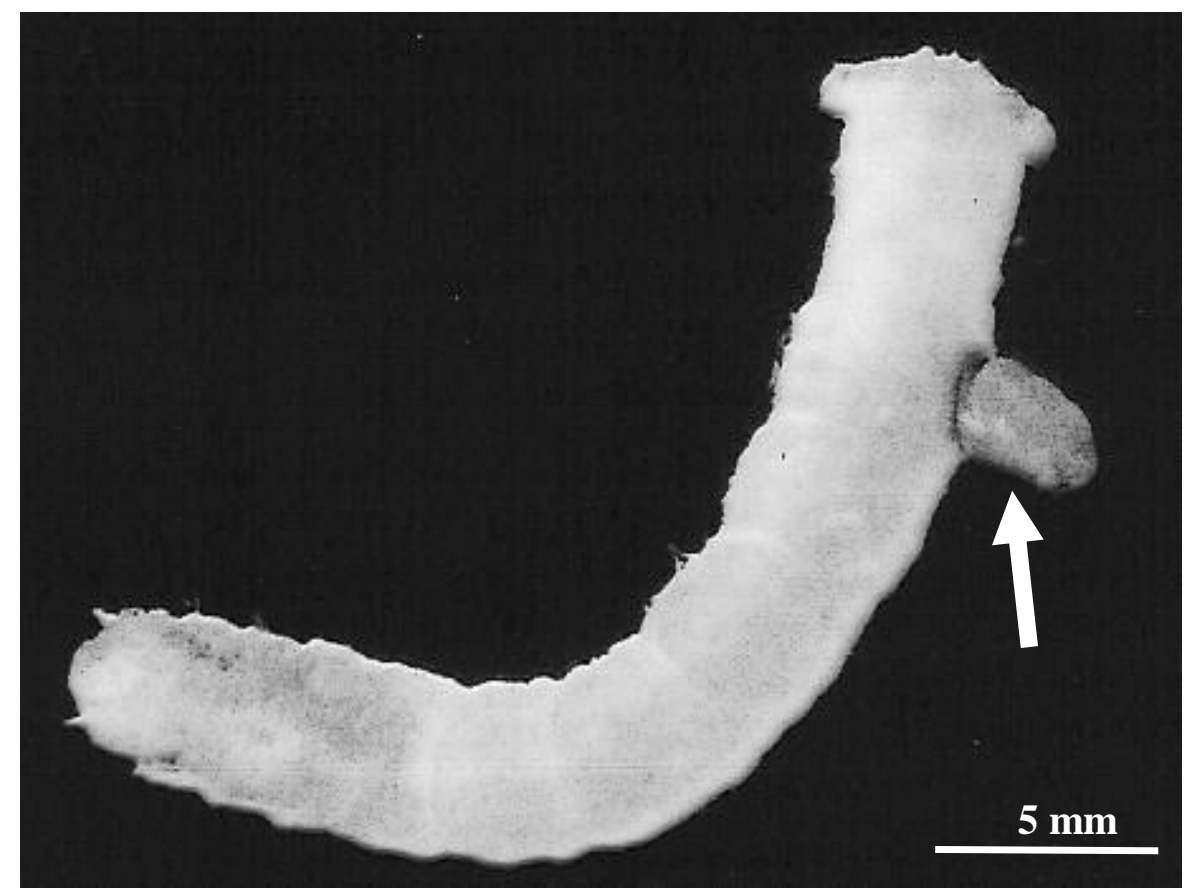

Figure 2. Ichneumonid parasitoid larva (indicated by arrow) emerging from a 5th instar Cleora scriptaria larva.

The tachinid fly we reared from Cleora scriptaria is possibly Pales feredayi Hutton 1881, but we were unable to confirm this identification. Valentine (1967) lists P. feredayi as a parasitoid of $C$. scriptaria amongst a range of other geometrid host species. This parasitoid is solitary and does not pupate until after its host has formed a pupa itself, and the remains of the tachinid's pupal case remain inside the pupal case of its host. Since the 
larvae of $C$. scriptaria pupate in the top soil and spin a lose cocoon around themselves (Hudson 1928), the tachinid parasitoid would have to emerge from the soil.

We observed between one and seven mermithid nematode individuals emerging from parasitised $C$. scriptaria larvae, with an average length of about $25 \mathrm{~mm}$. Nematodes of the family Mermithidae are known to parasitise a wide range of insects. The adult mermithids typically live free in the environment (G. Yeates, personal communication) and only sexually mature animals can be positively identified (Helmut 1991). Voucher specimens of all reared parasitoids have been deposited in the New ZealandArthropod Collection (NZAC) and at the Museum of New Zealand, Wellington (Te Papa Tongarewa), except for Z. binarius which we deposited only at NZAC.

\section{Acknowledgements}

We would like to thank the Karori Wildlife Sanctuary, the Wellington Regional Council, the City Councils of Wellington, Hutt City and Upper Hutt for collecting permission. Funding in part was provided by Victoria University of Wellington, the 21st Anniversary Research Fund of the Entomological Society NZ . For identification of specimens we would like to thank Jo Berry, John Dugdale, Allan Heath and Gregor Yeates. We also would like to thank Stephen Hartley, Vaughn Bell and all the "bug group" members at Victoria University of Wellington.

\section{References}

Baird KA. 1983. The Relationship between the Lepidopteran Cleora scriptaria and its Host Plant Macropiper excelsum. Unpublished MSc thesis, Auckland University, Auckland. 
Beever RE. 1987. The holes in the leaves of kawakawa (Macropiper excelsum). Auckland Botanical Society Newsletter 42:9-11.

Berry JA. 1997. Meteorus pulchricornis Wesmael (Hymenoptera: Braconidae: Euphorinae), a new record for New Zealand. New Zealand Entomologist 20:45- 48.

Berry JA. 1999. Revision of the New Zealand endemic eulophid genus Zealachertus Boucek (Hymenoptera: Chalcidoidea). Invertebrate Taxonomy 13:883-915.

Berry JA, Walker G.P. 2004. Meteorus pulchricornis (Wesmael) (Hymenoptera : Braconidae : Euphorinae): an exotic polyphagous parasitoid in New Zealand.

Helmut K. 1991. Terrestial and Semiterrestrial Mermithidae. In: Manual of Agricultural Nematology (ed WR Nickle), pp. 1035. Marcel Dekker, Inc, New York.

Hodge S, Frampton C, Marris J, Keesing V, Vink, C. 2001. The trophic structure of the arthropod assemblage on kawakawa, a New Zealand understory tree. Entomologist's Monthly Magazine 137:173-178.

Hodgson CJ, Henderson RC. 2000. Coccidae (Insecta: Hemiptera: Coccoidea). Fauna of New Zealand 41, Manaaki Whenua Press, Landcare Research, Lincoln, New Zealand. 264pp.

Hudson GV. 1928. The Butterflies and Moths of New Zealand. Ferguson and Osborne, New Zealand.

Singh P. 1983. A general purpose laboratory diet mixture for rearing insects. Insect Science and its Application 4:357-362.

Spiller DM, Wise KAJ. 1982. A catalogue (1860-1960) of New Zealand insects and their host plants. DSIR Science Information Division Bulletin. DSIR, Wellington.

Valentine EW. 1967. A list of the hosts of entomophagous insects of New Zealand. New Zealand Journal of Science 10:1100-1209. 


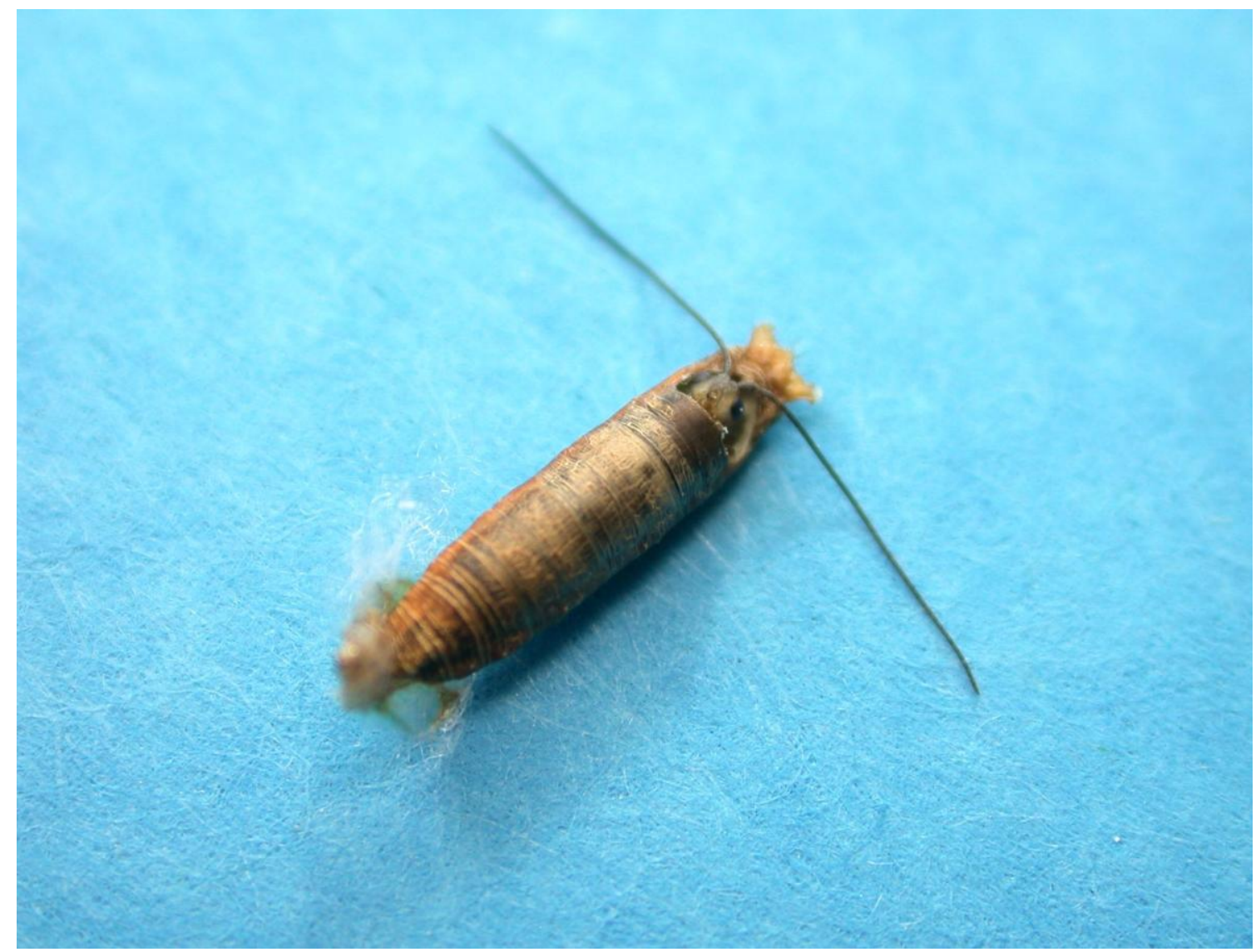

Aleiodes declanae emerging from the mummified remains of Cleora scriptaria 


\title{
Trophic level responses to forest fragmentation: Effects and implications
}

\begin{abstract}
"The bottom line is that complex landscapes beget complex interactions and it will require some clever manipulative experiments to untangle the often confounding effects of boundary quantity, boundary quality, matrix habitat, patch area and patch isolation ..."
\end{abstract}

(Hunter, 2002 p. 162)

\section{$5.1 \quad$ Introduction}

Aspects of the results from this thesis conflict with the trophic-level hypothesis of island biogeography, which states that species at higher trophic levels in a community are more prone to the effects of fragmentation than species at lower levels (Holt et al., 1999; Kareiva, 1987; Kruess \& Tscharntke, 1994). My findings do, however, reinforce the statement by van Nouhuys (2005) that species responses to habitat fragmentation at the higher trophic levels are inconsistent. I found both positive and negative parasitoid responses to habitat fragmentation, as have others (Doak, 2000; Roland \& Taylor, 1997; Roth, Roland \& Roslin, 2006; Thiel, Driessen \& Hoffmeister, 2006). More questions emerged from this thesis, which could lead on to future research. Species responses to forest fragmentation varied and differed between fragments, independent of the fragmentation properties measured. Given the findings of this thesis, the limited knowledge about the species biology and to conserve species diversity, my recommendations for the management of urban habitat reserves and forest fragments are, that all fragments should be considered valuable. I recommend maintaining and 
enhancing all types of existing forest fragments to prevent species extinctions. Below I discuss these findings further.

The three parasitoid wasp families Ichneumonidae, Pompilidae and Proctotrupidae from the Wellington region in New Zealand were used to assess the effects of forest fragmentation at higher trophic levels. I examined whether the abundances, richness or diversity of parasitoids, as well as the community assemblage, might be influenced by fragment area, isolation, and residential build-up within the landscape matrix or the plant species richness within a fragment (Chapter 2). The fragmentation effects were investigated for the three families combined, for each family individually and for different body-size classes. The effects of the fragment characteristics such as area, isolation, percentage residential area and plant species richness were analysed in combination. Subsequent models were searched to reveal the combination of fragment characteristics best describing any resulting patterns in the species communities. Individual species were used to show whether species distributions are a result of the fragmentation elements.

To explain other than habitat fragmentation, the relationship between plant and parasitoid community was investigated to predict community structure at higher trophic levels across a fragmented forest landscape (Chapter 3). Whether parasitoid presence or absence can be predicted by the herbivore's host plants was further examined by focusing on the known Ichneumonidae species identified in this study and the known host plants of these parasitoids' hosts. 
The research focus was narrowed down to investigate the effects of habitat reduction and fragmentation on parasitoids, their hosts, and host-parasitoid interactions (i.e. rate of parasitism) (Chapter 4). For this I used the trophic system comprised of the plantherbivore-parasitoid communities of the naturally occurring kawakawa Macropiper excelsum Forst. f. (Piperaceae), its herbivore Cleora scriptaria (Walker 1860) (= Selidosema panagrata) (Lepidoptera: Geometridae) and the parasitoids of C. scriptaria.

\subsection{Effects of the fragment properties: Area, isolation, percentage residential area and plant species richness.}

\subsubsection{Area and isolation}

Fragment area, isolation, and plant species richness had a marked influence on the parasitoid community composition, but had no significant negative influences on the abundance, species richness and diversity of parasitoids. The only exceptions were the abundance, species richness and diversity for the small-bodied parasitoid community, which were negatively affected by an increase in area and plant richness combined (Chapter 2). Similarly, parasitism rates and herbivory were not affected as expected by the fragment properties investigated (Chapter 4). Parasitism rates by one parasitoid were higher in isolated fragments, which was the opposite trend to what I had expected (Chapter 4). In all cases, patterns observed within this thesis appear to be the result of influences other than the measured habitat fragmentation properties. These results are in contrast with studies that found reduced insect species richness and diversity with decreasing habitat area and increasing isolation (Kruess \& Tscharntke, 2000; SteffanDewenter \& Tscharntke, 2002) and are not in support of the trophic level hypothesis of 
island biogeography (Komonen et al., 2000; Kruess \& Tscharntke, 1994). However, the results within this thesis, uphold that habitat fragmentation can influence species compositions (Davies \& Margules, 1998; Gibb \& Hochuli, 2002). Other researchers have found that a small habitat fragment can harbour more insect species than a single large habitat of equivalent area within a larger habitat (Hunter, 2002; Tscharntke et al., 2002a, b). However, from my work it needs to be recognised that large fragments often harbour species that do not occur in small fragments, and populations in large fragments are likely to be more persistent. If habitat fragmentation occurs, one management implication from my work would be to keep as many fragments as possible. Conservation of fragment numbers should therefore be irrespective of fragment size.

Individual negative or positive species responses to habitat fragmentation were demonstrated. However, most of the individual species in this analysis were not significantly affected by the investigated fragment properties (Chapter 2). In addition, the amount of herbivory and the parasitism rate by $M$. pulchricornis were both independent of fragment area, isolation and percentage of residential area (Chapter 4). The positive response in parasitism by $A$. declanae to increasing isolation (Chapter 4 ) contradicts the trophic level hypothesis of island biogeography. My work shows that it is difficult to make generalisations about species responses to habitat fragmentation and that responses to fragmentation may be dependent on a multitude of factors. Especially, the positive response in parasitism rate by $A$. declanae to increasing isolation was an unexpected result, but a comparable response has been shown in several recent studies, which also provided some possible explanations. These were: parasitoids optimising foraging in relation to distance travelled to a fragment, fragment edge preventing a parasitoid leaving a fragment and thus increasing frequency of host encounter, increased larval densities in 
isolated fragments and differences in a parasitoid's reproduction mode (Doak, 2000; Roland \& Taylor, 1997; Roth, Roland \& Roslin, 2006; Thiel, Driessen \& Hoffmeister, 2006). Similarly, parasitoid abundance and richness per plot for both study years combined showed a negative response to increasing fragment area and a decrease in isolation, which is opposite to the plant richness response to fragment area and isolation (Chapter 3). Fragment area in my studies appeared to be less influential on parasitoid communities than isolation. Area alone was found to have no influence on the parasitoid assemblages (Chapter 2), and area was shown to have no influence on herbivory or parasitism rates (Chapter 4). Isolation alone significantly affected the Ichneumonidae assemblages (Chapter 2) and the total parasitoid community (Chapter 3). This is also the opposite result to what was expected because these communities are dominated by larger parasitoids able to fly better than smaller parasitoids. However, this result was also difficult to interpret because only the medium-small bodied species were significantly affected by isolation in combination with plant richness, whereas the medium-large bodied species, representing the largest group were not affected at all. Plant species richness, however, was significantly correlated to isolation and therefore might play an important role in determining parasitoid distributions.

\subsubsection{Plant richness}

Plant species richness was the most common indicator describing the community assemblages followed by isolation, which was followed by area (Chapter 2). Plant richness on its own, however, was a significant predictor only for the Pompilidae community composition (Chapter 2). Plant richness was not a strong predictor for the Ichneumonidae community assemblage and was only significant in combination with area and/or isolation (Chapter 2). Distributions of individual plants could not be 
correlated with the Ichneumonidae species that are known to be associated with those plants through the parasitoids hosts (Chapter 3) but, from the investigation of individual responses to plant richness, three species showed a significant increase in their abundances with increasing plant richness (Chapter 2). In contrast, the parasitism rate of M. pulchricornis declined with increasing plant richness, but parasitism by A. declanae as well as herbivory was not affected by plant species richness (Chapter 4). The differences in responses to plant species richness might be due to different factors. Such factors could include searching behavior by individual species dependent on habitat structure, which might be determined by plant richness. Habitat structure has been shown previously to determine community assemblages (Fraser, Dytham \& Mayhew, 2007; Lassau \& Hochuli, 2005). For example, the Pompilidae examined herein are spider-hunting wasps and their foraging is habitat dependent (Harris, 1987). Their habitat dependency might have its origin in the distribution of their hosts. Web building spiders are known to depend on the structural frame work provided by plants for web building. Such a framework is likely to change with changes in plant richness influencing both spider and Pompilidae distributions. Similarly, changes in herbivorous insect species richness and/or their densities may be associated with increasing or decreasing plant richness. Phytophagous insect communities are known to be determined by vegetation structure (Strauss \& Biedermann, 2006). Therefore, the decline of parasitism by M. pulchricornis with increasing plant richness (Chapter 4) could be the result of increasing herbivore richness expanding this parasitoid's host range and releasing C. scriptaria populations from this parasitoid. 


\subsubsection{Percentage residential area}

The percentage of residential area surrounding the forest fragments investigated had no effect on parasitoid abundance, richness and diversity or on the parasitoid community composition (Chapter 2). Parasitism rates by the parasitoids investigated in Chapter 4 and herbivory were both unaffected by residential area within the landscape matrix. The results encountered in my studies might be a consequence of parasitoid responses to the surrounding landscape matrix. This matrix is composed of native bush fragments, scrubland and residential gardens. Urban parks, gardens and roadside plantings may provide refuges for a diverse range of insect species and may provide corridors for the movement of insects through the urban matrix (Clark \& Samways, 1997; Smith et al., 2006b). If the surrounding matrix contains sufficient host populations as well as food plants for parasitoids, then the parasitoids encountered in the study sites could be migrating individuals.

\subsubsection{Fragment properties other than area, isolation, percentage residential and plant} species richness

In addition to fragment area, isolation, residential area and plant richness, the analyses in Chapters 2 and 3 showed that there was a significant effect of the factor fragment on the parasitoid communities. In fact, the proportion of the variation in the parasitoid communities explained by the factor fragment was much higher than the variation explained by the fragment properties investigated (Chapters $2 \& 3$ ). This fact indicates that fragment properties other than those measured may be influential on the parasitoid communities. There is also an indication that even plot level properties might be more influential on the parasitoid communities than forest fragmentation. Parasitoid species richness and species abundances were shown to decline with increasing area and 
decreasing isolation when viewed at the plot level (Chapter 3). However, parasitoid richness and abundance appear to vary within a fragment and therefore, when viewed at the fragment level only, appear to be non-responsive to area and isolation (Chapter 2). Further support that properties other than those examined maybe more important in shaping the communities investigated are found in Chapter 4. Here it was shown that herbivory by the kawakawa moth larvae was not determined by any fragment properties and varied less than one percent between fragments. At the plot level, host-plant (kawakawa) abundance was a determinant for the degree of herbivory, and plant species richness was indicative of parasitism rates by $M$. pulchricornis. Variations in rates of parasitism by $A$. declanae were greatest between individual plants rather than between fragments or plots, and parasitism rates by A. declanae were determined by the overall parasitism rate from other parasitoids, with an indication that tree size may be important in addition to a significant negative response to reduction in isolation. Individual plant properties such as larval abundances per tree were influential on parasitism by $M$. pulchricornis, as was the amount of herbivory on kawakawa trees. Herbivory was larger on smaller trees (Chapter 4). Smaller trees in this instance either occur as natural regrowth alongside larger trees or result from disturbance such as frost or windfall. It is unclear if, or to what extent herbivory effects kawakawa growth. It has been speculated that $C$. scriptaria and kawakawa have co-evolved and the plant tolerates its herbivore well (Hodge, Keesing \& Wratten, 2000). In some species herbivory is known to enhance plant production (Belovsky \& Slade, 2000) and high herbivory on smaller kawakawa trees might facilitate growth. Further work could clarify the influence of herbivory on kawakawa growth patterns. 


\subsection{Limitations}

Individuals collected from a single trap cannot be representative of the total fauna present in a habitat (Clark \& Samways, 1997), therefore three sites per fragment were chosen for simultaneous collecting over a period of four days. It is possible that my limited amount of sampling might not reflect the entire hymenopteran diversity in the fragments, therefore setting traps for longer periods may reveal more accurate species compositions. A longer monitoring period could therefore be of advantage. Investigating temporal differences on a monthly perhaps even weekly basis might reveal trends not observed within this study. Such trends might reveal differences in species composition and abundances due to weather patterns. Both temperature and rainfall were not recorded for the studies herein, but may have influenced species composition and abundance. To achieve this, Malaise trap samples would have to be taken simultaneously for a consecutive time period. Such sampling would increase logistical difficulties associated with such large scale studies. Regular visits to research sites as well as sorting of insects, particularly from not very well known groups, are both very time consuming. This is especially the case with only one researcher, so increasing sampling sizes would inevitably mean a prolonged research time. This would have been beyond the scope of this thesis.

As is apparent from the significant interaction between year and fragments, there are differences in species assemblages between years (Chapter 2). Species assemblages differed between years one and two and similarly the larval abundance, herbivory and parasitism rates changed between years one and two (Chapter 4). The temporal abundance of some insects and species richness of parasitoid hosts often varies over a period of several years (Barbosa et al., 2001; Barlow, Beggs \& Barron, 2002). The 
species accumulation curves indicated that additional species are present in some of the forest fragments (Chapters $2 \& 3$ ). As discussed, changes in climate between years could be the driving factor for species absence or presence in forest fragments. Unfortunately, time restrictions on a $\mathrm{PhD}$ thesis did not allow sampling beyond two years of field work.

It could be speculated that the high number of rare species found within each fragment might be an indicator that the sampling regime used for this study has some limitations. Some species may not be sampled well by Malaise traps. However, the total sampling time for the whole region investigated, was approximately 460 trapping days with a total of 116 Malaise trap samples. Given the large number of species observed only once, it likely that some species that were encountered have very small populations and are rare. Such rare species might depend on some properties of the fragment from which they were collected. If my results do indicate extreme rarity for some species, consideration for conservation needs to be taken into account.

\subsection{Recommendations for future studies}

1. Why do parasitoids respond differently to habitat fragmentation effects?

The studies in this thesis, as well as emerging studies, show that a number of species respond differently to habitat fragmentation and many species do not respond at all (Doak, 2000; Roland \& Taylor, 1997; Roth, Roland \& Roslin, 2006; Thiel, Driessen \& Hoffmeister, 2006; van Nouhuys, 2005). It is hypothesised that a species' biology determines how a species responds to habitat fragmentation (Thiel, Driessen \& Hoffmeister, 2006). In addition, it has been shown that habitat quality or structure can determine community composition to a large extent (Fraser, Dytham \& Mayhew, 2007; Hunter, 2002; Lassau \& Hochuli, 2005; Lassau et al., 2005). However, very 
little is known about why particular species are tied to a particular fragment with a particular area, degree of isolation, quality or structure. What aspects of a species' biology determine such patterns? Potential factors to be examined in relation to habitat fragmentation effects could be a species' dispersal ability, host specificity, food source specificity, reproductive biology, host plant specificity of the larval host, competition with other parasitoids, host detecting mechanisms such as olfactory or visual cues, or micro climate within a fragment. Olfactory sensing of hosts, for example, could be further narrowed down to sensing of a host's sex pheromones, aggregation pheromones or volatiles realised from plants. An important next step would be to examine the above mentioned attributes to test why species respond negatively or positively to habitat fragmentation or do not respond at all. Such research could involve species from around the world and whose biology and interactions with their hosts are well known.

2. Revision of Hymenoptera taxa and development of diagnostic tools for identifying New

\section{Zealand Hymenoptera}

To better understand the mechanisms determining individual hymenopteran species responses to, for example, habitat fragmentation, a revision that includes biological species aspects is urgently needed. The different responses in parasitism rates by the two braconid parasitoids in Chapter 4 and similarly the species responses observed by Thiel et al. (2006) show that individual species' biological aspects are most important in the interpretation of community patterns observed. The inconclusive predictive power of the plant communities in relation to the parasitoid communities observed (Chapter 4) demonstrates the need for more detailed knowledge about each member in tri-trophic systems. 
In addition, the sorting and identification of Ichneumonidae and Proctotrupidae used within this study was very time-consuming. Keys for identification would have been helpful and would have considerably reduced the research time. However such keys do not exist for most of New Zealand's Hymenoptera taxa. For example, due to difficulties in identifying morpho-species within the genus Campoplex, this genus, as well as all ichneumonid males, were excluded from the work described herein. Hymenoptera are important components in ecological systems and can act as pollinators, predators or parasitoids. Parasitic Hymenoptera are, for example, frequently used to control pest species in horticulture. New Zealand's museums and the New Zealand Arthropod Collection at Landcare hold enough specimens to enable keys to New Zealand's ichneumonid fauna to be created.

3. Do other hymenopteran taxa and insect groups follow previously observed distribution patterns?

The studies introduced in this thesis could be extended to other hymenopteran taxa that were present in the Malaise trap catches but, due to logistical constraints, were excluded. Some of these taxa were, for example, the parasitic Hymenoptera families Braconidae, Eulophidae, Diapriidae, Mymaridae, Platygastridae and Scelionidae. Most of these families are well represented and are small in body size. Extending my research questions to these groups might give more power to answer the research question posed in Chapter 2 as to whether small-bodied parasitoids are more affected by habitat fragmentation than large-bodied parasitoids. 
4. Does parasitoid diversity from native fragments differ from parasitoid diversities in scrub, open land, and residential gardens in the surrounding landscape matrix?

Urban areas are known to be richer in plant species than surrounding rural areas (Kühn, Brandl \& Klotz, 2004; Kühn \& Klotz, 2006; Smith et al., 2006b; Wania, Kühn \& Klotz, 2006) and residential gardens can play an important role in arthropod conservation (Samways, 2007; Smith et al., 2006a). The following questions might be of interest especially with habitat conservation in mind: are parasitoid species restricted to native fragments within the landscape matrix or does the surrounding matrix composed of scrub, open land and residential gardens support similar parasitoid communities? Are endemic parasitoids predominantly found in native forest fragments and are exotic parasitoids more dominant in residential gardens?

5. Does continuous native forest support different parasitoid communities compared to parasitoid communities in urban forest fragments?

Whilst species compositions differed markedly between fragments (Chapters $2 \& 3$ ), the species richness observed within the landscape matrix studied might reflect well established communities resulting from past fragmentation events. If this is the case then hymenopteran species richness could be expected to be higher in continuous forest away from urban proximity. It has been suggested, however, that urban areas are more habitat diverse and therefore harbour a richer biodiversity (Rebele, 1994). Given such a scenario the hymenopteran diversity found in this study might actually be higher in the urban forest fragments than in continuously forested areas. 
6. Do invasive parasitoids replace endemic parasitoids with loss of habitat due to forest fragmentation?

Species do have different habitat requirements and there is a limited understanding of what specific mechanisms drive species extinctions. Invasive species have been linked to native species decline, which has been hypothesised to be the indirect consequence of habitat loss for native species (Didham et al., 2007; Didham et al., 2005). The invasive wasp species $M$. pulchricornis is known to have a wide range of host species in New Zealand and has been predominantly found in modified habitats (Berry \& Walker, 2004). Experimental as well as field studies of interactions between $M$. pulchricornis and other parasitoids utilising the same hosts in modified versus native habitat might give some answers to the above question.

7. Do female/male parasitoid species respond differently to forest fragmentation compared to female-only parasitoid species?

The study from Chapter 4 and Thiel et al. (2006) has shown that parasitism rates by parasitoids that have both females and males in their populations are higher in isolated fragments than in larger fragments. In contrast, parasitism rates were higher in continuous habitats (Thiel, Driessen \& Hoffmeister, 2006) or resulted in no change between different habitats (Chapter 4) for female-only parasitoid populations. Thiel et al. (2006) explained the behaviour by the female/male populations in continuous habitat as spreading of offspring reducing the risk of sib-mating. Persistence of native parasitic wasp populations that have both males and females might therefore experience inbreeding caused through the loss of habitat. Future experimental and field studies might show that elevated parasitism rates by female/male wasps in isolated habitats could prove to be an important indicator of habitat quality. This 
information could become a valuable tool in general as well as providing directions for urban planners for conservation management and the maintenance of communities depending on each trophic level.

8. Is a herbivore feeding on different host plant species equally parasitised by parasitoids on a different range of host plant species? Are there differences in host plant use by the herbivore and in associated parasitism rates due to forest fragmentation?

The kawakawa moth is widely considered to be the primary herbivore on kawakawa, which is also commonly known as its preferred food plant. However, records confirming the latter were not found and C. scriptaria is known to feed on at least six other tree species (Spiller \& Wise 1982). This opens several very interesting questions: would herbivory by $C$. scriptaria differ between the different plant species in relation to area or isolation. Does $A$. declanae parasitise $C$. scriptaria larvae on other host plants and if so, are there differences in parasitism between fragments of different area and degree of isolation? Other studies have found that parasitism rates by the same parasitoid on the same larval host to vary according to the host plant where the host is feeding (Barbosa et al., 2001). In modified habitats, parasitism by a generalist parasitoid shifted and the parasitoid became more specialised on one of its hosts in comparison to a wider host range of hosts in a non-modified habitat (Tylianakis, Tscharntke \& Lewis, 2007). Similar shifts might be occurring in herbivory by $C$. scriptaria and parasitism by A. declanae and/or M. pulchricornis between different food plants in general but dependant primarily on habitat fragmentation. 


\subsection{What are the consequences of fragmentation and isolation for the management of urban habitat reserves and forest fragments?}

There are estimates of between 2.7 - 10 million insect species on Earth (Gaston, 1991, 1992). Insects provide a variety of important ecosystem functions such as nutrient cycling, pollination, herbivory, predation and parasitism (Samways, 1994, 2005). Insects have been estimated to be presently more under threat of extinction than most other organisms (Samways, 2007). Urban areas could play an important role in insect conservation; however, urban areas often contain species associated with modified landscape rather than species native to the locality (Kühn, Brandl \& Klotz, 2004; Kühn \& Klotz, 2006; Samways, 1994, 2005; Smith et al., 2006b). Planning of the urban landscape matrix that allows for the selection and planning of multispecies habitat preserves (Scott \& Sullivan, 2000) therefore needs to take into account the conservation of native arthropods (Redak, 2000).

It has been suggested that small habitat fragments are important because they can harbour more insect species than equivalent patches within larger habitats patches. Therefore, a combination of large and small habitats in the landscape matrix might aid insect conservation (Hunter, 2002; Tscharntke et al., 2002a, b). This has been the subject of discussion in Chapter 2. However, as I have shown in Chapter 4 there may also be draw backs for certain insects. Many recent studies have shown that habitat structure and quality rather than fragmentation itself determine species composition in a habitat (Fraser, Dytham \& Mayhew, 2007; Hunter, 2002; Lassau \& Hochuli, 2005; Lassau et al., 2005). 
Didham et al. (2007; 2005) raise some interesting points in regards to species conservation, species invasion and loss of habitat. They postulate that native species extinction might be due to a combination of habitat loss and the establishment of exotic invasive species that find a favourable habitat in a modified landscape. These authors further say: “...if we are to better understand the impacts of invasive species and mitigate threats to native species, we must be able to distinguish between different causal mechanisms of population decline." (Didham et al., 2005, p. 471).

In light of this statement and the quote from Hunter at the beginning of this chapter, I would like to add that in order to achieve this we must understand the complex interactions between insects themselves and the plants upon which they depend. But foremost we must understand the complexity of individual insect species' biology. Usually we know very little and yet try to make generalisations without actually taking aspects of the insect's biology into account (Warren et al., 2001).

Due to the variation in species responses to the forest fragmentation properties and high variation in communities between fragments independent of the fragmentation effects, any existing recommendations for the management of urban habitat reserves and forest fragments that favour one habitat over another should be viewed with caution. Conservation implications may be different for the different families investigated, but also for individual species within one family. Many studies I have encountered stress the importance of considering the biological characteristics of a species when studying fragmentation effects (i. e. Ribas et al., 2005; Thiel, Driessen \& Hoffmeister, 2006), because biological characteristics of a species might determine its distribution and abundance. 
As I discussed before, many species were found in low numbers. Assuming that the low numbers in species are not an artefact of sampling and because many species are present only in one fragment, it would be of great importance to ensure the existence of all fragments. This is especially important because most fragments seemed to support different rare species. If any one of those fragments were to be lost then the rare species associated with that fragment could be lost forever from a region composed of many fragments. This applies to, for example, one of my fragments studied, which has prime views over the Wellington harbour. There has been speculation speculated about developing this area for residential purposes. As long as biological characteristics and underlying mechanisms determining different community assemblages are unknown, it may be advisable to have a precautionary approach and assure conservation of this fragment, but also any fragments that still exist in urban areas worldwide. Preserving and retaining native habitat still present in an urbanised environment and encouraging the establishment of native plant elements in residential gardens could be crucial in maintaining habitat for many rare and often unknown species, which otherwise might become extinct and be lost forever.

\subsection{Synopsis}

This thesis provides evidence that it is difficult to generalise from the trophic level hypothesis of island biogeography, which predicts that species at higher trophic levels in a community are more prone to the effects of fragmentation than species at lower levels. Trends in species richness, abundance and diversity as well as parasitism rates were shown to either not result from forest fragmentation or showed negative responses to an increase in fragment area or decrease in fragment isolation. Species compositions were 
shown to be affected by habitat fragmentation reflecting negative or positive responses by individual species. Most important, however, were species responses to fragment or plot factors other than those measured within this thesis. Such factors determining herbivory by $C$. scriptaria and parasitism rates by $A$. declanae and $M$. pulchricornis were host plant abundance and plant species richness at the plot level and larval host densities, tree size and overall parasitism rate at the individual plant level. Both, individual species responses at the community level as well as different parasitism rates for an endemic and an exotic parasitoid to forest fragmentation show that individual species' biology might be the most important factor in determining how a species responds to habitat changes.

\subsection{Literature cited}

Barbosa, P., Segarra, A.E., Gross, P., Caldas, A., Ahlstrom, K., Carlson, R.W., Ferguson, D.C., Grissell, E.E., Hodges, R.W., Marsh, P.M., Poole, R.W., Schauff, M.E., Shaw, S.R., Whitfield, J.B. \& Woodley, N.E. (2001) Differential parasitism of macrolepidopteran herbivores on two deciduous tree species. Ecology, 82(3), 698704.

Barlow, N.D., Beggs, J.R. \& Barron, M.C. (2002) Dynamics of common wasps in New Zealand beech forests: a model with density dependence and weather. Journal of Animal Ecology, 71(4), 663-71.

Belovsky, G.E. \& Slade, J.B. (2000) Insect herbivory accelerates nutrient cycling and increases plant production. Proceedings of the National Academy of Sciences, 250483797. 
Berry, J.A. \& Walker, G.P. (2004) Meteorus pulchricornis (Wesmael) (Hymenoptera : Braconidae : Euphorinae): an exotic polyphagous parasitoid in New Zealand. New Zealand Journal of Zoology, 31(1), 33-44.

Clark, T.E. \& Samways, M.J. (1997) Sampling arthropod diversity for urban ecological landscaping in a species-rich southern hemisphere botanic garden. Journal of Insect Conservation, 1(4), 221-34.

Davies, K.F. \& Margules, C.R. (1998) Effects of habitat fragmentation on carabid beetles - experimental evidence. Journal of Animal Ecology, 67(3), 460-71.

Didham, R.K., Tylianakis, J.M., Gemmell, N.J., Rand, T.A. \& Ewers, R.M. (2007) Interactive effects of habitat modification and species invasion on native species decline. Trends in Ecology \& Evolution, 22(9), 489-96.

Didham, R.K., Tylianakis, J.M., Hutchison, M.A., Ewers, R.M. \& Gemmell, N.J. (2005) Are invasive species the drivers of ecological change? Trends in Ecology \& Evolution, 20(9), 470-74.

Doak, P. (2000) The effects of plant dispersion and prey density on parasitism rates in a naturally patchy habitat. Oecologia, 122(4), 556-67.

Fraser, S.E.M., Dytham, C. \& Mayhew, P.J. (2007) Determinants of parasitoid abundance and diversity in woodland habitats. Journal of Applied Ecology, 44(2), $352-61$.

Gaston, K.J. (1991) The Magnitude of Global Insect Species Richness. Conservation Biology, 5(3), 283-96.

Gaston, K.J. (1992) Regional Numbers of Insect and Plant-Species. Functional Ecology, 6(3), 243-47. 
Gibb, H. \& Hochuli, D.F. (2002) Habitat fragmentation in an urban environment: large and small fragments support different arthropod assemblages. Biological Conservation, 106(1), 91-100.

Harris, A.C. (1987) Pompilidae (Insecta: Hymenoptera). Fauna of New Zealand, 12.

Hodge, S., Keesing, V.F. \& Wratten, S.D. (2000) Leaf damage does not affect leaf loss or chlorophyll content in the New Zealand pepper tree, kawakawa (Macropiper excelsum). New Zealand Journal of Ecology, 24(1), 87-89.

Holt, R.D., Lawton, J.H., Polis, G.A. \& Martinez, N.D. (1999) Trophic rank and the species-area realtionship. Ecology, 80(5), 1495-504.

Hunter, M.D. (2002) Landscape structure, habitat fragmentation, and the ecology of insects. Agricultural and Forest Entomology, 4(3), 159-66.

Kareiva, P. (1987) Habitat Fragmentation and the Stability of Predator Prey Interactions. Nature, 326(6111), 388-90.

Komonen, A., Penttila, R., Lindgren, M. \& Hanski, I. (2000) Forest fragmentation truncates a food chain based on an old-growth forest bracket fungus. Oikos, 90(1), 119-26.

Kruess, A. \& Tscharntke, T. (1994) Habitat fragmentation, species loss, and biological control. Science, 264(5165), 1581-84.

Kruess, A. \& Tscharntke, T. (2000). Effects of habitat fragmentation on plant-insect communities. In Interchanges of Insects between Agriculture and surrounding Landscapes. (eds B. Eckboom, M. Irwin \& Y. Robert), pp. 53-70. Kluwer, Dordrecht.

Kühn, I., Brandl, R. \& Klotz, S. (2004) The flora of German cities is naturally species rich. Evolutionary Ecology Research, 6(5), 749-64.

Kühn, I. \& Klotz, S. (2006) Urbanization and homogenization - Comparing the floras of urban and rural areas in Germany. Biological Conservation, 127(3), 292-300. 
Lassau, S.A. \& Hochuli, D.F. (2005) Wasp community responses to habitat complexity in Sydney sandstone forests. Austral Ecology, 30(2), 179-87.

Lassau, S.A., Hochuli, D.F., Cassis, G. \& Reid, C.A.M. (2005) Effects of habitat complexity on forest beetle diversity: do functional groups respond consistently? Diversity and Distributions, 11(1), 73-82.

Rebele, F. (1994) Urban Ecology and Special Features of Urban Ecosystems. Global Ecology and Biogeography Letters, 4(6), 173-87.

Redak, R.A. (2000) Arthropods and multispecies habitat conservation plans: Are we missing something? Environmental Management, 26, S97-S107.

Ribas, C.R., Sobrinho, T.G., Schoereder, J.H., Sperber, C.F., Lopes-Andrade, C. \& Soares, S.M. (2005) How large is large enough for insects? Forest fragmentation effects at three spatial scales. Acta Oecologica-International Journal of Ecology, 27(1), 31-41.

Roland, J. \& Taylor, P.D. (1997) Insect parasitoid species respond to forest structure at different spatial scales. Nature, 386(6626), 710-13.

Roth, D., Roland, J. \& Roslin, T. (2006) Parasitoids on the loose - experimental lack of support of the parasitoid movement hypothesis. Oikos, 115(2), 277-85.

Samways, M.J. (1994) Insect conservation biology, 1st edition. Chapman \& Hall.

Samways, M.J. (2005) Insect Diversity Conservation. Cambridge University Press, Cambridge, UK.

Samways, M.J. (2007) Insect conservation: A synthetic management approach. Annual Review of Entomology, 52, 465-87.

Scott, T.A. \& Sullivan, J.E. (2000) The selection and design of multiple-species habitat preserves. Environmental Management, 26(Suppl 1), S37-S53. 
Smith, R.M., Thompson, K., Hodgson, J.G., Warren, P.H. \& Gaston, K.J. (2006a) Urban domestic gardens (IX): Composition and richness of the vascular plant flora, and implications for native biodiversity. Biological Conservation, 129(3), 312-22.

Smith, R.M., Warren, P.H., Thompson, K. \& Gaston, K.J. (2006b) Urban domestic gardens (VI): environmental correlates of invertebrate species richness. Biodiversity and Conservation, 15(8), 2415-38.

Spiller, D.M. \& Wise , K.A.J. (1982). A catalogue (1860-1960) of New Zealand insects and their host plants. DSIR Science Information Division Bulletin. In, Vol. 231. DSIR, Wellington.

Steffan-Dewenter, I. \& Tscharntke, T. (2002) Insect communities and biotic interactions on fragmented calcareous grasslands - a mini review. Biological Conservation, 104(3), 275-84.

Strauss, B. \& Biedermann, R. (2006) Urban brownfields as temporary habitats: driving forces for the diversity of phytophagous insects. Ecography, 29(6), 928-40.

Thiel, A., Driessen, G. \& Hoffmeister, T.S. (2006) Different habitats, different habits? Response to foraging information in the parasitic wasp Venturia canescens. Behavioral Ecology and Sociobiology, 59(5), 614-23.

Tscharntke, T., Steffan-Dewenter, I., Kruess, A. \& Thies, C. (2002a) Characteristics of insect populations on habitat fragments: A mini review. Ecological Research, 17(2), 229-39.

Tscharntke, T., Steffan-Dewenter, I., Kruess, A. \& Thies, C. (2002b) Contribution of small habitat fragments to conservation of insect communities of grassland-cropland landscapes. Ecological Applications, 12(2), 354-63.

Tylianakis, J.M., Tscharntke, T. \& Lewis, O.T. (2007) Habitat modification alters the structure of tropical host-parasitoid food webs. Nature, 445(7124), 202-05. 
van Nouhuys, S. (2005) Effects of habitat fragmentation at different trophic levels in insect communities. Annales Zoologici Fennici, 42(4), 433-47.

Wania, A., Kühn, I. \& Klotz, S. (2006) Plant richness patterns in agricultural and urban landscapes in Central Germany - spatial gradients of species richness. Landscape and Urban Planning, 75(1-2), 97-110.

Warren, M.S., Hill, J.K., Thomas, J.A., Asher, J., Fox, R., Huntley, B., Roy, D.B., Telfer, M.G., Jeffcoate, S., Harding, P., Jeffcoate, G., Willis, S.G., Greatorex-Davies, J.N., Moss, D. \& Thomas, C.D. (2001) Rapid responses of British butterflies to opposing forces of climate and habitat change. Nature, 414(6859), 65-69. 